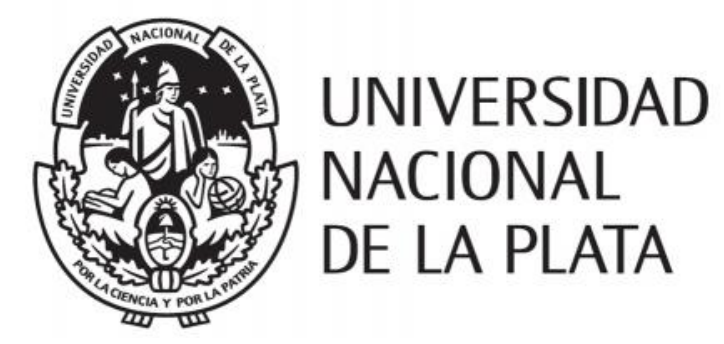

Tesis presentada para optar por el título de Doctora de la Facultad de Ciencias Agrarias y Forestales Universidad Nacional de La Plata

\title{
Evaluación de la plasticidad fenotípica de una especie nativa de la selva misionera (Cabralea canjerana (Vell.) Mart.) y determinación de pautas para manejar su regeneración
}

\author{
Ing. Ftal. Ana Paula Moretti \\ Directora: Dra. Corina Graciano \\ Co-director: Ing. Ftal. Juan Francisco Goya
}

Lugar de trabajo: Instituto de Fisiología Vegetal, INFIVE (CONICET-UNLP)

Fecha de presentación: 24 de mayo de 2019

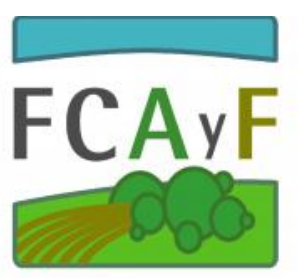




\section{Agradecimientos}

A mi directora, Corina Graciano, que desde un primer momento confió en mí para transitar este camino. Fue quien me acompaño y guió en todo momento para seguir adelante, siempre presente para charlar, enseñarme, ayudarme y compartir muchos momentos y experiencias. Una persona y profesional excelente.

A mi co-director, Juan Francisco Goya, por sus aportes valiosos para esta tesis, y su punto de vista.

A mi amiga y hermana doctoral Flavia Olguin por su aguante y compañerismo en este camino de doctorado, por su ayuda incondicional, su buena onda y alegría.

A mis amigos y compañeros de trabajo, Fermín Gortari y José Vera Bahima por su aguante y gran ayuda, principalmente en los viajes de campaña.

A Martín Pinazo, que estuvo siempre presente en las campañas en Misiones, por confiar en nosotros para trabajar y por sus aportes a esta tesis.

Al grupo enorme de personas que participaron de todos los viajes de campaña a Misiones para compartieron su tiempo y conocimientos: Corina Graciano, Martín Pinazo, Flavia Olguin, José Vera Bahima, Fermín Gortari, Tomás de Hagen, Martín Santiago, Mauro Bartolozzi, Celina Bertoni, Manuel de Hagen, Valeria Bernardo, Maia Plaza Behr, Sebastián Bonnin, Manuel Billieres, Juan Rodrigues, Ramón Alcaraz, Eugenio Sello, Vito Alves.

A Silvia Monteoliva por sus aportes, conocimientos en anatomía de la madera y en técnicas de análisis anatómicos.

A los trabajadores del Campo Anexo Manuel Belgrano EEA-INTA- Montecarlo, a Jorge Costa por recibirnos en cada uno de los viajes, y brindarnos el espacio para trabajar y su buena predisposición. A Ramón Alcaraz y Juan Rodrigues, quienes compartieron su gran conocimiento, trabajo, experiencia y buena predisposición en todos los trabajos a campo, su conocimiento fue muy valioso para las campañas realizadas y para esta tesis. 
A mi familia y amigos que estuvieron siempre y me acompañan en todo, especialmente a Leo que me acompaña cada día con una sonrisa, me contiene, da aliento y está siempre.

A todos mis amigos y compañeros del INFIVE que alegraron cada uno de mis días en el instituto: Fermín, Pepe, Agustina, Emilia, Alejandra, Flavia, Matías, Santiago, Maurito, Diana, Luján, Analía, Celeste, Irina, Mariela, Lucía, Diego, Facundo, Lorenza.

Al CONICET por becarme durante 5 años para poder desarrollar esta tesis. A los proyectos PIA 12010 y 14031 por el financiamiento para la realización de los ensayos y viajes de campaña. 


\section{Publicaciones derivadas de esta tesis}

\section{En revistas científicas con referato:}

Moretti, Ana P, Flavia Y. Olguin, Martin A. Pinazo, Fermín Gortari, José Vera Bahima, Corina Graciano (2019) Supervivencia y crecimiento de un árbol nativo maderable bajo diferentes coberturas de dosel en el Bosque Atlántico, Misiones, Argentina. Ecología Austral 29: 99-111. Disponible en: http://ojs.ecologiaaustral.com.ar/index.php/Ecologia_Austral/article/view/779/370

Moretti, Ana P, Flavia Y. Olguin, Martin A. Pinazo, Corina Graciano (2019) Water and light stresses drive acclimation during the establishment of a timber tree under different intensities of rainforest canopy coverage. CERNE 25 (1): 93-104. DOI: 10.1590/01047760201925012616

\section{Trabajos completos en Actas de reuniones científicas:}

Moretti, Ana Paula; Pinazo, Martín A; Graciano, Corina. 2013. Capacidad de crecimiento y aclimatación de plantas jóvenes de una especie nativa de alto valor maderero (Cabralea canjerana, cancharana) a diferentes condiciones de cobertura de dosel. 4to Congreso Forestal Argentino y Latinoamericano, AFOA, Iguazú, Argentina. 10pp. https://www.researchgate.net/publication/271501766 CAPACIDAD DE CRECIMIENTO Y ACLIM ATACION DE PLANTAS JOVENES DE UNA ESPECIE NATIVA DE ALTO VALOR MADERERO Cabr alea canjerana CANCHARANA A DIFERENTES CONDICIONES DE COBERTURA DE DOSEL

Moretti, Ana Paula; Martín A. Pinazo, Corina Graciano. 2014. Características fisiológicas que permiten a Cabralea canjerana Mart. tolerar los cambios súbitos en la disponibilidad de luz. XVI Jornadas Técnicas Forestales y Ambientales, Eldorado, Misiones, 15 al 17 de mayo de 2014: 107-114. En: http://es.scribd.com/doc/224456399/Actas-XVI-Jornadas\#download

Moretti, Ana Paula, Flavia Y. Olguin, Martin Pinazo, Fermín Gortari, José Vera Bahima, Corina Graciano (2017) Enriquecimiento de bosque nativo con una especie de valor maderero: Cabralea canjerana. XXXI JORNADAS FORESTALES DE ENTRE RIOS, Concordia, octubre de 2017.Disponible en: http://www.jornadasforestales.com.ar/jornadas/2017/Moretti-etal Enriquecimiento-Selva-Cancharana.pdf 


\section{Índice}

Resumen

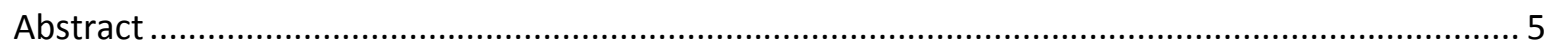

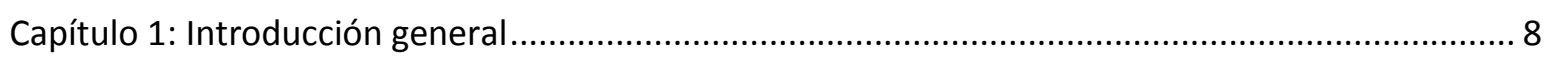

1.1 Situación actual de los bosques nativos de Misiones y área de estudio................................... 9

1.2 Dinámica de la selva y regeneración natural ........................................................................ 10

1.3 Cobertura arbórea y disponibilidad de luz en la selva ......................................................... 13

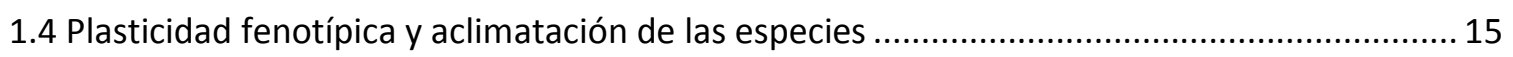

1.5 Definición de estrés leve, moderado y severo y características para describir el estrés por luz

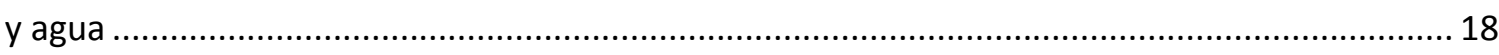

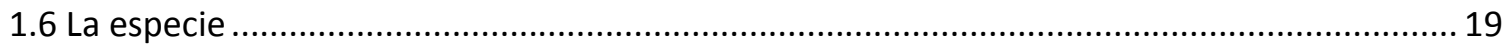

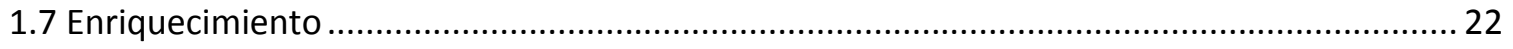

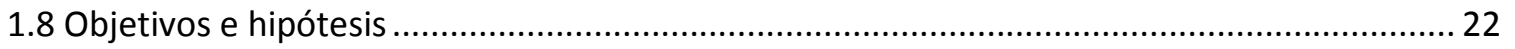

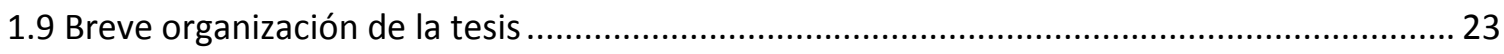

Capítulo 2: Sitio de estudio y metodología .................................................................................. 26

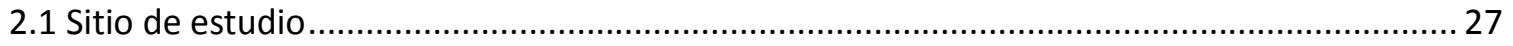

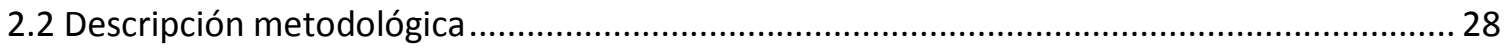

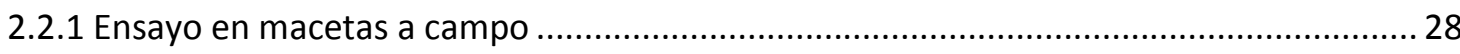

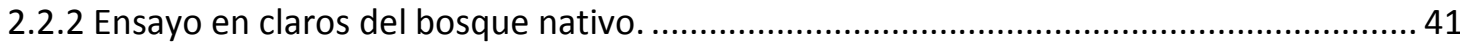

2.2.3 Ensayo en parcelas permanentes del bosque nativo .................................................... 46

Capítulo 3: Aclimatación morfo-fisiológica a coberturas de canopeo contrastantes ....................... 49

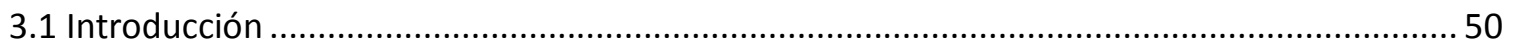

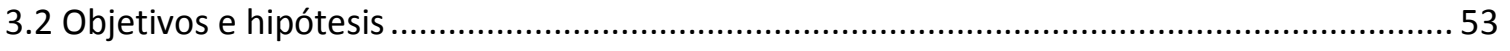

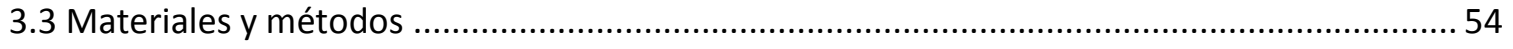

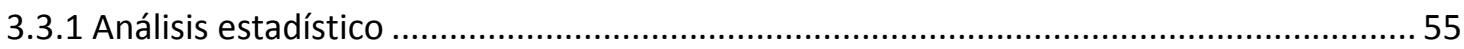

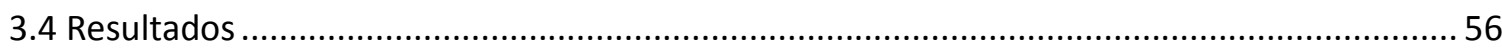

3.4.1 Morfología de las plantas, tamaño y partición de materia seca de plantas de sol y bajo

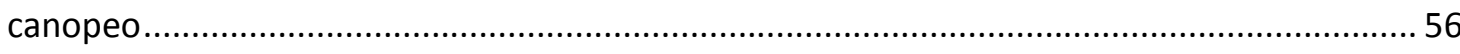

3.4.2 Características de la arquitectura hidráulica en plantas de sol y sombra....................... 58

3.4.3 Características relacionadas con el uso de la luz en plantas de sol y canopeo................61 61 
3.4.4 Respuestas morfológicas y fisiológicas en un gradiente de cobertura generado en los claros 62

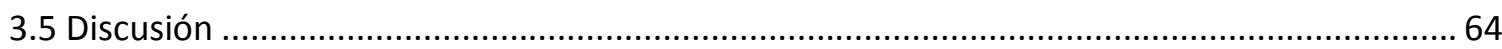

3.5.1 Morfología, crecimiento y partición de materia seca de plantas de canopeo y sol ........ 64

3.5.2 Rasgos de la Arquitectura hidráulica en plantas de sol y canopeo ..................................66

3.5.3 Rasgos relacionados con el uso de la luz en plantas de sol y canopeo ............................68

3.5.4 Respuestas morfológicas y fisiológicas a diferentes coberturas de canopeo en claros .. 70

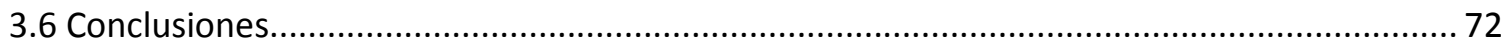

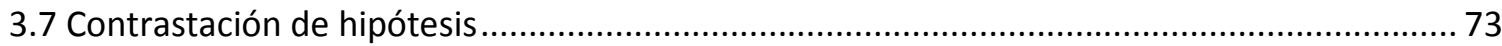

Capítulo 4: Supervivencia, crecimiento y capacidad de respuesta al cambio abrupto de cobertura

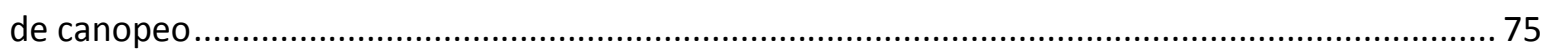

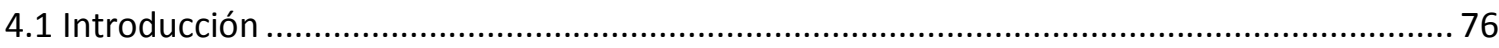

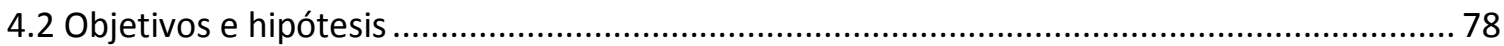

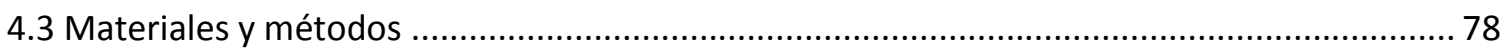

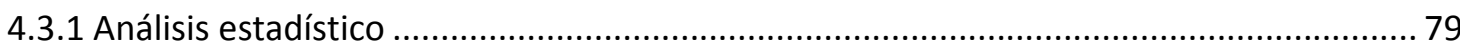

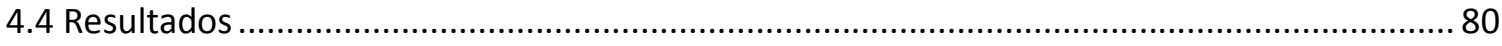

4.4.1 Morfología, crecimiento y partición de materia seca ................................................... 80

4.4.2 Características de la arquitectura hidráulica.............................................................. 83

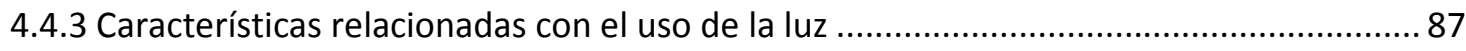

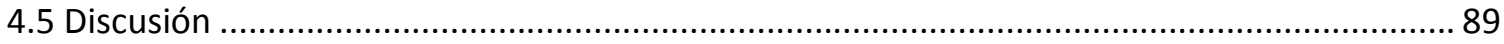

4.5.1 Morfología, crecimiento y partición de materia seca ..................................................... 89

4.5.2 Características de la arquitectura hidráulica.............................................................. 91

4.5.3 Características relacionadas con el uso de la luz ....................................................... 92

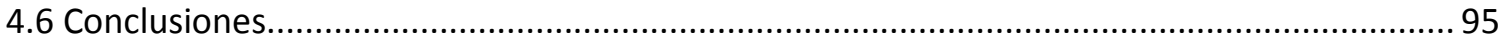

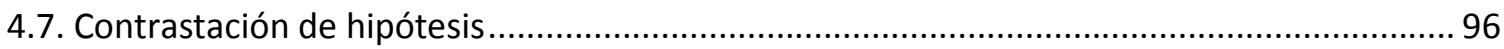

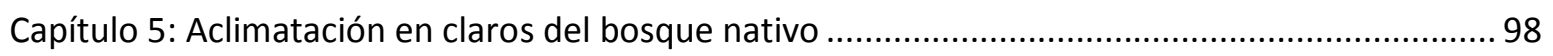

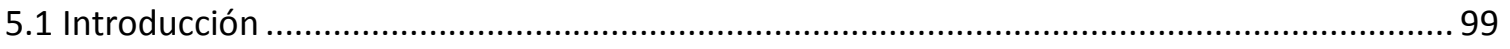

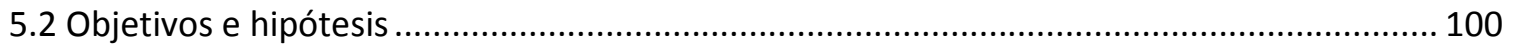

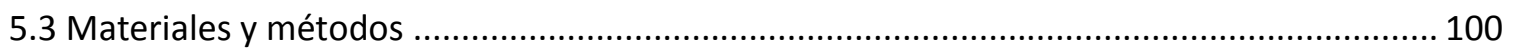

5.3.1 Análisis estadístico y visualización de los resultados .................................................... 101

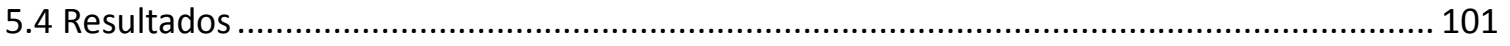

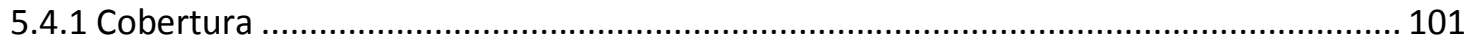




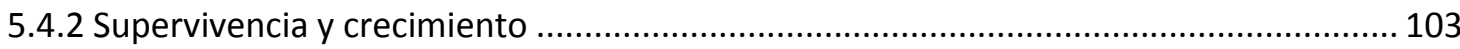

5.4.3 Respuestas morfológicas y fisiológicas a los diferentes niveles de luz .......................... 105

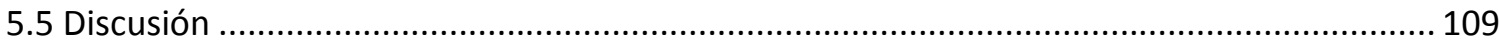

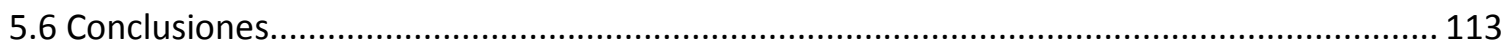

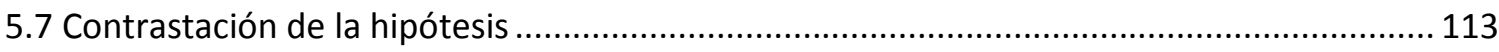

Capítulo 6: Regeneración natural de Cabralea canjerana ........................................................... 115

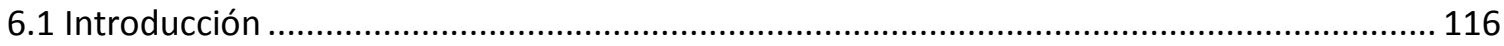

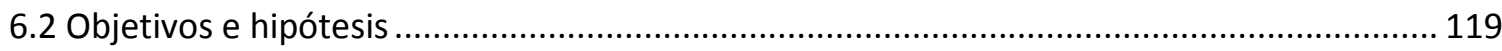

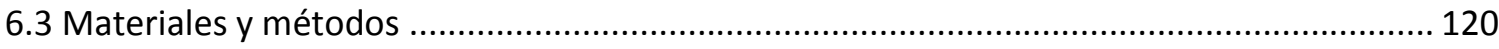

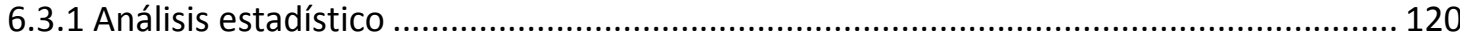

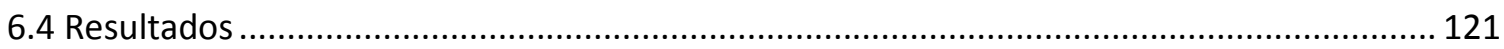

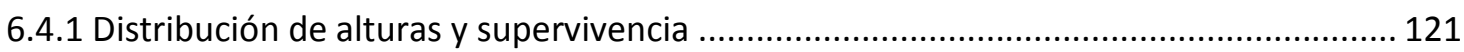

6.4.2 Distribución espacial de Cabralea canjerana ................................................................ 124

6.4.3 Análisis con función de correlación de marcas ............................................................ 129

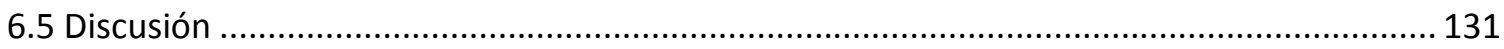

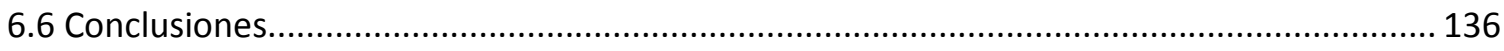

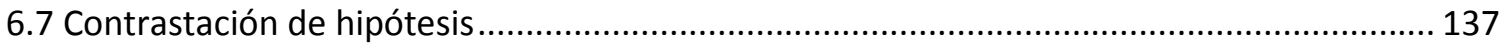

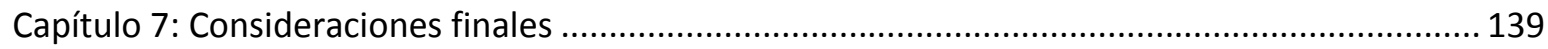

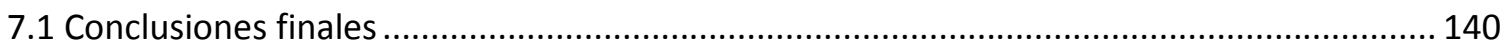

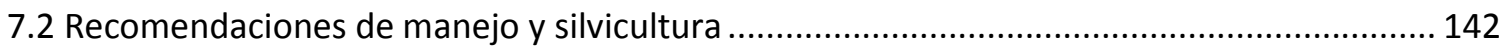

7.3 Aportes de la tesis para futuros trabajos ........................................................................... 143

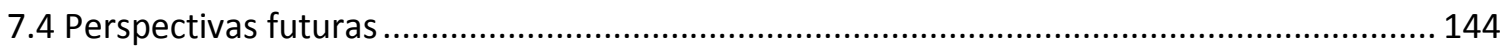

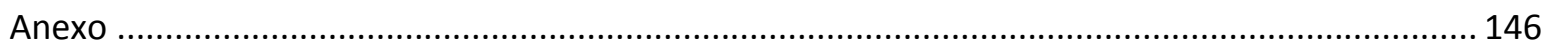

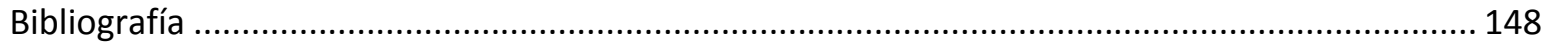




\section{Resumen}

La dinámica de los bosques comprende la regeneración, el crecimiento y la muerte de individuos o partes de los mismos, como caída de ramas y copas. Estos procesos generan cambios en los microambientes del bosque, especialmente relacionados con modificaciones en el ingreso de luz solar, y que se asocian con cambios en la temperatura del aire y del suelo, la humedad relativa del aire y el contenido de humedad en el suelo. Para comprender la capacidad de regeneración de Cabralea canjerana (Vell.) Mart (cancharana) en los diferentes ambientes producidos por la dinámica de los bosques y manejar la regeneración de esta especie, es importante conocer la plasticidad fenotípica de caracteres importantes para la supervivencia en diferentes condiciones de cobertura de dosel. Cabralea canjerana es potencialmente adecuada para evaluar una silvicultura basada en la regeneración natural y prácticas de enriquecimiento del bosque nativo dado que es una especie presente en el bosque degradado, posee abundante producción de semillas, la germinación y el establecimiento inicial ocurren espontáneamente en variados ambientes, algunos individuos llegan a los estratos intermedios y superiores del dosel. Adicionalmente es importante conocer la dinámica natural de regeneración en el bosque nativo para entender y describir la distribución espacial y las asociaciones entre individuos.

El objetivo general de esta tesis fue comprender la capacidad de regeneración de Cabralea canjerana en los diferentes ambientes producidos por cambios en la estructura de los bosques. Para alcanzar este objetivo general se plantearon 5 objetivos particulares: Objetivo 1: Describir la plasticidad fenotípica de Cabralea canjerana durante el establecimiento inicial a través de cambios morfológicos y fisiológicos en condiciones contrastantes de cobertura (sol y debajo del canopeo). Objetivo 2: Evaluar las respuestas ecofisiológicas de Cabralea canjerana a los 6 meses de plantación en un gradiente de cobertura en claros del bosque nativo. Objetivo 3: Evaluar las respuestas de aclimatación de Cabralea canjerana al cambio de cobertura de canopeo a sol pleno, en comparación con las plantas que continuaron a la sombra del canopeo. Objetivo 4: Evaluar la supervivencia, el crecimiento y la capacidad de aclimatación de Cabralea canjerana durante 3 años en un gradiente de cobertura en claros del bosque nativo. Objetivo 5: Analizar la dinámica de la regeneración natural de Cabralea canjerana en bosques secundarios de la selva misionera. 
Se realizó un ensayo con plantas en macetas expuestas a condiciones contrastantes de cobertura (sol y debajo de dosel), y posteriormente a un grupo de plantas que crecían debajo del dosel fueron expuestas a sol pleno para evaluar la capacidad de aclimatación al cambio abrupto de cobertura. Se midieron variables morfológicas y fisiológicas para evaluar si las plantas sufrían estrés por falta o exceso de luz, o estrés hídrico. Complementariamente, se plantaron plantas de 10 meses en 6 posiciones dentro de 3 claros del bosque nativo, que brindaban diferente nivel de cobertura. Se trabajó con 4 categorías de luz transmitida que representan desde 1,6 a $50 \%$ de luz con respecto al cielo abierto. En este ensayo se realizaron mediciones de supervivencia y crecimiento durante $3 \frac{1}{2}$ años y mediciones ecofisiológicas no destructivas durante $2 \frac{1}{2}$ años. El último ensayo se realizó en 4 parcelas permanentes de 1 ha de bosque nativo. En estas se realizó el relevamiento de la regeneración natural de Cabralea canjerana durante 4 años. La regeneración fue dividida en 3 categorías: plántulas pequeñas (PP), plántulas (P) y juveniles (J). Se analizó con patrones espaciales la distribución espacial de la regeneración.

Según los resultados de esta tesis, Cabralea canjerana es una especie intermedia en cuanto a los requerimientos de luz o parcialmente tolerantes a la sombra, ya que sobrevivió en el sotobosque por al menos 3 años. Sin embargo, luego de un año de establecidas, las plantas con mayor disponibilidad de luz crecieron más. Por otro lado, Cabralea canjerana se estableció y creció sin cobertura de dosel (tratamiento sol), pero las bajas temperaturas del invierno produjeron la muerte de la parte aérea de las plantas. Sin embargo, presentó una alta capacidad de rebrote durante la temporada siguiente. Las plantas que se establecieron en diferentes microambientes generados por los claros no fueron afectadas durante el invierno, lo que indica que el efecto amortiguador del claro es suficiente para evitar la muerte de la parte aérea de las plantas por las bajas temperaturas. Por otro lado, en los microambientes con mayor disponibilidad de luz (centro de los claros) las plantas crecieron más que en los demás microambientes donde la cobertura fue mayor.

Cabralea canjerana es una especie con una alta plasticidad fenotípica. En pocos meses modifica su morfología, fisiología y arquitectura hidráulica para aclimatarse a ambientes contrastantes de cobertura (sol y canopeo) y al cambio abrupto de cobertura. Por un lado, en cuanto a los rasgos morfológicos, las plantas de sol comparadas con las de canopeo realizaron cambios morfológicos y fisiológicos que son respuestas típicas a altas irradiancias. Estos cambios fueron acompañados de cambios en la arquitectura hidráulica, en respuesta a la mayor demanda evapotranspirativa de la atmósfera como una mayor conductividad hidráulica específica e índice 
estomático que las hojas de las plantas de canopeo. Por otro lado, las plantas de canopeo también se aclimataron mediante cambios a nivel de planta, con respuestas típicas a la baja irradiancia. Estas aclimataciones a los ambientes contrastantes dejaron en evidencia el estrés generado en las plantas de ambos tratamiento, sin embargo pudieron sobrevivir, y aclimatarse. Las plantas de sol sufrieron un estrés moderado por alta radiación, pero su plasticidad fisiológica y anatómica evitó daños significativos. Las plantas toleraron el shock lumínico, y tuvieron mayor peso seco total final y desarrollaron los cambios de aclimatación a la alta irradiancia.

Los microclimas generados en los claros del bosque nativo, principalmente donde la disponibilidad de luz fue mayor, favorecieron el crecimiento y el estado fisiológicos de las plantas. En los sitios con menor cobertura, las plantas encontraron un ambiente propicio para su crecimiento, que generó en $3 \frac{1}{2}$ años plantas de más de 3 metros de altura con un buen estado general. Los microambientes con entre 25 y $30 \%$ de cobertura, que recibieron por lo menos $50 \%$ de luz con respecto a un sitio abierto fueron los óptimos para plantar Cabralea canjerana. Como la especie demostró tener elevada capacidad de aclimatación, es posible plantarla en un amplio rango de microambientes, que incluyen situaciones a cielo abierto y debajo de canopeos densos, con menos de 5 moles fotones $\mathrm{m}^{-2}$ día $^{-1}$. Sin embargo, si la plantación se realiza debajo de canopeos densos el crecimiento será muy bajo, y deberá incrementarse la luz incidente dentro de los tres años de realizada la plantación.

En el bosque nativo, Cabralea canjerana es una especie que se estableció espontáneamente debajo del canopeo denso en agrupamientos de plántulas. Este agrupamiento continuó hasta la etapa juvenil de la especie. Las plántulas pequeñas (menores a $50 \mathrm{~cm}$ de altura) sobrevivieron por al menos 3 años en el sotobosque. En la categoría siguiente la frecuencia de individuos disminuyó, por lo tanto se deduce elevada mortalidad en la categoría menor en comparación con la mortalidad de categorías mayores. Esta alta mortalidad podría deberse a la cobertura. En consecuencia, prácticas de manejo como la liberación de las plantas del sotobosque serían de utilidad para propiciar el crecimiento de las plantas de categorías más pequeñas para que lleguen al dosel superior. Una cobertura de 90\% como máximo permite el crecimiento de Cabralea canjerana, aunque el mejor crecimiento se logrará con coberturas no mayores a 75\%.

En cuanto a la aplicación de los resultados, este estudio aporta información fundamental para los planes de restauración de áreas degradadas, ya que establece los microambientes en que se puede plantar y cuantifica los riesgos de pérdidas de plantas por estreses abióticos Por lo general a la hora de realizar la restauración o enriquecimiento, existe poca o nula información 


\section{Ana Paula Moretti - Tesis doctoral 2019}

acerca de los requerimientos de las especies y de los mecanismos fisiológicos que ponen en juego para aclimatarse a determinado microambiente. Esta generación de información es parte de la denominada ecología de la restauración. En este trabajo se llevó a cabo una práctica concreta y exitosa de enriquecimiento en claros del bosque nativo, en la que además de supervivencia y crecimiento, se midieron variables ecofisiológicos para poder entender el comportamiento de las plantas en microambientes de la selva. Además se realizó el análisis de la regeneración natural, con resultados que pueden ser utilizados para planificar estrategias silviculturales para el manejo de la especie. 


\section{Abstract}

Forest dynamic comprises regeneration, growth and death of plants or part of them, like branch and crown fall. These processes generate changes in the microenvironments in the rainforest, specially related with changes in sunlight, air and soil temperatures, and water content in air and soil. To understand Cabralea canjerana (Vell.) Mart regeneration capacity in different environments within the rainforest and to manage regeneration, it is important to know the phenotypic plasticity in traits related with survivor in different coverage conditions. Cabralea canjerana is a proper species to manage natural regeneration and enrichment in degraded forests, because it is a species that is present even in degraded forests, produces abundant seeds, germination and establishment occur spontaneously in many environments, and it reaches the upper canopy stratum. Additionally, it is important to understand the dynamic of natural regeneration in native rainforest to understand and describe spatial distribution and relationships between individuals.

The aim of this Thesis was to understand the regeneration capacity of Cabralea canjerana in different environments within the rainforest. Five specific aims were defined: 1) to describe the phenotypic plasticity during the early establishment through morphological and physiological changes in contrasting cover conditions (under full sun and below a dense forest canopy); 2) to evaluate ecophysiological responses of Cabralea canjerana 6 months after planting the seedling in a gradient of coverage in forest gaps; 3 ) to evaluate the response of Cabralea canjerana to sudden changes in forest coverage compared with plants that continued below the canopy; 4) to evaluate the survivorship, growth and acclimation of Cabralea canjerana to different microenvironments in the forest gaps along 3 years; 5) to analyze the dynamic of the natural regeneration of Cabralea canjerana in the secondary rainforest in Misiones.

Experiments at different scales were established to evaluate and reply to the aims of the Thesis. In a pot experiment under natural conditions, morphological and physiological traits were measured to identify stress by excess or deficit of light and by high evaporative demand. In a field experiment, 10 month old Cabralea canjerana plants was planted in different positions within 3 native forest gaps and ecophysiological traits were measured under different degrees of coverage 
between 1.6 and $50 \%$ of full sun. We measured survivorship and growth along $31 / 2$ and ecophysiological traits along $2 \frac{1}{2}$ years. Finally, we recorded natural regeneration of Cabralea canjerana in permanent plots of the native rainforest along 4 years. Regeneration was divided in small seedlings (PP), seedlings (P) and saplings (J). We analyzed the spatial patterns of spatial distribution.

The results of this Thesis indicate that Cabralea canjerana is an intermediate species considering the light requirements, or partially shade tolerant. It survived at least 3 years below the dense understory, but a year after the establishment it required more light intensity to grow. On the other hand, Cabralea canjerana can establish and grow at the full sun, but winter low temperatures can damage the aboveground part of the plants. However, Cabralea canjerana has the capacity of resprouting, during the following spring. Plants in different positions in the gaps were not affected by low temperature in winter; therefore the gaps buffered the temperatures in a way that plants were not frozen or chilled. On the other hand, in the microenvironments with lower coverage, plants grew more than in microenvironments with higher coverage.

Cabralea canjerana has high phenotypic plasticity, in a few months modified its morphology, physiology and hydraulic architecture to acclimate to contrasting environments (full sun and a dense forest canopy) and to a sudden change in coverage. Plants changed morphological and physiological traits described as responses to high light. Those changes occurred together with changes in the hydraulic architecture in response to the higher air evaporative demand, as higher specific hydraulic conductivity and stomatal index than in plants under the canopy coverage. On the other hand, plants below the canopy developed typical changes related with acclimation to low irradiance. Those acclimations to sun highlight the stress suffered by plants in that environment, but phenotypic plasticity avoided significant damages. Plants tolerated light shock, and had higher dry mass than plants that continued below the canopy.

The microenvironments in the forest gaps favored Cabralea canjerana growth, particularly in those with higher light availability. Those microenvironments are the better to plant growth and performance where plants reach $3 \mathrm{~m}$ of height in $3 \frac{1}{2}$ years. Microenvironments with 25 to $30 \%$ of coverage, that received at least $50 \%$ of full sun, were the optimum to plant Cabralea canjerana. As the species has high capacity of acclimation, it is possible to plant it in a wide range of microenvironments, as under full sun or below a dense canopy, with $<5$ moles photons $\mathrm{m}^{-2}$ day $^{-1}$. However, if plantation is done below a dense canopy, growth will be very low and incident light should increase during the first 3 years after plantation. 
In the native forest, Cabralea canjerana regenerated spontaneously below the dense forest in groups. This grouping continued until sapling category (J). Small seedlings $(<50 \mathrm{~cm}$ height) survived at least 3 years in the understory. Plant frequency in the following category (seedlings, $50<$ height $<130 \mathrm{~cm}$ ) was much lower, therefore high mortality occurred in PP category compared with higher categories. Mortality can be due to coverage. Therefore, management practices as understory vegetation control can be useful to stimulate seedling growth to reach the upper canopy. A $90 \%$ coverage allow plant to grow, but with a coverage lower than $75 \%$ growth will be higher.

With regard to the application of the results, this Thesis gives key information to develop restoration planes of degraded areas, because microenvironments where Cabralea canjerana can be planted are defined and abiotic stresses are quantified. It is possible to plant Cabralea canjerana in many microenvironments, because the species has high acclimation capacity. In this research, a concrete and successful enrichment was done in the rainforest, and ecophysiological traits were measured, in addition to growth and survivorship, to understand the responses of the plants to the environment. Furthermore, we analyzed natural regeneration, and the results have implications to develop silvicultural strategies to manage the rainforest. 


\section{Capítulo 1: Introducción general}






\subsection{Situación actual de los bosques nativos de Misiones y área de estudio}

El bosque Atlántico de Sudamérica está constituido por 15 ecorregiones de bosques tropicales y subtropicales que se extienden a lo largo de la costa atlántica de Brasil, Paraguay oriental y noreste de Argentina. Es una de las 200 ecorregiones en el mundo que contienen la mayor diversidad del planeta (Olson y Dinerstein 2002). Existen registros de 11.000 años de antigüedad del uso de estas tierras por los pueblos originarios, principalmente guaraníes. Sin embargo, a partir del siglo XVI, con la llegada de los europeos a esta región su uso se incrementó paulatinamente. En estos territorios se asentaron grandes urbes y se produjeron grandes cambios en el uso de las tierras para la producción agrícola-ganadera. Con el tiempo se asentó la industria, se desmontaron grandes extensiones de bosque para el aprovechamiento de la madera y se incorporaron las plantaciones de especies forestales de rápido crecimiento (principalmente pino y eucalipto) (Di Bitetti et al. 2003). Esta sobreexplotación de los recursos transformó la selva en un paisaje altamente fragmentado con una gran pérdida de la funcionalidad de los ecosistemas. Actualmente, sólo queda un $7,8 \%$ de su cobertura original de $1.713 .535 \mathrm{~km}^{2}$ (171.353.500 ha) y es uno de los bosques lluviosos más amenazados del mundo (Di Bitetti et al. 2003).

La selva misionera o Selva Paranaense (Burkart et al. 1999), pertenece específicamente a dos ecorregiones del Bosque Atlántico: el Bosque Atlántico del Alto Paraná que abarca la mayor parte del territorio y el Bosque Húmedo de Araucaria. Estos originalmente ocupaban la mayor superficie dentro del bosque atlántico, con una superficie de aproximadamente $471.000 \mathrm{~km}^{2}$ de bosques. Las variaciones en el ambiente local y el tipo de suelo permiten la existencia de diferentes comunidades vegetales, bosques en galería, selvas de bambú, bosques de palmito y bosques de araucaria. La ecorregión Bosque Atlántico del Alto Paraná se halla situada al sur del Macizo de Brasil. La topografía de la región comprende desde áreas relativamente planas con suelos profundos hasta altitudes entre 300-600 msnm. Hacia el este, en los sitios más elevados predomina la ecorregión del Bosque Húmedo de Araucaria. La temperatura media anual es de 16$22^{\circ} \mathrm{C}$ con una variación anual relativamente alta, las precipitaciones van desde los 1000 a 2200 $\mathrm{mm}$ anuales y las heladas duran pocas horas y ocurren en los meses de invierno (junio-agosto). Según las regiones fitogeográficas, la selva misionera pertenece a la región fitogeografica Neotropical, Dominio Amazónico, Provincia Paranaense. En Argentina, la Provincia Paranaense, 
abarca toda la provincia de Misiones y el extremo noreste de Corrientes, y está constituida por dos distritos fitogeográficos, el Distrito de las selvas mixtas y el distrito de los campos (Cabrera 1976).

En el mundo, entre el 2001 y 2015 se perdieron cerca de 3 millones de $\mathrm{km}^{2}$ de bosques. El $27 \%$ de los bosques que se perdieron fueron consideradas pérdidas permanentes, y las principales causas fueron el cambio de uso de la tierra para la agricultura (producción de soja, madera y carne vacuna). Por otro lado, el $73 \%$ de las pérdidas fueron atribuidas a procesos no permanentes, a actividades humanas que indirectamente degradan el bosque (por ejemplo, la agricultura de subsistencia y los incendios forestales) pero no son daños irreversibles. Según esta clasificación, en Misiones predominan actividades de agricultura de subsistencia, donde pequeñas área son cultivadas y luego abandonadas (categoría denominada: "shifting agriculture"), y actividades de degradación por cambio de uso de la tierra a plantaciones forestales (categoría denominada: "Forestry") (Curtis et al. 2018). Según el ordenamiento territorial de bosque nativo actualizado en 2017, la provincia de Misiones tiene 1.638.147 ha de bosque nativo distribuidas en las 3 categorías de conservación rojo, amarillo y verde (http://bosques.ambiente.gob.ar/geomaps\#heading1). Entre 2007 y 2016 se registró una pérdida de 47.388 ha de selva con un pico de 16.989 ha en 2007 (http://bosques.ambiente.gob.ar/geomaps\#heading1). La selva albergan la mayor diversidad vegetal del país, con más de 2.800 especies (Rodriguez et al. 2005). Aproximadamente el 37 \% de la superficie de la provincia de Misiones se encuentra protegida y fue declarada en el año 2.000 área de conservación y uso sustentable (Gomez y Ferrero 2011), también denominado corredor verde. El resto de las tierras forestales presenta actualmente un alto nivel de fragmentación, degradación y sustitución debido principalmente a: 1) la extracción selectiva de madera de alto valor; 2) al cambio de uso de la tierra llevado a cabo por colonos y campesinos desde 1.926, cuando se les otorgó por ley, 25 ha de tierra para llevar adelante las producciones de yerba mate y otros cultivos; y 3) al remplazo de grandes extensiones de bosques por plantaciones de pinos y eucaliptos, producido principalmente en la década del 70. Este cambio de uso de la tierra fue llevado a cabo por grandes empresas (2/3 de las tierras productivas pertenecen a grandes empresarios) (Drozd 2011).

\subsection{Dinámica de la selva y regeneración natural}

Los bosques tropicales y subtropicales se caracterizan por ser multietáneos, ya que están constituidos por cohortes de diferentes edades, y multiespecíficos porque tienen una gran 
diversidad de especies que conviven en diferentes estratos. Las especies son clasificadas en dominantes, codominantes, intermedias y suprimidas según la dominancia de copas. En los diferentes estratos arbóreos conviven individuos de diferentes especies de más de una categoría de copa, debido principalmente a pequeños disturbios que propician el crecimiento y regeneración de nuevas cohortes. El estrato superior está constituido por los individuos emergentes. El estrato siguiente se caracteriza por presentar una estructura de copas más densas donde las diferentes especies de la sucesión secundaria tardía y temprana conviven y compiten por los recursos. Los estratos inferiores están constituidos por individuos de bajo porte y por individuos jóvenes de las especies que luego podrían dominar el dosel superior. En el sotobosque se desarrollan especies herbáceas y arbustivas tolerantes a la sombra y además se instala la regeneración (Oliver y Larson 1996).

Las condiciones del clima, la estructura y dinámica de los rodales generan un continuo de microambientes donde se desarrollan las especies (Wright et al. 2003). La selva subtropical se caracteriza por tener estacionalidad marcada, veranos calurosos y muy húmedos con temperatura promedio de $25^{\circ} \mathrm{C}$, e inviernos suaves con temperatura promedio de $15^{\circ} \mathrm{C}$ y con periodos cortos de heladas con temperaturas bajo cero. Las precipitaciones varían entre 1500-2400 mm anuales.

Los disturbios en la naturaleza son frecuentes, y de diferentes magnitudes. Ocurren disturbios que arrasan con grandes áreas y otros de menor escala. Los disturbios de grandes áreas dejan sitios devastados donde comienzan una serie de etapas que definen el patrón espacial y la estructura del rodal. En pocas palabras, luego de un disturbio pocas especies aparecen en el área, y con el tiempo alteran el ambiente propiciando que otras especies se establezcan. Este proceso modifica nuevamente el ambiente y se establecen otras especies. Durante este proceso ocurren interacciones entre las especies y en consecuencia se producen incorporaciones, muertes y cambios constantes en el microambiente (Oliver y Larson 1996).

El patrón de regeneración de los árboles es generalmente agrupado al inicio, y con el paso del tiempo, surge un patrón espacial característico como resultado de una competencia inter e intraespecífica que causa la mortalidad de individuos y cambio en la frecuencia de las especies. Los árboles sobrevivientes cambian de agrupados a una distribución aleatoria y luego se aproximan a una distribución regular. Durante las etapas juveniles y adultas la competencia inter e intra específica juegan un papel importante en la supervivencia de los individuos y en el desarrollo de los patrones de distribución. La regeneración natural es uno de los procesos más importantes en la selva, ya que constituye la renovación y continuidad de las especies y la funcionalidad de los 
ecosistemas. Ésta ocurre continuamente en el piso forestal. El éxito del establecimiento de la regeneración va a depender de muchos factores. Por un lado, de la producción y viabilidad de las semillas, la presencia de agentes dispersores y la germinación y establecimiento de las plántulas (Norden 2014; González de Andrés et al. 2014). Una vez superada la barrera de la dispersión y establecimiento en un sitio, otros procesos ecológicos y factores ambientales como la luz y la humedad del suelo empiezan a jugar un rol fundamental. Si bien la luz es uno de los factores más importante y cambiantes para el establecimiento de algunas especies, principalmente heliófitas (Mulkey et al. 1996; Montagnini y Jordan 2005; González de Andrés et al. 2014), es sabido que el establecimiento de las plantas en los bosques tropicales y subtropicales ocurre principalmente en el sotobosque con doseles superiores densos y con múltiples estratos. Esto podría explica por qué la gran mayoría de las especies de árboles son tolerantes a la sombra en la fase inicial de establecimiento (Norden 2014). Otros factores bióticos y abióticos como los insectos, depredadores de semillas (Traissac y Pascal 2014), hongos, daños mecánicos por animales, la caída de árboles, la competencia de la vegetación rastrera (Schwartz et al. 2014), y la dependencia negativa de la distancia y la densidad explican la regeneración y la coexistencia de las especies (Norden 2014). La hipótesis de la dependencia negativa de la distancia y la densidad establece que la supervivencia de las plántulas se reduce con la cercanía a los adultos conespecíficos y la cercanía entre plántulas de la misma especie, debido a la presencia de agentes patógenos altamente especializados, y a que compiten por los mismos requerimientos (Comita et al. 2014). Por lo tanto, este mecanismo podría ser estabilizante de la coexistencia de las especies, ya que la competencia intraespecífica favorece el establecimiento de individuos de otras especies. Otros estudios han demostrado que las especies menos abundantes como adultos son las que sufrieron la dependencia negativa de la densidad más fuerte durante el establecimiento (Norden 2014).

Las características de los suelos, la disponibilidad de agua y nutrientes también condicionan el crecimiento de las plantas, que son afectadas principalmente por la falta de agua. La gran masa boscosa generada proporciona condiciones de humedad ambiente y de los suelos propicios para el desarrollo y crecimiento. Los suelos de los bosques tropicales y subtropicales son poco fértiles, debido a las altas temperaturas y el gran volumen de precipitaciones que aceleran los procesos de meteorización y lixiviación de nutrientes. Sin embargo, la gran circulación de materia orgánica aportada por el material vegetal de los diferentes estratos del bosque, la presencia de micorrizas y la captura de nutrientes del aire, propician el desarrollo de las selvas (Lamprecht 1990). 


\subsection{Cobertura arbórea y disponibilidad de luz en la selva}

La luz es sin dudas el factor ambiental que se encuentra en un mínimo relativo en las selvas tropicales y subtropicales (Lamprecht 1990). La luz llega a los diferentes estratos del bosque en diferentes calidades e intensidades, propiciando los procesos de regeneración, crecimiento y desarrollo de las plantas. La radiación directa que llega al bosque es absorbida principalmente por los estratos superiores e intermedios del dosel. Sin embargo, una pequeña cantidad de luz atraviesa el dosel superior y llega al sotobosque a través de flecos de luz. Los flecos de luz contribuyen potencialmente entre el 37 y $68 \%$ de la luz fotosintéticamente activa que llega al sotobosque (Canham et al. 1990). A medida que la luz atraviesa la copa de los árboles, su intensidad disminuye y es enriquecida proporcionalmente en rojo lejano, ya que la luz roja es absorbida preferencialmente por las hojas de las plantas. De este modo, la relación rojo/rojo lejano varía según la cobertura existente (Mulkey et al. 1996; Montagnini y Jordan 2005). Se ha reportado una relación rojo/rojo lejano de 0,26 para bosques maduros y 0,47 para el sotobosque de un bosque secundario (Valladares et al. 2012). El ingreso de luz a los estratos inferiores de la selva es dinámico y se produce por ejemplo, por la porosidad de las copas de los árboles, el movimiento de las hojas por el viento, la caída de las hojas de árboles caducos en invierno, y por la caída de ramas o de ejemplares enteros (Denslow 1987; Gandolfi et al. 2009). Por otro lado, la cantidad de luz que llega al sotobosque varía con la latitud a la que esté ubicado el bosque. Los bosques tropicales y subtropicales presentan variaciones en la cantidad de luz que llega a los estratos inferiores y en los sitios dentro de claros. En un bosque tropical, de 0 a 0,9 \% de radiación directa llega al sotobosque, y en un bosque subtropical llega mayor cantidad, de 0,4 a 3,4 \% (Canham et al. 1990).

Los disturbios podrían ser clasificados según su origen, tamaño, e incidencia en el sitio en: disturbios a escala de claro, disturbios de severidad intermedia y catástrofes (Hart et al. 2018). Los disturbios en la selva generan áreas abiertas donde la llegada de luz al sotobosque aumenta significativamente por un periodo variable de tiempo. Este aumento, propicia la regeneración de las especies, principalmente las demandantes de luz, denominadas heliófitas (Mulkey et al. 1996; Montagnini y Jordan 2005; González de Andrés et al. 2014). Sin embargo, la formación de los claros, no define la regeneración de todas las especies arbóreas, ya que la mayoría de las especies de la selva tienen la capacidad de regenerar bajo la cobertura densa del sotobosque. La apertura 
del claro también favorece el establecimiento definitivo y el crecimiento de aquellos individuos que se establecieron en las condiciones previas al disturbio. Por otro lado, si bien el aumento de la disponibilidad de luz es beneficioso, estos cambios repentinos de luz podrían afectar el crecimiento y desarrollo de las especies establecidas en el sotobosque, ya que podría causar daños al sistema fotosintético o causar estrés hídrico severo (Quevedo-Rojas et al. 2018) .

El tamaño, orientación, frecuencia y distribución espacial de los claros definen el microambiente y otorgan una gran heterogeneidad de los factores climáticos que condicionan la regeneración, la diversidad de especies y la estructura de la selva (Garbarino et al. 2012; Amir 2012). Por otro lado, el relieve, el tamaño de los árboles que rodean al claro y la presencia de especies remanentes dentro del claro condicionan el microclima de los mismos (Amir 2012). La acción antrópica también genera disturbios de muy variadas dimensiones. Disturbios a escala de claros pueden producirse por la extracción de individuos de gran porte de especies con valor comercial. Disturbios de mayores dimensiones pueden producirse por los rozados, que son el desmonte de superficies no muy extensas de bosque nativo para realizar agricultura durante 4 o 5 años, y que luego son abandonadas. A estos disturbios se los clasifica de severidad intermedia. Finalmente, disturbios a escala de claros de diferente magnitud pueden realizarse por la aplicación de diferentes prácticas de manejo que se emplean para restaurar áreas degradadas (Hart et al. 2018). El tamaño de los claros naturales puede variar desde menos de $10 \mathrm{~m}^{2}$ hasta más de $400 \mathrm{~m}^{2}$ en las selvas tropicales y subtropicales y de $20 \mathrm{~m}^{2}$ hasta $5000 \mathrm{~m}^{2}$ en ambientes templados (Denslow 1987; Coates 2002; De Lima y De Moura 2008). La variación en el tamaño del claro genera que en un día soleado, la duración de luz en el centro sea mayor en claros más grandes. Por ejemplo, en claros de $400 \mathrm{~m}^{2}$ llegan en promedio $500 \mu$ moles. $\mathrm{m}^{-2} \mathrm{~s}^{-1}$ de densidad fotónica de PAR, mientras que en un claros de $200 \mathrm{~m}^{2}$ llegan $100 \mu$ moles. $\mathrm{m}^{-2} \mathrm{~s}^{-1}$ (Denslow 1987). Por otro lado, la llegada de luz a los diferentes sitios dentro del claro y a los bordes del claro es mayor en los bosques subtropicales con respecto a los bosques tropicales o templados debido principalmente a la latitud y el clima (Canham et al. 1990). En un estudio donde evaluaron el patrón de la regeneración de individuos en claros de diferentes tamaños, concluyeron que la densidad de individuos regenerados no varió con el tamaño del claro. Sin embargo, el crecimiento en altura y diámetro a la altura del cuello de la regeneración fueron mayores en los bordes del claro (Wang et al. 2019). Luego de la formación del claro, además de cambios en la disponibilidad de luz, ocurren otros procesos importantes, como el aumento de la temperatura del aire y del suelo en el centro del claro (Denslow y Hartshorn 1994). También puede producirse, en ambientes con 
precipitaciones de baja intensidad, aumento de la humedad del suelo porque la intercepción de Iluvias por las copas se reduce, y por lo tanto aumenta la llegada de agua al suelo (Vanclay 2009). Sin embargo, en regiones con precipitaciones intensas como las tropicales y subtropicales, la evaporación de agua de la superficie del suelo en días sin precipitaciones podría contribuir a que la disponibilidad de agua en el suelo en el centro de los claros no sea suficiente para abastecer los requerimientos de las plantas (Camargo y Kapos 1995; Kitajima 1996). También en los claros pueden ocurrir cambios en la disponibilidad de nutrientes porque se acelera la descomposición de restos orgánicos y aumenta la mineralización de materia orgánica por la mayor temperatura, impacto de las gotas de lluvia y turbulencia del aire (Denslow et al. 1998). Asimismo, en el centro del claro disminuye la amortiguación de las bajas y alta temperaturas y disminuye la humedad relativa del aire (Fetcher et al. 1994). Es así, que la formación de claros no sólo impacta en la disponibilidad de luz, sino que también puede impactar en la disponibilidad de agua y nutrientes.

\subsection{Plasticidad fenotípica y aclimatación de las especies}

La heterogeneidad ambiental de la selva genera un continuo de microambientes donde se desarrollan las especies. Estas coexisten debido a que tienen diferentes requerimientos de recursos y plasticidad fenotípica. Muchas especies de la selva que viven en el sotobosque, han sido denominadas tolerantes a la sombra o especies esciófitas, caracterizadas por tener bajos requerimientos de luz. En el extremo opuesto están aquellas especies muy demandantes de luz denominadas heliófitas o pioneras, que germinan y crecen cuando la disponibilidad de luz es alta, por ejemplo luego de la ocurrencia de algún disturbio (Kitajima 1996). Por último, están las especies que tienen la capacidad de germinar y establecerse en condiciones de poca disponibilidad de luz, pero desde una edad temprana requieren luz para poder crecer y eventualmente llegar al dosel superior. Estas especies denominadas intermedias en cuanto a los requerimientos de luz o parcialmente tolerantes a la sombra (Lamprecht 1990), son las más frecuentes en las selvas tropicales y subtropicales (Lamprecht 1990; Montgomery y Chazdon 2002; Felton et al. 2006; Campanello et al. 2007). Esta estrategia podría deberse a que a lo largo de su evolución los individuos de la especie experimentaron cambios continuos de luz, y en consecuencia desarrollaron mayor plasticidad fenotípica que los individuos de otras especies, que poseen actualmente requerimientos más estrictos de luz o sombra. 
La plasticidad fenotípica es la capacidad que tienen las especies de aclimatarse mediante cambios morfológicos y fisiológicos a diferentes ambientes (Donoso 1994; Chambel et al. 2005). Se asume que las especies intolerantes a la sombra y las intermedias tienen mayor plasticidad que las especies tolerantes a la sombra, aunque estas últimas puedan ajustar fuertemente ciertos rasgos morfológicos a la luz comparado con especies intolerantes a la sombra (Valladares y Niinemets 2008). Las especies con mayor plasticidad son más fáciles de manejar cuando se trabaja en ambientes heterogéneos (Felton et al. 2006), porque la plasticidad es una propiedad que le permite a los individuos captar y retener recursos que están disponibles en niveles bajos y evitar daños producidos por exceso o escasez de otros recursos. En muchos ambientes, los recursos necesarios para el crecimiento de las plantas no están disponibles en rangos adecuados (Lambers et al. 1998). En primer lugar, algunas respuestas fisiológicas pueden ocurrir en minutos u horas, como el cierre estomático frente a un estrés por falta de agua y la degradación de la clorofila frente a un exceso de luz. Si el estrés es aliviado por estas respuestas, se denomina estrés leve. Si las primeras respuestas no son suficientes para terminar con el estrés, algunas modificaciones pueden ocurrir en días o meses, denominados procesos de aclimatación, como cambios en área foliar total, anatomía y fisiología de hojas, tallos y raíces y partición de materia seca (Lambers et al. 1998). Estos cambios pueden ser suficientes para sortear el estrés, por lo tanto, no se observa una disminución en el crecimiento total. Sin embargo, si la limitación o exceso de recursos está lejos del rango óptimo, y la aclimatación no es suficiente para prevenir la reducción del crecimiento (por ejemplo, acumulación de materia seca de la planta entera, altura), el estrés es severo. Por lo tanto, la aclimatación morfológica y fisiológica, así como la reducción del crecimiento son signos de estrés (Niinemets 2010).

Las respuestas de aclimatación a baja o alta irradiancias pueden ser morfológicas y fisiológicas. Algunas respuestas morfológicas de aclimatación a las bajas irradiancias son el mayor área foliar específica que permite mayor área de intercepción de luz con menor inversión de materia seca. También puede observarse hojas más grandes y delgadas que aumentan el área foliar expuesta a la radiación. En cuanto a la partición de materia seca, las plantas aclimatadas a baja radiación suelen tener mayor relación vástago/raíz, porque la planta destina proporcionalmente más fotoasimilados a tallos y hojas que permite interceptar más luz en detrimento de la raíz. Puede observarse también elongación de tallos hacia la fuente de luz mediada por los fitocromos y criptocromos, que son compuestos fotorreceptores que intervienen en la fotomorfogénesis de las plantas. Por otro lado, se pueden observar algunas respuestas 
fisiológicas a la baja irradiancia. Puede registrarse mayor concentración de clorofila por unidad de área foliar, ya que la clorofila es la molécula fotosensible, presente en las antenas colectoras de luz, que canaliza los fotones hacia el centro de reacción que inicia la fase fotoquímica de la fotosíntesis. Asimismo, suele observarse menor relación clorofila $a / b$, ya que proporcionalmente aumenta más la clorofila b que se encuentra en las antenas colectoras de luz asociadas a los fotosistemas (Walters 2005). En cuanto al balance de carbono, las plantas aclimatadas a baja radiación tienen menor tasa respiratoria, debido a tasas metabólicas más bajas, menor fotosíntesis neta a saturación lumínica, debido a que el aparato fotosintético satura a baja irradiancia ya que contiene grandes complejos colectores de energía pero menos centros de reacción, y menor punto de compensación lumínico como consecuencia de la menor tasa respiratoria (Strauss-Deberiedetti y Bazzaz 1996; Valladares y Niinemets 2008). También suele observarse en las plantas aclimatadas a baja irradiancia menor capacidad de disipar el exceso de radiación mediante mecanismos no fotosintéticos, que pueden estar dado, por ejemplo, por menor concentración de pigmentos caroteniodes (Krause et al. 2012).

Por otro lado, las condiciones de luz plena se asocian con alta demanda evapotranspirativa, de manera que la mortalidad o baja tasa de crecimiento en situación de apertura de claro puede deberse al estrés hídrico (Fetcher et al. 1994). Dicho estrés puede estar provocado por un bajo contenido de agua del suelo o porque la planta no logra abastecer de agua a las hojas y tejidos en crecimiento a la velocidad suficiente para compensar las pérdidas por transpiración (Rodríguez-Calcerrada et al. 2008). En estos casos, se podrá observar pérdida de turgencia de los tejidos, cierre estomático parcial o total, reducción del potencial hídrico de los tejidos y cavitación y embolismo de pecíolos, tallos o raíces (Campanello et al. 2008). Las especies pueden tener plasticidad fenotípica para las características que condicionan la capacidad de tolerar situaciones de sequía o altas demandas evapotranspirativas y pueden modificar su morfología y fisiología para aclimatarse a dichas condiciones (Chambel et al. 2005). Algunos cambios posibles son la reducción del área foliar que se asocia a menor superficie transpirante y el aumento de sistema radical absorbente que implica mayor partición de materia seca a las raíces en desmedro del vástago, pero aumenta el volumen de suelo explorado, y por lo tanto la cantidad de agua disponible (Fetcher et al. 1994). En el corto plazo, el cierre estomático ante el aumento del déficit de saturación de la atmósfera o frente a la reducción en el contenido de agua en el suelo, reduce inmediatamente la transpiración y evita la disminución del contenido de agua y del potencial hídrico de la planta (Brodribb y Jordan 2008). De manera similar, el ajuste osmótico o 
elástico en hojas y raíces permiten mantener un gradiente de potencial hídrico favorable al movimiento de agua desde el suelo hacia la planta a medida que el contenido de agua del suelo disminuye y consecuentemente se reduce el potencial hídrico (Shimizu et al. 2005). En la misma dirección, la generación de xilema menos vulnerable a la cavitación, la mayor conductividad hidráulica de raíces y tallos, son mecanismos que permiten mantener o aumentar el movimiento de agua en la planta sometida a estrés hídrico (Choat et al. 2007). Todos estos cambios tienden a mejorar el estado hídrico de los tejidos.

\subsection{Definición de estrés leve, moderado y severo y características para describir el estrés por luz y agua}

El crecimiento es un cambio irreversible en volumen o materia seca. Teóricamente, si las plantas pudieran crecer sin limitación de ningún recurso, se lograría el crecimiento máximo o potencial. Si los tamaños iníciales de dos plantas (i.e. altura, materia seca) son iguales, pero luego de transcurrido un periodo de tiempo determinado la planta del ambiente A llega a menor tamaño que la planta del ambiente $B$, el crecimiento en el ambiente $A$ fue menor que en el ambiente $B$, cualquiera sea el crecimiento potencial. Si bien no es posible en la práctica conocer el crecimiento potencial, si una planta tiene menor crecimiento en un ambiente $A$ que en un ambiente $B$, el ambiente A le impuso mayor estrés que el B. El nivel de estrés está relacionado con la cantidad de recursos disponibles y el tiempo que dure el exceso o limitación. Algunas respuestas fisiológicas para sortear el estrés pueden ocurrir en minutos u horas, otras en días o meses. Sin embargo, si la limitación o exceso de recursos está lejos del rango óptimo, y la aclimatación no es suficiente para prevenir la reducción del crecimiento, el estrés es severo, por más que se registre crecimiento. Bajo un estrés severo las plantas crecerán menos que en otra condición. Por lo tanto, la aclimatación morfológica y fisiológica, así como la reducción del crecimiento son signos de estrés (Niinemets 2010). Para esta tesis, y basado en los mecanismos explicados en el apartado 1.6, definimos que las respuestas reversibles en el corto plazo serán consideradas un estrés leve, aclimataciones sin reducción del crecimiento serán consideradas estrés moderado, y reducción en el crecimiento será considerado como estrés severo. Tanto para definir una aclimatación como para definir una reducción en el crecimiento, es necesario comparar al menos dos ambientes. Cuando se comparan distintas intensidades de cobertura del dosel, estos ambientes podrán imponer diferentes grados de estrés lumínico e hídrico. Los estreses por déficit de agua o de luz, o 
por exceso de luz podrían producir diferentes respuestas. Si las plantas sufren estrés leve por déficit de agua, se espera una reducción de la conductancia estomática y del potencial hídrico de las hojas al mediodía (Valladares et al. 2004). Si el estrés es moderado, se espera un incremento del índice estomático para reducir la resistencia del flujo de agua líquida, así como un incremento de la densidad estomática, como resultado de una menor expansión foliar; una disminución de la relación vástago/raíz para explorar proporcionalmente más suelo; un incremento de la relación área de xilema de tallo/área foliar para tener mayor superficie de conducción en tallo para abastecer con más agua a las hojas; un aumento de la conductancia hidráulica de las raíces, tallos y hojas para incrementar el movimiento del agua a lo largo de la planta y una reducción de área foliar total para reducir el área transpirante. Si el estrés es severo, además se espera una reducción del peso seco de la planta entera, y de la altura y/o del diámetro del cuello de las plantas. Por otro lado, sí las plantas sufren un estrés leve por exceso de luz, se espera una reducción en el rendimiento cuántico intrínseco y máximo del fotosistema II debido a un daño en el aparato fotosintético. Si el estrés es moderado, se espera una reducción de la concentración de clorofila que reduce la absorción de luz y una reducción en el área foliar específica que reduce la llegada de luz las células del interior del mesófilo. Si el estrés es severo, además se espera una reducción del peso seco de la planta entera, y de la altura y/o del diámetro del cuello de las plantas. Por último, si las plantas sufren un estrés leve por déficit de luz, se espera una baja tasa de transporte de electrones a nivel del fotosistema 2, debido a la baja radiación incidente. Si el estrés es moderado, se espera un incremento de la concentración de clorofila, de área foliar específica, de la elongación del tallo y relación vástago/ raíz, que se asocia con un aumento en la intercepción de luz. Por otro lado, se espera una baja relación clorofila a/b debido a un aumento del complejo de antenas captadoras de luz, menores tasas respiratorias y punto de compensación lumínico para tener un intercambio de carbono positivo con baja radiación. Si el estrés es severo, además se espera una reducción de peso seco de la planta entera (Lambers et al. 1998; Larcher 2003).

\subsection{La especie}

Cabralea canjerana (Vell.) Mart. (cancharana) es una espacie arbórea nativa de la Selva misionera de alto valor ecológico y maderero. Su área de distribución se extiende desde Costa Rica hasta el sur de Brasil, este de Paraguay y norte de Argentina (Schussler 2006). Es un árbol 
perennifolio o semicaducifolio, su arquitectura se caracteriza por ser de copa frondosa con tronco largo y recto, alcanzando alturas de $30 \mathrm{~m}$ y diámetros de $1 \mathrm{~m}$ (Figura 1.1.A). Con relación a su valor económico y calidad maderera posee características similares al cedro misionero. La corteza externa es de color gris, semi-áspera, con un ancho entre 10 a $18 \mathrm{~mm}$. Posee madera rojiza, con una densidad de $0,700 \mathrm{~g} / \mathrm{cm}^{-3}$ perteneciendo a las maderas semipesada y semidura (Tortorelli 2009). En cuanto a las características anatómicas de la madera se caracteriza por tener porosidad difusa con disposición de los vasos en patrón no especificado, agrupados generalmente en grupos radiales cortos (de 2-3 vasos). El promedio de vasos es de 6 a 12 vasos $/ \mathrm{mm}^{2}$ (hasta 25 vasos $/ \mathrm{mm}^{2}$ ) (Tortorelli 2009) (Figura 1.1.C).

Las hojas son compuestas, opuestas, imparipinadas de 20 a $50 \mathrm{~cm}$ de largo. Cada una tiene de 8 a 15 pares de folíolos oblongos, de 6 a $15 \mathrm{~cm}$ de largo y de 2 a $6 \mathrm{~cm}$ de ancho. Tiene el ápice puntiagudo, base asimétrica, es de color verde oscuro y las superficies de los folíolos son glabras. Las flores son en Inflorescencia en panículas laterales de 5 a $15 \mathrm{~cm}$ de largo; 5 a 20 flores hermafroditas, blanco verdosas, de 5 a $10 \mathrm{~mm}$ de largo, con cinco pétalos angostos. Si bien las flores son hermafroditas, la especie se comporta como dioica, ya que, las flores femeninas tienen anteras estériles, y las flores masculinas tienen los ovarios estériles (Felippi et al. 2015). Los frutos son cápsulas globosas, de 2 a $3 \mathrm{~cm}$ de diámetro, de color morado a rojizo, carnosas a semi-leñosas que se abren en cinco valvas (Figura 1.1.B). El inicio de la formación de los frutos ocurre entre los meses de noviembre y diciembre, presentándose una larga fase de maduración de los frutos de aproximadamente un año (González y Barth 2003). El pico de maduración ocurre en noviembrediciembre con abundante producción de semillas que son dispersadas principalmente por aves y hormigas que cumplen un papel importante como dispersores secundarios y facilitadores de la germinación (Pizo \& Oliveira 1998, Pizo \& Oliveira 2000). 


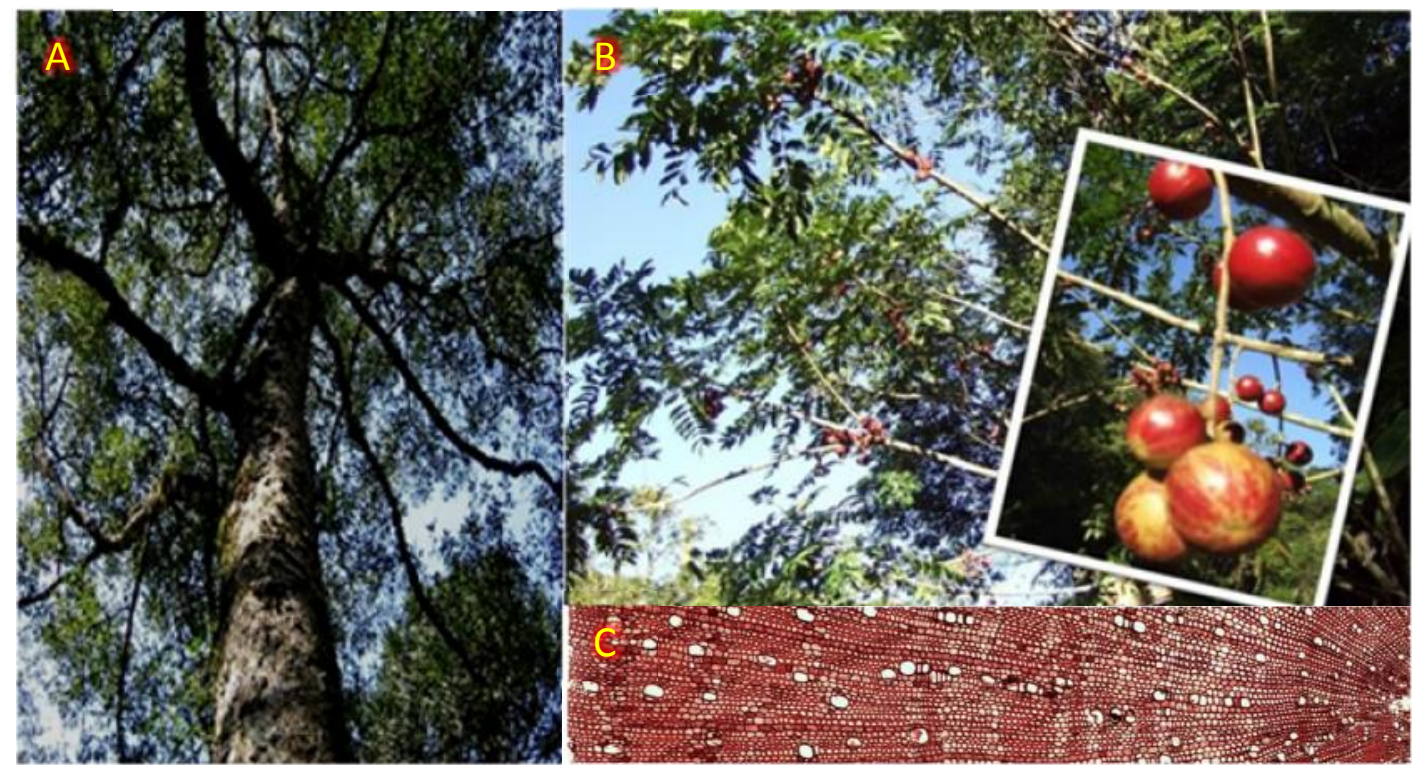

Figura 1.1: Árbol adulto de Cabralea canjerana (A), árbol adulto con frutos (B) y corte transversal de madera de Cabralea canjerana 10x (C).

Cabralea canjerana regenera naturalmente en diversos ambientes, bajo bosque denso, bosques secundarios (capueras) y áreas abiertas (Cargnelutti Filho et al. 2012; Carpenedo Aimi 2014). Se la ha clasificado como una especie secundaria tardía dentro de las etapas de sucesión de la selva, y se la considera tolerante a la sombra en las etapas juveniles (Carvalho 1996). En el bosque nativo se observan grupos de individuos de Cabralea canjerana que ocupan el estrato medio del bosque asociados a los árboles adultos de la misma especie, o en otros sitios, posiblemente asociados a árboles perchas utilizadas con más frecuencia por las aves dispersoras de esta especie (Pinazo et al. 2009b). Sin embargo, la mortalidad de individuos jóvenes antes de llegar a 1,3 m de altura es elevada. También se observa regeneración espontánea bajo plantaciones de Pinus spp y Araucaria angustifolia, aunque es poco frecuente observar plantas jóvenes a sol pleno. En síntesis, Cabralea canjerana es potencialmente adecuada para evaluar una silvicultura basada en la regeneración natural y prácticas de enriquecimiento del bosque nativo dado que es una especie presente en el bosque degradado, posee abundante producción de semillas, la germinación y el establecimiento inicial ocurren espontáneamente, algunos individuos llegan a los estratos intermedios y superiores del dosel y se conocen las técnicas de producción de plantas en vivero (Ríos et al. 2008; Moscovich et al. 2010). 


\subsection{Enriquecimiento}

La selva misionera ha sufrido alteraciones continuas en su estructura y composición específica con una consecuente degradación de los recursos y pérdida de funcionalidad del ecosistema. Estos ambientes podrían recuperarse solos, sin embargo, el hombre puede acelerar los procesos de recuperación mediante su intervención a través de la restauración ecológica. La restauración ecológica tiene como objetivo recuperar la funcionalidad de los ecosistemas en el tiempo (Clewell et al. 2004). Existen diversas herramientas para llevar a cabo la restauración ecológica, una de ellas es el enriquecimiento, que consiste en incorporar especies nativas de valor ecológico en sitos de bosques degradados sin alterar lo ya existente (Montagnini et al. 2006). Sin embargo, al momento de llevar adelante las prácticas de enriquecimiento en el bosque nativo, la falta de información acerca de cómo, dónde y cuándo llevar a cabo la acción de enriquecimiento o restauración impide tomar decisiones fundamentadas. Por lo tanto, es muy importante estudiar la autoecología de las especies y evaluar los sitios donde llevar a cabo los procesos de restauración para poder proponer prácticas de manejo y restauración. Estos estudios permiten disponer de evaluaciones científicas para encontrar respuestas a diversas preguntas prácticas: dónde plantar, con qué especies, con qué semillas, en qué época, qué características microambientales de los sitios favorecen el establecimiento y crecimiento, entre otras (Morales et al. 2018). Esta búsqueda científica de la información es denominada ecología de la restauración, que idealmente proporciona conceptos claros, modelos, metodologías y herramientas que apoyan la práctica de los profesionales (Clewell et al. 2004).

\subsection{Objetivos e hipótesis}

Para comprender la capacidad de regeneración de Cabralea canjerana en los diferentes ambientes producidos por cambios en la estructura de los bosques (Oliver y Larson 1996) y manejar la regeneración de esta especie, es importante conocer la plasticidad fenotípica de caracteres importantes para la supervivencia en diferentes condiciones de cobertura de dosel (Kuehne et al. 2014). Adicionalmente es importante conocer la dinámica natural de regeneración en el bosque nativo para entender y describir el ambiente en el que regenera y el que mejor propicia el crecimiento de la especie (Pinna et al. 2014). Con esta información disponible será 
posible desarrollar técnicas de manejo para ser aplicadas en restauración ecológica de aéreas degradadas con un fin de conservación o de producción sustentable (Elgar et al. 2014).

Objetivo general:

Comprender la capacidad de regeneración de Cabralea canjerana en los diferentes ambientes producidos por cambios en la estructura de los bosques.

Objetivos específicos:

Objetivo 1: Describir la plasticidad fenotípica de Cabralea canjerana durante el establecimiento inicial a través de cambios morfológicos y fisiológicos en condiciones contrastantes de cobertura (sol y debajo del canopeo)

Objetivo 2: Evaluar las respuestas ecofisiológicas de Cabralea canjerana a los 6 meses de plantación en un gradiente de cobertura en claros del bosque nativo.

Objetivo 3: Evaluar las respuestas de aclimatación de Cabralea canjerana al cambio de cobertura de canopeo a sol pleno, en comparación con las plantas que continuaron a la sombra del canopeo.

Objetivo 4: Evaluar la supervivencia, el crecimiento y la capacidad de aclimatación de Cabralea canjerana durante 3 años en un gradiente de cobertura en claros del bosque nativo.

Objetivo 5: Analizar la dinámica de la regeneración natural de Cabralea canjerana en bosques secundarios de la selva misionera.

Las hipótesis y predicciones se enuncian en el capítulo en que se describe cada objetivo específico.

\subsection{Breve organización de la tesis}

La tesis se estructura en 7 capítulos, un capítulo introductorio, un capítulo de metodología, 4 capítulos de resultados, un capítulo de consideraciones finales. Finalmente se incluye un Anexo con figuras suplementarias y la Bibliografía, donde se incluyeron las referencias bibliográficas de los textos citados en la tesis. 


\section{Capítulo 1: Introducción general}

Capítulo introductorio que contiene información general de la situación actual de los bosques misioneros y de la dinámica de la regeneración natural y las condiciones de cobertura. Por otro lado, se desarrollan conceptos teóricos de la aclimatación de las especies y la plasticidad fenotípica. Finalmente, se detallan los objetivos.

Capítulo 2: Sitio de estudio y metodología

Contiene la descripción metodológica detallada de los 3 ensayos realizados en esta tesis.

Capítulo 3: Aclimatación morfo-fisiológica a coberturas de canopeo contrastantes

En este capítulo se muestra la etapa 1 de los resultados del ensayo en macetas y las respuestas a los 6 meses de ensayo instalado en claros del bosque nativo. Para ambos ensayos se muestran los resultados de la aclimatación morfológica y fisiológica durante la primera etapa de crecimiento (luego de la primavera-verano). Si bien hay una diferencia de 2 meses entre las plantas de ambos ensayos, se incluyeron ambos resultados. En el caso del ensayo en macetas, los datos mostrados son del análisis y respuesta de las plantas a los 8 meses desde la instalación del ensayo (mayo de 2013). El experimento en macetas permite medir varios rasgos morfológicos y fisiológicos que pueden describir la capacidad de aclimatación y la tolerancia al estrés de una manera relativamente fácil. En el caso del ensayo en los claros del bosque nativo, se muestran los resultados de los primeros 6 meses desde la instalación del ensayo. Los resultados son mostrados mediante un análisis de componentes principales (ACP), para demostrar si algunas de las variables medidas en el experimento en macetas son útiles para predecir las respuestas al estrés y la aclimatación y crecimiento de las plantas plantadas en un gradiente de cobertura generado por claros del bosque nativo.

Capítulo 4: Supervivencia, crecimiento y capacidad de respuesta al cambio abrupto de cobertura de canopeo

En este capítulo se presentan los resultados de la etapa 2 del ensayo en macetas, cuando se realiza el traspaso de plantas de canopeo a sol pleno. Se analizan y evalúan las respuestas de aclimatación morfológica y fisiológica de las plantas de Cabralea canjerana luego del cambio 
abrupto de cobertura (tratamiento shock lumínico) y de los tratamientos canopeo y sol, hasta finalizar el ensayo 6 meses después.

Capítulo 5: Aclimatación en claros del bosque nativo

En este capítulo se presentan los resultados del ensayo en claros del bosque nativo, donde se integran los resultados de las mediciones de variables ambientales y de cobertura, de supervivencia y crecimiento hasta los $3 \frac{1}{2}$ años. Además, se presentan las respuestas de aclimatación de las plantas de Cabralea canjerana mediante la medición de variables morfológicas y fisiológicas en la primavera y otoño durante 2 1 12 años, desde la instalación de los ensayos.

Capítulo 6: Regeneración natural de Cabralea canjerana

En este capítulo se presentan los datos del relevamiento de la regeneración natural de Cabralea canjerana en el bosque nativo. Se realiza un análisis de patrones espaciales de puntos para describir la distribución de la regeneración natural.

\section{Capítulo 7: Consideraciones finales}

Este capítulo resume las conclusiones de la tesis y aporta algunas recomendaciones de manejo. 


\section{Capítulo 2: Sitio de estudio y metodología}

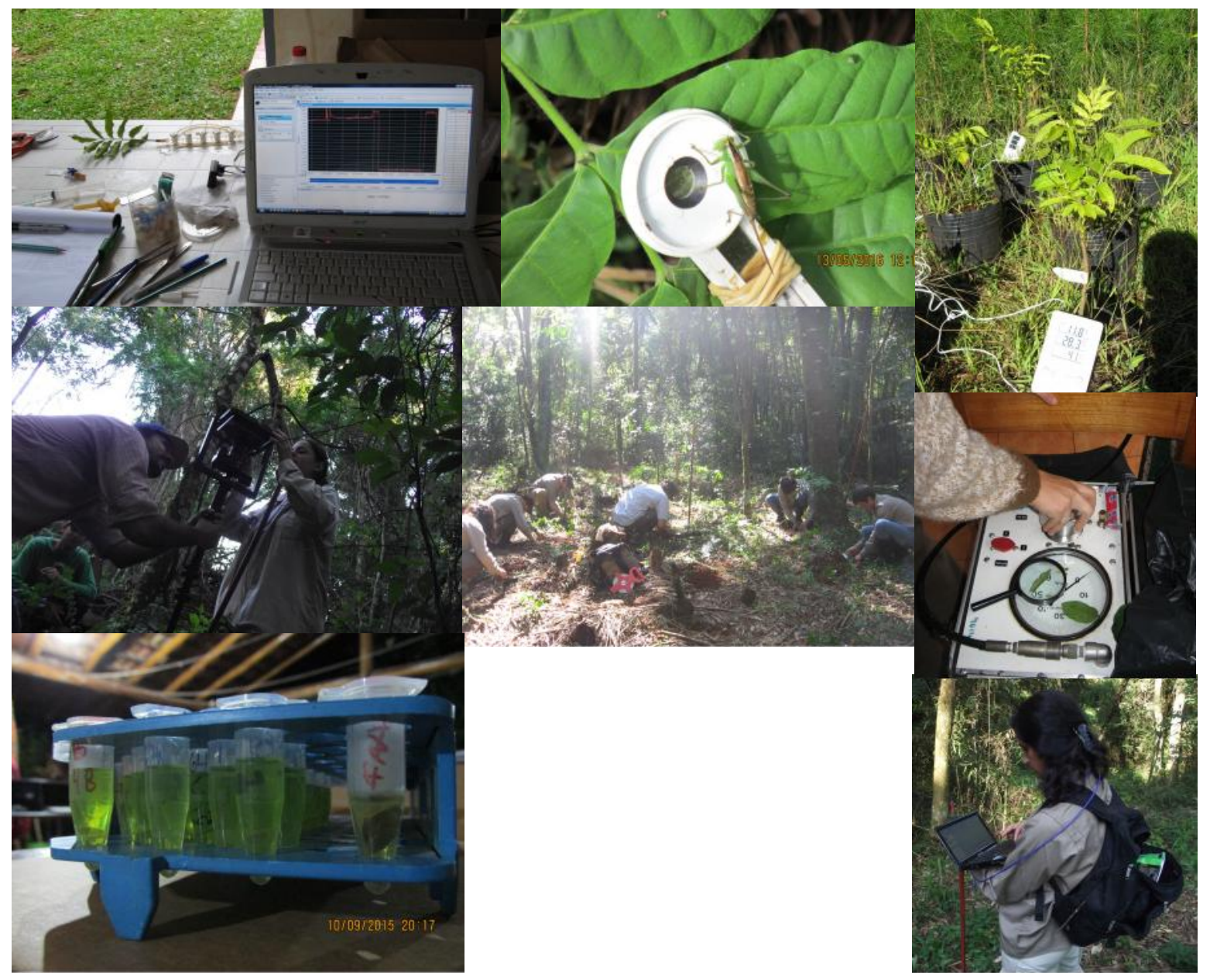




\subsection{Sitio de estudio}

Los ensayos fueron llevados a cabo en el predio del Campo Anexo Manuel Belgrano (CAMB) $\left(26^{\circ} 02^{\prime} 56,91^{\prime \prime} \mathrm{S} ; 53^{\circ} 46^{\prime} 14,15^{\prime \prime} \mathrm{W}, 552 \mathrm{msnm}\right)$, dependiente del INTA EEA Montecarlo, ubicado en San Antonio, Misiones, Argentina. El CAMB se encuentra sobre Ruta Nacional 101, en el Departamento Manuel Belgrano a 3 km de la localidad de San Antonio (Figura 2.1). Cuenta con una superficie de 2087 hectáreas, de las cuales, el $21 \%$ son una reserva estricta, el $23 \%$ plantaciones de araucarias, el $50 \%$ bosque nativo y el resto son sitios productivos e instalaciones del INTA.
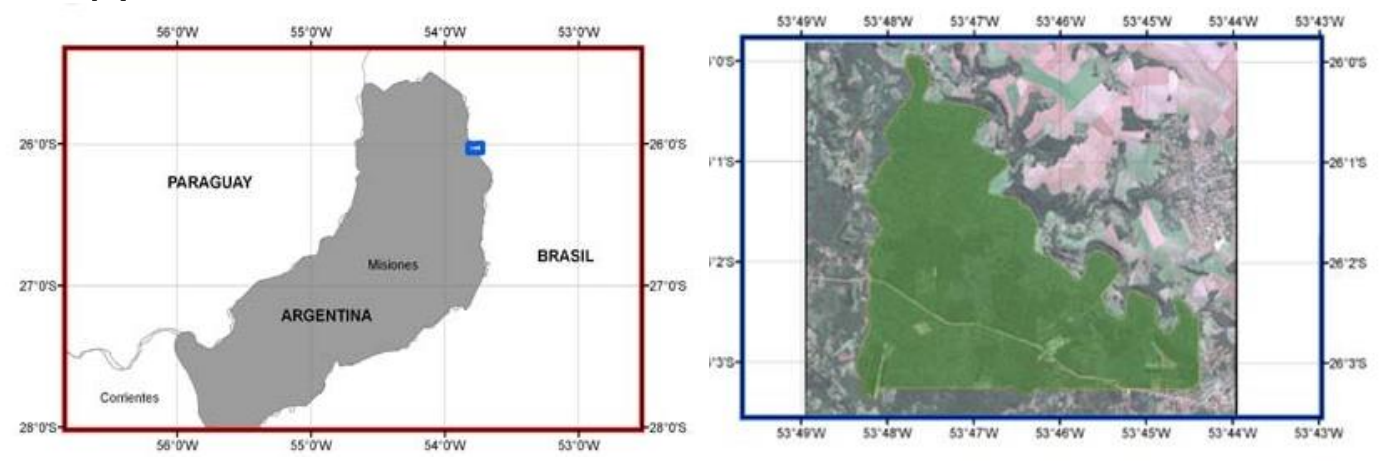

Figura 2.1: Provincia de Misiones, Argentina (imagen de la izquierda). Al noreste se encuentra ubicado el Campo Anexo Manuel Belgrano (CAMB) perteneciente al INTA Montecarlo, donde se realizaron los ensayos.

La temperatura media anual es de $20,4^{\circ} \mathrm{C}$; la mínima absoluta histórica de julio es $-7^{\circ} \mathrm{C}$ y la máxima absoluta histórica de julio es $30,5^{\circ} \mathrm{C}$; la temperatura máxima absoluta histórica de enero es $36,5^{\circ} \mathrm{C}$ y la temperatura mínima absoluta histórica de enero $8,9^{\circ} \mathrm{C}$. Las precipitaciones rondan los $2100 \mathrm{~mm}$ anuales, distribuidas homogéneamente a lo largo del año. El promedio de días con lluvia para los últimos 34 años es de 116 días al año (Datos climáticos del CAMB). El tipo de suelo corresponde al grupo de los rojos profundos (Kandiudultes), de buen drenaje y textura arcillosa, con arcillas con baja capacidad de intercambio. En sitios muestreados dentro del predio, los primeros $10 \mathrm{~cm}$ de profundidad tienen pH bajo, de 4,2 (1:1 en $\mathrm{KCl}$ ) y 4,9 (1:1 en agua), alta concentración de materia orgánica $(4,3 \%)$ y de $N$ total $(0,20 \%)$, intermedia de $P(0,002 \%)$ y valores promedio de CIC (10 cmol/kg) y saturación de bases (42\%)(Plata et al. 2003). 


\subsection{Descripción metodológica}

Ensayos para responder a los objetivos:

- Ensayo en macetas a campo, incluye 2 etapas consecutivas.

- Ensayo de plantación en claros del bosque nativo.

- Ensayo en parcelas permanentes del bosque nativo, para el relevamiento y análisis de la distribución espacial de la regeneración natural de Cabralea canjerana.

\subsubsection{Ensayo en macetas a campo}

Este ensayo duró aproximadamente 19 meses, desde octubre de 2012 hasta abril de 2014 (Figura 2.2). Se estructuró en 2 etapas consecutivas:

Etapa 1: desde octubre de 2012 hasta mayo de 2013. En esta se evalúa la aclimatación de Cabralea canjerana a 2 ambientes contrastantes de cobertura: debajo de sol pleno (sol) y debajo de canopeo denso (canopeo).

Etapa 2: A partir de septiembre de 2013 hasta finalizar el ensayo en abril de 2014. En esta etapa se evalúa el cambio abrupto de cobertura ya que se pasaron plantas que estaban creciendo debajo del canopeo a sol pleno (shock lumínico).

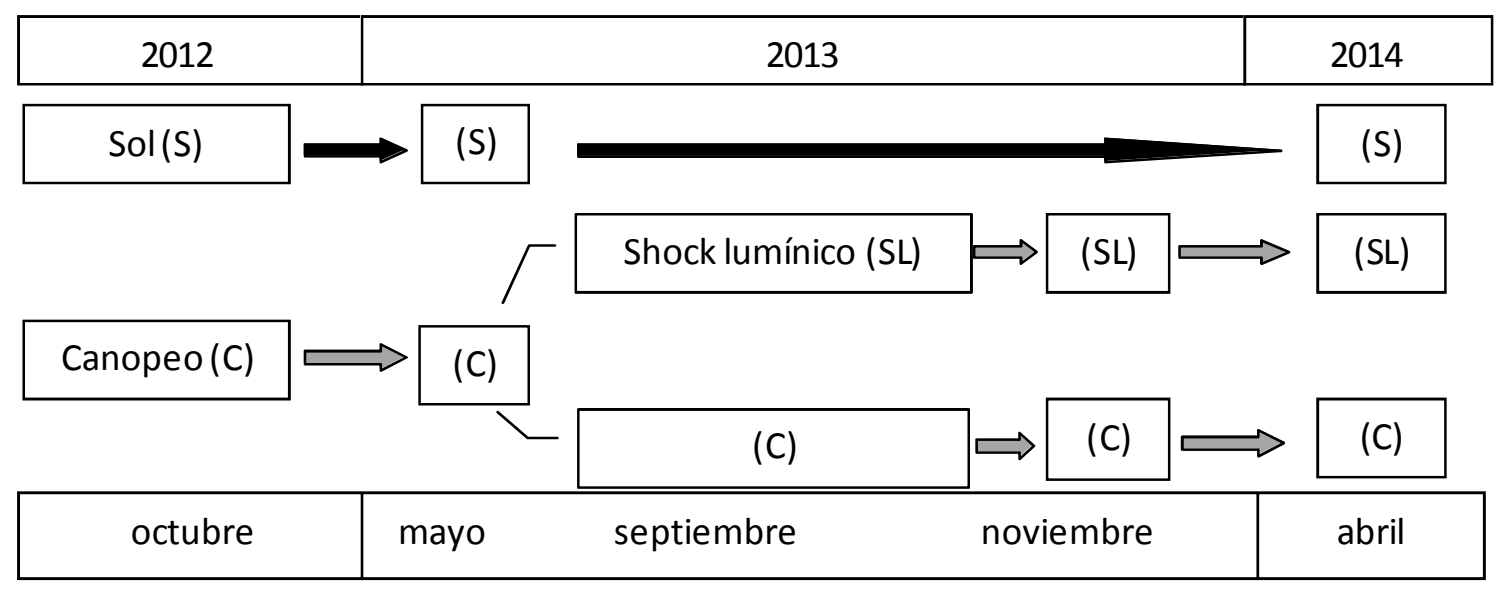

Figura 2.2: Línea de tiempo del ensayo en macetas completo. Desde el inicio (octubre 2012-primavera) hasta abril de 2014 (otoño). En septiembre de 2013 (primavera) se realizó el shock lumínico a plantas que estaban creciendo bajo canopeo denso. 
Para iniciar el ensayo se recolectaron semillas de varios individuos adultos de la selva, este trabajo estuvo a cargo del personal del CAMB. Las semillas fueron puestas a germinar en bandejas y transplantadas a tubetes de $350 \mathrm{~cm}^{3}$, con sustrato de mezcla de compost de pino y suelo del monte en una relación 50/50. Las plantas crecieron en invernáculo cubiertas con media sombra verde hasta el inicio del experimento en la primavera de 2012. La media sombra permitía el pasaje del $40 \pm 8 \%$ del flujo fotónico fotosintético (PAR) $(400$ a $700 \mathrm{~nm}$ ), 40\% \pm 10 de la radiación rojo (680 $\mathrm{nm}), 40 \pm 13 \%$ de la radiación rojo lejano $(730 \mathrm{~nm}), 40 \pm 7$ de la radiación verde $(550 \mathrm{~nm}), 40 \pm 9 \%$ de

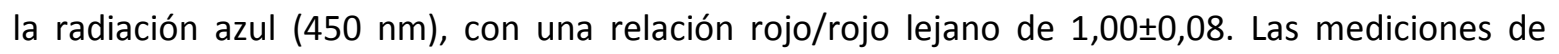
calidad de luz se realizaron en 3 posiciones en el invernáculo y 3 afuera a radiación plena, al mediodía, con un espectroradiómetro (Red Tide USB 650, Ocean Optics, Dunelin, Florida, USA).

En la primavera de 2012, 102 plantas de Cabralea canjerana de 8 meses de edad, con un promedio de $15 \mathrm{~cm}$ de altura, fueron repicadas a macetas de 7 litros con mezcla de suelo y sustrato de corteza de pino. Luego, las macetas con las plantas fueron colocadas en 2 tratamientos de cobertura contrastante: 34 plantas fueron colocadas a sol pleno (tratamiento sol (S)), y 68 plantas fueron colocadas debajo del canopeo denso en el bosque (tratamiento canopeo (C)) (Figura 2.3). Las plantas que fueron colocadas debajo del canopeo denso fueron el doble, ya que, estas plantas fueron utilizadas para la segunda etapa. Las plantas de sol fueron regadas todos los días, y en los días de mucho calor, las plantas del tratamiento sol fueron regadas dos veces por día con un sistema de riego con aspersores de encendido manual, que es activado rutinariamente por el personal del campo. Las plantas de canopeo fueron controladas semanalmente para corroborar que el suelo estuviera húmedo. No fue necesario regarlas en ningún momento.

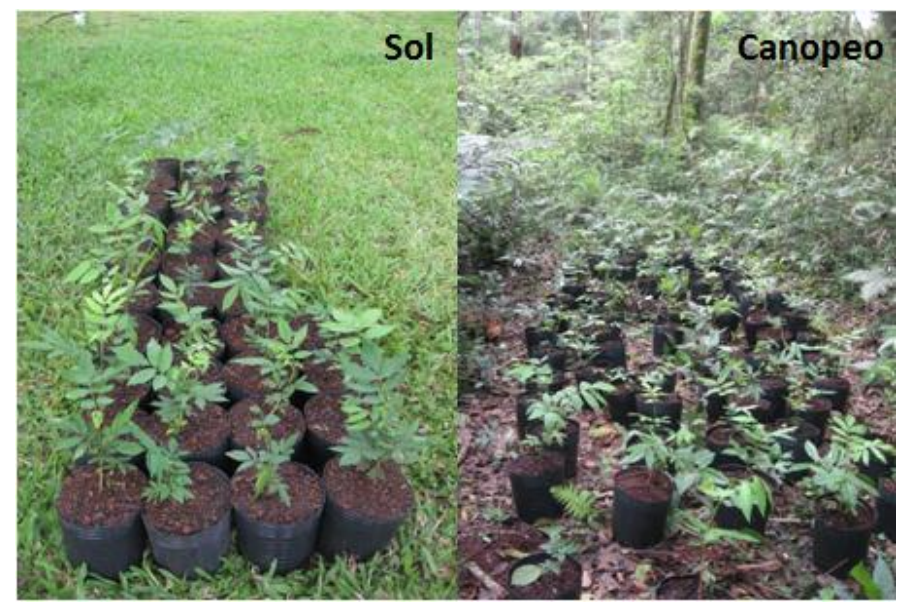

Figura 2.3: Ensayo en macetas instalado en octubre de 2012 
En la primavera de 2013, 24 plantas que estaban creciendo debajo del canopeo (tratamiento canopeo) fueron traspasadas a sol pleno para generar el tratamiento shock lumínico (SL), para simular el cambio abrupto en la cobertura. El resto de las plantas de canopeo y sol continuaron hasta finalizar el ensayo en abril de 2014.

Las condiciones contrastantes de cobertura no solo implicaron diferencias en la radiación incidente, sino también varios cambios en las condiciones ambientales. Se midió la temperatura del aire y del suelo, la humedad relativa del aire con termohigrómetros (TFA 30.5000.02, Wertheim, Germany). Estas mediciones se realizaron en otoño de 2013 durante 3 días consecutivos soleados y en diferentes momentos del día (9:00. 12:00. 14:00 y 17:00 horas). Las mediciones se realizaron en las 2 condiciones de cobertura contrastante, sol y canopeo. En 10 plantas por tratamiento (sol y canopeo) seleccionadas al azar, se colocaron los sensores en los distintos horarios de medición. Además, se midió la intensidad de flujo fotónico fotosintético (PAR) encima de cada una en las 10 plantas seleccionadas. Estas mediciones también se realizaron durante 3 días soleados y en diferentes momentos del día (9:00. 12:00. 14:00 y 17:00 horas), con ceptómetro (Cavadevices, Buenos Aires, Argentina). Por último, se midió la calidad de luz con espectroradiómetro (Red Tide USB 650, Ocean Optics, Dunelin, Florida, USA) encima de cada planta seleccionada. Estas mediciones se realizaron durante un día soleado y en diferentes momentos del día (9:00. 12:00. 14:00 y 17:00 horas). Cada medición fue realizada en 6 plantas por tratamiento.

Al mediodía la temperatura media del suelo fue de $27,7^{\circ} \mathrm{C}$ a sol pleno, registrándose un aumento a $30,3^{\circ} \mathrm{C}$ hacia las 14 horas. La temperatura media del suelo ascendió a $17,4^{\circ} \mathrm{C}$ debajo del canopeo, y a 18,3 hacia las 14 horas. La temperatura media del aire al mediodía fue de $27,4^{\circ} \mathrm{C}$ y a las 14 horas de $28,8^{\circ} \mathrm{C}$ al sol. Debajo del canopeo se registraron valores de $28^{\circ} \mathrm{C}$ al mediodía con un leve descenso hacia las 14 horas. Prácticamente la temperatura al mediodía fue igual al sol y debajo del canopeo posiblemente debido al ingreso de haces de luz de elevada intensidad hacia el suelo del bosque, combinado con poca turbulencia del aire. Sin embargo, a las 14 horas se registró una diferencia de 2 grados más al sol, debido a que los haces de luz a esa hora atraviesan el canopeo en menor magnitud que al mediodía. La humedad relativa media del aire (HR) fue de 31,8 $\%$ y $39 \%$ al sol y bajo canopeo denso, respectivamente. La densidad de flujo fotónico fotosintético (PAR) varió entre 66 y $1799 \mu$ moles de fotones $\mathrm{m}^{-2} \mathrm{~s}^{-1}$ a lo largo del día en las plantas de sol, mientras que la variación a lo largo del día para las plantas bajo canopeo denso fue entre 19 y 213 $\mu$ moles de fotones $\mathrm{m}^{-2} \mathrm{~s}^{-1}$ (Figura 2.4). La cantidad y calidad de radiación fue diferente en las dos 
condiciones. La radiación fotosintética total fue 6 veces más alta a sol pleno que bajo canopeo, y la radiación debajo del canopeo fue enriquecida con rojo lejano (Tabla 2.1).

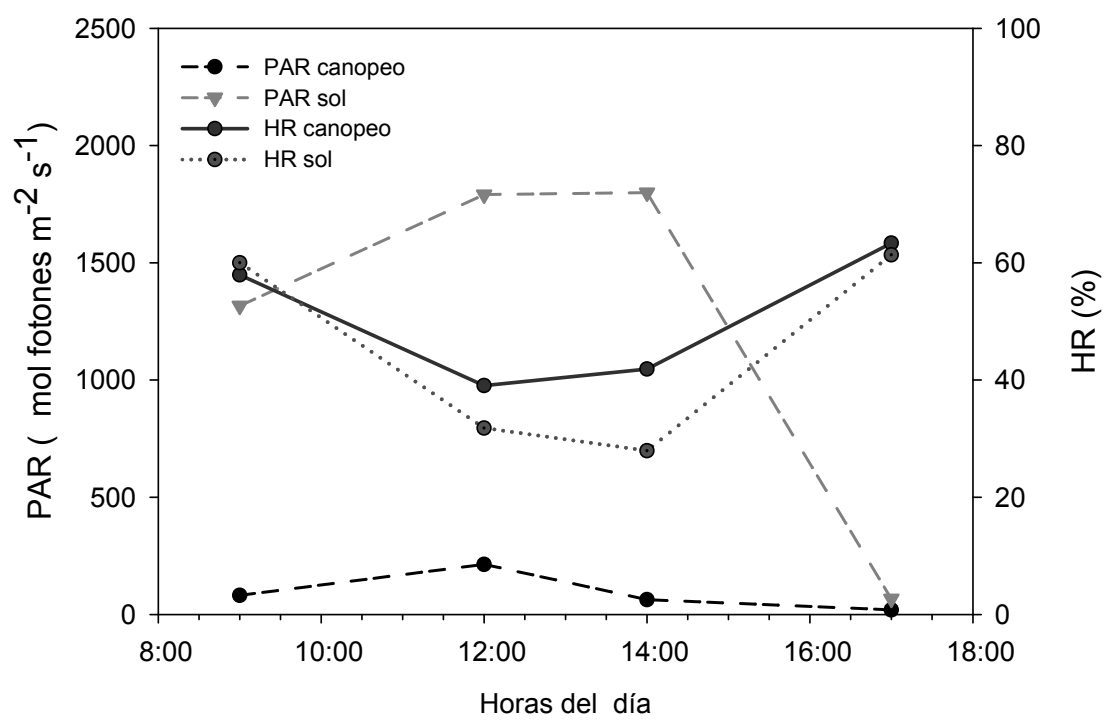

Figura 2.4: Densidad de flujo fotónico fotosintético (PAR, $\mu \mathrm{mol}$ fotones $\mathrm{m}^{-2} \mathrm{~s}^{-1}$ ) y humedad relativa del aire (HR:\%) a lo largo del día a sol (sol) y debajo del canopeo (canopeo).

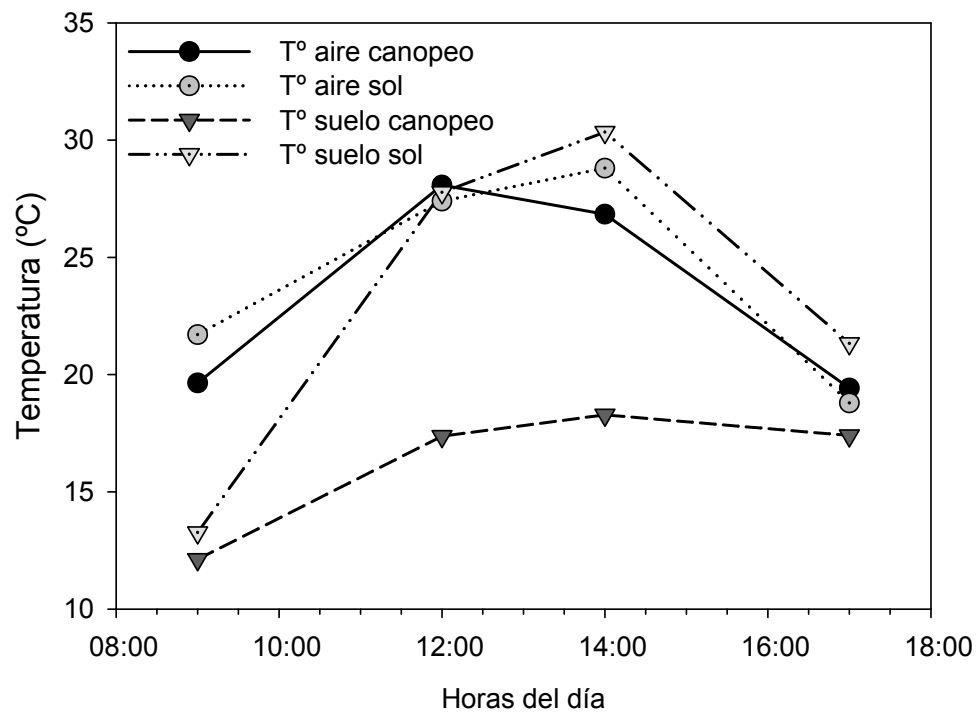

Figura 2.5: Temperatura del aire y del suelo $\left({ }^{\circ} \mathrm{C}\right)$ a lo largo del día en las plantas que crecieron a sol (S) y debajo del canopeo (C). 
Tabla 2.1: Calidad de la luz a lo largo del día a sol (S) y debajo del canopeo (C). Valores medios y desvío estándar (DE)

\begin{tabular}{|c|c|c|c|c|c|c|c|c|c|}
\hline Hora & Tratamiento & & $\begin{array}{c}\% \\
\text { Rojo } \\
\end{array}$ & $\begin{array}{c}\% \\
\text { Rojo lejano } \\
\end{array}$ & $\begin{array}{c}\% \\
\text { Verde } \\
\end{array}$ & $\begin{array}{c}\% \\
\text { Azul } \\
\end{array}$ & $\begin{array}{c}\% \\
\text { UVB } \\
\end{array}$ & $\mathrm{R}: \mathrm{RL}$ & $\begin{array}{c}\text { PAR } \\
\mu \text { moles } \mathrm{m}^{-2} \mathrm{~s}^{-1}\end{array}$ \\
\hline \multirow{4}{*}{ 09:00 } & \multirow{2}{*}{ Sol } & Media & 13,86 & 14,01 & 12,79 & 11,56 & 0,89 & 0,99 & 1774 \\
\hline & & $\mathrm{DE}$ & 1,06 & 1,01 & 0,11 & 1,01 & 0,18 & 0,02 & 394 \\
\hline & \multirow{2}{*}{ Canopeo } & Media & 14,55 & 28,62 & 10,89 & 14,36 & 3,07 & 0,51 & 296 \\
\hline & & $\mathrm{DE}$ & 0,34 & 1,93 & 0,33 & 0,24 & 0,32 & 0,03 & 34 \\
\hline \multirow{4}{*}{$12: 00$} & \multirow{2}{*}{ Sol } & Media & 13,73 & 13,25 & 13,15 & 11,10 & 0,39 & 1,04 & 1956 \\
\hline & & $\mathrm{DE}$ & 0,06 & 0,20 & 0,04 & 0,07 & 0,02 & 0,01 & 101 \\
\hline & \multirow{2}{*}{ Canopeo } & Media & 13,60 & 18,90 & 13,02 & 11,78 & 1,10 & 0,75 & 1061 \\
\hline & & $\mathrm{DE}$ & 0,44 & 4,40 & 0,33 & 1,09 & 0,72 & 0,17 & 746 \\
\hline \multirow{4}{*}{$14: 00$} & \multirow{2}{*}{ Sol } & Media & 14,08 & 14,16 & 12,95 & 11,08 & 0,67 & 0,99 & 1877 \\
\hline & & $\mathrm{DE}$ & 0,13 & 0,27 & 0,09 & 0,14 & 0,16 & 0,01 & 99 \\
\hline & \multirow{2}{*}{ Canopeo } & Media & 12,56 & 25,75 & 13,10 & 13,13 & 1,40 & 0,52 & 564 \\
\hline & & $\mathrm{DE}$ & 0,52 & 7,03 & 0,53 & 0,75 & 0,29 & 0,14 & 137 \\
\hline \multirow{4}{*}{$17: 00$} & \multirow{2}{*}{ Sol } & Media & 13,66 & 15,32 & 11,98 & 13,05 & 1,38 & 0,89 & 53 \\
\hline & & $\mathrm{DE}$ & 0,11 & 0,26 & 0,04 & 0,05 & 0,08 & 0,01 & 2 \\
\hline & \multirow{2}{*}{ Canopeo } & Media & 14,55 & 22,87 & 11,45 & 13,36 & 2,31 & 0,64 & 31 \\
\hline & & $\mathrm{DE}$ & 0,36 & 1,29 & 0,24 & 0,15 & 0,22 & 0,02 & 5 \\
\hline
\end{tabular}

\section{Etapa 1:}

En mayo de 2013 fueron medidos rasgos morfológicos y fisiológicos para caracterizar la aclimatación de Cabralea canjerana a cada ambiente contrastante ( $\mathrm{S}$ y $\mathrm{C}$ ). Se realizaron mediciones de diferentes variables implementando muestreos destructivos y no destructivos. El número de repeticiones de los muestreos varió según la variable medida y el tipo de muestreo, debido al tiempo de trabajo, las condiciones de trabajo, y la disponibilidad de equipos.

Las variables morfológicas medidas en los muestreos no destructivos fueron: altura $(\mathrm{cm})$, diámetro al cuello $(\mathrm{mm})$ y número de hojas. Estas variables se midieron en todas las plantas por tratamiento $(n=34)$.

Las variables fisiológicas medidas en los muestreos no destructivos fueron: conductancia estomática (gs) ( $\mathrm{mmol} \mathrm{H}_{2} \mathrm{O} \mathrm{m}^{-2} \mathrm{~s}^{-1}$ ), potencial hídrico de la hoja ( $\left.\Psi\right)(\mathrm{MPa})$, densidad estomática ( $\mathrm{n}^{\circ}$ 
de estomas $\mathrm{mm}^{-2}$ ), índice estomático (IE), tasa de transporte de electrones del fotosistema II (ETR) $\left(\mu \mathrm{mol} \mathrm{e}^{-} \mathrm{m}^{-2} \mathrm{~s}^{-1}\right.$ ), rendimiento cuántico intrínseco del fotosistema II ( $\mathrm{P}$ PSII), concentración de clorofila total en base al área foliar $\left(\mathrm{mg} \mathrm{cm}^{-2}\right)$ y en base al peso seco de hojas $\left(\mathrm{mg} \mathrm{g}^{-1}\right)$, relación clorofila $\mathrm{a} / \mathrm{b}$, rendimiento cuántico máximo del fotosistema II (Fv/Fm). Estas variables fueron medidas en un total de entre 9 y 18 plantas por tratamiento, dependiendo la variable.

Las variables morfológicas medidas en el muestreo destructivo fueron: área foliar (AF) $\left(\mathrm{cm}^{2}\right)$, peso seco de hojas, tallo y raíces finas y gruesas, peso seco total y del vástago (PS) (g), densidad de vasos $\left(\mathrm{n}^{\circ} \mathrm{mm}^{-2}\right)$. Estas variables se midieron en 6 plantas por tratamiento. Además, se calcularon las relaciones entre peso seco del vástago y el peso seco total de raíces, la relación entre el peso seco de hojas y el peso seco de la planta entera, la relación entre el peso seco de la planta entera y el peso seco total las raíces, el área foliar específica (AFE) $\left(\mathrm{cm}^{-2} \mathrm{~g}^{-1}\right)$, y la distribución diamétrica de los vasos.

Las variables fisiológicas medidas en el muestreo destructivo fueron: conductancias y conductividades hidráulicas de hojas, peciolos, tallo, vástago, raíces, y planta entera:

- Conductancia hidráulica de la planta entera (Kplanta) $\left(\mathrm{g} \mathrm{Mpa}^{-1} \mathrm{~h}^{-1}\right)$ : Se calculó con la formula Kplanta= 1 / ((1 / Kraíz) (1 / Kvástago)), que incluye Kraíz y Kvástago.

- Conductancia hidráulica del vástago (Kvástago) $\left(\mathrm{g} \mathrm{Mpa}^{-1} \mathrm{~h}^{-1}\right)$, medido en el vástago (tallo con hojas).

- Conductancia hidráulica de las raíces (Kraíz) $\left(\mathrm{g} \mathrm{Mpa}^{-1} \mathrm{~h}^{-1}\right)$.

- Conductividad hidráulica del tallo (khtallo) ( $\left.\mathrm{g} \mathrm{m} \mathrm{Mpa}^{-1} \mathrm{~h}^{-1}\right)$ : Se calculó al multiplicar la conductancia (Ktallo) del segmento de tallo por la longitud del segmento.

- Conductividad hidráulica del pecíolo (khpecíolo) (g m Mpa-1 ${ }^{-1}$ ): Se calculó al multiplicar la conductancia (Kpecíolo) del segmento de pecíolo por la longitud del segmento.

- Conductancia hidráulica de las hojas (Khoja) $\left(\mathrm{g} \mathrm{Mpa}^{-1} \mathrm{~h}^{-1}\right)$ medido en la hoja

Conductancias y conductividades hidráulicas estandarizadas por el área de xilema (AX), el área foliar (AF) y el peso seco de los compartimentos.

- Conductividad hidráulica de la planta entera estandarizada por el peso seco total de la planta, (Kplanta/Peso seco total) (g Mpa $\left.{ }^{-1} h^{-1} g^{-1} \mathrm{PS}\right)$.

- Conductancia hidráulica del vástago (Kvástago) estandarizada por el área foliar (AF), (Kvástago/AF) (g MPa $\left.{ }^{-1} h^{-1} \mathrm{~m}^{-2}\right)$. 
- Conductancia hidráulica de la raíz (Kraíz) estandarizada por peso seco total de raíces (Kraíz/peso seco raíces) (g Mpa $\left.{ }^{-1} \mathrm{~h}^{-1} \mathrm{~g}^{-1} \mathrm{PS}\right)$,

- Conductividad hidráulica específica del tallo (kstallo): Se calculó al dividir khtallo por el área de xilema activo. (khtallo/AX) $\left(\mathrm{g} \mathrm{m} \mathrm{MPa}^{-1} \mathrm{~h}^{-1} \mathrm{~m}^{-2}\right) \times 10^{3}$

- Conductividad hidráulica foliar específica del tallo (kltallo): Se calculó al dividir khtallo por el área foliar abastecida por dicho tallo, (khtallo/AF) (g m MPa ${ }^{-1} h^{-1} \mathrm{~m}^{-}$ $\left.{ }^{2}\right)$.

- Conductividad hidráulica específica del pecíolo (kspecíolo): Se calcula al dividir khpecíolo por el área de xilema activo, (khpecíolo/AX) (g m MPa-1 $\left.\mathrm{h}^{-1} \mathrm{~m}^{-2}\right) \times 10^{3}$.

- Conductividad hidráulica foliar específica del pecíolo (klpecíolo): Se calcula al dividir khpecíolo por el área foliar de la hoja medida, (khpecíolo/AF) (g m MPa` $\left.{ }^{1} h^{-1} m^{-2}\right)$.

- Conductividad hidráulica especifica de la hoja (khoja/AF): Se calculó dividiendo khoja por el área foliar de la hoja, (Khoja/AF) (g m-2 MPa-1h-1).

- Valor de Huber (área de xilema del tallo/AF): Esta es la relación entre el área de xilema del tallo y el área foliar total.

Otras variables medidas fueron la tasa de fotosíntesis neta a saturación lumínica en base al área foliar (AsatAF) ( $\mu \mathrm{mol} \mathrm{CO}_{2} \mathrm{~m}^{-2} \mathrm{~s}^{-1}$ ), la respiración mitocondrial aparente en base al área foliar (RAF) ( $\mu \mathrm{mol}$ de $\mathrm{CO} 2 \mathrm{~m}^{-2} \mathrm{~s}^{-1}$ ) y el punto de compensación lumínico (PCL) ( $\mu$ mol photones $\mathrm{m}^{-2} \mathrm{~s}^{-1}$ ). Además, la tasa de fotosíntesis neta a saturación lumínica se calculó en base al peso seco de hojas (AsatPSF) ( $\mu \mathrm{mol} \mathrm{CO}_{2} \mathrm{~g}^{-1} \mathrm{~s}^{-1}$ ) y la respiración mitocondrial aparente en base al peso seco foliar (RPSF) ( $\mu \mathrm{mol}$ de $\mathrm{CO}_{2} \mathrm{~g}^{-1} \mathrm{~s}^{-1}$ ). Las variables se midieron en 6 plantas por tratamiento.

\section{Etapa 2:}

En septiembre y noviembre de 2013 se reportan los datos de los tratamientos canopeo y shock lumínico, ya que, las plantas del tratamiento de sol sufrieron daño por temperaturas bajo cero, y en consecuencia murió la parte aérea del 100\% de las plantas. Pasada la primavera (septiembre de 2013) el $62 \%$ de las plantas rebrotaron desde la base, pero los resultados del tratamiento sol pleno (S) solo son mostrados en abril de 2014, junto con los de canopeo y shock lumínico. 
En septiembre y noviembre de 2013 fueron medidos rasgos morfológicos y fisiológicos para caracterizar la aclimatación de Cabralea canjerana a cada ambiente contrastante (tratamiento canopeo y shock lumínico). Al igual que en mayo de 2013 se realizaron muestreos destructivos y no destructivos. Se muestran los resultados de las siguientes variables medidas:

El diámetro al cuello $(\mathrm{mm})$ en septiembre se midió en ambos tratamiento con $\mathrm{n}=24$ y en noviembre $n=21$. Las variables fisiológicas medidas en los muestreos no destructivos fueron:

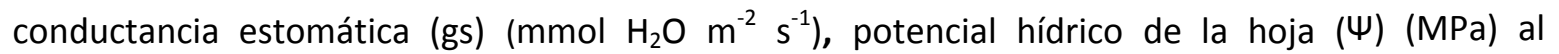
mediodía, densidad estomática $\left(\mathrm{n}^{\circ}\right.$ de estomas $\mathrm{mm}^{-2}$ ), índice estomático (IE), concentración de clorofila total en base al peso seco de hojas $\left(\mathrm{mg} \mathrm{g}^{-1}\right)$ y la relación clorofila a/b, tasa de transporte de electrones del fotosistema II (ETR) ( $\left.\mu \mathrm{mol} \mathrm{e}^{-} \mathrm{m}^{-2} \mathrm{~s}^{-1}\right)$, promedio a lo largo del día del rendimiento cuántico intrínseco del fotosistema II ( $\phi$ PSII), rendimiento cuántico máximo del fotosistema II (Fv/Fm). Estas variables fueron medidas en un total de entre 9 y 18 plantas por tratamiento, dependiendo de la variable.

Las variables morfológicas medidas en el muestreo destructivo fueron: peso seco de hojas, tallo y raíces finas y gruesas, peso seco total y del vástago (PS) (g). Estas variables se midieron en 3 plantas por tratamiento en septiembre y en 5 plantas por tratamiento en noviembre. Además se calculó el área foliar específica (AFE) $\left(\mathrm{cm}^{-2} \mathrm{~g}^{-1}\right)$. Las variables fisiológicas del muestreo destructivo fueron las conductancias y conductividades hidráulicas estandarizadas por el área de xilema (AX), el área foliar (AF) y el peso seco (PS) de los compartimentos, tal como se detalló arriba. Las variables de conductancia y conductividad se midieron en 3 plantas por tratamiento en septiembre y en 5 plantas por tratamiento en noviembre.

En abril de 2014, los rasgos morfológicos y fisiológicos medidos en los tres tratamientos fueron:

Se midió en diámetro al cuello $(\mathrm{mm})$. Esta variable se midió en los 3 tratamientos $(\mathrm{n}=16)$. Las variables fisiológicas medidas en los muestreos no destructivos fueron: conductancia

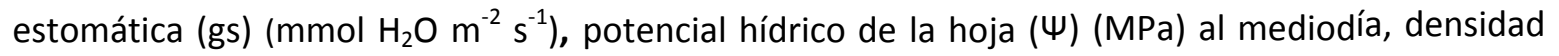
estomática ( $\mathrm{n}^{\circ}$ de estomas por $\mathrm{mm}^{2}$ ), índice estomático (IE), concentración de clorofila total en base al peso seco de hojas ( $\mathrm{mg} \mathrm{g}^{-1}$ ) y la relación clorofila a/b, tasa de transporte de electrones del fotosistema II (ETR) ( $\mu \mathrm{mol} \mathrm{e}^{-} \mathrm{m}^{-2} \mathrm{~s}^{-1}$ ), promedio a lo largo del día del rendimiento cuántico intrínseco del fotosistema II ( $\phi$ PSII), rendimiento cuántico máximo del fotosistema II (Fv/Fm). Estas variables fueron medidas en un total de entre 9 y 18 plantas por tratamiento, dependiendo la variable. 
Las variables morfológicas medidas en el muestreo destructivo fueron: peso seco de hojas, tallo y raíces finas y gruesas, peso seco total y del vástago (PS) (g), área foliar (cm) para calcular el área foliar específica (AFE) $\left(\mathrm{cm}^{-2} \mathrm{~g}^{-1}\right)$. Estas variables se midieron en 6 plantas por tratamiento.

En abril se midió la distribución diamétrica de los vasos y las conductancias y conductividades hidráulicas estandarizadas igual que en septiembre. Estas variables se midieron en 6 plantas por tratamiento, solo en los tratamientos canopeo y shock lumínico.

A continuación se detalla la metodología para cada variable medida.

\subsubsection{Morfología de las plantas, tamaño y partición de materia seca de plantas de sol y canopeo}

Las variables altura, diámetro y peso seco, se midieron en las diferentes fechas en cada tratamiento. Un aumento de la variable entre dos fechas de muestreo indica crecimiento de las plantas, ya que se genera una pendiente entre 2 puntos.

Se midió la altura $(\mathrm{cm})$ con cinta métrica, el diámetro del cuello $(\mathrm{mm})$ con calibre y se contó el número de hojas en todas las plantas. Dependiendo de la fecha de medición, el $\mathrm{n}$ fue disminuyendo, debido al muestreo destructivo (mayo $n=34$; septiembre $n=24$; noviembre $n=21$ y abril=16). En las plantas que se tomaron para el muestreo destructivo, se midió área foliar total de la planta $(\mathrm{AF})(\mathrm{cm})$ y se calculó el área foliar específica $(\mathrm{AFE})\left(\mathrm{cm} \mathrm{g}^{-1}\right)$ dividiendo el AF por el peso seco de las hojas. Para medir el área foliar, se cortaron las hojas de cada planta y se acomodaron una superficie plana (hoja blanca) calibrada con una regla. Luego se tomaron fotos con cámara digital y luego con el software imagen Tool v 1.28 CMEIAS Update (Liu et al. 2001) se midió el AF. Finalmente, las 6 plantas se descalzaron y fueron seccionadas en tallo, raíces finas y gruesas, y junto a las hojas fueron puestas a secadas en estufa a $60^{\circ} \mathrm{C}$ hasta peso constante. Se determinó el peso seco de cada compartimento (tallo, hojas, raíces finas y gruesas) y luego se calculó el peso seco de la planta entera (g) y el peso seco del vástago. Además se calcularon las relaciones entre peso seco del vástago y el peso seco total de raíces, la relación entre el peso seco de hojas y el peso seco de la planta entera y la relación entre el peso seco de la planta entera y el peso seco total las raíces.

Para medir la densidad estomática, el número de células epidérmicas por $\mathrm{mm}^{2}$ y calcular el índice estomático, se realizó el muestreo en 9 plantas por tratamiento elegidas al azar. Se tomaron 2 discos (diámetro $=5 \mathrm{~mm}$ ) de 2 hojas (uno por hoja) superiores totalmente expandidas de 9 
plantas por tratamiento $(n=18)$. Los discos se sacaron con sacabocado de lámina de la hoja evitando la nervadura principal. Esa hoja no fue utilizada posteriormente para otras mediciones, y se considera que el daño producido a nivel de planta es despreciable, y no amerita descartar la planta para las demás mediciones. Los discos fueron fijados en FAA (50 etanol/ 10 formaldehido/ 5 ácido acético/ 35 agua desionizada). Luego se realizó el tratamiento de diafanizado en alcohol 96, $\mathrm{NaOH} 3 \%$ y posteriormente se trató con $\mathrm{NaClO} 50 \%$. Finalmente fueron teñidos con safranina $1 \%$. Una vez terminado el montaje se tomaron fotos con el microscopio (320x) (Carl Zeiss Photomicroscope II, Oberkochen, Germany). En cada foto se contaron el número de estomas y las células epidérmicas con el software Image Tool v. 1.28 CMEIAS Update (Liu et al. 2001). El índice estomático se calculó como la relación entre el número de estomas y el número de células epidérmicas en un área determinada (Haworth et al. 2011).

\subsubsection{Características de la arquitectura hidráulica en plantas de sol y canopeo}

Para describir el estado hídrico de las plantas se realizaron mediciones de conductancias hidráulicas en 6 plantas por tratamiento (son las mismas plantas que al finalizar las mediciones fisiológicas se realizó materia seca). Para esto se utilizó el medidor de flujo hidráulico por caída de presión (Figura 2.6) (Melcher et al. 2012). La perfusión se hizo con agua filtrada des-gaseada, utilizando una presión de 4,5 kPa. Antes de describir cómo se realizaron las mediciones, hay que tener en cuenta que la letra K mayúscula se refiere a conductancia, y es utilizada cuando la longitud del camino hidráulico es desconocida, por ejemplo hojas, raíces, planta entera y vástago, mientras que la k minúscula es usada para hacer referencia a la conductividad, que se puede calcular si la longitud del camino hidráulico puede ser medida, por ejemplo tallos y pecíolo.

Inicialmente se midió la conductancia hidráulica del vástago (Kvástago). Se tomó la planta entera y se cortó a la altura del cuello debajo del agua, y el vástago (tallo con hojas) fue conectado inmediatamente al perfusor. La conductancia hidráulica del vástago se midió cuando se estabilizó el flujo de agua durante al menos 3 minutos. Después de la medición de Kvástago, se cortó el tallo a $10 \mathrm{~cm}$ de la base y se midió la conductancia hidráulica del tallo. Con la conductancia hidráulica del tallo (Ktallo) multiplicada por la longitud del tallo, se calculó la conductividad hidráulica de tallo (khtallo). Luego, el tallo fue removido y una hoja totalmente expandida fue colocada para medir la conductancia hidráulica de las hojas (Khoja) (Figura 2.5). Posteriormente, la lámina de la hoja fue 
removida, quedando un segmento de pecíolo, al cual se le midió la conductancia hidráulica del pecíolo (Kpeciolo). Luego con la Kpeciolo multiplicada por la longitud del pecíolo se calculó la conductividad hidráulica del pecíolo (khpecíolo). Finalmente, el sistema radical completo fue conectado al flujo de agua para medir la conductancia hidráulica de las raíces (Kraíz). Para esto, se conectó la parte final de las raíces para perfundir agua hacia el cuello, en el sentido natural del movimiento del agua.

La conductancia hidráulica de la planta entera (Kplanta) se calculó como en (Tyree, M.T. \& Zimmermann 2002):

$$
\text { Kplanta = } 1 /((1 / \text { Kraíz })+(1 / \text { Kvástago }))
$$

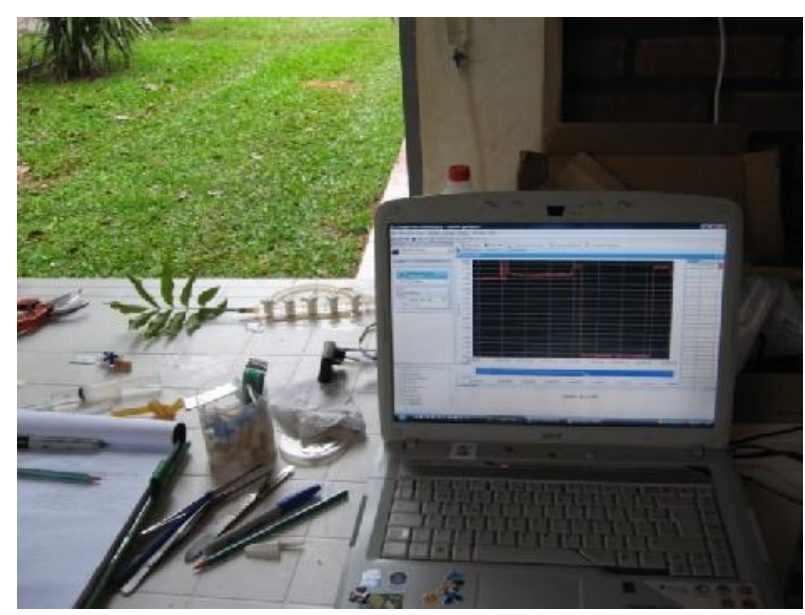

Figura 2.6: Medidor de flujo hidráulico por caída de presión. En este caso se está midiendo la conductancia hidráulica de la hoja.

Para analizar si hubo cambios en la conductancia específica (independientemente de cualquier cambio de tamaño de la planta), cada conductancia fue estandarizada por el peso seco (PS), el área foliar (AF) o el área de xilema activo (AX). Kplanta fue expresado en base al peso seco de la planta entera (Kplanta/peso seco total) $\left(\mathrm{kg} \mathrm{Mpa}^{-1} \mathrm{~h}^{-1} \mathrm{~kg}^{-1}\right)$. La conductividad hidráulica foliar específica (kltallo), se calculó dividiendo khtallo por el área foliar abastecida por dicho tallo (kg $\mathrm{MPa}^{-1} \mathrm{~h}^{-1} \mathrm{~m}^{-2}$ ). La conductancia hidráulica de la raíz (Kraíz) estandarizada por peso seco total de raíces (Kraíz/peso seco raíces) $\left(\mathrm{kg} \mathrm{MPa}^{-1} \mathrm{~h}^{-1} \mathrm{~kg}^{-1}\right)$. La conductividad hidráulica específica del tallo (kstallo), calculada al dividir khtallo por el área de xilema activo (khtallo/AX) (g m MPa $\left.\mathrm{m}^{-1} \mathrm{~m}^{-2}\right)$. La conductividad hidráulica específica del pecíolo (kspecíolo) fue calculada al dividir khpecíolo por el área de xilema activo (khpecíolo/AX) $\left(\mathrm{g} \mathrm{m} \mathrm{MPa}^{-1} \mathrm{~h}^{-1} \mathrm{~m}^{-2}\right) \times 10^{3}$. La conductividad hidráulica específica 
foliar del tallo (kltallo), calculada al dividir khtallo por el área foliar de la planta (kltallo=khtallo/AF) (g m MPa ${ }^{-1} \mathrm{~h}^{-1} \mathrm{~m}^{-2}$ ), y la conductividad hidráulica específica foliar del pecíolo (klpecíolo), calculada al dividir khpecíolo por el área foliar de la hoja (khpeciolo/AF) (g m MPa ${ }^{-1} h^{-1} \mathrm{~m}^{-2}$ ). La conductancia hidráulica de la hoja (Khoja/AF) calculada al dividir la conductancia hidráulica de las hojas (Khoja) por el área foliar $\left(\mathrm{g} \mathrm{m}^{-2} \mathrm{MPa}^{-1} \mathrm{~h}^{-1}\right)$. Complementariamente, se calculó el valor de Huber que es la relación entre el área de xilema del tallo y el área foliar total (área de xilema del tallo/AF) (Carter y White 2009), de cada una de las 6 plantas por tratamiento usadas para medir las conductancias hidráulicas. El área de xilema del tallo fue medido descortezando el tallo que se utilizó para medir la conductividad hidráulica de tallo.

Con el fin de evaluar el estado hídrico de las plantas a lo largo del día fueron medidos la conductancia estomática (gs) ( $m m^{2} \mathrm{H}_{2} \mathrm{O} \mathrm{m}^{-2} \mathrm{~s}^{-1}$ ) y el potencial hídrico de las hojas ( $\Psi$ ) (MPa) en 4 momentos del día, a las 9:00, 12:00, 14:00 y 17:00 horas. Para medir conductancia estomática (gs) fueron seleccionadas al azar 6 plantas por tratamiento, repetido 3 días $(n=18)$. Se pinzó una hoja superior totalmente expandida con el porómetro de flujo estacionario Decagon SC1 (DecagonDevices, Pullman, Washington, USA), durante 30 segundos y se registró el valor de gs. Para medir el potencial hídrico de las hojas $(\Psi)$ fueron seleccionadas al azar 3 plantas por tratamiento, repetido 3 días $(n=9)$. De cada planta se cortó una hoja superior totalmente expandida y se la colocó en la cámara de presión tipo Schölander (BioControl, Buenos Aires, Argentina).

Para calcular la frecuencia absoluta de vasos por clase diamétrica y la densidad de vasos se utilizaron secciones de tallo de 6 plantas por tratamiento (los utilizados en el muestreo destructivo) de donde se tomaron 3 fotos por tratamiento $(n=18)$. Los tallos fueron cortados a 4 $\mathrm{cm}$ desde el cuello y puestos a hervir 2 horas. Luego, con un micrótomo se cortaron las muestras de la sección transversal de tallo. El montaje se realizó con la técnica de obtención de preparados transitorios: método de safranina ( $1 \%$ en agua). Pasos del montaje: a) se clarificaron los cortes obtenidos con el micrótomo con hipoclorito de $\mathrm{Na}$ al 50\% hasta que se observaron blancos; b) se retiraron y lavaron las muestras con agua destilada (2 a 3 veces) para eliminar los restos de lavandina; c) se colorearon con safranina en agua; d) se montaron en gelatina-glicerina. Luego se tomaron fotos de los preparados con cámara digital Sony DXC-390 (Sony, Tokyo, Japan) y posteriormente con el software Image Tool v. 1.28 CMEIAS Update (Liu et al. 2001) se realizó el recuento de vasos y el diámetro de vasos que sirvió para calcular la frecuencia absoluta de vasos 
por clase diamétrica y la densidad de vasos. El análisis estadístico se detalla en la sección análisis estadístico.

\subsubsection{Características relacionadas con el uso de la luz en plantas de sol y canopeo}

Para calcular la concentración de clorofila se extrajo con sacabocado un disco $(5 \mathrm{~mm}$ de diámetro) de una hoja superior totalmente expandida. Cada disco fue sacado de 1 hoja en 10 plantas diferentes de cada tratamiento, y colocado intacto en un mililitro de $\mathrm{N}, \mathrm{N}$ Dimetilformamida, durante 48 horas a oscuridad. La medición de la concentración de clorofila extraída se realizó con un espectrofotómetro, con lectura de absorbancia (A) a 647 y 664,5 nm de longitud de onda y fueron calculadas las concentraciones de clorofilas. Las ecuaciones utilizadas fueron: clorofila total $=17,9 * A_{647}+8,08 * A_{664,5} ; \quad$ clorofila $a=12,7 * A_{664,5}-2,79 * A_{647} ; \quad$ clorofila $b=20,7 * A_{647}-4,62 * A_{664,5}$ (Inskeep y Bloom 1985). Se calculó la concentración de clorofila total y se la expresó en $\mathrm{mg} \mathrm{cm}^{-2}$ y en $\mathrm{mg} \mathrm{g}^{-1}$, y luego se calculó la relación clorofila a/b. Para calcular la concentración de clorofila en $\mathrm{mg} \mathrm{g}^{-1}$ se extrajeron muestras de 50 discos que fueron secados y pesados en estufa, para calcular el peso seco.

Para evaluar la capacidad fotosintética de las plantas aclimatadas a cada ambiente, se seleccionaron 6 plantas por tratamiento, las mismas que las que se utilizaron para las demás variables medidas con muestreo destructivo. En estas plantas se midió entre las 11 hs a las 15 hs la tasa de fotosíntesis neta a saturación lumínica en base al área foliar (AsatAF) ( $\mu \mathrm{mol} \mathrm{CO}_{2} \mathrm{~m}^{-2} \mathrm{~s}^{-1}$ ), la respiración mitocondrial aparente en base al área foliar (RAF) ( $\mu \mathrm{mol}$ de $\mathrm{CO} 2 \mathrm{~m}^{-2} \mathrm{~s}^{-1}$ ) y el punto de compensación lumínico (PCL) ( $\mu \mathrm{mol}$ photones $\mathrm{m}^{-2} \mathrm{~s}^{-1}$ ). Para esto se utilizó el analizador de gases infra rojo (IRGA Ciras 2, PP System, Amesbury, USA). Las condiciones de la cámara fueron: 360 ppm de $\mathrm{CO}_{2}$ ambiental y $25^{\circ} \mathrm{C}$. La densidad de flujo fotónico fotosintético se incrementó desde 0 a $2000 \mu \mathrm{mol} \mathrm{m} \mathrm{m}^{-2} \mathrm{~s}^{-1}$.Además fueron calculados la tasa de fotosíntesis neta a saturación lumínica en base al peso seco de hojas (AsatPSF) $\left(\mu \mathrm{mol} \mathrm{CO}_{2} \mathrm{~g}^{-1} \mathrm{~s}^{-1}\right.$ ) y la respiración mitocondrial aparente en base al peso seco foliar (RPSF) ( $\mu \mathrm{mol}$ de $\mathrm{CO}_{2} \mathrm{~g}^{-1} \mathrm{~s}^{-1}$ ).

El rendimiento cuántico máximo del fotosistema II (Fv/Fm) fue medido en 10 plantas de cada tratamiento seleccionadas al azar. Esta medición es un indicador del daño del sistema fotosintético. Fv/Fm se midió con el método de pulsos saturantes de luz (FMS2, Hansatech, Norfolk, UK), luego de 30 minutos de aclimatación a la oscuridad. 
Para evaluar la tasa fotosintética a lo largo del día en las 2 condiciones de cobertura se midió la tasa de trasporte de electrones del fotosistema II (ETR) ( $\left.\mu \mathrm{mol} \mathrm{e}^{-} \mathrm{m}^{-2} \mathrm{~s}^{-1}\right)$. Además, se midió el rendimiento cuántico intrínseco del fotosistema II ( $\phi$ PSII), que es un estimador del rendimiento del transporte de los electrones. Estas mediciones se realizaron durante 3 días soleados y en diferentes momentos del día $(9: 00,12: 00,14: 00$ y 17:00 horas). En cada medición fueron seleccionadas al alzar 10 plantas por tratamiento. Las mediciones fueron realizadas con un fluorímetro (FMS2, Hansatech, Norfolk, UK).

\subsubsection{Ensayo en claros del bosque nativo.}

Los sitios utilizados se ubicaron en un bosque remanente de 5 ha que fue aprovechado por última vez hace más de 50 años. En septiembre de 2014 se seleccionaron y limpiaron 3 claros producidos naturalmente de un sector de bosque nativo secundario (Figura 2.7). Una vez realizada la limpieza de los claros se procedió a la marcación y medición del área para ubicar 6 subparcelas, de las cuales 5 subparcelas están en el claro (centro, norte, sur, este y oeste) y otra ubicada debajo del canopeo denso (bosque) (Figura 2.8). Las plantas fueron colocadas en diferentes posiciones dentro del claro (desde el sotobosque al centro del claro) de manera de exponerlas a un gradiente de cobertura arbórea. Para proceder al establecimiento de las subparcelas, primero se instaló la parcela centro. Luego con una brújula se establecieron las posiciones norte, sur, este y oeste. La última parcela denominada bosque (posición que recibe la menor disponibilidad de luz) se estableció debajo del canopeo denso, con orientación norte (Figura 2.8). Las subparcelas norte, sur, este y oeste se establecieron desde el borde de la proyección de copas hacia adentro del bosque (Amir 2012). Los claros seleccionados tenían 68, 119 y $172 \mathrm{~m}^{2}$ de área, los tamaños de esos claros se encuentran en el rango de tamaño de los claros que frecuentemente se observan en los bosques tropicales secundarios (Brokaw 1982; Martins y Ribeiro Rodrigues 2002; De Lima y De Moura 2008).

Las plantas de Cabralea canjerana fueron producidas en tubetes en el vivero del CAMB en la primavera del año anterior (2013). Las semillas utilizadas fueron recolectadas de 3 a 5 individuos femeninos dentro del CAMB de árboles semilleros que el personal del campo tiene marcados.

En total se plantaron 162 plantas de 10 meses de edad con un promedio de $14 \pm 4 \mathrm{~cm}$ (media \pm desvío estándar) y el diámetro del cuello $5 \pm 1 \mathrm{~mm}$. En cada claro y por posición se ubicaron grupos de 9 plantas distanciadas $1,5 \mathrm{~m}$ una de otra formando una cuadricula de $3 \times 3$ 
plantas. Los claros fueron desmalezados 2 veces al año, en primavera y otoño, unos días antes de realizar las mediciones. El desmalezado se realizó alrededor de cada planta.

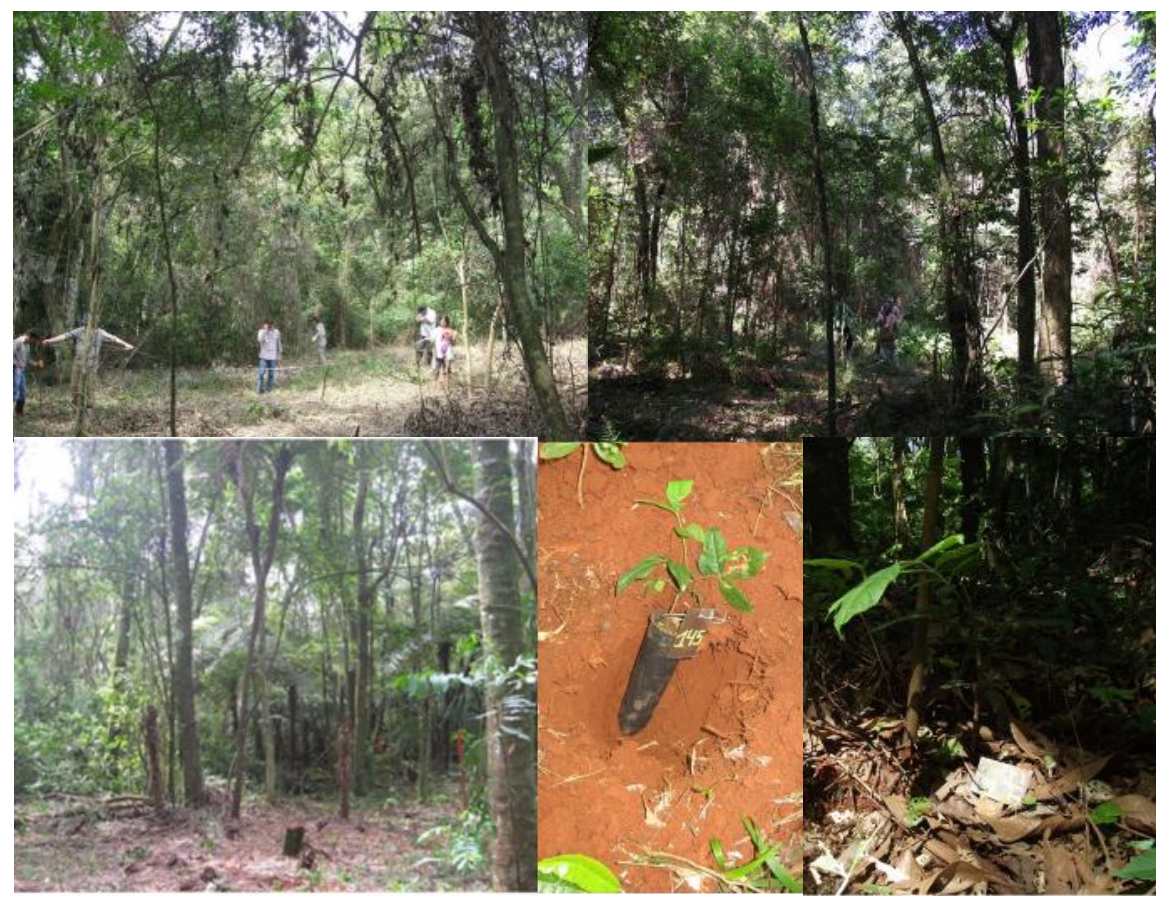

Figura 2.7: Instalación del ensayo en septiembre de 2014

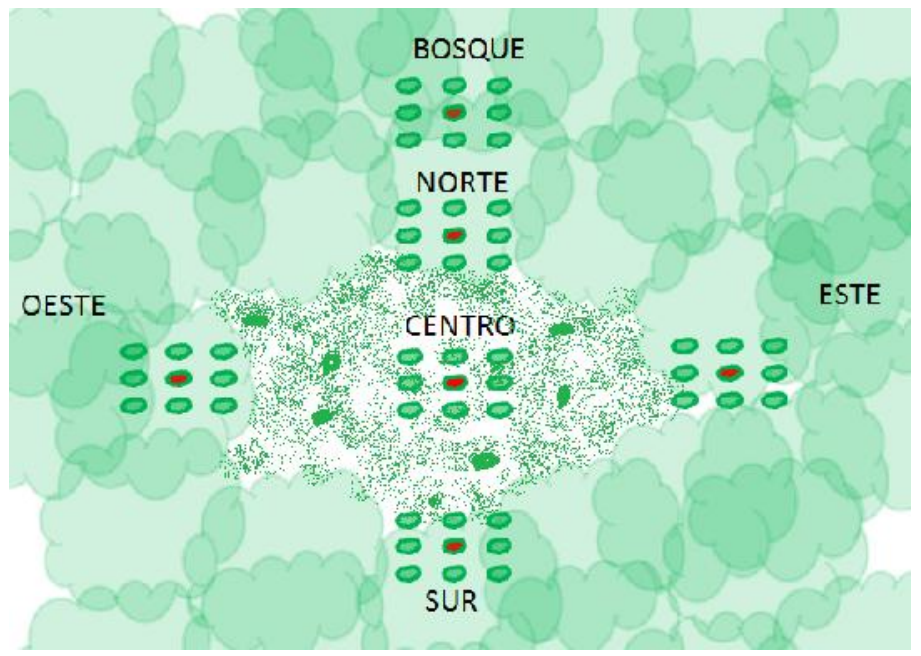

Figura 2.8: Croquis de un claro con las 6 posiciones (centro, norte, bosque, este, oeste, sur)

Para evaluar las respuestas de las plantas a un gradiente de cobertura generado por la apertura de un claro, se realizaron mediciones la de supervivencia y crecimiento hasta los $3 \frac{1}{2}$ años 
y de variables morfológicas y fisiológicas en la primavera y otoño durante $2 \frac{1}{2}$ años, desde la instalación de los ensayos. Las metodologías se describen en las secciones siguientes. Además se realizaron mediciones de variables ambientales y de cobertura para caracterizar los ambientes.

\subsubsection{Cobertura}

Para caracterizar el gradiente de cobertura en el que se establecieron las plantas se midieron diferentes variables: encima de cada planta durante el mediodía se midió la densidad de flujo fotónico de la radiación fotosintéticamente activa (PAR) ( $\mu$ moles $\mathrm{m}^{-2} \mathrm{~s}^{-1}$ ) con ceptómetro (Cavadevices, Buenos Aires, Argentina) ( $n=147)$. Esta medición, si bien es puntual y está influida por las condiciones climáticas, permite describir la cobertura exactamente encima de cada planta, en un segmento de $1 \mathrm{~m}$, centrado en la planta. Las fotos hemisféricas cubren una superficie mayor y no permiten distinguir niveles de cobertura diferentes en posiciones cercanas (por ej $2 \mathrm{~m}$ ), ni permite captar si hay intercepción de luz por plantas herbáceas, ya que la foto debe ser tomada a $1 \mathrm{~m}$ del suelo para evitar la interferencia del operador de la cámara. En el centro de cada posición por claro se midió la relación rojo/rojo lejano ( $R / R L)$ con un espectroradiómetro Red Tide USB 650 (OceanOptics, Dunedin, Florida, USA), a $670 \mathrm{~nm}$ y $730 \mathrm{~nm}$ respectivamente. También, en cada posición se tomó una foto hemisférica con lente de ojo de pez en el centro de cada posición de cada claro, ubicando la cámara a un metro de altura sobre el piso (fish-eye de 180 Nikon FC-E9 incorporado al sistema auto-nivelante SML-6, Delta T Devices, y cámara digital Nikon Coolpix 8400 adaptada a la lente mediante adaptador UR-E16 de Nikon). Las fotos fueron tomadas antes de la salida del sol, para evitar los rayos de sol directos que distorsionan las estimaciones. Luego con el software GLA (Gap Light Analyzer) se estimó la media diaria de luz directa transmitida total (luz) (moles $\mathrm{m}^{-2}$ día $^{-1}$ ) y el porcentaje de canopeo abierto en cada posición por claro (Frazer et al. 1999). Las variables descriptas anteriormente caracterizan la condición de cobertura inicial de los claros.

A los 6 meses se registró la temperatura del aire (Taire), la temperatura del suelo (Tsuelo) y el porcentaje de humedad relativa del aire (HR) en el centro de cada posición de cada claro, al mediodía durante 1 día. Por otro lado, fue medió el contenido de agua en el suelo gravimétricamente. Se tomó una muestra por posición por claro entre los $0-20 \mathrm{~cm}$ de profundidad del suelo. Para calcular el porcentaje de agua en el suelo, se midió peso inicial, peso seco y el peso a saturación en cada muestra. No se observaron diferencias en el tipo de suelo en las muestras tomadas. 


\subsubsection{Supervivencia y crecimiento}

Para evaluar la supervivencia se realizó un registro en cada fecha de medición. Para la supervivencia de las plantas se contabilizó el número de plantas vivas a los $3,6,12,20,25,32,36$ y 44 meses. Se consideró que la planta estaba muerta si la totalidad de la parte aérea (vástago) estaba muerta o no estaba. En algunos casos, plantas registradas como muertas rebrotaron desde la raíz, por lo que se consideraron vivas en la medición siguiente. No se corrigió la mortalidad previa al registro de una planta rebrotada porque con este registro se quiere reflejar la existencia de plantas en cada muestreo, que se verifica con la existencia de la parte aérea.

Para evaluar el crecimiento se midió la altura total $(\mathrm{cm})$ de cada planta viva en cada fecha (a los 6 meses en $n$ fue de 147). Las fechas en que se muestrearon fueron, a los 3, 6, 12, 20, 25, 32, 36 y 44 meses desde instalado el ensayo. Las mediciones de altura se realizaron desde el suelo hasta el ápice, con cinta métrica y barras métricas. Las barras métricas son barras rígidas de 2 metros de altura construidas para facilitar la medición a campo. El número de repeticiones por muestreo fue disminuyendo acorde a la mortalidad de las plantas.

A los 6 meses de instalado el ensayo se realizó la medición del diámetro del cuello (DAC) (mm) con calibre de todas las plantas de los 3 claros ( $n=147)$.

\subsubsection{Mediciones fisiológicas y morfológicas}

Para caracterizar la aclimatación de las plantas al gradiente de cobertura generado por los claros, se realizaron mediciones morfológicas y fisiológicas de diferentes variables implementando muestreos no destructivos. Estos muestreos se realizaron en diferentes meses a lo largo de la duración del ensayo, a los 3, 6, 12, 20, 25 y 32 meses de instalado el ensayo. El número de repeticiones de los muestreos varió según la variable medida, debido principalmente a las condiciones climáticas, tiempo y condiciones de trabajo y a la disponibilidad de equipos. Para lograr un número de repeticiones adecuado para los análisis, se muestrearon 3 plantas de cada posición de cada claro (principalmente para las variables fisiológicas) seleccionadas al azar de las 9 plantas por posición. 
A los 6 meses se realizaron mediciones durante un día o 3 días dependiendo de la variable medida, como se detalla en la descripción de las variables. En el resto de los meses (3, 12, 20, 25 y 32 meses) las mediciones se realizaron durante un día.

Para medir el área foliar del folíolo (AFF) $\left(\mathrm{cm}^{2}\right)$, se utilizaron los folíolos de una hoja superior totalmente expandida por planta, para evitar la defoliación de las plantas. Se tomaron los folíolos, se identificaron escribiéndoles el número de planta y se acomodaron en una superficie plana (hoja blanca) calibrada con una regla. A cada folíolo se le sacó una foto con cámara digital, luego se midió el área foliar con el software Imagen-tool Tool v 1.28 CMEIAS Update (Liu et al. 2001). Cada folíolo fue puesto a secar a estufa a $60{ }^{\circ} \mathrm{C}$ hasta peso constante para determinar el peso seco. Finalmente, con el área foliar del folíolo (AFF) y el peso seco se calculó área foliar específica del folíolo (AFEf) ( $\mathrm{cm} \mathrm{g}^{-1}$ ). Las mediciones se realizaron a los 3, 6, 12, 20, 25 y 32 meses de instalado el ensayo. Para los meses 3,6 y 12 se tomó un folíolo de cada hoja de cada planta viva, en cada posición de cada claro. Para los meses 20,25 y 32 se tomó un folíolo de cada hoja de 3 plantas en cada posición de cada claro.

Se midió la conductancia estomática (gs) $\left(\mathrm{mmol} \mathrm{H}_{2} \mathrm{Om}^{-2} \mathrm{~s}^{-1}\right)$ al mediodía, en una hoja superior totalmente expandida. Las mediciones se realizaron con porómetro de flujo estacionario Decagon SC1 (DecagonDevices, Pullman, Washington, USA). Las mediciones se realizaron a los 3, 6, 12, 20, 25 y 32 meses de instalado el ensayo. Para los meses 3, 6 y 12, se midió en una hoja superior totalmente expandida de 3 plantas, en cada posición de cada claro, repetido en 3 días. En el caso que una planta haya sido medida más de un día, estos valores se promediaron para la planta. Para los meses 20, 25 y 32, se midió en una hoja de 3 plantas, en cada posición de cada claro, un día.

Para evaluar la tasa fotosintética al mediodía en el gradiente de cobertura generado por los claros, se midió la tasa de trasporte de electrones del fotosistema II (ETR) ( $\mu \mathrm{mol} \mathrm{e} \mathrm{m}^{-2} \mathrm{~s}^{-1}$ ). Las mediciones fueron realizadas en las plantas con un fluorímetro (FMS2, Hansatech, Norfolk, UK). Las mediciones se realizaron a los 6, 12, 20 y 32 meses de instalado el ensayo. Para los meses 6, 12 y 20 se midió en una hoja superior totalmente expandida de cada planta viva, en cada posición de cada claro, un día. Para las mediciones a los 32 meses, se midió la hoja superior totalmente expandida de 3 planta en cada posición de cada claro, un día. Las mediciones se realizaron entre las 11 y las 13 hs en días despejados, y cada hoja se mantuvo en la posición en que estaba.

Para estimar el daño del sistema fotosintético, se midió el rendimiento cuántico máximo del fotosistema II (Fv/Fm), ya que es un estimador del daño. Las mediciones se realizaron en una 
hoja superior totalmente expandida de 3 plantas en cada posición de cada claro, durante un día. Las mediciones se realizaron con el fluorímetro (FMS2, Hansatech, Norfolk, UK), con el método de pulso saturante de luz, luego de aclimatar a la oscuridad durante 30 minutos a las hojas. Las mediciones se realizaron a los 6,12 y 20 meses de instalado el ensayo. Los datos del mes 25 se perdieron por problemas en el equipo. En los meses 3 y 32 no se midió.

Para medir la concentración de clorofila se eligieron hojas superiores totalmente expandidas de 3 plantas de cada posición de cada claro. De cada hoja se tomó un disco (5mm de diámetro) con sacabocado. Inmediatamente, cada disco fue colocado en un mililitro de N,NDimetilformamida. La concentración fue medida con un espectrofotómetro a 647 y $664,5 \mathrm{~nm}$ de longitud de onda y fueron calculados los parámetros de concentración de clorofila según (Inskeep y Bloom 1985). Se calculó la concentración de clorofila total y se la expresó en $\mathrm{mg} \mathrm{cm}^{-2}$ (Tclor.area) y en $\mathrm{mg} \mathrm{g}^{-1}$ (Tclor.PS), se calculó la concentración de clorofila a y de clorofila b, para luego calcular la relación clorofila a/b. Las mediciones se realizaron a los 3, 6, 12, 20, 25 y 32 meses de instalado el ensayo.

\subsubsection{Ensayo en parcelas permanentes del bosque nativo}

2.2.3.1 Descripción de la metodología del relevamiento de la regeneración natural de Cabralea canjerana en el bosque nativo

Los relevamientos fueron llevados a cabo en el predio del Campo Anexo Manuel Belgrano (CAMB), dependiente del INTA EEA Montecarlo. Se trabajó en 4 parcelas permanentes de bosque nativo de 1 ha cada una, instaladas por el Ing. Ftal. Martín Pinazo en los años 2006, 2007, 2011 y 2015, en el marco de proyectos del INTA Montecarlo (Figura 2.9). Estas parcelas fueron georeferenciadas y todos los individuos adultos de todas las especies fueron mapeados, identificados y numerados con una etiqueta de chapa. Estos registros fueron realizados por Ing. Ftal. Martín Pinazo. Se consideró adultos a todos los individuos mayores o iguales a $10 \mathrm{~cm}$ de DAP (diámetro a la altura del pecho, a 1,3 metro de altura). En mayo de 2015 se realizó el primer relevamiento de la regeneración de Cabralea canjerana en las 4 parcelas permanentes. Se denominó regeneración a todos los individuos menores a $10 \mathrm{~cm}$ de DAP (Pinazo et al. 2009b; de Carvalho et al. 2017). Para facilitar el relevamiento y el posterior análisis, se realizó una clasificación de los individuos relevados y se los dividió en 3 categorías: las plantas entre $10 \mathrm{~cm}$ y 
$50 \mathrm{~cm}$ de altura fueron consideradas plántulas pequeñas (PP); plantas entre $50 \mathrm{~cm}$ y 1,30 m de altura total al ápice fueron consideradas plántulas (P); las plantas con DAP (diámetro a la altura del pecho medido a $1,30 \mathrm{~m}$ de altura) hasta $10 \mathrm{~cm}$ de DAP fueron consideradas juveniles (J) y las plantas de más de $10 \mathrm{~cm}$ de DAP fueron consideradas adultas de Cabralea canjerana (AC). Estas categorías fueron elegidas ya que son similares a las descriptas en los trabajos (Pinazo et al. 2009a; de Carvalho et al. 2017).

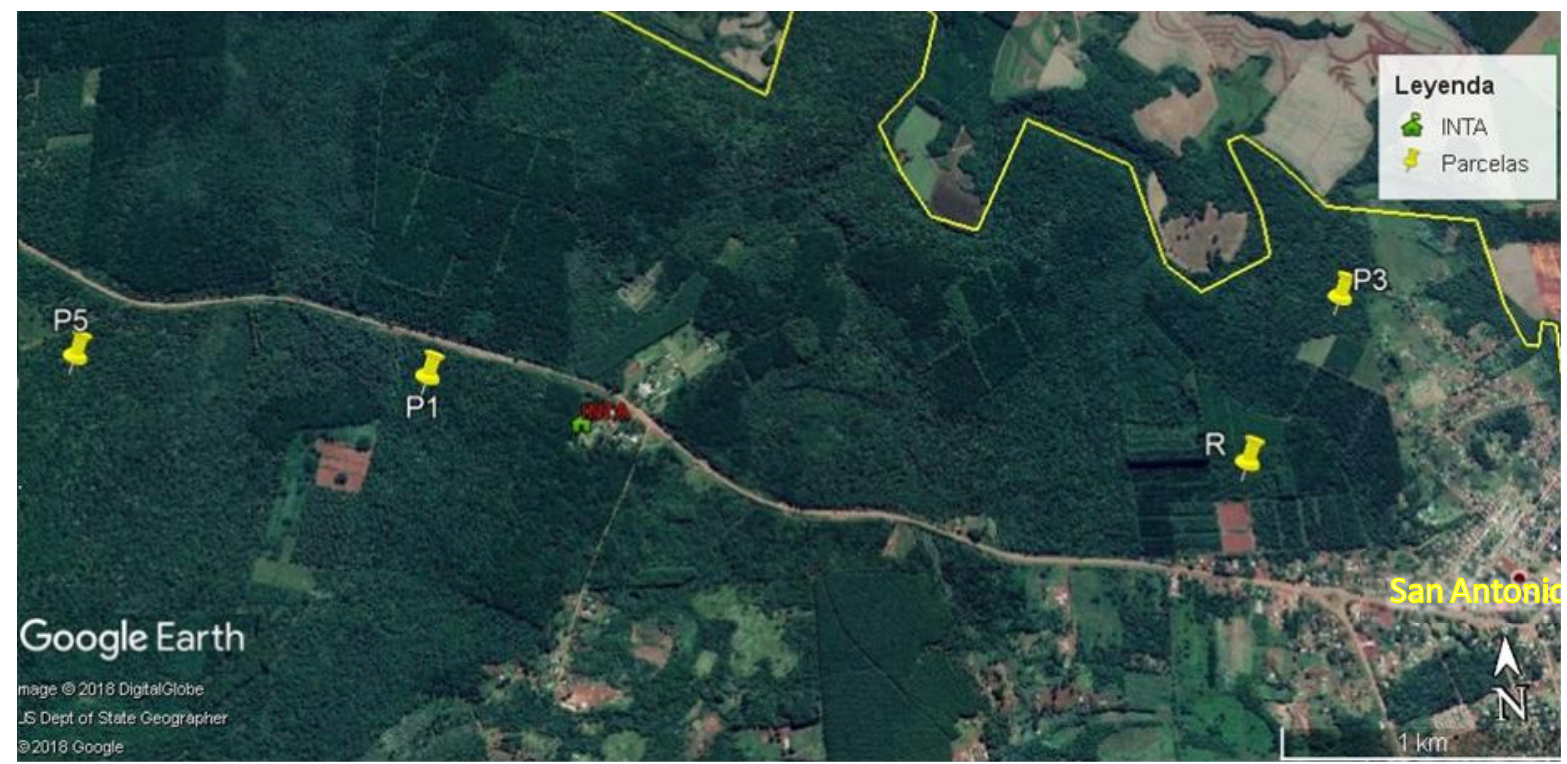

Figura 2.9: Imagen del predio del Campo Anexo Manuel Belgrano (CAMB), dependiente del INTA EEA Montecarlo. Los puntos son los sitios donde están las parcelas permanentes de 1 ha. Parcela 1, 3, 5 y R.

Las 4 parcelas de 100×100 m fueron divididas en subparcelas de $10 \times 10 \mathrm{~m}$ para facilitar el relevamiento (Figura 2.10). En las 100 subparcelas de cada parcela se mapearon y midieron todos los individuos de Cabralea canjerana de las categorías P, J y AC, además en 16 subparcelas seleccionadas sistemáticamente se etiquetaron, mapearon y midieron los individuos de la categoría PP (cuadros amarillos) (Figura 2.10). A cada planta se le colocó una chapa numerada y se registraron las coordenadas $x$ e y con cinta métrica de $50 \mathrm{~m}$. Se midió la altura de cada planta desde la base hasta el ápice principal con cintas métricas y barras métricas en las 3 categorías (PPP-J), y los diámetros con calibre digital en la categoría J. Estos registros se realizaron anualmente en mayo de 2015, 2016, 2017 y 2018. Para el análisis se utilizaron los datos de las mediciones a partir de 2016. 


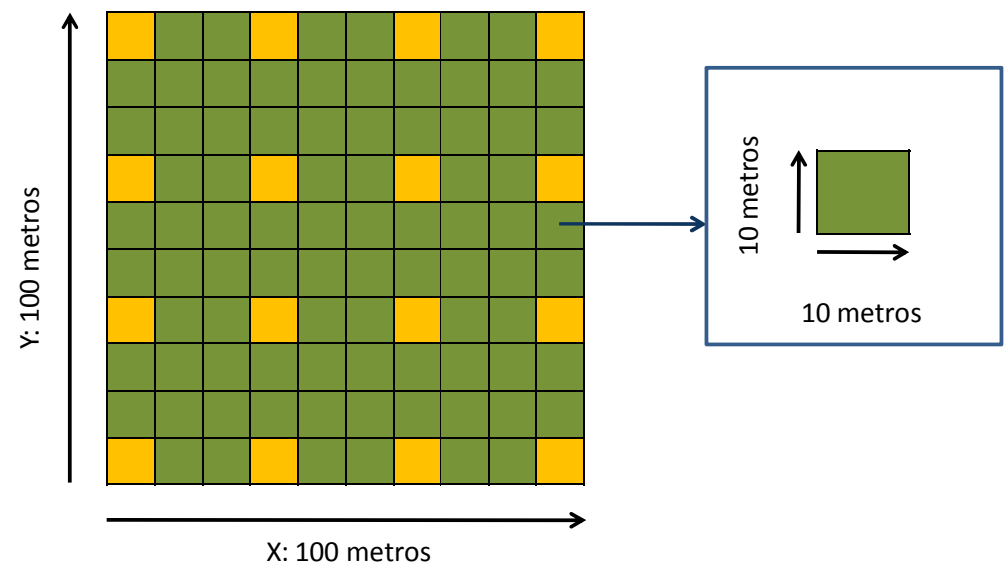

Figura 2.10: Representación de 1 ha dividida en 100 subparcelas de 10x10m. Los cuadros amarillos son las 16 subparcelas en donde además de las categorías plántulas y juveniles, se midieron las plántulas pequeñas. El mismo diseño se aplicó en 4 parcelas.

\section{Análisis estadístico}

Los análisis estadísticos realizados para el análisis de los datos relevados, se describen en cada capítulo, para simplificar la comprensión de los resultados. 
Capítulo 3: Aclimatación morfo-fisiológica a coberturas de canopeo contrastantes

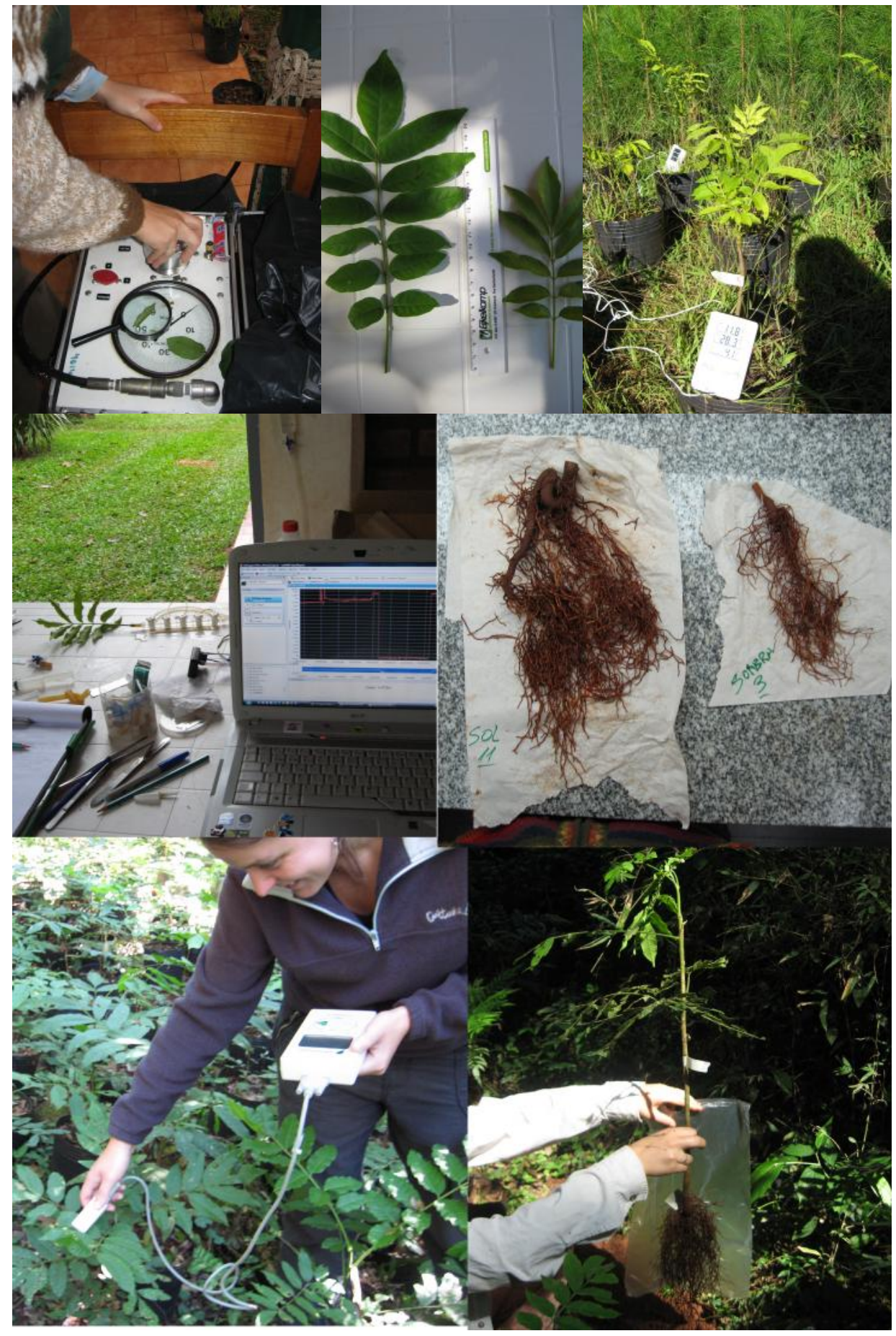




\subsection{Introducción}

El establecimiento y crecimiento de plantas jóvenes en la selva están influenciados por la disponibilidad de luz en el sotobosque. La cantidad y calidad de luz que llega al sotobosque cambia constantemente, y su aumento estimula el proceso de germinación de especies intolerantes a la sombra e incrementa el crecimiento de individuos de otras especies que germinaron previamente debajo del canopeo denso (Montgomery y Chazdon 2002; Felton et al. 2006). La capacidad de las plantas de sobrevivir y crecer en diferentes ambientes generados por la cobertura del canopeo está asociada con los requerimientos intrínsecos de las especies (por ejemplo, tolerante a la sombra o demandante de luz), pero también con la plasticidad fenotípica, que es la capacidad de los genotipos de generar diferentes fenotipos dependiendo del ambiente (Chambel et al. 2005). Por otro lado, cambios en la luz incidente en el sotobosque están asociados con cambios en la disponibilidad de agua del suelo y en el déficit de vapor atmosférico (Kitajima 1996).

Para manejar adecuadamente el enriquecimiento de los bosques degradados, es necesario conocer la capacidad de las especies para aclimatarse a diferentes microclimas a los que pueden estar expuestas naturalmente. Es importante identificar si las plantas bajo sol pleno pueden adecuar su fisiología y morfología para evitar el estrés por déficit de agua y exceso de luz. Por otro lado, es necesario evaluar si las plantas que crecen bajo canopeo denso están estresadas por falta de luz. Especies con mayor plasticidad fenotípica serán más fáciles de manejar en ecosistemas complejos como las selvas, caracterizadas por cambios dinámicos de la cobertura (Kitajima 1996; Felton et al. 2006), porque la plasticidad permite a las especies captar y utilizar recursos. Por ejemplo, para individuos que se establecen debajo de canopeo cerrado, la aclimatación a la sombra es necesaria y en el caso de individuos que quedan expuestos por la formación de un claro, es necesaria la aclimatación a la mayor irradiancia y demanda evapotranspirativa. Es importante destacar que en muchos microambientes del bosque, los recursos necesarios para el crecimiento de las plantas no siempre están disponibles en rangos adecuados.

Para evaluar la aclimatación de las plantas y determinar el nivel de estrés al que se encuentran expuestas, es necesario medir diferentes variables que nos permitan mensurar las respuestas. Se deben considerar variables relacionadas al crecimiento y partición de materia seca, variables morfológicas y fisiológicas relacionadas al uso del agua y al uso de la luz. El crecimiento puede conocerse mediante el aumento en la altura, el diámetro del cuello, número de hojas, área foliar (AF) y peso seco total en el tiempo. Estas variables nos permiten entender el impacto que 
genera el ambiente en el crecimiento. La determinación del área foliar específica (AFE) y peso seco de hojas, tallo y raíces finas y gruesas permite conocer la asignación de recursos a los diferentes órganos de las plantas. Si las plantas están limitadas por luz, se suele registrar una aumento del AFE, aumento en la partición de materia seca hacia tallos en desmedro de las raíces, aumento en la elongación de tallos, posiblemente con menor diámetro, aumento del AF total (Valladares y Niinemets 2008). Si las plantas están sometidas a alta irradiancia esperamos que disminuya el AFE debido a la formación de más capas de parénquima de empalizada que reduce el impacto de la luz en las células del mesófilo que contienen cloroplastos (Strauss-Deberiedetti y Bazzaz 1996). Dado que la alta radiación suele asociarse a altas temperaturas y demandas evapotranspirativas, se suele reducir el área foliar que implica una disminución en el área transpirante, aumentar la partición de materia seca hacia raíces para garantizar mayor exploración del suelo y por la tanto mayor abastecimiento de agua al vástago (Kitajima 1996; Valladares et al. 2004). También puede registrarse un engrosamiento de los tallos que aumenta el área de xilema que se asocia con mayor capacidad de conducir agua hacia las hojas. Los cambios en las variables fisiológicas y morfológicas relacionadas al uso del agua, nos indican el estado hídrico de las plantas y nos permiten visualizar los cambios en la arquitectura hidráulica. La conductancia estomática (gs) se relaciona con la transpiración, que es la pérdida de agua de la planta, que se mueve de la planta a la atmósfera en estado de vapor. Esta pérdida se produce principalmente a través de los estomas; por eso gs es mayor en plantas con buena disponibilidad de agua en el suelo, y disminuye si se reduce el contenido de agua en el suelo o si la demanda evapotranspirativa de la atmósfera es tan elevada que el sistema de conducción de agua no es suficiente par a abastecer la pérdida de agua por transpiración. Cuando esto ocurre, el potencial hídrico de la hoja $(\Psi)$ disminuye. El cierre estomático parcial o total es una respuesta en el corto plazo que puede frenar la caída en el potencial hídrico, aunque con un costo en la reducción en la fijación de carbono, ya que el dióxido de carbono ingresa al mesófilo a través de los estomas (McDowell et al. 2008). En el mediano plazo, la transpiración foliar puede modificarse mediante cambios en la densidad estomática y el índice estomático (IE), que es la relación entre número de estomas y número de células epidérmicas. Un aumento en la densidad estomática o IE implica que la tasa transpiratoria foliar puede ser mayor y por lo tanto la refrigeración puede ocurrir más rápidamente, en caso de que la temperatura foliar aumente debido a la elevada irradiancia y temperatura del aire (Schymanski et al. 2013). Sin embargo, el cierre estomático total o parcial posibilita la regulación del flujo transpiratorio cuando la refrigeración no sea necesaria. La mayor tasa transpiratoria a nivel foliar 
requiere de un adecuado abastecimiento de agua. Para describir la capacidad de la planta de abastecer agua a las hojas, se puede analizar la densidad de vasos y la distribución diamétrica de los vasos. Se espera que las plantas expuesta a mayor radiación y demanda evapotranspirativa tengan mayor área de xilema activo (mayor diámetro de tallos) con mayor densidad de vasos y mayor frecuencia de vasos más chicos (Rungwattana y Hietz 2018). Los vasos más chicos se asocian con menor riesgo de embolismo y cavitación porque el riesgo a la cavitación es mayor en vasos de mayor diámetro, aunque otros factores como punteaduras grandes y la existencia de poros en las punteaduras excepcionalmente grandes pueden aumentar el riesgo de embolismo (Christman et al. 2009). También si los vasos tienen asociado fibras y parénquima vasicéntro axial y radial el riesgo de embolismo es menor que si los vasos están agrupados (Barotto et al. 2018). Los cambios en la anatomía del xilema pueden reflejarse en diferente conductancia y conductividad del tallo, pero también es importante conocer la capacidad conductiva de los demás órganos (hojas y raíces) para interpretar los ajustes en la arquitectura hidráulica que ocurren en la planta en respuesta al ambiente. Se espera que las plantas expuestas a alta radiación y alta demanda evapotranspirativa tengan sistemas radicales, vástagos y tallos con mayor conductancia hidráulica. Esta mayor conductancia podrá lograrse por reducción del camino hidráulico de los órganos, por un aumento en el número de conductos (mayor área de xilema) y/o por aumento en la capacidad específica de conducir agua de cada unidad de tejido (conductancia estandarizada por el tamaño del órgano) que implica que disminuyó la resistencia al movimiento de agua (Siefritz et al. 2002). Es así que en las plantas de sol se espera mayor conductancia estandarizada en hojas, debido a menor tamaño foliar, mayor densidad estomática y mayor conductividad de los pecíolos, tallos y raíces. Por último, las variables fisiológicas y morfológicas relacionadas al uso de la luz, nos indican el estado del aparato fotosintético de las plantas. La tasa de fotosíntesis neta a saturación lumínica (Asat), la respiración mitocondrial aparente, el punto de compensación lumínico (PCL) y la tasa de transporte de electrones del fotosistema II (ETR) se espera que sean mayores en plantas expuestas irradiancias óptimas para la especie, en comparación con plantas que estén a irradiancias limitantes. Si la radiación incidente es insuficiente para sostener la fotosíntesis neta positiva, se suele observar un aumento en la concentración de clorofilas y una disminución en la relación de clorofila $a / b$, de la tasa respiratoria y de la fotosíntesis neta a saturación lumínica (Valladares y Niinemets 2008). Estos cambios aumentan la absorción de radiación incidente en las hojas que permitirá la asimilación de carbono de la atmósfera y disminuyen las catabolización de fotoasimilados, de manera que el balance entre fijación y pérdida de carbono se mantenga 
positivo. En general, el rendimiento cuántico intrínseco $(\phi)$ disminuye en hojas expuestas a alta radiación, porque se satura la capacidad de los fotosistemas de conducir electrones cuando la densidad de flujo fotónico es elevada. Sin embargo, si no se produjo daño en el aparato fotosintético por exceso de luz, $\phi$ se recupera apenas baja la intensidad de radiación (Mohammed et al. 2003). En casos en que la radiación produzca daño, se registra una disminución del rendimiento máximo del fotosistema II (Fv/Fm) aún luego de que la hoja se aclimate a la oscuridad por más de 30 minutos. Es así que si se registra disminución en Fv/Fm en plantas de sol se puede interpretar que la radiación produjo daño en el sistema fotosintético (Krause et al. 2001).

En este capítulo, se analizan los rasgos relacionados con el uso de luz y agua para identificar si las plantas de Cabralea canjerana sufrieron estrés por exceso o déficit de luz y por déficit de agua, cuando éstas crecieron bajo coberturas contrastantes de canopeo.

\subsection{Objetivos e hipótesis}

Objetivo 1: Describir la plasticidad fenotípica de Cabralea canjerana durante el establecimiento inicial a través la identificación de cambios morfológicos y fisiológicos en respuesta a condiciones contrastantes de cobertura (sol y debajo del canopeo)

Hipótesis 1: Las plantas jóvenes de Cabralea canjerana pueden crecer tanto a pleno sol como bajo canopeo, y presentan diferencias morfológicas y fisiológicas según la condición de cobertura a la que están expuestas.

Predicciones para Hipótesis 1:

1. Las plantas de Cabralea canjerana sobreviven en las dos condiciones de cobertura pero crecen menos a sol pleno, debido a que sufren estrés porque están expuestas a mayores irradiancias, temperaturas y déficit de saturación de agua del aire.

2. Las plantas expuestas a sol pleno desarrollan mayor volumen de raíces que las que crecen bajo canopeo denso porque las primeras están expuestas a estrés hídrico por baja humedad en el suelo y alta demanda evapotranspirativa de la atmósfera.

3. Las plantas que crecen bajo canopeo denso tienen mayor área foliar específica, mayor relación vástago/raíz y mayor concentración de clorofila total que las plantas que crecen a 
sol pleno porque realizan cambios morfológicos y fisiológicos para aumentar la intercepción de luz en un ambiente en que la luz incidente es baja.

4. Las plantas que crecen a sol pleno sufren daños del aparato fotosintético por el exceso de luz (menor Fv/Fm), tienen menor eficiencia en el transporte de electrones, mayor fotosíntesis neta a saturación lumínica, mayor tasa respiratoria y mayor punto de compensación lumínico que las plantas aclimatadas a la sombra.

5. Las plantas que crecen a sol pleno tienen mayor conductancia estomática, menor potencial hídrico foliar al mediodía y mayor conductividad hidráulica general que las plantas aclimatadas a la sombra porque están expuestas a mayor demanda evapotranspirativa de la atmósfera y menor contenido de agua en el suelo.

Objetivo 2: Evaluar las respuestas ecofisiológicas de Cabralea canjerana a los 6 meses de plantación en un gradiente de cobertura en claros del bosque nativo.

Hipótesis 2: Las plantas de Cabralea canjerana que crecen con menor cobertura en los claros, están expuestas a mayor estrés hídrico y lumínico.

Predicción para la hipótesis 2:

1. Las plantas que crecen con menor cobertura, crecen menos que las plantas que crecen bajo dosel, y poseen las características morfológicas y fisiológicas que reflejan estrés hídrico y lumínico.

\subsection{Materiales y métodos}

En este capítulo se muestran los resultados de la etapa 1 del ensayo en macetas: se comparan plantas que crecen bajo sol pleno (sol) con plantas que crecen bajo canopeo de bosque nativo (canopeo). Además, se complementan estos resultados con los resultados de los primeros 6 meses de crecimiento de las plantas de Cabralea canjerana plantadas en 6 posiciones en claros del bosque nativo, que implican diferentes niveles de cobertura. La metodología detallada de cada ensayo se detalla en el Capítulo 2.

El experimento en macetas permite medir varios rasgos morfológicos y fisiológicos que pueden describir la capacidad de aclimatación y la tolerancia al estrés de una manera 
relativamente fácil. Los resultados del ensayo de los claros sirve para demostrar si algunas de las variables medidas en el experimento en macetas son útiles para predecir las respuestas al estrés y la aclimatación y crecimiento de las plantas plantadas en un gradiente de cobertura generado por claros del bosque nativo.

\subsubsection{Análisis estadístico}

\section{Ensayo en macetas a campo}

Los datos fueron analizados con InfoStat (Di Rienzo et al. 2015). Las variables morfológicas y fisiológicas fueron analizadas con ANOVA con un factor y 2 niveles (sol y canopeo). En el caso de las variables medidas a lo largo del día, se consideraron 2 factores: condición de cobertura (sol y canopeo) y tiempo (4 niveles: 9, 12, 14 y 17 horas), y la interacción entre factores. Si el ANOVA indicó que el factor tiempo o la interacción fue significativo $(p<0,05)$ las medias se compararon con el test de Duncan con $\mathrm{p}<0,05$.

Los vasos se clasificaron en 10 clases de diámetro. La distribución de frecuencia absoluta de vasos de las plantas de sol y canopeo fueron comparadas con la distribución de Weibull y con un análisis de contingencia. Estos análisis son 2 posibles caminos para analizar la distribución de vasos. La distribución de Weibull se ajusta a una curva asimétrica con 2 parámetros: un parámetro de escala $(\alpha)$ y un parámetro de forma ( $\beta$ ). Si $\beta$ es cercano a 3 , su forma es similar a la de una distribución normal (simétrica), mientras que si $\beta$ es menor que 3 , hay más frecuencia de los diámetros menores. Se realizaron 6 curvas por tratamiento, y los parámetros fueron comparados con ANOVA. Complementariamente la distribución de frecuencia de vasos fue comparada con un análisis de contingencia, y las comparaciones entre tratamientos se realizaron con el test de Chicuadrado. El análisis de contingencia indica si las frecuencias de vasos en alguna clase son diferentes entre tratamiento. Ambos análisis fueron realizados con InfoStat (Di Rienzo et al. 2015).

Ensayo en claros del bosque nativo

Se realizó la estadística descriptiva de cada variable medida a los 6 meses, tomando todas las plantas juntas. Se reporta media, desvío estándar, mínimo y máximo. Además, los datos fueron analizados con análisis de componentes principales (ACP) con el software $R$, utilizando la librería FactoMineR (Le et al. 2008). La librería missMDA fue utilizada para estimar los valores faltantes 
(Josse y Husson 2016). El análisis de componentes principales evalúa las relaciones entre variables, que son representadas con vectores. Flechas en la misma dirección y sentido tienen una correlación positiva, mientras que flechas en sentido opuesto indican una correlación negativa. Si las flechas son perpendiculares, las variables no están correlacionadas.

\subsection{Resultados}

3.4.1 Morfología de las plantas, tamaño y partición de materia seca de plantas de sol y bajo canopeo

Las plantas desarrolladas debajo del canopeo fueron más altas y tuvieron menor diámetro del cuello que las de sol (Tabla 3.1). El peso seco del tallo y hojas fue similar para ambos tratamientos. Sin embargo, el peso seco de las raíces finas y gruesas fue mayor en plantas de sol que en las de canopeo (Figura 3.1; Tabla 3.1). Por lo tanto, el peso seco total de la planta fue mayor en las de sol (Tabla 3.1). En consecuencia, se observó una mayor relación tallo/raíces y hojas/planta entera. A pesar de que el peso seco de las hojas fue similar en ambos tratamientos, el área foliar específica (AFE) fue mayor en las plantas de canopeo que en las de sol. Las plantas de canopeo desarrollaron mayor número de hojas y más amplias. Por otro lado, el número de estomas y de células epidérmicas fue mayor en las plantas de sol que en las de canopeo. El índice estomático (IE) en las plantas de sol fue el doble que en las de canopeo (Tabla 3.1). 


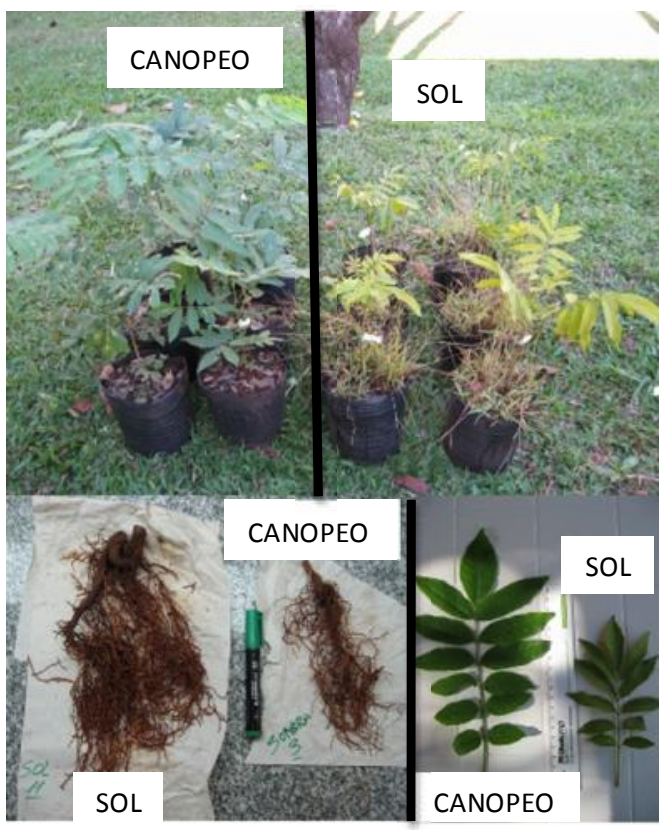

Figura 3.1: Plantas de Cabralea canjerana a los 8 meses de instalado el ensayo en macetas (figura superior), Raíces (figura inferior izquierda) y hojas (figura inferior derecha) a los 8 meses de instalado el ensayo.

Tabla 3.1: Características morfológicas de plantas de Cabralea canjerana que crecen bajo canopeo denso (canopeo) y sin cobertura de dosel (sol). Altura, diámetro del cuello, número de hojas, área foliar total, área foliar específica, densidad estomática, número de células epidérmicas, índice estomático, partición de materia seca (tallos, hojas, raíces finas y raíces gruesas) y peso seco de la planta entera fueron medidos en plantas luego de 8 meses de aclimatación a cada ambiente. Se muestran los valores de $F$ y $p$-valor del ANOVA realizado, además se muestra el error estándar

\begin{tabular}{lcccc}
\hline Variables morfológicas & sol & canopeo & $\mathrm{F}$ & p-valor \\
\hline Altura (cm) & $21,1 \pm 1,4$ & $29,3 \pm 1$ & 23,7 & $<\mathbf{0 , 0 1}$ \\
Diámetro del cuello(mm) & $10,5 \pm 0,4$ & $7,1 \pm 0,3$ & 51,96 & $<\mathbf{0 , 0 1}$ \\
Número de hojas & $5 \pm 0,5$ & $11 \pm 0,4$ & 75,09 & $<\mathbf{0 , 0 1}$ \\
Área foliar total $\left(\mathrm{cm}^{2}\right.$ ) & $283 \pm 54$ & $964 \pm 83$ & 47,34 & $<\mathbf{0 , 0 1}$ \\
Área foliar específica $\left(\mathrm{cm}^{2} \mathrm{~g}^{-1}\right.$ ) & $118 \pm 9$ & $245 \pm 10$ & 87,3 & $<\mathbf{0 , 0 1}$ \\
Densidad estomática $\left(\mathrm{N}^{\circ}\right.$ de estomas $\mathrm{mm}^{-2}$ ) & $109 \pm 8,4$ & $54 \pm 2,2$ & 39,17 & $<\mathbf{0 , 0 1}$ \\
Número de células epidérmicas $\left(\mathrm{N}^{\circ} \mathrm{cel}_{\mathrm{mm}}{ }^{-2}\right.$ ) & $1315 \pm 36$ & $1194 \pm 45$ & 4,35 & $\mathbf{0 , 0 4}$ \\
Índice estomático & $8,6 \pm 0,7$ & $5,3 \pm 0,3$ & 19,6 & $<\mathbf{0 , 0 1}$ \\
Peso seco del tallo(g) & $3,7 \pm 0,62$ & $2,4 \pm 0,4$ & 3,2 & 0,10 \\
Peso seco de hojas(g) & $2,6 \pm 0,6$ & $4,0 \pm 0,4$ & 3,68 & 0,08 \\
Peso seco de raíces finas(g) & $3,5 \pm 0,5$ & $1,2 \pm 0,1$ & 21,03 & $<\mathbf{0 , 0 1}$ \\
Peso seco de raíces gruesas (g) & $7,7 \pm 1,6$ & $2,1 \pm 0,4$ & 11,87 & $<\mathbf{0 , 0 1}$ \\
Peso seco de la planta entera (g) & $17,4 \pm 3,1$ & $9,6 \pm 1,2$ & 5,48 & $\mathbf{0 , 0 4}$ \\
Relación de peso seco vástago/raíz & $0,6 \pm 0,7$ & $2,0 \pm 0,15$ & 72,78 & $<\mathbf{0 , 0 1}$ \\
Relación peso seco hojas/planta entera & $0,1 \pm 0,01$ & $0,4 \pm 0,03$ & 81,92 & $<\mathbf{0 , 0 1}$ \\
Peso seco de la planta entera/ raíz & $0,6 \pm 0,03$ & $0,3 \pm 0,02$ & 98,76 & $<\mathbf{0 , 0 1}$ \\
\hline
\end{tabular}




\subsubsection{Características de la arquitectura hidráulica en plantas de sol y sombra}

La conductancia hidráulica de la planta entera y la conductancia hidráulica de cada órgano (tallo, raíces, hojas y pecíolos) fueron similares en las plantas de sol y canopeo (Tabla 3.2) a pesar de las diferencias en la morfología de la planta y partición de materia seca (Tabla 3.1). Sin embargo, cuando la conductancia se estandarizó por el tamaño de los órganos, se encontraron diferencias entre tratamientos (Tabla 3.2).

Tabla 3.2: Conductancia hidráulica de la planta entera (Kplanta), del vástago (Kvástago), de las raíces (Kraíz) y de las hojas (Khoja), y conductividad hidráulica del tallo (khtallo) y del pecíolo (khpecíolo). Conductancias y conductividades hidráulicas estandarizadas: Planta entera (Kplanta/Peso seco total), Kvástago estandarizada por el área foliar (AF) (Kvástago/AF), Kraíz estandarizado por peso seco total de raíces (Kraíz/peso seco raíces), conductividad hidráulica específica del pecíolo y del tallo (kstallo y kspecíolo), conductividad hidráulica específica foliar (kltallo y klpecíolo), Khoja estandarizado por el área foliar (Khoja/AF) y el valor de Huber (área de xilema del tallo/AF) para plantas de Cabralea canjerana que se desarrollaron durante 8 meses en un área abierta (sol) y bajo canopeo denso (canopeo) durante el verano. Se muestran los valores de $\mathrm{F}$ y $\mathrm{p}$-valor del ANOVA realizado, además se muestra el error estándar.

\begin{tabular}{lllll}
\hline Variables de arquitectura hidráulica & sol & canopeo & $F$ & $p$-valor \\
\hline
\end{tabular}

Conductancia y conductividad

$\begin{array}{lccrr}\text { Kplanta }\left(\mathrm{g} \mathrm{Mpa}^{-1} \mathrm{~h}^{-1}\right) & 2,7 \pm 0,4 & 1,7 \pm 0,5 & 2,8 & 0,12 \\ \text { Kvástago }\left(\mathrm{g} \mathrm{Mpa}^{-1} \mathrm{~h}^{-1}\right) & 2,9 \pm 0,5 & 1,7 \pm 0,4 & 2,8 & 0,12 \\ \text { Kraíz }\left(\mathrm{g} \mathrm{Ma}^{-1} \mathrm{~h}^{-1}\right) & 70 \pm 10 & 60 \pm 17 & 0,2 & 0,70 \\ \text { khtallo }\left(\mathrm{g} \mathrm{m} \mathrm{Mpa}^{-1} \mathrm{~h}^{-1}\right) & 5,1 \pm 0,8 & 3,9 \pm 0,7 & 1,2 & 0,31 \\ \text { khpecíolo }\left(\mathrm{g} \mathrm{m} \mathrm{Mpa}^{-1} \mathrm{~h}^{-1}\right) & 4,8 \pm 1,1 & 4,1 \pm 0,5 & 0,3 & 0,61 \\ \text { Khoja }\left(\mathrm{g} \mathrm{Mpa}^{-1} \mathrm{~h}^{-1}\right) & 1,9 \pm 0,5 & 1,1 \pm 0,4 & 1,5 & 0,25\end{array}$

Estandarizaciones

\begin{tabular}{lcccc} 
Kplanta/peso seco total planta $\left(\mathrm{g} \mathrm{Mpa}^{-1} \mathrm{~h}^{-1} \mathrm{~g}^{-1} \mathrm{PS}\right)$ & $0,18 \pm 0,04$ & $0,17 \pm 0,03$ & 0,01 & 0,92 \\
Ksvástago/AF (g MPa $\left.\mathrm{h}^{-1} \mathrm{~m}^{-2}\right)$ & $115 \pm 24$ & $19 \pm 5$ & 15,6 & $<\mathbf{0 , 0 1}$ \\
Kraíz/peso seco de raíces $\left(\mathrm{g} \mathrm{MPa}^{-1} \mathrm{~h}^{-1} \mathrm{~g}^{-1} \mathrm{PS}\right)$ & $6,7 \pm 1,2$ & $18,2 \pm 4,7$ & 5,5 & $\mathbf{0 , 0 4}$ \\
kstallo (khtallo/AX) $\left(\mathrm{g} \mathrm{m} \mathrm{MPa}^{-1} \mathrm{~h}^{-1} \mathrm{~m}^{-2}\right) \times 10^{3}$ & $195 \pm 57$ & $210 \pm 39$ & 0,05 & 0,82 \\
kltallo (khtallo/AF) $\left(\mathrm{g} \mathrm{m} \mathrm{MPa} \mathrm{m}^{-1} \mathrm{~m}^{-2}\right)$ & $203 \pm 38$ & $43 \pm 10$ & 16,8 & $<\mathbf{0 , 0 1}$ \\
kspecíolo (khpecíolo/AX) $\left(\mathrm{g} \mathrm{m} \mathrm{MPa}^{-1} \mathrm{~h}^{-1} \mathrm{~m}^{-2}\right) \times 10^{3}$ & $718 \pm 65$ & $290 \pm 99$ & 13,2 & $\mathbf{0 , 0 2}$ \\
klpecíolo (khpecíolo/AF) $\left(\mathrm{g} \mathrm{m} \mathrm{MPa}^{-1} \mathrm{~h}^{-1} \mathrm{~m}^{-2}\right)$ & $594 \pm 61$ & $138 \pm 17$ & 51,2 & $<\mathbf{0 , 0 1}$ \\
Khoja/AF $\left(\mathrm{g} \mathrm{m}^{-2} \mathrm{MPa}^{-1} \mathrm{~h}^{-1}\right)$ & $219 \pm 62$ & $42 \pm 10$ & 7,8 & $\mathbf{0 , 0 2}$ \\
Valor de Huber $\times 10^{3}$ & $1,6 \pm 0,6$ & $0.3 \pm 0.1$ & 25,0 & $<\mathbf{0 , 0 1}$ \\
\hline
\end{tabular}

La conductancia hidráulica de la planta entera estandarizada, y la conductividad hidráulica específica del tallo (kstallo) fueron similares para ambos tratamientos. Sin embargo, la conductividad foliar específica del tallo (kltallo), que es kh normalizada por el área foliar, fue 
mayor en las plantas de sol que en las de canopeo. Además, las plantas de sol tuvieron una mayor conductancia hidráulica de las hojas estandarizada por el área foliar (Khoja/AF) que las de canopeo. También las plantas de sol tuvieron una mayor conductividad hidráulica específica de los pecíolos estandarizados por el área de xilema (kspecíolo y por el área foliar (klpecíolo) que las plantas de canopeo. Las plantas de canopeo tuvieron una mayor conductancia de raíces estandarizada por el peso seco de raíces (Kraíz/ peso seco total de raíces) que las plantas de sol (Tabla 3.2). El valor de Huber (la inversión en xilema por unidad de área foliar) fue 6 veces más grande en plantas de sol que en plantas de canopeo.

En las plantas de sol, la conductancia estomática (gs) fue constante a lo largo del día (Figura 3.2), y significativamente menor que bajo canopeo al mediodía (interacción tratamiento*hora: $\mathrm{F}=13,31$ y $\mathrm{p}$-valor $<0,01$ ), momento con mayor demanda evapotranspirativa (Figura 3.2). Consistentemente, el potencial hídrico de las hojas de sol descendió los valores más bajos al mediodía (tratamiento*hora: $\mathrm{F}=2,57$ y $\mathrm{p}$-valor=0,04). El potencial hídrico de las hojas de canopeo fue mayor que el potencial hídrico de las plantas de sol al mediodía, aunque se visualiza un leve descenso al mediodía (Figura 3.2).

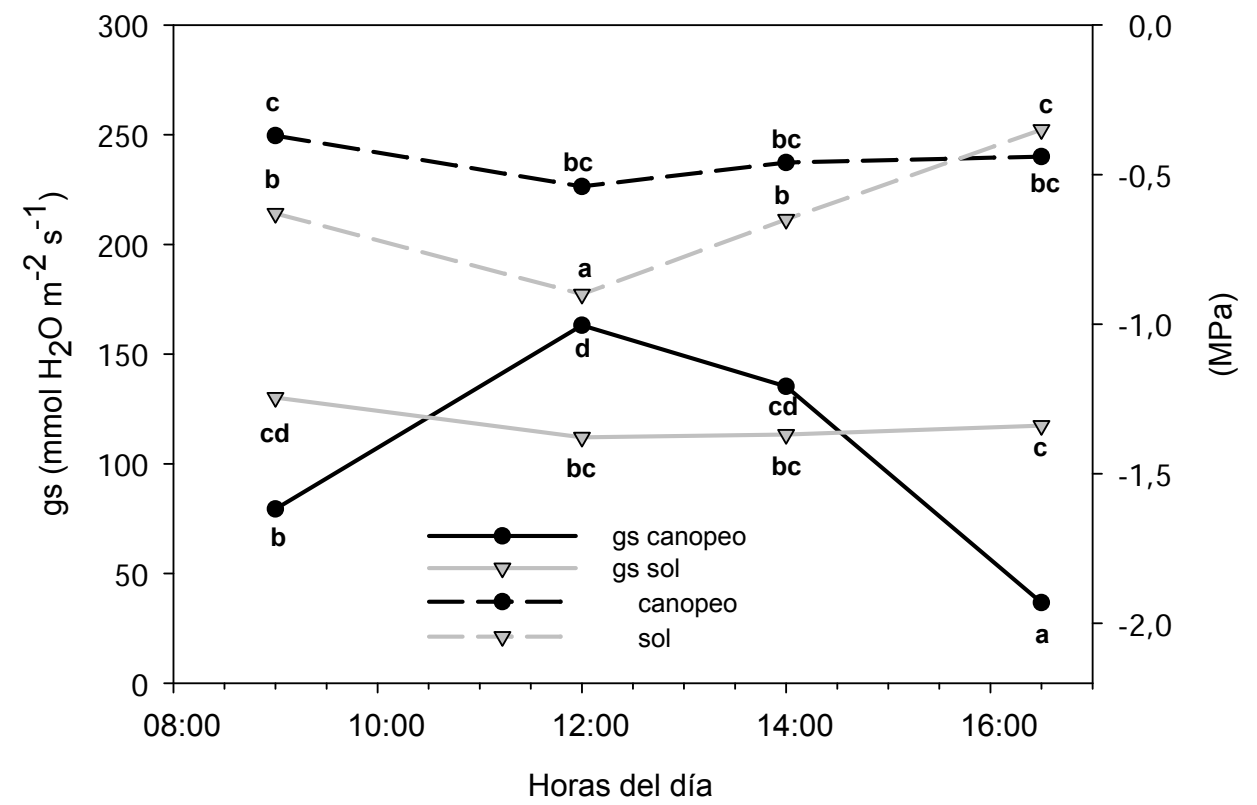

Figura 3.2: Conductancia estomática (gs) $\left(\mathrm{mmol} \mathrm{H}_{2} \mathrm{O} \mathrm{m}^{-2} \mathrm{~s}^{-1}\right.$ ) y potencial hídrico de la hoja ( $\Psi$ ) (MPa) a lo largo del día en plantas de Cabralea canjerana que crecen a sol (sol) y debajo del canopeo (canopeo) después del verano. Letras diferentes indican diferencias significativas entre las medias de la interaación tratamiento*hora $(p<0,05)$. 
Las plantas de sol tuvieron 62 vasos por $\mathrm{mm}^{2}$ de xilema, mientras que las plantas de canopeo tuvieron 50 vasos por $\mathrm{mm}^{2}$. La distribución de frecuencia de vasos por clase diamétrica fue diferente entre las plantas de sol y canopeo en el análisis de contingencia (Figura 3.3; Figura 3.4). La distribución de Weibull indica que las plantas de sol tendieron a tener vasos más chicos que las plantas de canopeo. Consistentemente, en las plantas de canopeo se registraron vasos en las clases diamétricas de vasos más grandes, mientras que las plantas de sol no tuvieron vasos en las dos clases diamétricas más grandes.

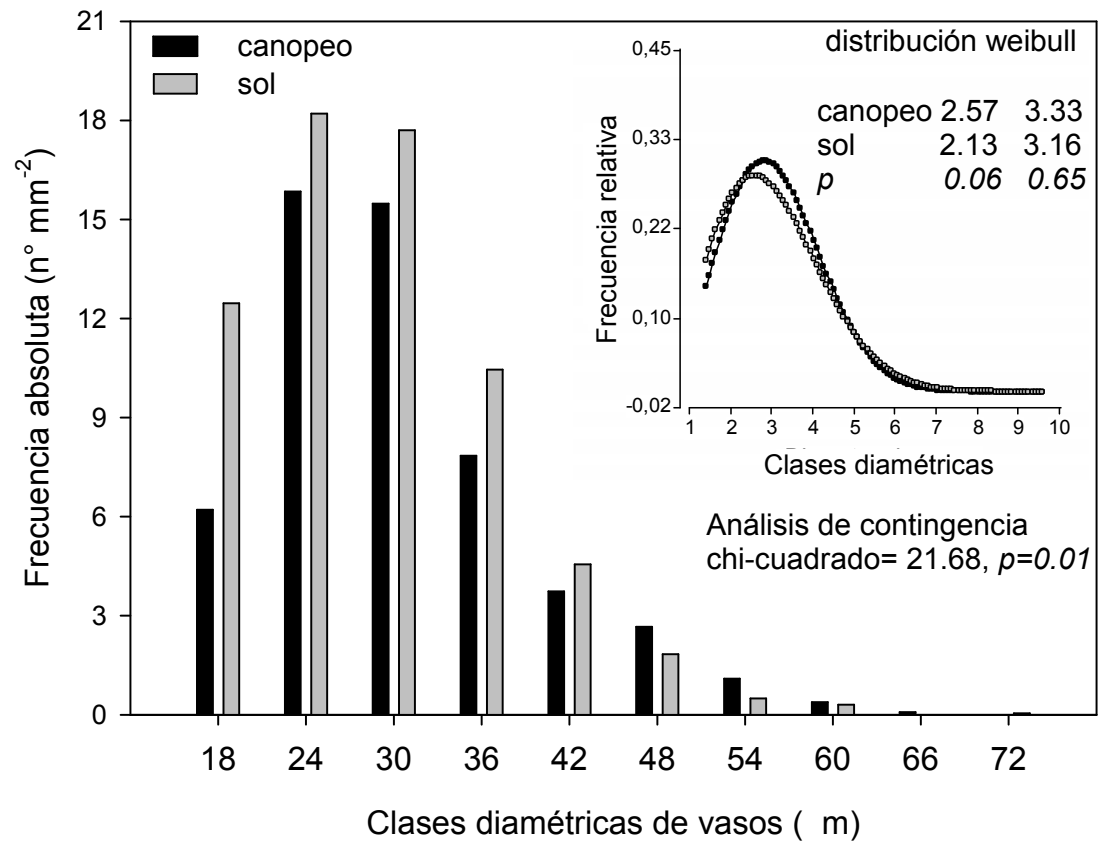

Figura 3.3: Frecuencia absoluta de vasos por área de xilema $\left(\mathrm{mm}^{2}\right)$ por clase de diámetro $(\mu \mathrm{m})$ de plantas de Cabralea canjerana que crecen debajo del canopeo (canopeo) y en un área abierta (sol) durante el verano. La frecuencia total de vasos es 50 y 62 vasos $\mathrm{mm}^{-2}$ para plantas de canopeo y sol, respectivamente. La frecuencia relativa en las clases diamétricas es diferente de acuerdo con el análisis de contingencia $(p=0,01)$. La distribución de Weibull indica que la frecuencia relativa de vasos más chicos es mayor en plantas de sol que en las plantas de canopeo.

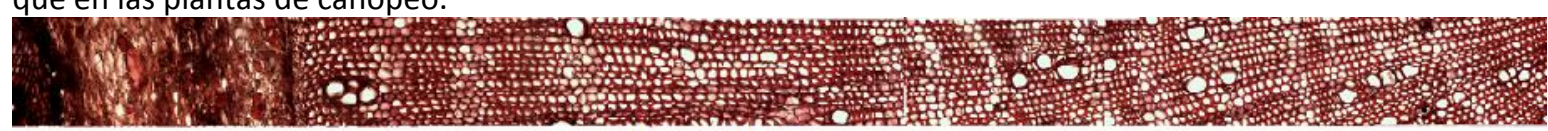

Canopeo-10x

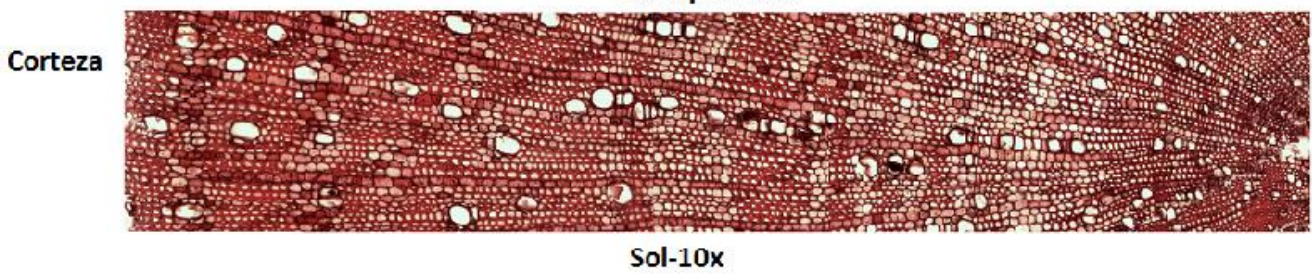

Médula

Figura 3.4: Cortes microscópicos de plantas de Cabralea canjerana desde la corteza hasta la médula. 


\subsubsection{Características relacionadas con el uso de la luz en plantas de sol y canopeo}

Las plantas de sol tuvieron menor concentración de clorofila expresada en área y peso seco, que las plantas de canopeo. La relación clorofila a/b fue menor en las plantas de canopeo que en las de sol (Tabla 3.3). La tasa de fotosíntesis neta máxima a saturación lumínica expresada en base al área foliar (Asat/AF), la tasa respiratoria (R/AF) y el punto de compensación lumínico (PCL) fueron similares para ambos tratamientos (Tabla 3.3; Figura A.1). La tasa de fotosíntesis neta máxima a saturación lumínica y la tasa respiratoria en base al peso seco de las hojas (Asat/PSF y R/PSF, respectivamente) fueron mayores en las plantas de canopeo que en las de sol (Tabla 3.3). Las diferencias entre las tasas de fotosíntesis y respiración expresadas en área foliar respecto de aquellas expresadas en peso seco de hojas están relacionadas con las diferencias de área foliar específica entre tratamientos (Tabla 3.1). El rendimiento cuántico máximo del fotosistema II (Fv/Fm) fue menor en plantas de sol que en plantas de canopeo (Tabla 3.3).

Tabla 3.3: Variables fisiológicas de plantas de Cabralea canjerana que crecen a sol pleno (sol) y debajo del canopeo denso (canopeo) durante el verano: concentración de clorofila total en base al área foliar (Clor t/AF) y en base al peso seco de hojas (Clor t/PSF), relación clorofila a/b, tasa de fotosíntesis neta a saturación lumínica en base al área foliar (Asat/AF), respiración mitocondrial aparente en base al área foliar $(\mathrm{R} / \mathrm{AF})$, punto de compensación lumínico $(\mathrm{PCL})$, tasa de fotosíntesis neta a saturación lumínica en base al peso seco de hojas (Asat/PSF), respiración mitocondrial aparente en base al peso seco foliar (R/PSF), rendimiento cuántico máximo del fotosistema II (Fv/Fm). Se muestran media \pm error estándar y los estadístico $\mathrm{F}$ y $\mathrm{p}$-valor para el ANOVA. Se resaltan en negrita por $\mathrm{p}<0,05$.

\begin{tabular}{lllll}
\hline Variables fisiológicas & sol & canopeo & $\mathrm{F}$ & $\mathrm{p}$-valor \\
\hline Clor t/AF $\left(\mu \mathrm{gm}^{-2}\right)$ & $20,7 \pm 2.8$ & $48,8 \pm 2.6$ & 54,3 & $<\mathbf{0 , 0 1}$ \\
Clor t/PSF $\left(\mathrm{mg} \mathrm{g}^{-1}\right)$ & $1,2 \pm 0,1$ & $6,0 \pm 0,4$ & 126,5 & $<\mathbf{0 , 0 1}$ \\
Clorofila a/b & $2,5 \pm 0,06$ & $2,1 \pm 0,07$ & 16,3 & $<\mathbf{0 , 0 1}$ \\
Asat/AF $\left(\mu \mathrm{mol} \mathrm{de} \mathrm{CO}_{2} \mathrm{~m}^{-2} \mathrm{~s}^{-1}\right)$ & $4,3 \pm 0,7$ & $5,4 \pm 0,47$ & 0,8 & 0,39 \\
$\mathrm{R} / \mathrm{AF}\left(\mu \mathrm{mol} \mathrm{de} \mathrm{CO}_{2} \mathrm{~m}^{-2} \mathrm{~s}^{-1}\right)$ & $2,6 \pm 0,4$ & $2,2 \pm 0,4$ & 0,4 & 0,53 \\
$\mathrm{PCL}\left(\mu \mathrm{mol}\right.$ fotones m $\left.\mathrm{s}^{-1}\right)$ & $13,2 \pm 2,5$ & $8,4 \pm 1,7$ & 2,6 & 0,14 \\
Asat/PSF $\left(\mu \mathrm{mol} \mathrm{de} \mathrm{CO}_{2} \mathrm{~g}^{-1} \mathrm{~s}^{-1}\right) \times 10^{-3}$ & $10 \pm 3$ & $66 \pm 6$ & 34,3 & $<\mathbf{0 , 0 1}$ \\
$\mathrm{R} / \mathrm{PSF}\left(\mu \mathrm{mol} \mathrm{de} \mathrm{CO} 2 \mathrm{~g}^{-1} \mathrm{~s}^{-1}\right) \times 10^{-3}$ & $12 \pm 3$ & $27 \pm 10$ & 5,2 & $\mathbf{0 , 0 4}$ \\
Fv/Fm & $0,5 \pm 0,03$ & $0,8 \pm 0,01$ & 121,1 & $<\mathbf{0 , 0 1}$ \\
\hline
\end{tabular}

La tasa de transporte de electrones del fotosistema II (ETR) fue mayor en las plantas de sol que en las de canopeo desde la mañana hasta pasado el mediodía (interacción tratamiento* hora: $\mathrm{F}=9,04$ y $\mathrm{p}$-valor $<0,01$ ), pero fue similar en ambos tratamientos en el horario de la tarde (Figura 
3.5). El rendimiento cuántico del fotosistema II (QPSII) fue mayor en las plantas de sol que en plantas de canopeo lo largo del día (interacción tratamiento* hora: $F=21,66$ y $p$-valor $<0,01$ ). Las plantas de canopeo usaron alrededor del $70 \%$ de la radiación incidente mientras que las plantas de sol utilizaron entre un 10-30 \% de la radiación (Figura 3.5).

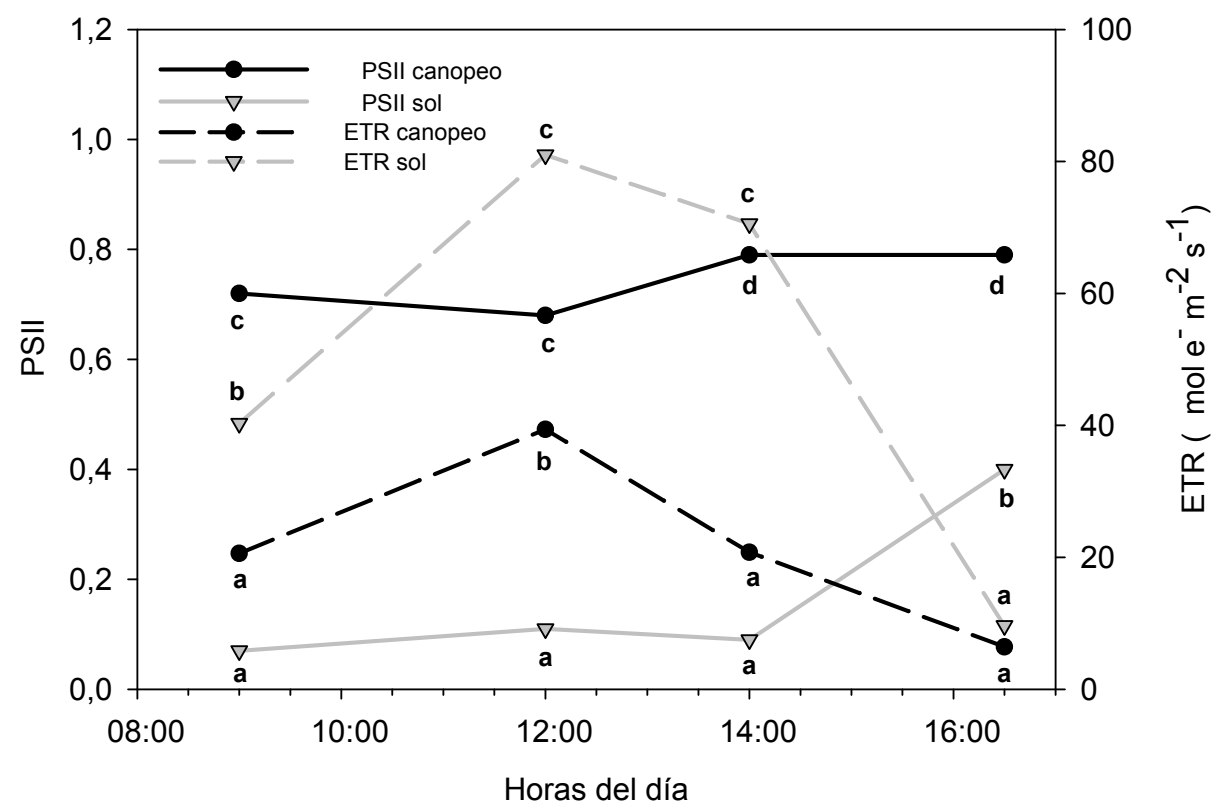

Figura 3.5: Rendimiento cuántico intrínseco del fotosistema II (\$PSII) y tasa de transporte de electrones (ETR) ( $\mu \mathrm{mol} \mathrm{e} \mathrm{m}^{-2} \mathrm{~s}^{-1}$ ) a lo largo del día en plantas de Cabralea canjerana que crecen a sol pleno (sol) y bajo canopeo denso (canopeo) durante el verano. La interacción en tratamiento*hora para cada variable fue significativa. Letras diferentes indican las diferencias $(p<0,05)$.

\subsubsection{Respuestas morfológicas y fisiológicas en un gradiente de cobertura generado en los} claros

Seis meses después de haber sido plantadas, la altura de las plantas de Cabralea canjerana varió entre 4 y $58 \mathrm{~cm}$, y el diámetro del cuello entre 2,5 y 9,5 mm (Tabla 3.4). Algunas plantas fueron más chicas que cuando fueron plantas, ya que, el vástago fue dañado total o parcialmente. El contenido gravimétrico de agua del suelo varió entre $35 \%$ en el centro del claro y $51 \%$ debajo del canopeo, con una media de $41 \%$ para todos los datos (Tabla 3.4). Sin embargo, no hubo diferencias significativas en el contenido de agua del suelo entre posiciones. En el análisis de componentes principales (ACP) se puede observar una alta correlación entre el PAR y la 
temperatura del suelo y del aire (Tsuelo, Taire), y una correlación negativa con la HR del aire (HR) y el contenido de agua en el suelo (CH) (Figura 3.6). La tasa de trasporte de electrones (ETR) y la conductancia estomática (gs) se correlacionaron positivamente con el PAR y la luz transmitida (Luz), por lo tanto plantas con mayor disponibilidad de luz tuvieron los estomas más abiertos y realizaron más fotosíntesis que las plantas con baja disponibilidad de luz (Figura 3.6).

Tabla 3.4: Media, desvío estándar (D.E.), mínimo (Min) y máximo (Max) de las variables incluidas en el ACP de las plantas de Cabralea canjerana creciendo en tres claros del bosque nativo durante 6 meses. Las variables fueron: densidad de flujo fotónico fotosintético (PAR), porcentaje de luz transmitida (Luz), temperatura del aire (Taire), temperatura del suelo (Tsuelo), humedad relativa del aire (HR), diámetro del cuello (DC), altura (H), área foliar del folíolo (AFF), área foliar específica del folíolo (AFEf), clorofila total por área (Tclor.área), clorofila total por peso seco (Tclor.PS), relación clorofila a/b (clor ab), rendimiento cuántico máximo del fotosistema II (Fv/Fm), tasa de transporte de electrones del fotosistema II (ETR), conductancia estomática (gs), contenido de agua en el suelo (CH).

\begin{tabular}{|c|c|c|c|c|}
\hline Variable & Media & D.E. & Min & Max \\
\hline PAR $\left(\mu\right.$ moles $\left.\mathrm{m}^{-2} \mathrm{~s}^{-1}\right)$ & 275,59 & 436,24 & 3 & 1752 \\
\hline Luz (\%) & 25,31 & 14,04 & 1,69 & 49,63 \\
\hline Taire (으) & 27,6 & 3,1 & 23,9 & 37,0 \\
\hline Tsuelo (으) & 22,9 & 2,0 & 21,1 & 30,9 \\
\hline HR (\%) & 58,8 & 9,1 & 33,0 & 71,0 \\
\hline $\mathrm{DC}(\mathrm{mm})$ & 5,62 & 1,3 & 2,45 & 9,53 \\
\hline $\mathrm{H}(\mathrm{cm})$ & 24 & 11 & 4 & 58 \\
\hline $\operatorname{AFF}\left(\mathrm{cm}^{2}\right)$ & 14,25 & 6,83 & 3,54 & 38,53 \\
\hline $\operatorname{AFEf}\left(\mathrm{cm}^{2} \mathrm{~g}^{-1}\right)$ & 319,14 & 81,45 & 133,39 & 589,09 \\
\hline Tclor.area $\left(\mu \mathrm{g} \mathrm{cm}^{-2}\right)$ & 41,94 & 7,17 & 25,21 & 57,12 \\
\hline Clor.ab & 2,1 & 0,18 & 1,67 & 2,67 \\
\hline Tclor.PS (mg g ${ }^{-1}$ ) & 13,24 & 2,91 & 6,92 & 19,65 \\
\hline $\mathrm{Fv} / \mathrm{Fm}$ & 0,87 & 0,05 & 0,61 & 0,91 \\
\hline $\operatorname{ETR}\left(\mu \mathrm{mol} \mathrm{e}^{-} \mathrm{m}^{-2} \mathrm{~s}^{-1}\right)$ & 38,18 & 47,13 & 0,96 & 286,59 \\
\hline $\mathrm{Gs}\left(\mathrm{mmol} \mathrm{H} \mathrm{H}_{2} \mathrm{~m}^{-2} \mathrm{~s}^{-1}\right)$ & 118,95 & 48,03 & 38,9 & 260,4 \\
\hline $\mathrm{CH}(\%)$ & 41 & 5 & 35 & 51 \\
\hline
\end{tabular}

El área foliar del folíolo (AFF), el diámetro del cuello (DC) y la altura de las plantas (H) se correlacionaron positivamente con la luz (Figuras 3.6). El área foliar específica (AFE) se correlacionó negativamente con la luz y con las variables de tamaño (H, DC, AFF) (Figura 3.6). La concentración de clorofila basada en el peso seco de hojas (TclorPS) se correlacionó negativamente con la luz, así como la concentración de clorofila basada en el área foliar (Tclor.area) (Figura 3.6). El rendimiento cuántico del fotosistema II (FvFm) se correlacionó negativamente con el PAR. La relación clorofila a/b (clorab) se correlacionó positivamente con la luz, y negativamente con la concentración de clorofila total (Tclor área y Tclor PS) (Figura 3.6). 


\section{Variables factor map (PCA)}

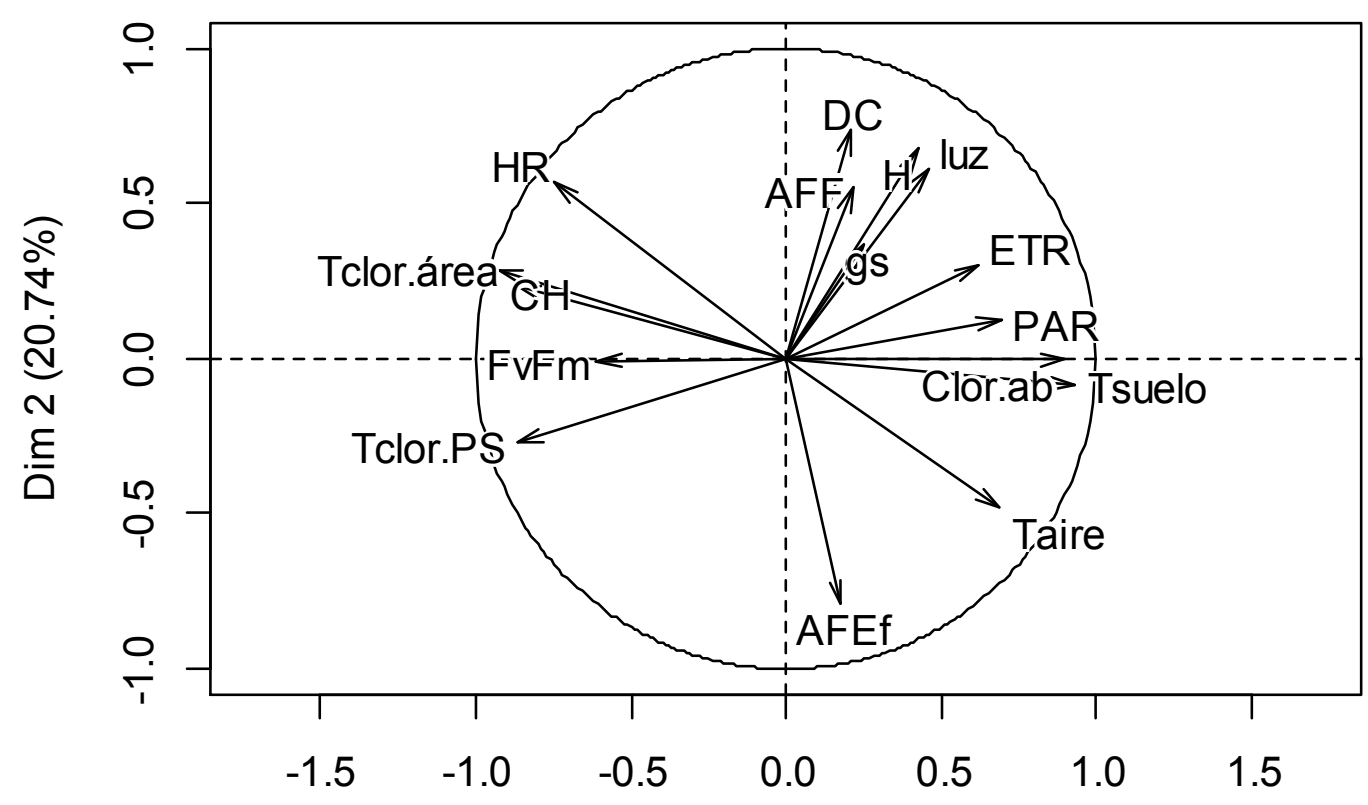

$\operatorname{Dim} 1(42.92 \%)$

Figura 3.6: Análisis de componentes principales de las variables medidas en plantas de Cabralea canjerana que crecen en diferentes posiciones de 3 claros del bosque nativo: densidad de flujo fotónico fotosintético (PAR) ( $\mu$ mol fotones $\mathrm{m}^{-2} \mathrm{~s}^{-1}$ ), luz transmitida (luz) (\%), humedad relativa del aire (HR) (\%), temperatura del aire (Taire) $\left({ }^{\circ} \mathrm{C}\right)$, temperatura del suelo $($ Tsuelo $)\left({ }^{\circ} \mathrm{C}\right)$, altura $(\mathrm{H})(\mathrm{cm})$, diámetro del cuello $(\mathrm{DC})(\mathrm{mm})$, área foliar del folíolo(AFF) $\left(\mathrm{cm}^{2}\right)$, área foliar específica del folíolo (AFEf) $\left(\mathrm{cm}^{2} \mathrm{~g}^{-1}\right)$, clorofila total por área foliar (Tclor.área) $\left(\mathrm{mg} \mathrm{cm}^{-2}\right)$, clorofila total por peso seco (Tclor.PS) $\left(\mathrm{mg} \mathrm{g}^{-1}\right)$, relación clorofila $\mathrm{a} / \mathrm{b}$ (clor.ab), rendimiento cuántico máximo del fotosistema II (FvFm), tasa de transporte de electrones del fotosistema II (ETR) ( $\mu \mathrm{mol} \mathrm{e} \mathrm{m}^{-2} \mathrm{~s}^{-1}$ ), conductancia estomática (gs) (mmoles $\mathrm{m}^{-2} \mathrm{~s}^{-1}$ ), Contenido de agua en el suelo (CH) (\%).

\subsection{Discusión}

\subsubsection{Morfología, crecimiento y partición de materia seca de plantas de canopeo y sol}

Las plantas tuvieron plasticidad fenotípica, reflejada en diferentes mecanismos morfológicos y fisiológicos para aclimatarse a cambios en el ambiente (Givnish 1988). Se asume que las especies intolerantes a la sombra y las intermedias en cuanto a los requerimientos de luz, son más plásticas que las especies tolerantes a la sombra, porque las primeras deben desarrollar mecanismos para evitar la falta de luz, aunque las tolerantes a la sombra puedan ajustar 
fuertemente ciertos rasgos morfológicos y fisiológicos para sobrevivir a la sombra, como bajo punto de compensación lumínico, baja tasa respiratoria, síntesis de metabolitos secundarios de defensa, entre otros (Valladares y Niinemets 2008). Las plantas de Cabralea canjerana modificaron sus rasgos estructurales en respuesta a las disponibilidades de luz contrastantes, aunque haya sido clasificada como una especie tolerante a la sombra (Schussler 2006; Cargnelutti Filho et al. 2012). Las plantas de canopeo fueron más altas y delgadas que las de sol (Tabla 3.1). Esta respuesta de elongación de los tallos se produce en plantas que crecen con baja disponibilidad de luz, donde la relación rojo/rojo lejano es menor. Esta es una típica respuesta de especies intolerantes o semitolerantes a la sombra para optimizar la intercepción de luz en sitios con una densidad de cobertura alta, donde llega luz directa a través de flecos de luz (Schall et al. 2012). Consistentemente, las plantas de canopeo desarrollaron hojas más amplias y delgadas que las plantas de sol (Tabla 3.1), estas son modificaciones morfológicas para maximizar la intercepción de luz debajo del canopeo con una baja inversión de carbono. Varias especies de árboles tropicales semi-tolerantes a la sombra, también desarrollaron mayor AFE a bajas irradiancias dentro de un invernáculo con condiciones controladas (Shimizu et al. 2005). Por otro lado, Toona ciliata, una especie de la sucesión temprana, tuvo un área foliar mayor cuando las plantas crecían a bajas irradiancias que cuando crecían a altas irradiancias (Murphy et al. 2014). Sin embargo, también las condiciones de luz eran controladas con luz artificial dentro de cámaras de crecimiento. En nuestro trabajo la cobertura es natural, no se utilizó media sombra ni luz artificial. Esta es una ventaja que permite entender la respuesta en un ambiente natural con las fluctuaciones en la luz incidente típicas de los bosques, y por lo tanto es esperable este tipo de respuesta morfológica en el campo.

Otros cambios morfológicos a nivel de las hojas fueron la mayor densidad estomática e índice estomático (IE) en las plantas de sol con respecto a las de sombra (Tabla 3.1). Es importante remarcar que el incremento en el número de estomas por unidad de área no fue solo el efecto de la menor expansión foliar (células más pequeñas o mayor número de células por unidad de área), sino que, la proporción de estomas formados por cada célula epidérmica fue también mayor en plantas de sol que en plantas de sombra. El incremento en el número de estomas podría estar relacionado con la necesidad de mayor refrigeración de las hojas de las plantas, debido a la alta irradiancia, baja humedad relativa del aire y altas temperaturas (Figura 2.4; Figura 2.5). En algunas especies de otras familias también fueron observados altos IE en ambientes con altas radiación (Camacho y Bellefleur 1996; Brodribb y Jordan 2011; Murphy et al. 2012; Nascimento et al. 2015). 
Las plantas de canopeo acumularon menor peso seco de raíces que las plantas de sol (Tabla 3.1). Una reducción en el volumen de raíces y un aumento en la relación vástago/raíz en respuesta a la menor irradiancia, fueron observados en Fagus sylvatica (L.) (haya) y en Picea abies (L.) Karst (Schall et al. 2012). Un mayor volumen de raíces de las plantas de sol puede incrementar la exploración de suelo y aumentar el abastecimiento de agua a la planta. Sin embargo, el cierre parcial de estomas y la caída del potencial hídrico al mediodía en las plantas de sol, refleja que el incremento del volumen de raíces no fue suficiente para contrarrestar las pérdidas de agua por transpiración (Figura 3.2; Tabla 3.1).

\subsubsection{Rasgos de la Arquitectura hidráulica en plantas de sol y canopeo}

Además de la plasticidad en los rasgos morfológicos como la altura, el diámetro del tallo y la morfología de las hojas, las plantas de Cabralea canjerana ajustaron su arquitectura hidráulica durante la primera estación de crecimiento, combinando cambios en diferentes órganos. Las plantas pudieron desarrollar cambios en 8 meses para ajustar no solo la morfología, sino también la funcionalidad de los órganos en respuesta al ambiente, para adquirir los recursos que son limitantes para su crecimiento. Las plantas de sol aumentaron la conductividad hidráulica específica de la hoja (Khoja/AF) y la conductividad hidráulica específica de los pecíolos (klpecíolo) (Tabla 3.2). Un incremento en la conductividad hidráulica especifica de los pecíolos fue observado en Cedrela fissilis (Campanello et al. 2008). Consistentemente, en Nothofagus cunninghamii (Hook) Oerstla, la mayor conductancia hidráulica de las hojas de las plantas de sol fue asociada con una mayor densidad estomática y mayor densidad de venación de las hojas con respecto a hojas de sombra (Brodribb y Jordan 2011). El incremento en la conductividad hidráulica a nivel de hojas y el mayor IE (Tabla 3.2; Tabla 3.1) permite abastecer con suficiente agua a la planta para mantener la hidratación de las hojas cuando están expuestas a una alta demanda evapotranspirativa en condiciones de sol pleno, mantener los estomas parcialmente abiertos y refrigerar la hojas (Figura 3.2). Esta alta capacidad de abastecer de agua a las hojas evitó que el potencial hídrico foliar cayera a valores perjudiciales, como se observó incluso al mediodía (Figura 3.2). Los potenciales hídricos perjudiciales son aquellos que producen daños irreversibles en los tejidos de las hojas, y defoliación. Dado que los potenciales hídricos se incrementaron al atardecer y no se observó marchitamiento al amanecer, consideramos que no ocurrió daño irreversible. Además, las plantas de sol tuvieron una mayor conductividad hidráulica foliar especifica del tallo 
kltallo (kltallo=khtallo/AF) (Tabla 3.2), lo que significa que cada $\mathrm{cm}^{2}$ de hoja de las plantas de sol es abastecido por una mayor cantidad de xilema que las hojas de las plantas de canopeo. La capacidad de conducir agua por unidad de área del xilema (kstallo) fue similar en las plantas de ambos tratamientos. Sin embargo, ocurrieron cambios anatómicos en a nivel de xilema. Las plantas de sol tuvieron una mayor densidad de vasos y frecuencia de vasos más pequeños que las plantas de canopeo (Figura 3.3). Posiblemente, el aumento en la densidad de vasos incrementa la capacidad de conducir agua, y los vasos más pequeños tienen menor vulnerabilidad a la cavitación (Lens et al. 2011). Estas modificaciones son esperables en las plantas de sol ya que están expuestas a un ambiente más estresante debido a las altas temperaturas y mayor demanda evapotranspirativa. En otras tres especies de la selva misionera también se observó que la capacidad de conducir agua (kstallo) fue la misma en diferentes ambientes de luz ,aunque en otras dos especies kstallo fue mayor cuando crecieron expuestas a mayor irradiancia (Campanello et al. 2008). Esto indica que hay especies que tienen plasticidad en este atributo, mientras otras no. Además, la mayor kltallo en las plantas de sol fue debido a la reducción del área foliar y el incremento en diámetro del tallo, reflejado en el valor de Huber que fue 6 veces mayor en plantas de sol que de canopeo (Tabla 3.2). El valor de Huber refleja la capacidad de las plantas de ajustar la partición de materia seca entre el xilema y las hojas para mantener la homeostasis en relación al abastecimiento de agua en las hojas (Carter y White 2009). En el caso de las plantas de sol, el incremento de la inversión en tejidos de conducción del tallo por unidad de área foliar está relacionado con la mayor transpiración en esta condición, y está reforzado con la mayor conductividad hidráulica de los pecíolos y las hojas (Tabla 3.2).

Al mediodía, las plantas de sol no cerraron totalmente los estomas y el potencial hídrico decreció (Figura 3.2), pero no a valores perjudiciales para causar la muerte de la planta. Si bien, las plantas de sol tuvieron hojas y los pecíolos más conductivos (Tabla 3.2) y mayor volumen de raíces que las de canopeo, estos no fueron suficientes para abastecer de suficiente agua a las hojas en los momentos de mayor déficit de vapor de agua. Cuando el abastecimiento de agua no puede contrarrestar las pérdidas por traspiración, las hojas cierran parcial o totalmente los estomas para prevenir la deshidratación, y en consecuencia se podría reducir la capacidad de fijar carbono por fotosíntesis. Sin embargo, la caída en el potencial hídrico de las hojas en las plantas de sol fue leve para producir el cierre total de estomas, y solo se produjo un cierre parcial. De manera similar, en otro trabajo con árboles tropicales de la sucesión temprana e intermedia, se observó una caída del potencial osmótico al mediodía en las plantas de sol en comparación con las de sombra (Shimizu 
et al. 2005). Es así que los árboles que crecen en ambientes húmedos como los trópicos y subtrópicos pueden registrar estrés hídrico al mediodía si están expuestos a alta radiación.

Las plantas de canopeo desarrollaron menos raíces que las de sol (Tabla 3.1), pero estas fueron más conductivas (Kraíz/PS total de raíces) (Tabla 3.2). Una alta conductancia específica de raíces fue observada en 5 especies de árboles que crecieron a la sombra (Shimizu et al. 2005). Con esta estrategia las plantas pueden abastecer de suficiente agua a los tallos de las plantas con una baja inversión de carbono en raíces. Como ya se mencionó, las plantas bajo canopeo invirtieron mayor cantidad de fotoasimilados hacia la parte aérea, reflejado en mayor área foliar y número de hojas, con mayor área foliar específica. Las plantas de canopeo tuvieron una alta conductancia estomática al mediodía, sin una disminución del potencial hídrico de la hoja (Figura 3.2). Las plantas de canopeo mantuvieron los estomas abiertos al mediodía sin comprometer la hidratación de las hojas, aunque tuvieron menor conductividad hidráulica de la hoja por unidad de área foliar (Khojas/AF) (Tabla 3.2) y menor índice estomático (Tabla 3.1) que las plantas de canopeo. La apertura estomática al mediodía está relacionada posiblemente con una mayor incidencia de la luz en ese momento del día debajo del canopeo (Tabla 2.1), entonces posiblemente se relacione con mayor la actividad fotosintética en ese horario. Teniendo en cuenta todos los cambios en las características relacionadas al uso del agua, es evidente que las plantas de sol pleno desarrollaron cambios para minimizar el impacto negativo de la alta demanda evaporativa y las altas temperaturas. En consecuencia, la condición de sol pleno implica un estrés moderado para las plantas de Cabralea canjerana, ya que no se registró una reducción del crecimiento en comparación con las plantas de canopeo, que estaban expuestas a condiciones de menor demanda evapotranspirativa.

\subsubsection{Rasgos relacionados con el uso de la luz en plantas de sol y canopeo}

Las plantas de sol posiblemente sufrieron algún daño moderado en el aparato fotosintético, reflejado en el menor Fv/Fm respecto de las plantas de canopeo, que tuvieron valores óptimos (Tabla 3.3). Una disminución de 0,8 a 0,5 en Fv/Fm puede ser clasificado como un daño moderado (Mohammed et al. 2003). El rendimiento cuántico máximo del fotosistema II (Fv/Fm) representa el balance entre la tasa de foto-daño y la tasa de reparación del fotosistema II, es decir indica la proporción de centros del fotosistema II funcionales (Aro et al. 1993). Este es independiente de cambios en la absorción de la luz de la hoja, dados por cambios en el contenido 
de clorofila, área foliar específica y el contenido de agua (Fracheboud y Leipner 2003; Kalaji et al. 2014), como los observados en las plantas en cada condición de cobertura. Sin embargo, el daño en las plantas de sol fue moderado (Tabla 3.3) y la capacidad global para fijar carbono fue más alta en las plantas de sol que en las de canopeo, reflejado por el mayor peso seco total de las plantas de sol (Tabla 3.1). Similarmente, en otro trabajo se observó una reducción en Fv/Fm y en la concentración de clorofila total en 3 árboles tropicales tolerantes a la sombra, expuestos a altas irradiancias. Esta reducción produjo impactos negativos en el crecimiento, sin embargo los árboles tolerantes se pudieron aclimatar a altas irradiancias (Krause et al. 2012). La menor concentración de clorofila (Tabla 3.3) y las hojas más gruesas (Tabla 3.1) desarrolladas en plantas de sol podría contribuir a evitar los daños por exceso de luz. Sin embargo, las plantas de sol al mediodía usaron solo entre un 10 y 30 \% de la luz incidente a lo largo del día, reflejándose en el bajo rendimiento cuántico intrínseco del fotosistema II (Figura 3.5). Cómo la radiación incidente a sol pleno fue alta, ETR para las plantas de sol fue el doble que para las plantas de canopeo, aunque estas últimas usaron más del 70\% de la radiación incidente (Figura 3.5). La alta capacidad de fijar carbono a lo largo del tiempo se ve reflejada en el mayor peso de la planta entera de las plantas de sol con respecto a las de canopeo. Por lo tanto, las plantas de sol estuvieron expuestas a un estrés moderado por alta radiación, pero su plasticidad fisiológica y anatómica evitó daños significativos y la reducción de crecimiento, reflejado en el mayor peso seco final.

Por otro lado, las plantas de canopeo realizaron cambios que le permitieron incrementar la intercepción de luz: aumentaron el AFE, es decir que construyeron mayor superficie fotosintética por cada unidad de materia seca invertida en hojas, aumentaron el área foliar total y tuvieron mayor elongación del tallo (Tabla 3.1). Sorpresivamente, la curva de la tasa de asimilación neta expresada por área foliar fue similar para las plantas que crecieron en ambas condiciones de cobertura (sol y canopeo) (Tabla 3.3; Anexo Figura A.1). Es así que la tasa de asimilación de carbono neta dada cierta intensidad de luz es similar para las plantas que se aclimataron a sol y bajo canopeo En árboles tropicales aclimatados a diferentes niveles de luz en un claro, las curvas de la tasa de asimilación de carbono en respuesta a la luz fueron diferentes entre sitios para 3 especies intolerantes a la sombra, mientras que no hubo diferencias entre las curvas de dos especies tolerantes a la sombra (Guzmán y Cordero 2013). Sin embargo, en cuatro especies tolerantes a la sombra, las curvas de respuesta a la luz fotosintética fueron diferentes si las plantas crecieron debajo del canopeo, en un claro pequeño o en un claro grande (Kuehne et al. 2014), siguiendo el patrón esperado de aclimatación a la sombra. Las plantas de Cabralea canjerana no 
desarrollaron las diferencias típicas entre hojas de sol y de sombra, posiblemente porque las plantas de canopeo pueden usar los flecos de luz de alta intensidad que llegan al sotobosque a través de la porosidad del canopeo (Schurr et al. 2006; Smith y Berry 2013), y que hemos registrado en las mediciones del mediodía debajo del canopeo (Tabla 2.1).

Sin embargo, si la tasa fotosintética máxima neta es expresada en base al peso seco de las hojas, las plantas de canopeo tienen una mayor tasa fotosintética máxima neta, debido a la mayor concentración de clorofila (Tabla 3.3) y AFE (Tabla 3.1). La fotosíntesis neta en base al peso seco, expresa los costos de construcción de las hojas (Givnish 1988), por lo tanto, las plantas de canopeo pueden fijar más carbono por unidad de peso seco invertida en hojas. Sin embargo, como la radiación incidente debajo del canopeo es más baja que a sol pleno (Tabla2.1), la fijación de carbono acumulado a lo largo del tiempo fue menor en las plantas de canopeo que en las de sol. La menor tasa de fijación de carbono es corroborada con la menor tasa de transporte de electrones (ETR) (Figura 3.5) y el menor peso seco acumulado (Tabla 3.1) en las plantas de canopeo con respecto a las de sol. Por lo tanto, aunque las plantas de canopeo desarrollaron una mayor área foliar (Tabla 3.1), con mayor contenido de clorofila y antenas colectoras de luz más grandes (reflejadas en una baja relación clorofila a/b) y alta capacidad para utilizar altas intensidades de luz (Tabla 3.3), la baja intensidad de luz limitó la acumulación de peso seco de las plantas de canopeo comparado con las de sol, debido principalmente a la reducción en la acumulación de peso seco en la raíz. Por lo tanto, la cobertura del canopeo impuso un estrés severo a las plantas de Cabralea canjerana por baja radiación.

\subsubsection{Respuestas morfológicas y fisiológicas a diferentes coberturas de canopeo en claros}

La altura y el diámetro de cuello (H y DC) se correlacionaron positivamente con el PAR y la luz transmitida, así como el área foliar del folíolo (AFF); por lo tanto las plantas con mayor disponibilidad de luz desarrollaron mayor altura y diámetro del cuello que las plantas con baja disponibilidad de luz (Figura 3.6). Esta respuesta podría interpretarse como un mayor crecimiento, ya que las plantas partieron de la misma altura. En un bosque tropical, especies tolerantes a la sombra así como especies demandantes de luz crecieron más en altura con alta disponibilidad de luz transmitida que debajo del sotobosque (Chou et al. 2017), con luz transmitida máxima similar a nuestros claros (Tabla 3.4). También, en una plantación mixta, plantas de 1 año de una especie de árbol demandante de luz plantadas en una plantación de alerces crecieron más en altura y en ancho en claros grandes $\left(160 \mathrm{~m}^{2}\right)$ que debajo de una plantación densa. En el mismo experimento, 
el crecimiento de las especies tolerantes a la sombra fue similar en los claros de diferentes tamaños y debajo de la plantación densa, pero la supervivencia fue mayor en los claros (Lu et al. 2018). Por lo tanto, la respuesta a la mayor disponibilidad de luz depende de los requerimientos de las especies, pero también del tamaño de los claros y de la radiación incidente, e incluso los árboles tolerantes a la sombra son favorecidos por la apertura del canopeo.

Por otro lado, hubo una correlación negativa entre el área foliar del folíolo (AFF) y el área foliar específica del folíolo (AFEf), porque el AFF fue mayor en plantas con menor cobertura (mayor luz), en contraste con los resultados obtenidos cuando las plantas de sol y canopeo fueron comparadas en el ensayo en macetas. Estas diferencias podrían deberse al mayor tamaño de las plantas en los claros con respecto a las plantas de sol, y a la cobertura generada por el claro. Sin embargo, no se puede descartar el efecto de la maceta, aunque consideramos que el tamaño del envase no limitó el crecimiento de la planta a los 6 meses tenían menos de 2 g de materia seca por litro de contenedor, tal como recomienda (Poorter et al 2012), y además las plantas continuaron creciendo por un año más, sin que se evidenciaran síntomas de restricción al crecimiento por el contenedor. A medida que las plantas crecen, algunos cambios morfológicos y fisiológicos ocurren independientemente del ambiente, relacionados con el desarrollo de las plantas y no con la plasticidad fenotípica en respuesta al ambiente (Chambel et al. 2005). Por lo tanto, en este contexto la correlación negativa entre AFEf y el crecimiento ( $H$ y $D C)$, se debe a que el mayor crecimiento ocurrió en posiciones en los claros con mayor luz. Consistentemente ETR fue mayor y el contenido de clorofila total y Fv/Fm fueron bajos en las plantas con mayor radiación en los claros (Figura 3.6), así como lo observados en los resultados de los tratamientos sol y canopeo (Tabla 3.3). La conductancia estomática (gs) al mediodía se correlacionó positivamente con el PAR. Una respuesta similar fue observada en bosques templados, donde plantas que regeneraron naturalmente debajo del canopeo denso tuvieron una menor conductancia estomática que los individuos expuestos a altas irradiancias (Siegert y Levia 2011). Sin embargo, en el experimento de sol y canopeo, gs al mediodía fue mayor en plantas de canopeo que en plantas de sol (Figura 3.2). Las diferencias entre experimentos podrían ser derivadas de la heterogeneidad de luz a lo largo del día en el centro del claro (posición con mayor incidencia de radiación solar), que recibe sombra durante la mañana y la tarde. Al contrario, en el experimento en macetas, las plantas de sol recibieron luz a lo largo de todo el día. De hecho, las conductancias estomáticas registradas en los claros fueron mayores que las registradas en las plantas de sol del experimento en macetas. Es 
posible pensar que los centros de los claros son menos estresantes para las plantas de Cabralea canjerana que las áreas sin cobertura.

La exposición al sol en un bosque nunca es mayor que en un área sin cobertura. Consecuentemente, en las situaciones en las que plantas de Cabralea canjerana puedan regenerar naturalmente, las plantas pueden desarrollar cambios morfológicos y fisiológicos para tolerar excesos de luz (por ejemplo, bajo contenido de clorofila, reducción del área foliar, menor área foliar específica) y tolerar estrés por agua (por ejemplo, mayor conductancia hidráulica de las hojas, valores altos de Huber, índices estomáticos altos, cierre parcial de estomas) que le permita un mayor crecimiento. Por lo tanto, las plantas no sufrieron estrés hídrico o estrés por exceso de luz en los claros. En contraposición, abajo del canopeo cerrado, las plantas se aclimataron a la baja radiación incrementando la concentración de clorofila total y de clorofila b y además incrementaron el área foliar específica, aunque la tasa fotosintética y el intercambio de agua en estado de vapor fueron bajos. Sin embargo, el crecimiento de las plantas debajo del canopeo denso fue limitado por la baja irradiancia, por tanto, el estrés por déficit de luz fue severo, aunque las plantas crecieron menos que las de sol y pudieron sobrevivir. La mejor condición de crecimiento para Cabralea canjerana en claros en el bosque es en las posiciones con menor cobertura. Es evidente la alta plasticidad fenotípica de Cabralea canjerana para aclimatarse a diferentes ambientes. Por lo tanto, es una especie adecuada para ser utilizada en planes de reforestación del bosque nativo, en áreas donde la cobertura del canopeo cambie en el tiempo y en el espacio.

\subsection{Conclusiones}

Bajo sol pleno, la aclimatación de las plantas respondió al estrés moderado por déficit de agua y por exceso de luz. La plasticidad en los rasgos relacionados con el uso del agua son tan o más importantes que los rasgos relacionados con el uso de la luz. Por otro lado, la baja disponibilidad de luz limitó el crecimiento de las plantas debajo del canopeo, imponiendo un estrés severo por baja radiación. La capacidad de Cabralea canjerana de aclimatarse a alta y baja cobertura la hace apropiada para ser utilizada en planes de enriquecimiento en sitios con microambientes variables. 


\subsection{Contrastación de hipótesis}

Hipótesis 1: Las plantas jóvenes de Cabralea canjerana pueden crecer tanto a pleno sol como bajo canopeo, y presentan diferencias morfológicas y fisiológicas según la condición de cobertura a la que están expuestas.

Predicciones para Hipótesis 1:

1. Las plantas de Cabralea canjerana sobreviven en las dos condiciones de cobertura pero crecen menos a sol pleno, debido a que sufren estrés porque están expuestas a mayores irradiancias, temperaturas y déficit de saturación de agua del aire.

Esta predicción se cumplió parcialmente. Las plantas de Cabralea canjerana sobrevivieron en las dos condiciones de cobertura, pero las plantas expuestas a sol pleno crecieron más en peso seco que las expuestas a canopeo. Los estreses hídrico y por exceso de luz fueron moderados en las plantas de sol, y las aclimataciones morfológicas y fisiológicas fueron suficientes para evitar estrés severo.

2. Las plantas expuestas a sol pleno desarrollan mayor volumen de raíces que las que crecen bajo canopeo denso porque las primeras están expuestas a estrés hídrico por baja humedad en el suelo y alta demanda evapotranspirativa de la atmósfera.

Esta predicción se cumplió.

3. Las plantas que crecen bajo canopeo denso tienen mayor área foliar específica, mayor relación vástago/raíz y mayor concentración de clorofila total que las plantas que crecen a sol pleno porque realizan cambios morfológicos y fisiológicos para aumentar la intercepción de luz en un ambiente en que la luz incidente es baja.

Esta predicción se cumplió

4. Las plantas que crecen a sol pleno sufren daños del aparato fotosintético por el exceso de luz (menor Fv/Fm), tienen menor eficiencia en el transporte de electrones, mayor fotosíntesis neta a saturación lumínica, mayor tasa respiratoria y mayor punto de compensación lumínico que las plantas aclimatadas a la sombra.

Esta predicción se cumplió parcialmente. Las plantas de sol tuvieron menor Fv/Fm y menor eficiencia en el transporte de electrones. Sin embargo, las plantas de sol y de 
canopeo tuvieron curvas similares de fotosíntesis neta en respuesta a la irradiancia, lo que implica similar fotosíntesis neta a saturación lumínica y punto de compensación lumínico.

5. Las plantas que crecen a sol pleno tienen mayor conductancia estomática, menor potencial hídrico foliar al mediodía y mayor conductividad hidráulica general que las plantas aclimatadas a la sombra porque están expuestas a mayor demanda evapotranspirativa de la atmósfera y menor contenido de agua en el suelo.

Esta predicción se cumplió parcialmente. Las plantas de sol tuvieron menor conductancia estomática y potencial hídrico foliar al mediodía que las plantas de canopeo, aunque la conductancia estomática a la mañana temprano y a la tarde fue mayor en las plantas de sol que de canopeo. Las plantas en ambas condiciones tuvieron la misma capacidad total de conducir agua. Sin embargo, debido a los cambios en partición de materia seca, las plantas de sol tuvieron mayor conductancia y conductividad específicas de los tallos y hojas, mientras que menor conductancia específica de las raíces.

Hipótesis 2: Las plantas de Cabralea canjerana que crecen con menor cobertura en los claros, están expuestas a mayor estrés hídrico y lumínico.

Predicciones para Hipótesis 2: Las plantas que crecen con menor cobertura, crecen menos que las plantas que crecen bajo dosel, y poseen las características morfológicas y fisiológicas que reflejan estrés hídrico y lumínico.

Esta predicción no se cumplió. Dentro del claro, las plantas crecieron más en las posiciones con menor cobertura. Las plantas ubicadas en lugares con menor cobertura sufrieron estrés moderado por exceso de luz y estrés hídrico leve. La exposición plena (plantas de sol) impone un nivel de estrés superior al que impone el centro del claro. Sin embargo, en los claros, las posiciones con elevada cobertura imponen estrés severo por falta de luz. 


\section{Capítulo 4: Supervivencia, crecimiento y capacidad de respuesta al cambio abrupto de cobertura de canopeo}

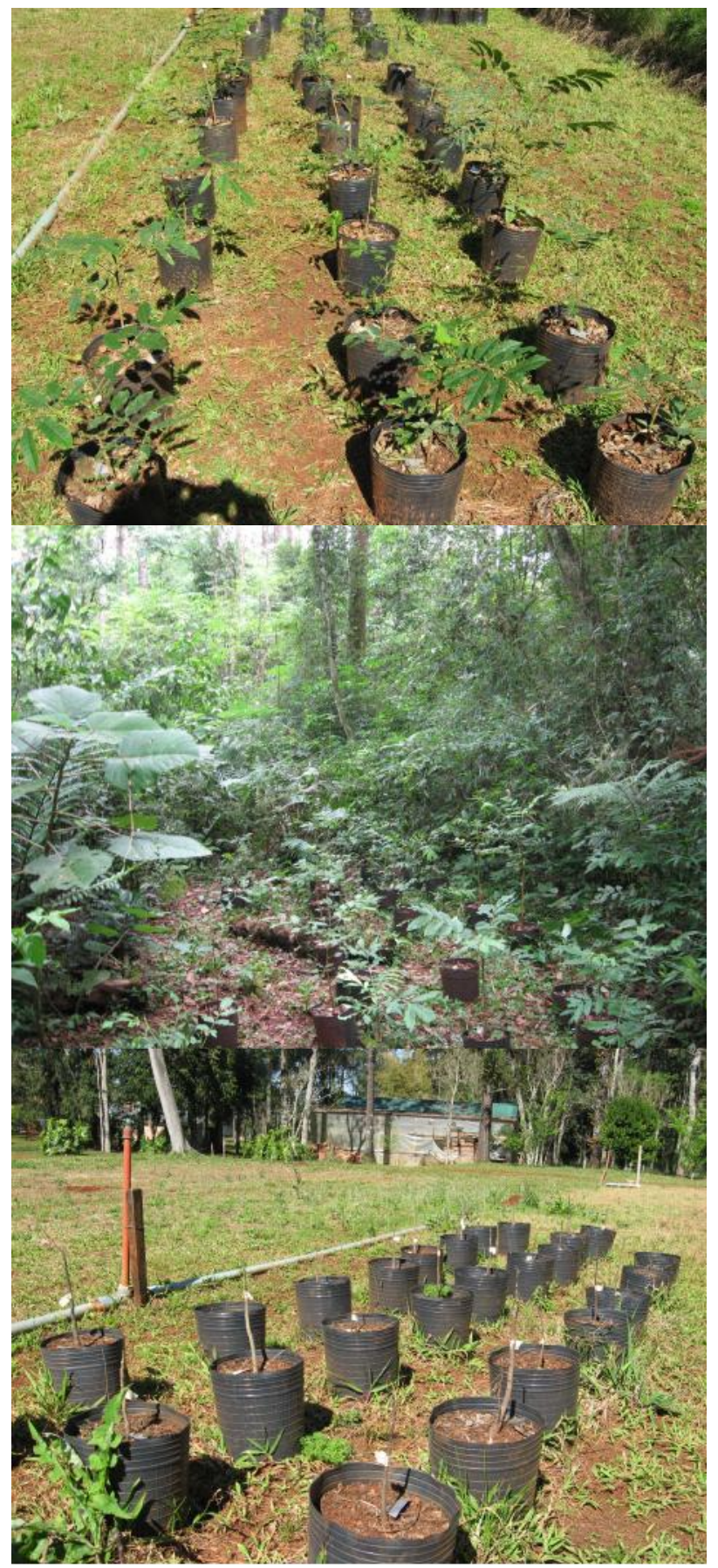




\subsection{Introducción}

La luz llega a los diferentes estratos del bosque en diferentes calidades e intensidades. Esta situación es dinámica en la selva y se produce por ejemplo, por la porosidad de las copas de los árboles, el movimiento de las hojas por el viento, la caída de las hojas de árboles caducos en invierno, y por la caída de ramas o de ejemplares enteros (Denslow 1987; Gandolfi et al. 2009). La gran mayoría de las especies que conviven en la selva son consideradas intermedias en cuanto a los requerimientos de luz. Esta estrategia podría deberse a que a lo largo de su vida las plantas experimentaron cambios continuos de luz, y que resultaron más exitosos en la reproducción los individuos con mayor capacidad de respuesta al ambiente cambiante, y en consecuencia una mayor plasticidad fenotípica fue seleccionada positivamente. Sin embargo, los cambios repentinos de luz podrían afectar el crecimiento y desarrollo de las especies establecidas en el sotobosque (Wright et al. 2003; Campanello et al. 2012). La formación de claros causa cambios significativos de la intensidad de luz que llega a los estratos inferiores (Garbarino et al. 2012; Amir 2012). En el capítulo anterior reportamos una variación del PAR en los claros de entre 3 y $1752 \mu$ moles $\mathrm{m}^{-2} \mathrm{~s}^{-1}$ al mediodía. La aclimatación a las altas irradiancias se produce en el mediano plazo (días o meses) a nivel fisiológico y morfológico de las hojas, generando por ejemplo, menor área foliar específica, mayor densidad de estomas y alta tasa de asimilación de carbono (Valladares et al. 2004; Valladares y Niinemets 2008). Un exceso repentino de luz podría causar daños en el aparato fotosintético produciendo la fotoinhibición del fotosistema II, que podría derivar en la muerte de las plantas (Mohammed et al. 2003). Sin embargo, éstas han desarrollado diferentes mecanismos para reparar el daño y para evitarlo. La fotoinhibición ocurre cuando la tasa de daño excede la de reparación del fotosistema II. Para su reparación intervienen compuestos fotoprotectores que se activan frente a un exceso de luz en el fotosistema II (Aro et al. 1993). Además, las plantas desarrollan otros mecanismos de fotoprotección como la evitación de la luz por el movimiento de las hojas, y de los cloroplastos, sistema de captura de especies activas del oxígeno (ROS), disipación de la luz en energía térmica (Takahashi y Badger 2011). Tal como se explicó en el capítulo anterior, el rendimiento cuántico máximo del fotosistema II (Fv/Fm) es un estimador del daño aparato fotosintético. Valores cercanos a 0,80 indican que el fotosistema está funcionando bien, valores menores a estos, nos indican un posible daño del aparato fotosintético (Mohammed et al. 2003). Por ejemplo, en un estudio con plantas tolerantes a la sombra e intermedias, a los 15 
días de haber sido expuestas a mayores irradiancias, tuvieron menor Fv/Fm que las que continuaron debajo del canopeo (Quevedo-Rojas et al. 2018).

Los cambios en la luz incidente en el sotobosque están asociados con cambios en la disponibilidad de agua del suelo, en el déficit de vapor atmosférico, en la temperatura del aire y del suelo (Denslow 1987; Gálhidy et al. 2006; Vilhar y Simončič 2012). En general en todos los climas la temperatura del aire y del suelo es menor bajo coberturas densas, debido a que radiación solar incidente es menor. También, en la mayoría de los climas, debajo del canopeo la humedad relativa del aire es mayor, porque la turbulencia es menor $y$, como la temperatura es menor, también lo es el déficit de saturación de vapor de la atmósfera y por lo tanto la demanda evapotranspirativa. En cuanto a la humedad del suelo, el régimen de precipitaciones influye marcadamente el contenido de humedad, ya que si las precipitaciones son de baja intensidad, la intercepción de agua de las copas será elevado, y por lo tanto debajo del canopeo llegará baja cantidad de agua y el contenido de humedad del suelo será menor que en áreas abiertas. Sin embargo, en climas tropicales y subtropicales, con precipitaciones de elevada intensidad, el contenido del agua del suelo suele ser mayor debajo del canopeo que en áreas abiertas, porque la intercepción de las precipitaciones por las copas es baja y la pérdida de agua del suelo por evaporación es menor debajo del canopeo que en áreas despejadas, porque la temperatura es menor y la humedad relativa del aires es mayor (Vanclay 2009). Estos cambios están asociados a modificaciones morfo-fisiológicas a nivel de planta entera para aclimatarse al nuevo microclima. Se pueden esperar cambios en la arquitectura hidráulica, como aumento de la conductividad hidráulica de los pecíolos y hojas; cambios en la anatomía del tallo y hojas, como el aumento de la frecuencia de vasos de diámetros chicos; y cambios en la morfología de tallos, hojas y raíces, menor elongación del tallo e incremento de su espesor y un aumento del volumen de raíces (Calzavara et al. 2015), tal como se explicó en el capítulo anterior. Todas estas aclimataciones permiten a la planta tolerar la mayor radiación incidente, la mayor demanda evapotranspirativa y la menor disponibilidad de agua en el suelo, asociadas a la mayor radiación incidente. Sin embargo, no todas las especies tienen la capacidad de aclimatarse a cambios abruptos en la cobertura, y en algunos casos puede producirse daños parciales en algunas hojas, o generalizados en todo el follaje e incluso los ápices, produciendo la muerte de las plantas (Szymańska et al. 2017). Asimismo, la falta de aclimatación a situaciones de déficit hídrico puede producir reducción del crecimiento, defoliación e incluso la muerte (McDowell et al. 2008). Todas estas respuestas tienen una base genética que define la plasticidad de los individuos de una especie. No hay 
información sobre los mecanismos de aclimatación de Cabralea canjerana a cambios abruptos de cobertura, pero al ser una especie de la sucesión intermedia, esperamos que posea la capacidad de aclimatarse a cambios abruptos en la cobertura de dosel, tal como se observó en Cedrela fissilis (Sanches et al. 2017).

\subsection{Objetivos e hipótesis}

Objetivo 3: Evaluar las respuestas de aclimatación de Cabralea canjerana al cambio de cobertura de canopeo a sol pleno, en comparación con las plantas que continuaron creciendo a la sombra del canopeo.

Hipótesis 3: El cambio abrupto de cobertura genera estrés lumínico e hídrico. Ambos estreses estimulan el pasaje gradual de las características típicas de la plantas de sombra a plantas de sol. El período de aclimatación implica reducción en la tasa de crecimiento.

Predicciones para la hipótesis 3:

1. Las plantas aclimatadas a la sombra del canopeo que son expuestas a sol pleno modifican gradualmente su morfología y fisiología en respuesta al cambio en la cobertura: pasarán de la fisiología y morfología de plantas de canopeo descriptas en las predicciones de la hipótesis 1 a las características morfo-fisiológicas de las plantas de sol descriptas en las predicciones de la misma hipótesis.

2. Las plantas de canopeo crecen más que las plantas que se encuentra bajo shock lumínico, porque el cambio de cobertura genera un nuevo estrés a las plantas, que se aclimatan mediante respuestas morfo-fisiológicas y en consecuencia se reduce el crecimiento.

\subsection{Materiales y métodos}

En este capítulo se muestran los resultados de la etapa 2 del ensayo en macetas. Se evalúa las respuestas morfológicas y fisiológicas de plantas de Cabralea canjerana aclimatadas a la sombra al cambio abrupto de cobertura al exponerlas a sol pleno. La metodología detallada puede visualizarse en el Capítulo 2. 


\subsubsection{Análisis estadístico}

Ensayo en macetas a campo

Etapa 2:

Los datos fueron analizados con el programa InfoStat (Di Rienzo et al. 2015). Las variables morfológicas y fisiológicas medidas fueron analizadas usando ANOVA con 1 factor (cobertura) y 2 niveles (canopeo y shock lumínico) para septiembre y noviembre de 2013. Para abril de 2014 se utilizó el mismo factor cobertura pero con 3 niveles (sol, canopeo y shock lumínico). En el caso de las variables medidas a lo largo del día, se consideraron 2 factores: cobertura con 2 o 3 niveles (canopeo y shock lumínico para septiembre y noviembre, y sol, canopeo y shock lumínico para abril), y tiempo con 4 niveles (9:00,12:00, 14:00 y 17:00 horas), además se evaluó la interacción entre factores cobertura y tiempo. En el caso de los 2 factores o la interacción fueran significativos en el ANOVA $(p<0,05)$, las medias se compararon con el test de Duncan con $p<0,05$. Las variables Tasa de transporte de electrones (ETR) y Rendimiento cuántico intrínseco del fotosistema II (\$PSII), fueron analizadas usando modelos lineales generales y mixtos; cuando las varianzas fueron heterogéneas, se modelaron, y luego se eligió el modelo con mejor ajuste, basado en la reducción de AIC y BIC. Para analizar ETR se tuvieron en cuenta 2 factores: cobertura con 2 o 3 niveles (canopeo y shock lumínico para septiembre y noviembre, y sol, canopeo y shock lumínico para abril) y tiempo con 4 niveles $(9: 00,12: 00,14: 00$ y 17:00 horas) además se evaluó la interacción entre factores cobertura y tiempo. En caso de ser significativo el análisis, los análisis de comparación de media fueron realizados con el test Duncan con $\mathrm{p}<0,05$.

La frecuencia absoluta de vasos fue dividida en 10 clases de diámetro de vasos. La distribución de frecuencia de vasos de las plantas de sol y canopeo fueron comparadas con la distribución de Weibull y con un análisis de contingencia. Estos análisis son 2 posibles caminos para analizar la distribución de vasos. La distribución de Weibull se ajusta a una curva asimétrica con 2 parámetros: un parámetro de escala $(\alpha)$ y un parámetro de forma $(\beta)$. Si $\beta$ es cercano a 3 , su forma es similar a la de una distribución normal (simétrica), mientras que si $\beta$ es menor que 3, hay más frecuencia de los diámetros menores. Se realizaron 6 curvas por tratamiento, y los parámetros fueron comparados con ANOVA. Complementariamente la distribución de frecuencia 
de vasos fue comparada con un análisis de contingencia, y las comparaciones entre tratamientos se realizaron con el test de Chi-cuadrado. El análisis de contingencia indica si las frecuencias de vasos en alguna clase son diferentes entre tratamiento. Ambos análisis fueron realizados con InfoStat (Di Rienzo et al. 2015)

\subsection{Resultados}

\subsubsection{Morfología, crecimiento y partición de materia seca}

Trascurrido el invierno de 2013, la parte aérea del $100 \%$ de plantas del tratamiento sol murió a causa de las bajas temperaturas. Las plantas de canopeo denso no sufrieron daño por frío. En la primavera siguiente (primavera 2013) el 62\% de las plantas del tratamiento sol rebrotaron desde la base, y al finalizar del ensayo crecieron un promedio de $7 \mathrm{~mm}$ de DAC (Figura 4.1; Figura 4.2). En la primavera de 2013 el tratamiento sol no fue medido debido a que las plantas estaban recién rebrotando y las hojas estaban en expansión.

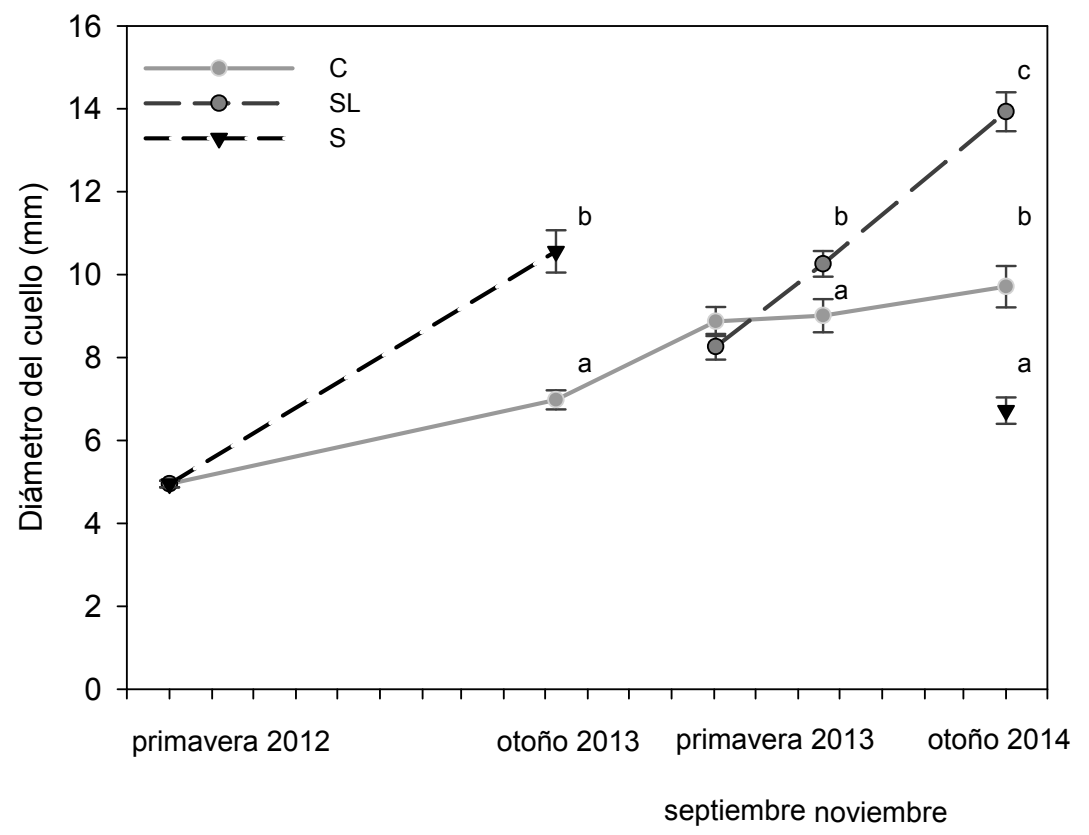

Figura 4.1: Diámetro del cuello $(\mathrm{mm})$ de plantas de Cabralea canjerana durante 2 periodos de crecimiento. El primer periodo las plantas crecieron en 2 condiciones de luz contrastante (sol y canopeo; S y C respectivamente). En la primavera siguiente (septiembre 2013) la mitad de las plantas del tratamiento canopeo fueron expuestas a sol pleno (shock lumínico; SL), simulando el cambio abrupto en la cobertura. El tratamiento sol aparece nuevamente al final del ensayo. Letras diferentes muestran diferencias significativas entre tratamientos para cada fecha de medición $(p<0,05)$. 


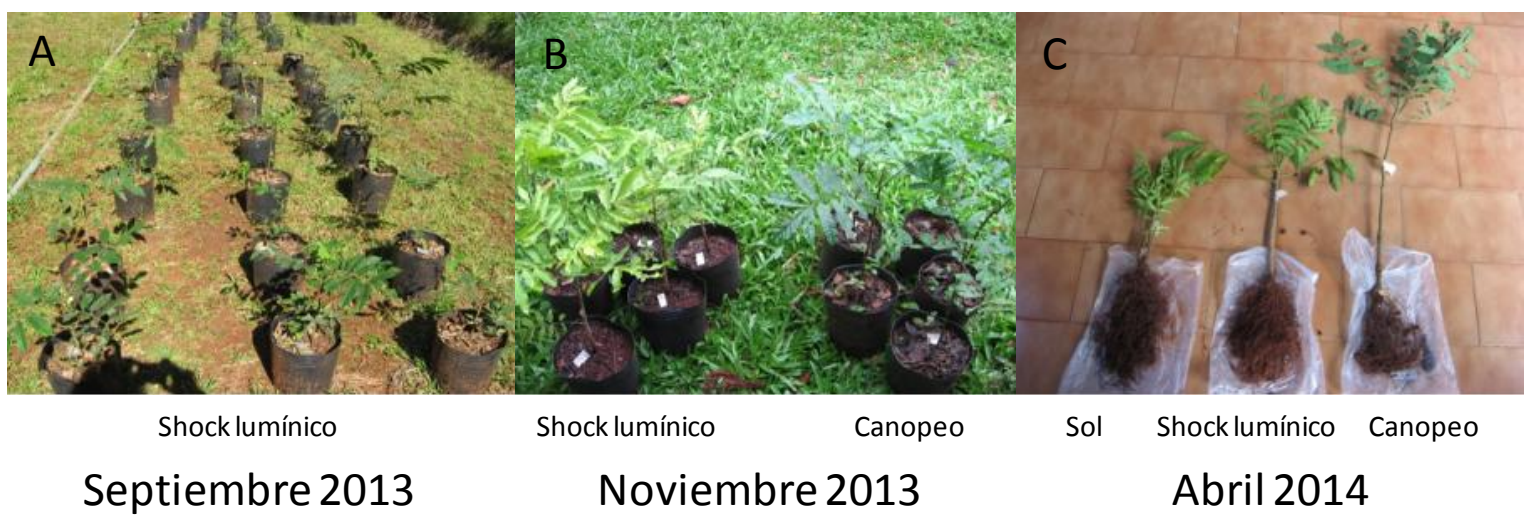

Figura 4.2: Imágenes del ensayo en macetas. A) Plantas del shock lumínico recién traspasadas a sol pleno (septiembre 2013); B) plantas de Cabralea canjerana a los 3 meses de producido el cambio; C) Planta entera descalzada para las mediciones destructivas de cada tratamiento (S, C, SL) cuando finalizó el ensayo (abril 2014).

Luego de 3 meses de realizado el cambio abrupto de cobertura (noviembre) las plantas del tratamiento shock lumínico (SL) crecieron significativamente más en diámetro del cuello, y tuvieron significativamente más peso seco de raíces finas que las plantas de canopeo (Figura 4.1; Figura 4.3). Las plantas del SL a los 3 meses del cambio de cobertura, desarrollaron mayor cantidad de raíces finas que las de canopeo (Figura 4.3), y el peso seco total de las plantas de SL fue significativamente mayor que en las plantas de canopeo (20,92 g - 12,29 g respectivamente; $F=6,1$ y $p$-valor=0,03). Al finalizar el ensayo, las plantas del tratamiento SL crecieron significativamente más en peso seco de hojas, tallo y raíces finas y gruesas que las de canopeo y sol (Figura 4.3). En consecuencia, el peso seco total fue mayor para las plantas de shock lumínico que para las de canopeo y sol $(38,11 \mathrm{~g}$ - $16,08 \mathrm{~g}$ y 13,23 g respectivamente; $\mathrm{F}=24,3$ y $\mathrm{p}$-valor $<0,01)$. Por otro lado, las plantas del tratamiento canopeo no crecieron en diámetro luego de los 6 meses, y su peso seco tampoco varió hasta finalizar el ensayo (Figura 4.1; Figura 4.3).

Las plantas del tratamiento shock lumínico a los 3 meses (noviembre) desarrollaron hojas con menor área foliar específica en relación a las plantas que permanecieron debajo del canopeo (Tabla 4.1). Además, duplicaron la densidad de estomas y tuvieron un mayor índice estomático que las pantas del canopeo. Al finalizar el ensayo las plantas del shock lumínico tuvieron valores de IE cercanos a los de las plantas de sol (Tabla 4.1). 


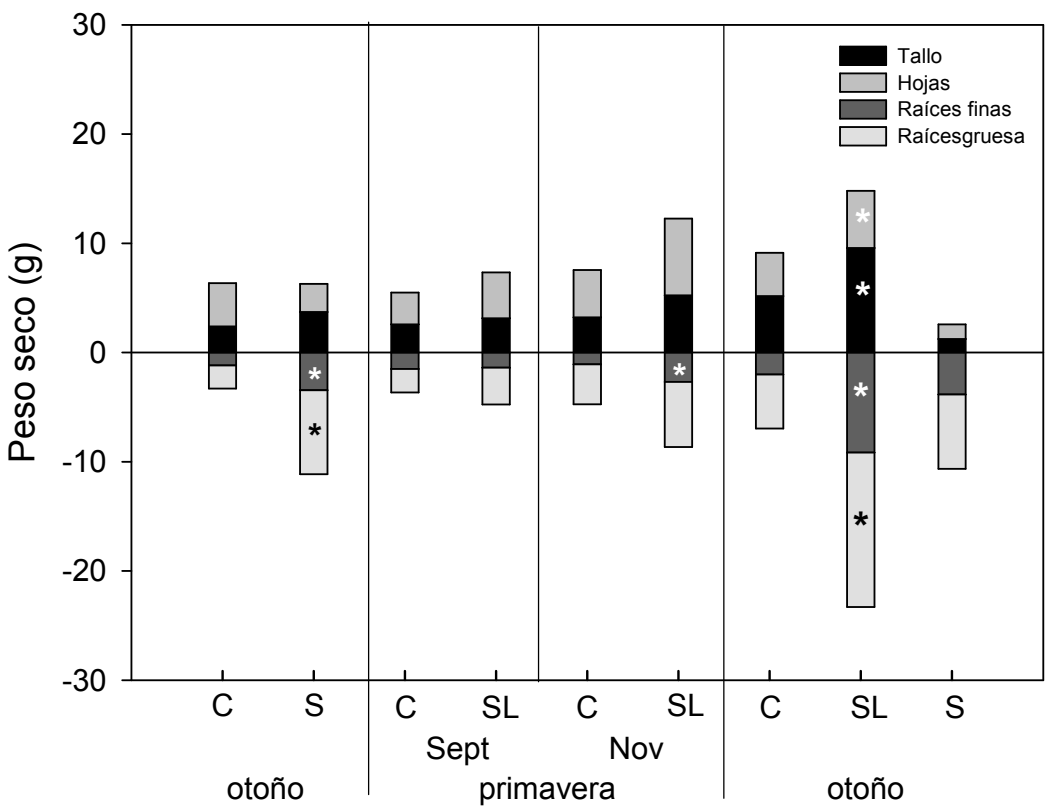

Figura 4.3: Peso seco (g) y partición de materia seca (tallo, hojas, raíces finas y gruesas) de plantas de Cabralea canjerana que crecieron debajo del canopeo (C), a sol pleno (S) y luego del cambio de cobertura shock lumínico (SL). Los asteriscos indican diferencias significativas entre tratamiento para cada compartimento, en cada fecha $(p<0,05)$.

Tabla 4.1: Área foliar específica, densidad estomática e índice estomático, medidos para cada tratamiento en cada fecha en plantas de Cabralea canjerana expuestas a sol pleno (S), debajo de canopeo denso (C) y luego del cambio de cobertura (SL).Letras diferentes indican diferencias significativas entre medias de tratamiento para cada fecha de medición cuando el factor tiene más de dos niveles $(p<0,05)$.

\begin{tabular}{|c|c|c|c|c|}
\hline Variables & tratamiento & septiembre & noviembre & abril \\
\hline \multirow{4}{*}{ AFE $\left(\mathrm{cm}^{2} \mathrm{~g}^{-1}\right)$} & $\mathrm{C}$ & $199 \pm 15$ & $162 \pm 6$ & $199 \pm 18$ \\
\hline & SL & $187 \pm 16$ & $107 \pm 4$ & $93 \pm 5$ \\
\hline & $\mathrm{F}$ & 0,27 & 57,38 & 33,57 \\
\hline & $\mathrm{p}$-valor & 0,63 & $<0,01$ & $<0,01$ \\
\hline \multirow{5}{*}{ Densidad estomática } & $\mathrm{S}$ & & & $153 \pm 5$ (c) \\
\hline & C & & $59 \pm 2$ & $74 \pm 3$ (a) \\
\hline & SL & & $107 \pm 6$ & $138 \pm 5(b)$ \\
\hline & $\mathrm{F}$ & & 57,22 & 84,44 \\
\hline & $\mathrm{p}$-valor & & $<0,01$ & $<0,01$ \\
\hline \multirow{5}{*}{ IE } & $S$ & & & $13 \pm 0,7$ (c) \\
\hline & $C$ & & $6 \pm 0,3$ & $6 \pm 0,2(a)$ \\
\hline & SL & & $9 \pm 0,4$ & $11 \pm 0,3(b)$ \\
\hline & $F$ & & 25,53 & 68,56 \\
\hline & $\mathrm{p}$-valor & & $<0,01$ & $<0,01$ \\
\hline
\end{tabular}




\subsubsection{Características de la arquitectura hidráulica}

A los pocos días del shock lumínico, las plantas no respondieron con cambios en la conductividad hidráulica, aunque se registraron valores de kspecíolo y klpecíolo que tendieron a ser mayores en estas plantas que en las de canopeo (Figura 4.4). Luego del verano, las plantas del shock lumínico tuvieron una mayor conductividad hidráulica específica de las hojas y pecíolos (klpecíolo y khoja) que las de canopeo, (klpecíolo: $F=7,45$; p-valor=0,02 y khoja: $F=10,13$, p-valor $<0,01$ ) (Figura 4.4). La conductancia hidráulica de la planta entera estandarizado por el peso seco total no varió entre tratamientos para ninguna fecha.

La distribución de frecuencia de vasos por clase diamétrica fue diferente entre las plantas del shock lumínico y las de canopeo en el análisis de contingencia (Figura 4.5). La distribución de Weibull indica que las plantas del shock lumínico tendieron a tener más vasos en las clases diamétricas más grandes que las plantas de canopeo (Figura 4.5). 


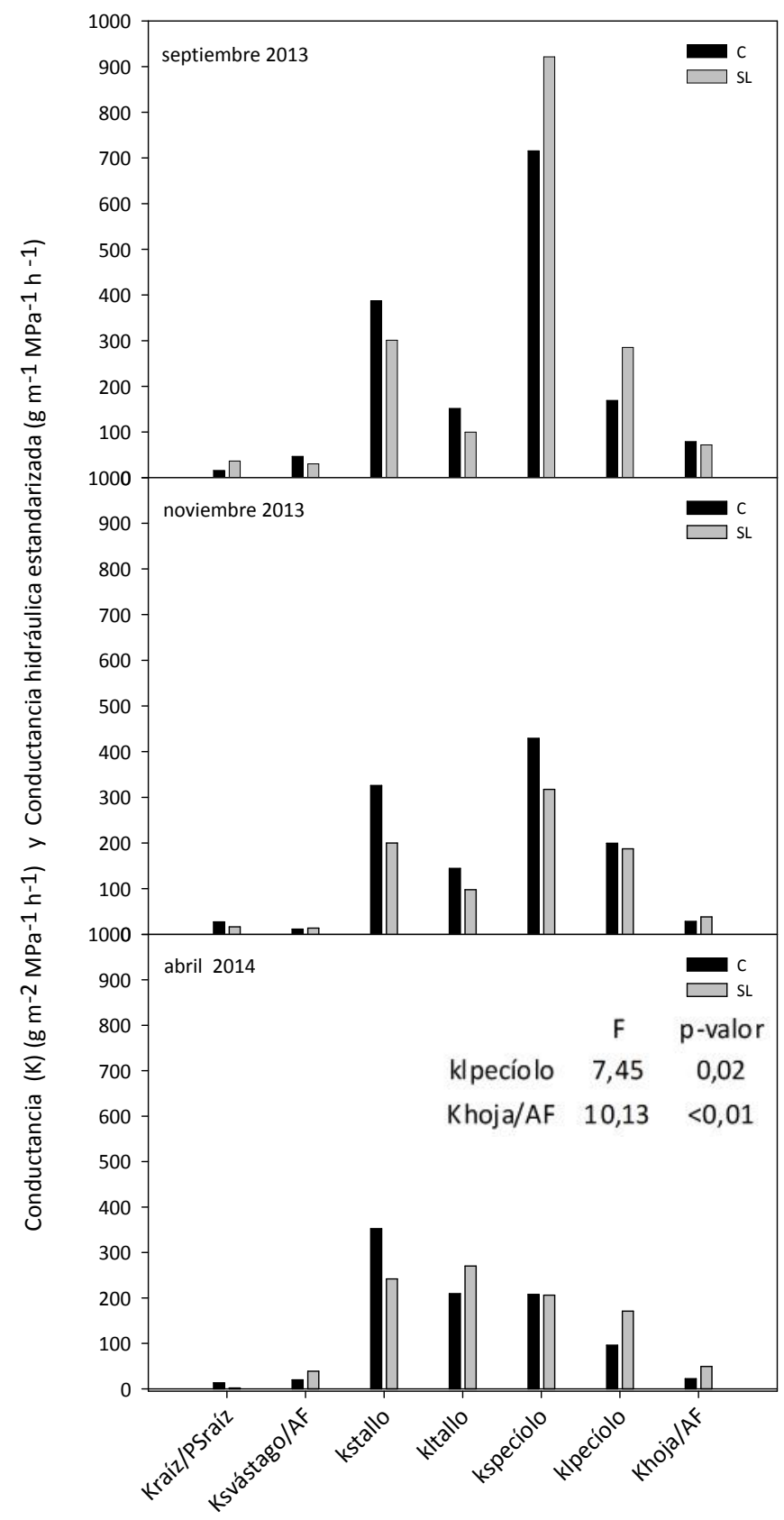

Figura 4.4: Conductancias y conductividades hidráulicas estandarizadas: Kraíz estandarizado por peso seco total de raíces (Kraíz/peso seco raíces) $\left(\mathrm{g} \mathrm{MPa}^{-1} \mathrm{~h}^{-1} \mathrm{~g}^{-1} \mathrm{PS}\right.$ ), Kvástago estandarizada por el área foliar (AF) (Kvástago/AF) (g MPa ${ }^{-1} \mathrm{~h}^{-1} \mathrm{~m}^{-2}$ ), conductividad hidráulica específica del tallo y del pecíolo ( $\mathrm{kstallo=}$ khtallo/AX y kspecíolo $=$ khpecíolo/AX) $\left(\mathrm{g} \mathrm{m} \mathrm{MPa}^{-1} \mathrm{~h}^{-1} \mathrm{~m}^{-2}\right) \times 10^{3}$, conductividad hidráulica específica foliar (kltallo $=$ khtallo/AF y klpecíolo $=$ khpecíolo/AF) $\left(\mathrm{g} \mathrm{m} \mathrm{MPa}^{-1} \mathrm{~h}^{-1} \mathrm{~m}^{-2}\right)$, khojas estandarizado por el área foliar (Khojas/AF) ( $\left.\mathrm{g} \mathrm{m}^{-2} \mathrm{MPa}^{-1} \mathrm{~h}^{-1}\right)$, para plantas de Cabralea canjerana que crecieron bajo canopeo denso (barras negras- C) y shock lumínico (barras grises-SL) durante las diferentes fechas. Sólo hay diferencias significativas entre tratamientos para Klpecíolo y Khoja/AF en abril de 2014. 


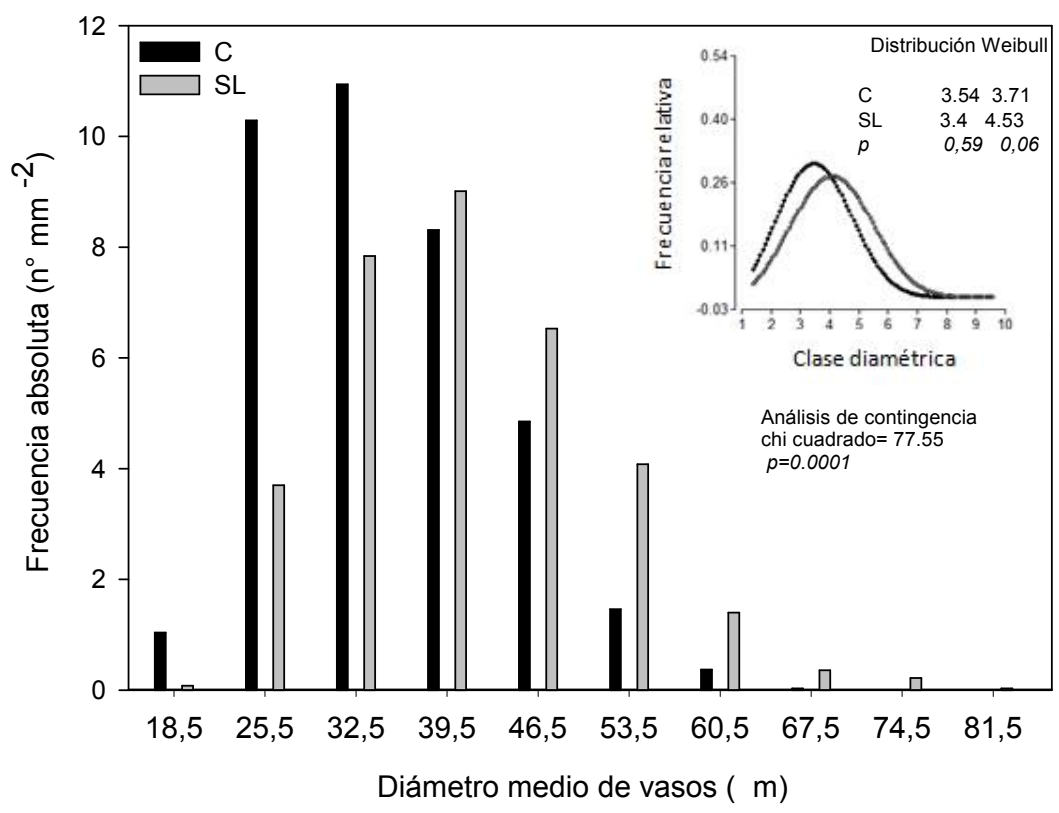

Figura 4.5: Frecuencia absoluta de vasos por área de xilema $\left(\mathrm{mm}^{2}\right)$ por clase de diámetro $(\mu \mathrm{m})$ de plantas de Cabralea canjerana que crecen debajo del canopeo (C) y después del shock lumínico (SL). Frecuencia relativa de distribución de vasos por case diamétrica analizado con la distribución de Weibull (gráfico inserto arriba a la derecha).

La conductancia estomática de las plantas de Cabralea canjerana durante los 3 días posteriores a haber sido expuestas al shock lumínico, se mantuvo constante a lo largo del día con un leve decrecimiento al mediodía y hacia la tarde (Figura 4.6). Consistentemente, el potencial hídrico de la hoja al mediodía de las plantas del shock lumínico fue significativamente menor que las de canopeo (Tabla 4.2). Transcurridos 3 meses (noviembre) la conductancia (gs) de las plantas del tratamiento shock lumínico fue el doble que las de canopeo, manteniendo los estomas abiertos durante el día, con un leve decaimiento al mediodía (Figura 4.6).

Las plantas de canopeo mantuvieron una conductancia estomática alrededor de $100 \mathrm{mmol}$ $\mathrm{H}_{2} \mathrm{O} \mathrm{m}^{-2} \mathrm{~s}^{-1}$ a lo largo del día y en todas las fechas de medición (Figura 4.6). Consecuentemente, en estas plantas no se registraron potenciales tan bajos como los que se reportaron para las plantas de sol pleno (Tabla 4.2). En abril de 2014, en las plantas de sol pleno se observó un cierre estomático parcial desde el mediodía que se puede visualizar en la caída de la conductancia, acompañado de una fuerte caída del potencial al mediodía (Figura 4.6; Tabla 4.2). 


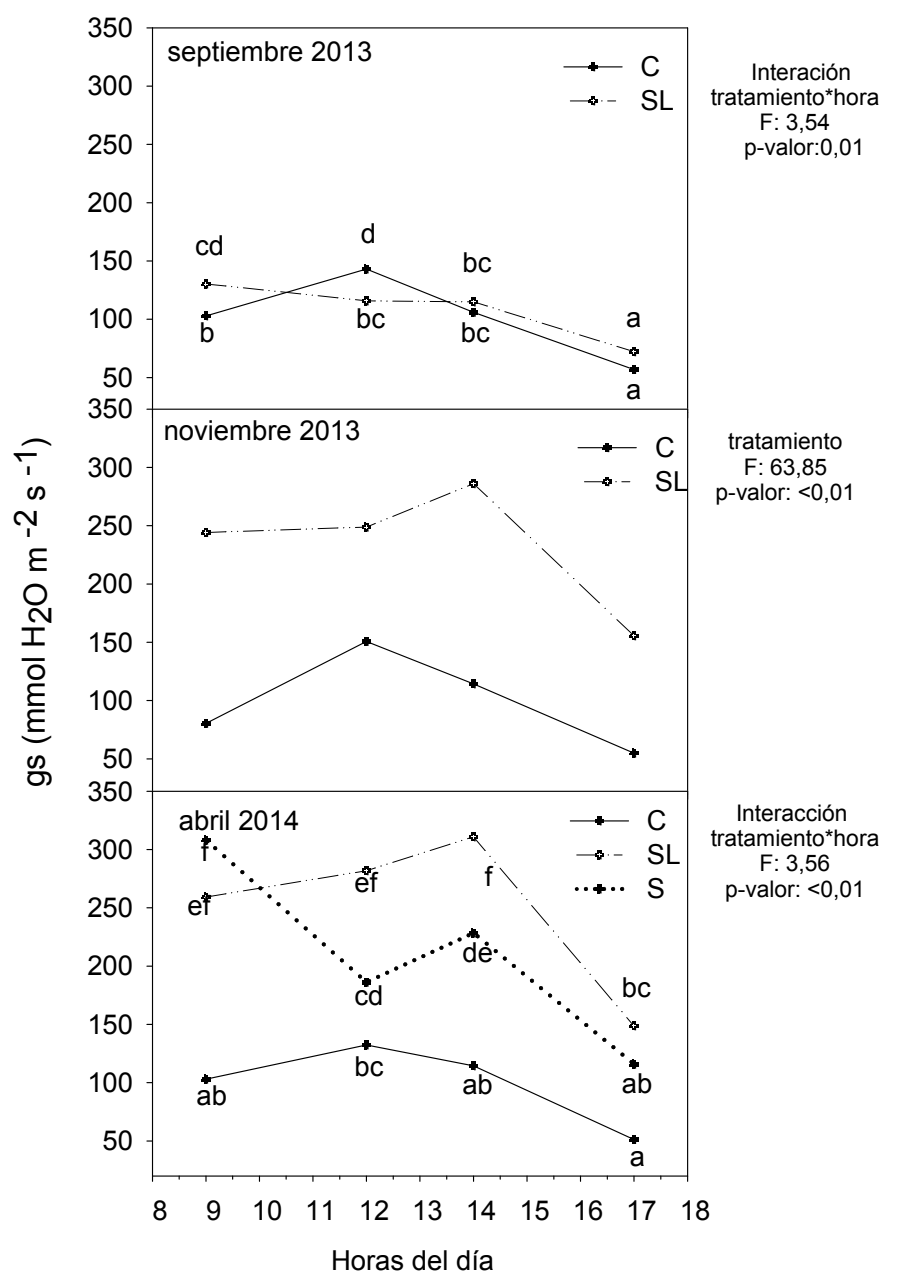

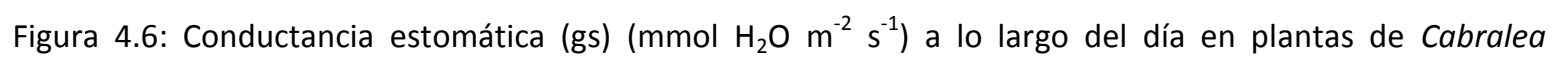
canjerana que crecen debajo del canopeo denso (C), a sol pleno luego del cambio de cobertura (SL) y a sol pleno (S). En septiembre y noviembre de 2013 se compara canopeo y shock lumínico, y en abril se comparan los tres tratamientos. Letras diferentes muestran diferencias significativas $(p<0,05)$.

Tabla 4.2: Potencial hídrico de la hoja $(\Psi)(\mathrm{MPa})$ al mediodía en plantas de Cabralea canjerana que crecen a sol (S), debajo del canopeo (C) y a sol pleno después del shock lumínico (SL), para las diferentes fechas de medición. Letras diferentes muestran diferencias significativas entre tratamiento para cada fecha $(p<0,05)$.

\begin{tabular}{cccc}
\hline & \multicolumn{2}{c}{ primavera } & otoño \\
\hline tratamiento & septiembre & noviembre & abril \\
\hline S & & & $-1,07 \pm 0,09$ (b) \\
C & $-0,44 \pm 0,04$ & $-0,38 \pm 0,16$ & $-0,55 \pm 0,08$ (a) \\
SL & $-0,89 \pm 0,14$ & $-0,61 \pm 0,23$ & $-0,75 \pm 0,08(a)$ \\
\hline F & 9,54 & 0,73 & 10,09 \\
p-valor & $<0,01$ & 0,42 & $<0,01$ \\
\hline
\end{tabular}




\subsubsection{Características relacionadas con el uso de la luz}

La concentración de clorofila total y la relación clorofila a/b fue similar en las plantas de canopeo y de shock lumínico a los pocos días de realizarse el cambio de cobertura (Tabla 4.3). Sin embargo el rendimiento cuántico máximo del fotosistema II (Fv/Fm) fue menor en las plantas del shock lumínico que en las de canopeo (Tabla 4.3). A los 3 meses del shock lumínico, las plantas de SL tuvieron menor clorofila total que las de canopeo (C). A los 6 meses esta diferencia se triplicó (Tabla 4.3). Luego del verano la relación clorofila a/b en las plantas de sol y de shock lumínico fue mayor que en las plantas de canopeo (Tabla 4.3).

Tabla 4.3: Concentración de clorofila total por gramo de hoja $\left(\mathrm{mg} \mathrm{g}^{-1}\right)$, relación clorofila a/b y rendimiento cuántico máximo del fotosistema II (Fv/Fm), de plantas que crecieron a sol pleno (S), debajo del canopeo denso (C) y luego del shock lumínico (SL). Letras diferentes indican diferencias entre las medias de los tratamientos para cada fecha $(\mathrm{p}<0.05)$.

\begin{tabular}{|c|c|c|c|c|}
\hline \multirow[b]{2}{*}{ variables } & \multirow[b]{2}{*}{ tratamiento } & \multicolumn{2}{|c|}{ primavera } & \multirow{2}{*}{$\begin{array}{c}\text { otoño } \\
\text { abril } \\
\end{array}$} \\
\hline & & septiembre & noviembre & \\
\hline & S & & & $1,86 \pm 0,27(a)$ \\
\hline \multirow[t]{5}{*}{ Clorofila total } & $\mathrm{C}$ & $9,00 \pm 0,43$ & $3,99 \pm 0,71$ & $6,34 \pm 0,90(b)$ \\
\hline & SL & $8,34 \pm 0,4$ & $1,86 \pm 0,26$ & $2,13 \pm 0,26(a)$ \\
\hline & $\mathrm{F}$ & 1,23 & 7,9 & 19,77 \\
\hline & $\mathrm{p}$-valor & 0,27 & 0,01 & $<0,01$ \\
\hline & $\mathrm{S}$ & & & $2,34 \pm 0,04(b)$ \\
\hline \multirow[t]{5}{*}{ Clorofila a/b } & $\mathrm{C}$ & $1,83 \pm 0,06$ & $1,25 \pm 0,18$ & $1,91 \pm 0,09(a)$ \\
\hline & SL & $1,78 \pm 0,04$ & $1,02 \pm 0,13$ & $2,48 \pm 0,07(b)$ \\
\hline & $\mathrm{F}$ & 0,5 & 1,07 & 19,47 \\
\hline & $\mathrm{p}$-valor & 0,48 & 0,31 & $<0,01$ \\
\hline & $S$ & & & $0,70 \pm 0,03(a)$ \\
\hline \multirow[t]{4}{*}{$\mathrm{Fv} / \mathrm{Fm}$} & $\mathrm{C}$ & $0,85 \pm 2,8 \mathrm{E}-03$ & $0,84 \pm 4,60 \mathrm{E}-03$ & $0,84 \pm 3,50 \mathrm{E}-03(\mathrm{~b})$ \\
\hline & SL & $0,63 \pm 0,01$ & $0,72 \pm 0,02$ & $0,73 \pm 0,02(a)$ \\
\hline & $\mathrm{F}$ & 222 & 24,24 & 10,87 \\
\hline & $p$-valor & $<0,01$ & $<0,01$ & $<0,01$ \\
\hline
\end{tabular}

A los pocos días de realizado el cambio de cobertura, la tasa de transporte de electrones (ETR) fue mayor en las plantas de Cabralea canjerana del tratamiento shock lumínico que en las de canopeo, aunque no hubo diferencias significativas al mediodía (Figura 4.7). Sin embargo, el rendimiento cuántico intrínseco del fotosistema II ( $\phi$ PSII) fue menor en las plantas del shock 
lumínico que en las de canopeo (Tabla 4.4). A los 3 meses del shock lumínico, las plantas duplicaron la tasa de trasporte de electrones (ETR) con respecto a las de canopeo (Figura 4.7). El rendimiento cuántico intrínseco del fotosistema II ( $\phi$ PSII) continuó siendo más bajo en las plantas del shock lumínico que en las plantas de canopeo, aunque pudieron canalizar el $51 \%$ de la radiación incidente. Pasado el verano (abril 2014) la tasa de transporte de electrones (ETR) fue mayor en las plantas de Cabralea canjerana del tratamiento shock lumínico que en las de canopeo y sol. El rendimiento cuántico intrínseco del fotosistema II ( $\phi$ PSII) continuó siendo más bajo en las plantas del shock lumínico que en las plantas de canopeo (Tabla 4.4).

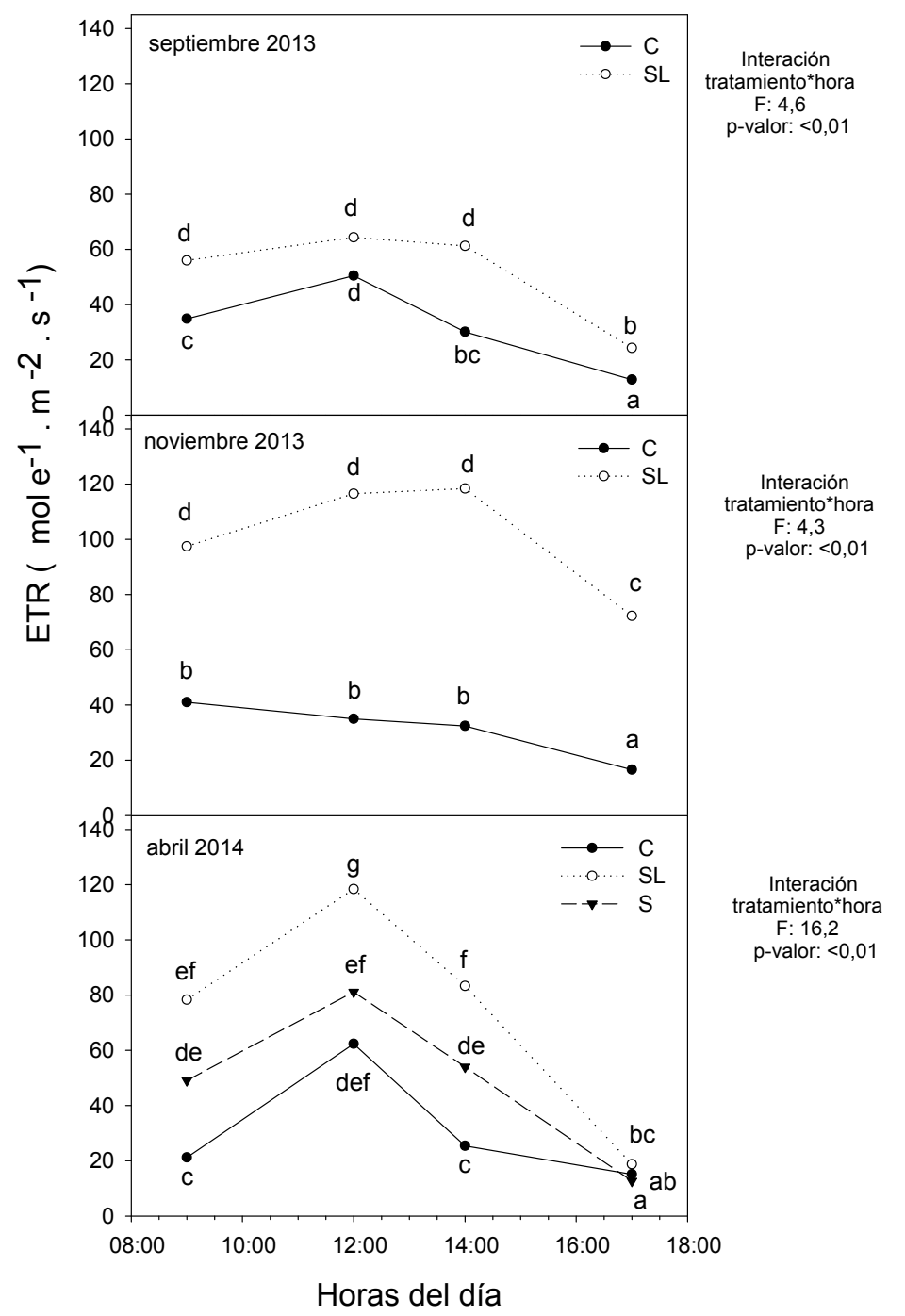

Figura 4.7: Tasa de transporte de electrones (ETR) ( $\mu \mathrm{mol} \mathrm{e} \mathrm{m}^{-2} \mathrm{~s}^{-1}$ ) a lo largo del día y en las diferentes fechas de medición, en plantas de Cabralea canjerana que crecen debajo del canopeo denso (C), que recibieron shock lumínico (SL) y a sol pleno (S) durante el verano. Interacción tratamiento*hora. Letras diferentes indican diferencias significativas $(p<0,05)$. 
Tabla 4.4: Promedio del Rendimiento cuántico intrínseco del fotosistema II (\$PSII) de plantas de Cabralea canjerana que crecen debajo del canopeo denso (C), que recibieron shock lumínico (SL) y a sol pleno (S), en las diferentes fechas de medición. Se reportan los valores de $\mathrm{F}$ y $\mathrm{p}$. letras diferentes indican diferencias significativas entre tratamientos $(p<0,05)$.

\begin{tabular}{cccc}
\hline tratamiento & septiembre & Noviembre & abril \\
\hline S & & & $0,33 \pm 0,03$ (a) \\
C & $0,60 \pm 0,01$ & $0,64 \pm 0,01$ & $0,52 \pm 0,01$ (c) \\
SL & $0,33 \pm 0,02$ & $0,51 \pm 0,02$ & $0,38 \pm 0,03$ (b) \\
F & 202 & 221 & 39 \\
p-valor & $<0,01$ & $<0,01$ & $<0,01$ \\
\hline
\end{tabular}

\subsection{Discusión}

\subsubsection{Morfología, crecimiento y partición de materia seca}

La luz es uno de los factores más importantes para el establecimiento y crecimiento de las plantas, sin embargo, cuando se plantan árboles a cielo abierto, otros factores climáticos como las temperaturas altas y bajas, y la menor HR del aire pueden condicionar su crecimiento. Durante el invierno las bajas temperaturas podrían dañar las plantas. El daño por frío puede producirse por una acumulación de horas de temperaturas bajas, superiores a $0^{\circ} \mathrm{C}$ (daño por frío), o por heladas con temperaturas menores a $0^{\circ} \mathrm{C}$ (congelamiento) (Larcher 2005). Durante el invierno de 2013 (post plantación), las temperaturas mínimas absolutas mensuales fueron de $3^{\circ} \mathrm{C},-3^{\circ} \mathrm{C}$, y $-2,5^{\circ} \mathrm{C}$ para los meses de junio, julio y agosto, respectivamente (datos de la estación meteorológica del CAMB). Por otro lado, en los registros climáticos de los últimos 30 años se han reportado mínimas absolutas mensuales para los meses de invierno de entre $8^{\circ} \mathrm{C}$ y $-7^{\circ} \mathrm{C}$. Por lo tanto, es posible que ocurran heladas de corta duración en esta zona. Cabralea canjerana se estableció y creció en condiciones de cobertura contrastante desde octubre de 2013 hasta mayo de 2013 (S y C del Capítulo 2). Sin embargo, las bajas temperaturas del invierno de 2013 afectaron la parte aérea de las plantas de sol provocando la muerte del vástago. Por otro lado, las plantas de canopeo no sufrieron daño por frío, posiblemente debido al efecto amortiguador del dosel superior del bosque. Si bien el experimento no fue diseñado para evaluar daño por frío, el resultado es contundente, ya que todas las plantas expuestas a sol pleno sufireron la muerte del vástago. Esto 
nos indica que las plantas necesitan una protección inicial contra el frío al menos durante el primer año de vida. En otro trabajo, también las temperaturas bajo cero produjeron la muerte de un $10 \%$ de Enterolobium contortisiliquum (Vell) Morong (timbó) y daños de más del 50 \% de la planta entera del resto de las plantas establecidas a cielo abierto (Crechi et al. 2005). Posiblemente, el mayor porcentaje de muerte registrado en este estudio comparado con el de timbó, se deba a que en el trabajo con timbó no ocurrieron heladas durante el invierno post transplante. Por otro lado, las plantas de timbó establecidas bajo cubierta de pino no registraron daños por temperaturas bajo cero durante los 2 primeros años (Crechi et al. 2005), similar a lo que observamos en Cabralea canjerana.

Cabralea canjerana posee diferentes estrategias para aclimatarse a las distintas coberturas y al cambio de la misma. Por un lado, desarrolla cambios morfológicos de la planta entera y de las hojas. Estos cambios morfológicos se empezaron a visualizar en el corto plazo (meses). A los 3 meses del shock lumínico, las plantas de Cabralea canjerana crecieron significativamente más en diámetro del cuello (Figura 4.1), y en peso seco total en comparación con las plantas que continuaron debajo del canopeo. Sin embargo, destinaron mayor cantidad de fotoasimilados hacia las raíces, evidenciándose en el mayor peso seco de raíces finas (Figura 4.3). La generación de raíces finas posiblemente sea una respuesta morfológica de corto plazo para explorar mayor volumen de suelo y abastecer de agua a las hojas que fueron súbitamente expuestas a un ambiente con un alto déficit de saturación y mayores temperaturas. Posiblemente en estos ambientes las plantas están estresadas por falta de agua y la generación de raíces finas es una respuestas al estrés leve por sequia (McDowell et al. 2008). De forma similar, plantas de dos especies de Quercus tuvieron mayor masa de raíces en los claros que debajo del canopeo (Rodríguez-Calcerrada et al. 2008). A los 6 meses del shock lumínico, las diferencias en peso seco total y por compartimento entre las plantas del shock lumínico y canopeo fueron más marcadas (Figura 4.3). Finalmente las plantas del SL crecieron más en peso seco de la planta entera y en diámetro del cuello que las de canopeo. En otro ensayo en la misma región, plantas de Cedrela fissilis Vell. (Meliaceae) también aumentó el peso seco total de las plantas y el diámetro del cuello cuando fueron expuestas al cambio de la disponibilidad de luz (Sanches et al. 2017). Estas respuestas de aclimatación nos indican que Cabralea canjerana tiene la capacidad de aclimatarse en el corto plazo (días o meses) al cambio abrupto de cobertura. Las plantas de Cabralea canjerana que estaban debajo del canopeo denso no variaron su peso seco total a lo largo del tiempo, y siempre crecieron menos en peso seco que las plantas del shock lumínico (Figura 4.3). 
Durante esta etapa las plantas de canopeo mantuvieron las estrategias de aclimatación a la sombra a las descriptas en el Capítulo 2. Las plantas de canopeo tuvieron una AFE mayor que las plantas del shock luminico (Tabla 4.1): tuvieron mayor superficie foliar para captar mayor cantidad de luz, con hojas más delgadas. Por otro lado, en las plantas de canopeo mantuvieron una menor relación clorofila a/b. Las plantas que crecen con baja disponibilidad de luz tienden a tener una baja relación clorofila a/b (Greer et al. 2017). En contraposición, las plantas expuestas al shock lumínico generaron hojas con menor concentración de clorofila, mayor relación clorofila a/b y menor AFE, características típicas de plantas expuestas a altas radiaciones, tal como se discutió en el Capítulo 3.

Otros cambios a nivel morfológico de las hojas fueron la mayor densidad estomática e índice estomático de las plantas del SL con respecto a las de canopeo. Al finalizar el ensayo (abril) las plantas de sol (que rebrotaron desde la base luego de haber sufrido la muerte del vástago en el invierno), también desarrollaron mayor densidad estomática e índice estomático que las de canopeo y shock lumínico (Tabla 4.1). Esta estrategia de aclimatación podría deberse a la necesidad de refrigerar las hojas que están expuestas a un ambiente de mayor temperatura (Crawford et al. 2012) después del mediodía, que supera en 2 grados la temperatura de debajo del canopeo (Figura 2.5) , altas irradiancias (Tabla 2.1) y baja humedad relativa (Figura 2.4). En Toona ciliata M. Roem., se observó una mayor densidad estomática en microambientes con alta radiación (Murphy et al. 2012), aunque no hay reportes de cambios en la densidad estomática en respuesta a cambios abruptos de radiación.

\subsubsection{Características de la arquitectura hidráulica}

A los pocos días de realizado el cambio de cobertura, las plantas del shock lumínico mostraron respuestas rápidas para aclimatarse a la nueva condición de mayor radiación, temperatura y menos humedad relativa $(H R)$ del ambiente. Esta capacidad de cambio rápido puede explicarse porque la especie ha evolucionado para poder establecerse en el bosque, donde las condiciones microambientales cambian abruptamente por la caída de árboles que disminuye la intercepción de luz del dosel (Denslow 1987; Montgomery y Chazdon 2002). Por un lado, en el corto plazo (3 días), las plantas del shock lumínico mantuvieron los estomas parcialmente abiertos a lo largo del día, con una leve caída al mediodía (Figura 4.6). En consecuencia sufrieron una deshidratación de las hojas, evidenciado en una leve caída del potencial hídrico al mediodía (Tabla 
4.2). Esta estrategia de mantener parcialmente abiertos los estomas a pesar de la caída de potencial, le permite a las plantas realizar fotosíntesis para mantener un balance positivo de carbono, es decir, compensar las pérdidas de carbono por respiración y disponer de un excedente de fotoasimilados para el funcionamiento de las rutas metabólicas y catabólicas (Franks et al. 2007). Además, les permite mantener las hojas refrigeradas, ya que el cierre estomático puede conducir a un aumento en la temperatura foliar (Crawford et al. 2012). A los 6 meses del cambio, las plantas del SL no solo mantuvieron los estomas abiertos para realizar fotosíntesis, sino que aumentaron la conductividad hidráulica de los pecíolos y hojas (Figura 4.4). Un aumento en la conductividad y conductancia a nivel foliar es fundamental para garantizar el flujo de agua hacia las hojas y mantener la expansión celular y el crecimiento (Prado y Maurel 2013) en condiciones de alta demanda evapotraspirativa y altas temperaturas. En Fagus sylvatica L. (haya), se observó que las plantas también aumentaron la conductancia hidráulica especifica foliar a los 8 meses luego del cambio de luz (Caquet et al. 2009). Por otro lado, las plantas de sombra mantuvieron la misma frecuencia de vasos que en mayo de 2013. Sin embargo, las plantas del shock lumínico tuvieron tallos más gruesos con vasos más grandes que las de canopeo (Figura 4.5). Los vasos de mayor tamaño en las plantas sujetas a shock lumínico posiblemente se debe a que al incrementarse el diámetro del tallo, se incrementa el diámetro de los vasos y disminuye su frecuencia (Rungwattana y Hietz 2018). Por lo tanto, las plantas ajustaron todo el sistema de conducción de agua, desde las raíces, tallos y hojas para aumentar el flujo de agua hacia las hojas en respuesta al shock lumínico. Las plantas que continuaron creciendo debajo del canopeo denso mantuvieron su arquitectura hidráulica y no registraron cambios con respecto a las respuestas iníciales.

\subsubsection{Características relacionadas con el uso de la luz}

En nuestro trabajo, a los pocos días de realizado el cambio de cobertura, el rendimiento cuántico máximo del fotosistema II (Fv/Fm) fue menor en las plantas del shock lumínico que en las de canopeo $(0,63$ y 0,85 respectivamente), lo que nos indica que posiblemente sufrieron un fotodaño en el aparato fotosintético debido al cambio abrupto en la cobertura (Tabla 4.3). La densidad de flujo fotónico fotosintético (PAR) varió entre 66 y 1799 mmoles de fotones $\mathrm{m}^{-2} \mathrm{~s}^{-1}$ a lo largo del día al sol, mientras que la variación a lo largo del día bajo canopeo fue entre 19 y 213

$\mu$ moles de fotones $\mathrm{m}^{-2} \mathrm{~s}^{-1}$ (Figura 2.4). Este daño redujo la eficiencia del trasporte de electrones 
( PSII) en las plantas del SL, que solo pudieron canalizar el $33 \%$ de la luz incidente (Tabla 4.4). Sin embargo, las plantas del shock lumínico fotosintetizaron más que las de canopeo a lo largo del día, reflejado en el mayor ETR (Figura 4.7). Las plantas de Cabralea canjerana que crecieron aclimatadas a bajas irradiancias, tuvieron la misma capacidad para realizar fotosíntesis que las plantas aclimatadas a sol pleno (Capítulo 3). Por lo tanto, es de esperar que puedan utilizar la luz en la nueva condición de cobertura, aunque con un daño leve del fotosistema. En otros trabajos, también se registró una caída de Fv/Fm en las plantas del shock lumínico a los pocos días de realizado el cambio (Sanches et al. 2017; Quevedo-rojas et al. 2018). En el corto plazo (3 meses) las plantas de Cabralea canjerana del shock lumínico desarrollaron mecanismos de aclimatación morfológica y fisiológica al nuevo ambiente con mayor irradiancia y temperaturas. Esto les permitió aumentar aún más las tasas de transporte de electrones (ETR), mejorando la eficiencia del transporte (\$PSII). Además, se registró un leve aumento de Fv/Fm hacia el final del tratamiento, indicando menor estrés por exceso de luz, aunque este continuó siendo menor a 0,8, evidenciando un leve daño del aparato fotosintético (Fracheboud y Leipner 2003). En otro trabajo con Caseariata chirensis, una especie intermedia en requerimientos de luz, también se registraron aumentos en Fv/Fm, фPSII y ETR a los 3 meses del shock lumínico. Sin embargo, ETR fue siempre menor en las plantas del shock lumínico que en las de sombra (Quevedo-Rojas et al. 2018), porque el ETR de las plantas aclimatadas a alta y baja irradiancia fue medida a la misma intensidad de luz. Es esperable que, como las plantas de menor irradiancia tenían mayor concentración de clorofila y mayor AFE, la ETR a altas irradiancias sea mayor que en las plantas aclimatadas a mayor radiación. La clorofila total por gramo de hoja disminuyó en las plantas de SL con respecto a las de canopeo a los 3 y 6 meses, incluso con respecto al momento del cambio (en septiembre). Esta reducción posiblemente se debe a que las hojas de las plantas expuestas al shock lumínico disminuyeron cantidad de clorofila a y b al disminuir la cantidad de antenas cosechadoras de luz como respuesta a la alta irradiancia. Por otro lado también se registró mayor la relación clorofila a/b de las plantas de shock lumínico y sol con respecto a las de canopeo. Esta respuesta es esperable ya que las plantas aclimatadas a la sombra desarrollan mayor cantidad de receptores de luz, junto con una mayor superficie foliar, y estos mecanismos se revierten al exponer a las plantas a mayor radiación.

Las plantas de canopeo a los 6 meses mantuvieron los rasgos morfológicos y fisiológicos de aclimatación a la sombra, como mayor AFE, mayor contenido de clorofila total, baja relación clorofila a/b, elongación de los tallos y aumento de la conductividad hidráulica de raíces (Capítulo 
3). Sin embargo, estas aclimataciones, si bien permitieron a las plantas sobrevivir, no fueron suficientes para lograr un crecimiento similar al logrado por las plantas de sol o expuestas al shock lumínico. Esto nos indica que las plantas de canopeo están sufriendo un estrés severo por deficit de luz, que se refleja en un bajo crecimiento. En otros trabajos con especies leñosas tropicales, también se registró un bajo crecimiento cuando las plantas continuaron creciendo debajo de canopeo denso, y respuestas de aclimatación similares (Paulilo et al. 2007; Sanches et al. 2017). Posiblemente estas especies, al igual que Cabralea canjerana, pueden aclimatarse y establecerse en ambientes con poca luz, pero esta aclimatación no es suficiente para que se registren altas el crecimiento, similares a las registradas en plantas que crecen con mayor irradiancia. Esta respuesta nos indica que las plantas necesitan más radiación para crecer.

Las plantas de sol pleno que rebrotaron en septiembre continuaron creciendo hasta finalizar el ensayo. Desarrollaron pocas hojas, y en consecuencia se registró un menor peso seco en comparación con las plantas de shock lumínico. Sin embargo las plantas desarrollaron un mayor número de estomas e índice estomático que las de canopeo y shock lumínico. Esta aclimatación es esperable en plantas que crecen a altas irradiancias (Greer et al. 2017). Esto podría deberse a que las hojas fueron desarrolladas desde el inicio a sol pleno y como ya hemos descripto en el Capítulo 3, Cabralea canjerana tiene la capacidad de aumentar el número de estomas en respuesta a la exposición a sol pleno (Tabla 3.1). Las plantas de sol mantuvieron los estomas abiertos a lo largo del día, sin embargo se registró una caída de gs al mediodía (Figura 4.6) debido a una fuerte disminución del potencial al mediodía (Tabla 4.2). Durante el mediodía se registró un aumento de ETR, aunque sólo el 33\% de la irradiancia pudo ser canalizada por el fotosistema (Figura 4.7). Posiblemente Cabralea canjerana tenga mecanismos para disipar el exceso de energía no utilizada. Si bien no fueron medidos en este estudio, es sabido que las plantas cuentan con mecanismos para hacerlo, como la disipación térmica y el quenching no fotoquímico (Fracheboud y Leipner 2003). Al igual que en el ensayo anterior se registró fotodaño del sistema fotosintético evidenciándose en el menor Fv/Fm (Tabla 4.3). Sin embargo, este daño les permitió generar fotoasimilados y destinarlos a la aclimatación para seguir creciendo. Al finalizar el ensayo, las plantas que crecieron siempre a sol pleno no lograron igualar en peso seco a las plantas expuestas al shock lumínico (Figura 4.3). Asimismo, a pesar de que los tallos y hojas de las plantas de sol se formaron con elevada radiación desde el inicio, las hojas se encuentran en un estado de hidratación más bajo que las de las plantas del shock lumínico, reflejado en menor gs y potencial hídrico (Figura 4.6 : Tabla 4.2). 


\subsection{Conclusiones}

Las plantas de Cabralea canjerana tienen una alta plasticidad fenotípica que le permitió aclimatarse no solo a ambientes contrastantes de cobertura, sino al cambio abrupto en la disponibilidad de luz. Las plantas que crecieron debajo de canopeo denso, desarrollaron inicialmente estrategias de aclimatación relacionada con la inversión de fotoasimilados hacia la parte aérea para interceptar mayor cantidad de luz. Son ejemplos de las aclimataciones a la sombra expresadas por Cabralea canjerana el aumento del AF y AFE, de la concentración de clorofila total y la disminución de la relación clorofila a/b, elongación del tallo y aumento en la conductividad hidráulica de las raíces. Estos cambios registrados le permitieron a la planta mejorar la intercepción de la luz que llega al sotobosque. Sin embargo, estas aclimataciones no fueron suficientes para que las plantas acumulen materia seca luego de los 6 meses de la plantación, tal como se refleja en el estancamiento del crecimiento en peso seco y diámetro del cuello a lo largo del tiempo. El estancamiento en la acumulación de materia seca es debido principalmente a la falta de luz, ya que no se evidenciaron síntomas de estrés por falta de agua, por lo tanto proponemos que las plantas sufrieron estrés severo por falta de luz.

Las plantas que estaban aclimatadas a bajas irradiancias y fueron sometidas al cambio abrupto de cobertura (tratamiento shock lumínico) también pudieron aclimatarse mediante cambios morfológicos y fisiológicos a la nueva situación lumínica. Por un lado, las plantas a los pocos días de realizado el cambio activaron rápidamente los mecanismos de respuestas fisiológicas a nivel de hojas. Inicialmente se registró una disminución de la eficiencia en el trasporte de electrones (PSII) y un daño del fotosistema II dado por la caída de Fv/Fm. Además, estas plantas experimentaron un cierre parcial de los estomas y una caída del potencial hídrico al mediodía. Sin embargo, pudieron seguir fotosintetizando y acumularon más materia seca que las plantas de canopeo. Por otro lado, a los 3 meses de realizado el cambio se registraron cambios morfológicos y fisiológicos a nivel de la planta entera. Aumentaron significativamente el peso seco de raíces, la densidad estomática e índice estomático y ETR. Por último en el mediano plazo (6 meses) se registraron cambios fisiológicos y anatómicos. Por un lado se registró una distribución de vasos en las clases diamétricas mayores, y un aumento de la conductividad hidráulica de las hojas y pecíolos cuando se comparan a las plantas sometidas a shock lumínico con las plantas que continuaron debajo del canopeo. 
Las plantas de sol luego de sufrir el daño por frío, tuvieron una alta capacidad de rebrote y lograron aclimatarse nuevamente al sol pleno. Para esto desarrollaron mecanismos similares a los descriptos en el Capítulo 2 en las plantas de sol.

Las diferentes estrategias de aclimatación desarrolladas por las plantas de Cabralea canjerana son características de las especies denominadas intermedias. Esta estrategia de aclimatación podría deberse a que a lo largo de su desarrollo las plantas experimentan cambios continuos de luz, y en consecuencia desarrollaron una gran plasticidad fenotípica (Valladares y Niinemets 2008).

\subsection{Contrastación de hipótesis}

Hipótesis 3: El cambio abrupto de cobertura genera estrés lumínico e hídrico. Ambos estreses estimulan el pasaje gradual de las características típicas de la plantas de sombra a plantas de sol. El período de aclimatación implica reducción en la tasa de crecimiento.

Predicciones para la hipótesis 3:

1. Las plantas aclimatadas a la sombra del canopeo que son expuestas a sol pleno modifican gradualmente su morfología y fisiología en respuesta al cambio en la cobertura: pasarán de la fisiología y morfología de plantas de canopeo descriptas en las predicciones de la hipótesis 1 a las características morfo-fisiológicas de las plantas de sol descriptas en las predicciones de la misma hipótesis.

Esta predicción se cumplió. Las plantas expuestas a un cambio abrupto de cobertura modificaron gradualmente la partición de materia seca, las características morfológicas y fisiológicas desde las características de plantas aclimatadas a la sombra hacia las de plantas aclimatadas al sol.

2. Las plantas de canopeo crecen más que las plantas que se encuentra bajo shock lumínico, porque el cambio de cobertura genera un nuevo estrés a las plantas, que se aclimatan mediante respuestas morfo-fisiológicas y en consecuencia se reduce el crecimiento

Esta predicción no se cumplió. El crecimiento de las plantas expuestas al shock lumínico fue mayor en peso seco que el de las plantas de canopeo y las de sol. Esto se debe a que las plantas de canopeo, pasados los 6 meses, sufrieron estrés severo por falta de luz, mientras que las plantas de sol sufrieron muerte del vástago por frío. Las plantas 


\section{Ana Paula Moretti - Tesis doctoral 2019}

expuestas al shock lumínico son las que lograron mayor crecimiento y menor estrés por déficit hídrico y sin deficiencia de luz. 


\section{Capítulo 5: Aclimatación en claros del bosque nativo}

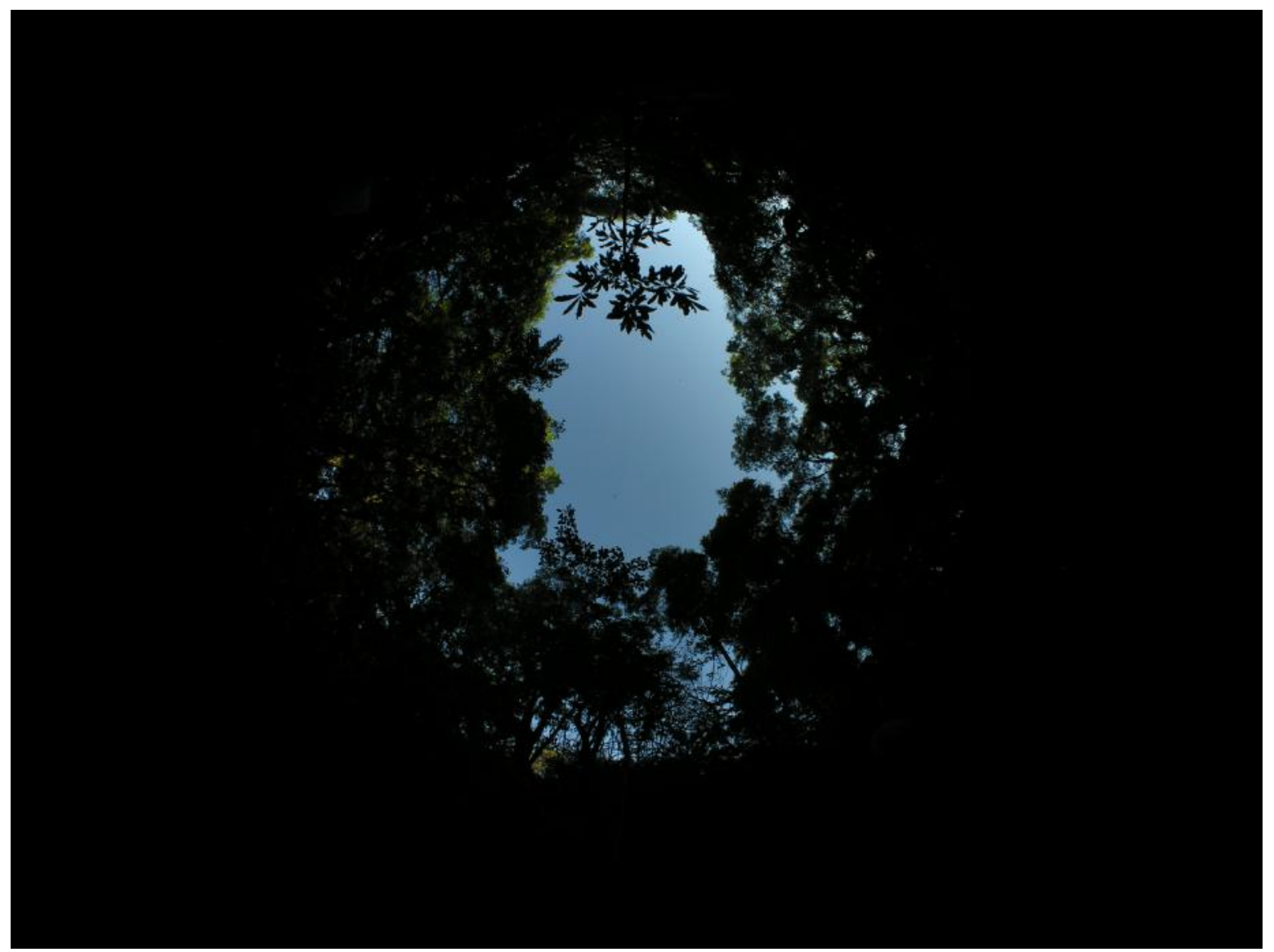




\subsection{Introducción}

La ocurrencia de pequeños disturbios, como caída de ramas y árboles enteros producen la formación de claros en la selva, que favorece la llegada de luz directa al sotobosque y altera las condiciones microambientales del sitio (Denslow 1987; Garbarino et al. 2012; Amir 2012). Las especies coexisten en el continuo de microambientes ya que tienen diferentes requerimientos de recursos y plasticidad fenotípica. Los disturbios a nivel de claros son uno de los eventos más importantes para la regeneración y establecimiento de especies pioneras de rápido crecimiento, y para aquellas especies que inicialmente se establecieron en el sotobosque, pero luego de un tiempo requieren mayor cantidad de luz para crecer y llegar a los estratos superiores (Montgomery y Chazdon 2002; Felton et al. 2006; Campanello et al. 2007). Además los claros propician el establecimiento de otras especies arbustivas y herbáceas de rápido crecimiento que dominan el sotobosque generando una elevada competencia por los recursos (Dalling et al. 2004; Muñoz et al. 2012). Los factores más importantes que definen los microambientes en el bosque son la frecuencia y distribución espacial de los claros, el tamaño y la orientación y las causas que lo originan (Garbarino et al. 2012; Amir 2012). Por otro lado el relieve, el tamaño de los árboles que rodean al claro y la presencia de especies remanentes dentro de éstos también determinan las condiciones microambientales (Denslow 1987). Los claros en la selva se producen naturalmente por la caída de grandes ramas de árboles, por la muerte de un ejemplar o varios, o por otras causas como el volteo por el viento (Runkle 1992). La extracción selectiva de ejemplares maderables es una causa antrópica de generación de claros, y de la degradación de los bosques húmedos (Lussetti et al. 2016).

Un gradiente ambiental puede generar diferentes respuestas en supervivencia y crecimiento. En principio, es de esperar que las especies heliófitas sobrevivan y crezcan más en microambientes más iluminados. En un trabajo con nueve especies tropicales demandantes de luz, la supervivencia durante el primer año de vida fue mayor en los microambientes más sombreados que en los más iluminados, respuesta contraria a la esperada. Sin embargo, el crecimiento en altura y en materia seca fue mayor con mayor disponibilidad de luz (Yang et al. 2011). Por lo tanto, en estas especies la cobertura de dosel contribuyó a la supervivencia inicial, pero el crecimiento fue favorecido positivamente con los menores niveles de cobertura.

El conocimiento de los ambientes lumínicos generados por la estructura de la selva, y los requerimientos de las especies, nos permitirán entender el funcionamiento de los ecosistemas y 
generar información para idear estrategias de manejo para restaurar áreas de bosques degradadas de la selva misionera. Las preguntas específicas que guían este capítulo son: ¿Se puede enriquecer el bosque nativo con Cabralea canjerana? ¿Cómo afecta el microambiente de plantación a la supervivencia y el crecimiento de Cabralea canjerana? ¿Dónde conviene plantar? Con estas preguntas buscamos entender en qué condiciones de cobertura las plantas de Cabralea canjerana sobreviven y crecen mejor, para sugerir prácticas de manejo que aseguren el éxito del enriquecimiento.

\subsection{Objetivos e hipótesis}

Objetivo 4: Evaluar la supervivencia, el crecimiento y la capacidad de aclimatación de Cabralea canjerana durante 3 años en un gradiente de cobertura en claros del bosque nativo.

Hipótesis 4: Las plantas de Cabralea canjerana plantadas en microambientes con menor cobertura están expuestas a mayor estrés hídrico y lumínico que las plantadas con mayor cobertura, durante el primer año posterior al transplante. Pasado el primer año, las plantas con menor cobertura no sufren estrés hídrico ni lumínico severo debido a que están aclimatadas a dicho microambiente.

Predicción para la hipótesis 4: Durante el primer año, las plantas con menor cobertura crecen menos en altura y diámetro del cuello que las plantas con mayor cobertura y poseen características morfológicas y fisiológicas, que reflejan estreses hídrico y lumínico descriptos en las predicciones de la hipótesis 1 para plantas de sol. Sin embargo, a medida que pasan los años las plantas del centro del claro crecerán más porque la aclimatación será suficiente para evitar el estrés hídrico y lumínico.

\subsection{Materiales y métodos}

En este capítulo se muestran los resultados del ensayo de plantación de Cabralea canjerana en los claros del bosque nativo. Se evalúa las respuestas morfológicas y fisiológicas de 
plantas de Cabralea canjerana creciendo en un gradiente de cobertura generado por las diferentes posiciones dentro de los claros. La metodología detallada puede visualizarse en el Capítulo 2.

\subsubsection{Análisis estadístico y visualización de los resultados}

Ensayo en claros del bosque nativo

Se realizó un gráfico 3D tomando como ejes: 1) la altura de las plantas en los diferentes meses de medición $(\mathrm{cm}), 2$ ) la luz transmitida total (moles $\mathrm{m}^{-2}$ día ${ }^{-1}$ ) integrada para todo el año por posición en cada claro y 3) el tiempo (meses). Con este gráfico se puede visualizar el crecimiento en altura de las plantas en las diferentes condiciones de luz a lo largo del tiempo.

Los análisis estadísticos fueron realizados con InfoStat (Di Rienzo et al. 2015). Se realizó un análisis de regresión no lineal a dos tramos, tomando como variables dependientes las alturas medias de las plantas en 4 categorías de luz transmitida total elegidas en base a la observación de los datos, de manera que quedaran en rangos equidistantes y representaran los ambientes que se observan en los claros: menor a 5 moles $\mathrm{m}^{-2}$ día $^{-1}$ (luz<5), entre 5 y 10 moles m$^{-2}$ día $^{-1}$ (luz 5-10), entre 10 y 15 moles $\mathrm{m}^{-2}$ día $^{-1}$ (luz 10-15) y mayor a 15 moles $\mathrm{m}^{-2}$ día $^{-1}$ (luz >15); y como variable regresora el tiempo en meses. Para analizar la supervivencia se calculó el porcentaje de plantas vivas y muertas por clase de PAR.

Las variables morfológicas y fisiológicas medidas fueron analizadas usando Modelos Lineales Generales y Mixtos con 2 factores, el factor fijo cobertura con 4 niveles de irradiancia (categorías de luz: luz < 5, luz entre 5-10, luz entre 10-15 y luz $>15$ ) y el claro como factor aleatorio. Las comparaciones se realizaron entre niveles de cobertura para cada fecha de medición, porque no se buscó analizar los cambios de las variables a lo largo del tiempo. Para los factores fijos significativos las medias se compararon con el test de Duncan $(p<0,05)$.

\subsection{Resultados}

\subsubsection{Cobertura}

El gradiente de cobertura fue amplio, el porcentaje de canopeo abierto varió desde 1,2 \% en sitios con mayor cobertura, hasta $32,4 \%$ en sitios con menor cobertura (Figura 5.1). En estos 
sitios la luz transmitida total media varió entre 0,6 y 18,7 moles $\mathrm{m}^{-2}$ día $^{-1}$, relacionado al porcentaje de canopeo abierto (Figura 5.1). La luz transmitida total media a cielo abierto fue calculada a partir de las fotos hemisféricas, esta fue de 37,65 moles $\mathrm{m}^{-2}$ día ${ }^{-1}$, por lo que el porcentaje de luz transmitida total para las diferentes posiciones del claro varió entre 1,6 y $50 \%$ de luz con respecto al cielo abierto. EI PAR registrado al mediodía con ceptómetro varió de 3 a más de $1946 \mu \mathrm{mol} \mathrm{m}{ }^{-2}$ $\mathrm{s}^{-1}$ en las diferentes coberturas (Tabla 5.1). .

La relación rojo/rojo lejano $(\mathrm{R} / \mathrm{RL})$ al mediodía aumentó a medida que disminuyó la cobertura del dosel (Tabla 5.1), a mayor luz transmitida total mayor fue la relación R/RL, valores similares fueron registrados a sol pleno en el ensayo en maceta (Capítulo 2) (Tabla 2.1).

Tabla 5.1: Relación rojo-rojo lejano (R/RL) al mediodía y promedio con error estándar (E.E.), máximo y mínimo del PAR a los 3 meses, por categoría de luz transmitida total: luz <5, luz 5-10, luz 10-15 y luz >15.

\begin{tabular}{lc|ccc}
\hline & & \multicolumn{3}{|c}{ PAR $\left(\mu \mathrm{mol} \mathrm{m}^{-2} \mathrm{~s}^{-1}\right)$} \\
\hline luz & Relación R/RL & Promedio $\pm E . E$. & Mínimo & Máximo \\
\hline$<5$ & 0,58 & $153 \pm 40$ & 3 & 1025 \\
$5-10$ & 0,68 & $212 \pm 59$ & 11 & 1877 \\
$10-15$ & 0,76 & $329 \pm 54$ & 15 & 1837 \\
$>15$ & 0,96 & $1126 \pm 147$ & 67 & 1946 \\
\hline
\end{tabular}
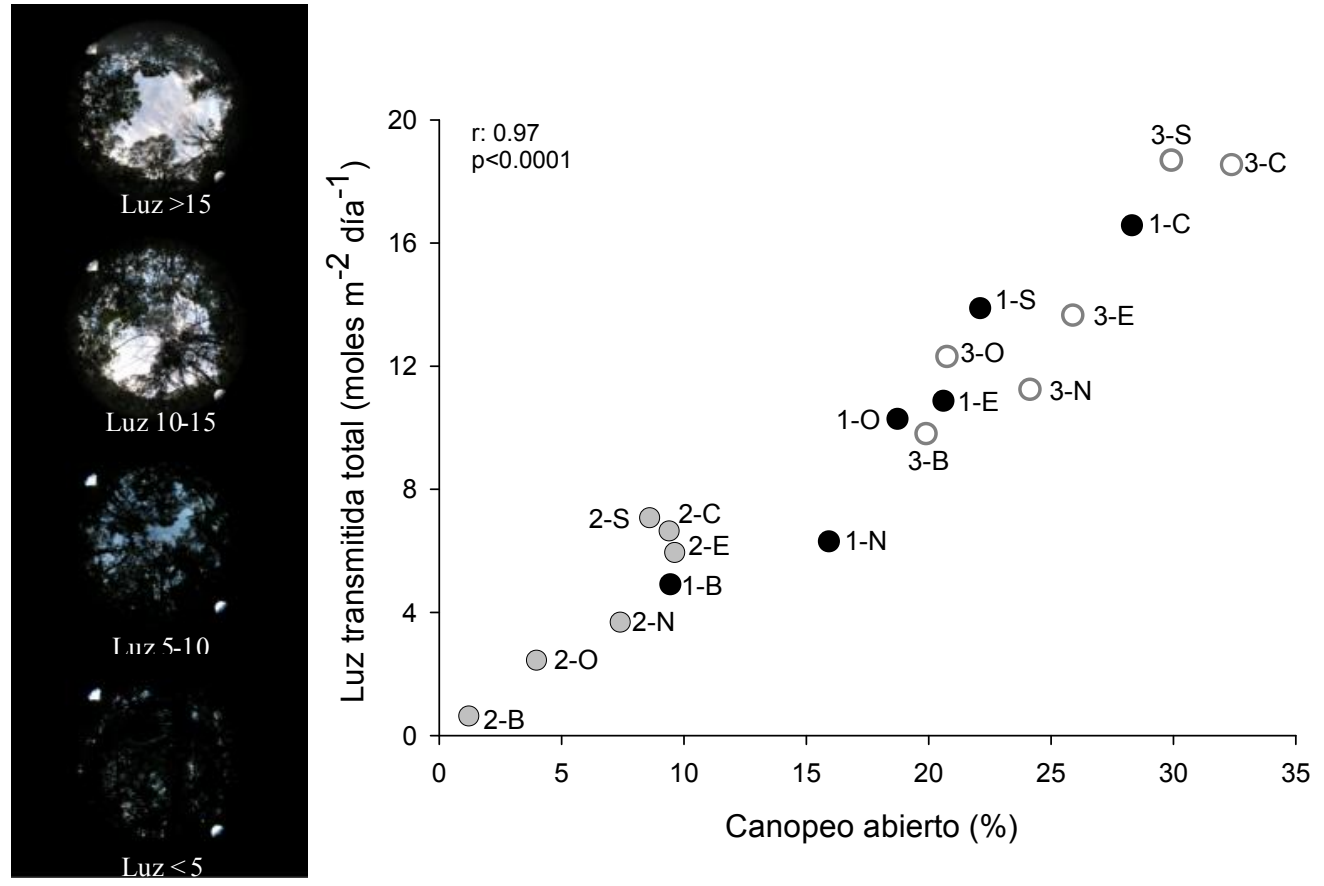

Figura 5.1: Fotos hemisféricas de 4 sectores del claro que reciben luz menor a 5 moles $^{-2}$ día $^{-1}$ (Luz $<5$ ), luz entre 5-10 moles $\mathrm{m}^{-2} \mathrm{día}^{-1}$, luz entre 10 y 15 moles $\mathrm{m}^{-2} \mathrm{dí}^{-1}$, y luz $>15$ moles moles $\mathrm{m}^{-2} \mathrm{dí}^{-1}$ (imagen de la 
izquierda). Correlación entre la luz transmitida total (moles moles $\mathrm{m}^{-2}$ día $^{-1}$ ) y \% de canopeo abierto medido en cada posición por claro para los 3 claros (ensayo en claros). Los números 1 a 3 indican el claro. Las letras indican la posición dentro del claro: B (debajo del bosque), N (norte), S (sur), E (este), O (oeste), C (centro).El tamaño de cada claro es: 1) $119 \mathrm{~m}^{2}$ (círculos grises oscuros), 2) $68 \mathrm{~m}^{2}$ (círculos negros) y 3) $172 \mathrm{~m}^{2}$ (círculos grises claros) de área extendida (imagen de la derecha).

\subsubsection{Supervivencia y crecimiento}

La supervivencia inicial (3 meses) de Cabralea canjerana fue del $95 \%$. Transcurrido el primer periodo de crecimiento ( 6 meses) la supervivencia de las plantas de Cabralea canjerana en las diferentes coberturas establecidas continuó siendo elevado, mayor al 90 \% (Tabla 5.2). Sin embargo, la supervivencia en los microambientes con mayor cobertura (<5) fue mayor que en los microambientes con menor cobertura ( $>5$ ) (Tabla 5.2), aunque en estos sitios ( $>5$ ) las plantas crecieron más en altura que en los microambientes con mayor cobertura (<5) (Figura 5.3). A los 12 meses, luego del primer invierno, se registró una elevada supervivencia de los individuos (89 \%). Sin embargo, a los 44 meses la supervivencia descendió a 70 \%, con los valores más bajos de supervivencia en la categoría $<5$, al contrario de lo ocurrido a los 6 meses. El menor porcentaje de supervivencia se registró en la categoría de luz $<5$. En la categoría de luz $>15$ la supervivencia fue un $20 \%$ más que a $<5$ a los 44 meses (Tabla 5.2).

Tabla 5.2: Supervivencia de la parte aérea (\%) de las plantas de Cabralea canjerana en los claros a lo largo del tiempo $(3,6,12,20,25,32,36$ y 44 meses) desde la instalación de los ensayos y \% de supervivencia por categoría de luz (luz $<5$, luz 5-10, luz 10-15 y luz $>15$.)

\begin{tabular}{cccccc}
\hline & & \multicolumn{4}{c}{ categorías de luz } \\
\hline Meses & \% de supervivencia total & $<5$ & $5-10$ & $10-15$ & $>15$ \\
\hline 3 & 95 & 100 & 93 & 96 & 89 \\
6 & 91 & 97 & 87 & 93 & 89 \\
12 & 89 & 86 & 87 & 93 & 89 \\
20 & 82 & 89 & 78 & 80 & 85 \\
25 & 82 & 83 & 82 & 81 & 85 \\
32 & 78 & 78 & 76 & 76 & 85 \\
36 & 77 & 75 & 76 & 76 & 81 \\
44 & 70 & 61 & 64 & 76 & 81 \\
\hline
\end{tabular}

La altura de las plantas que crecieron con mayor cobertura (luz $<5$ moles $\mathrm{m}^{-2}$ día $^{-1}$ ) no varió a lo largo del tiempo, contrariamente a lo observado en las plantas que crecieron con menor 
cobertura (Figura 5.2; Figura 5.3). Esto se evidencia en su menor tasa de crecimiento en altura (Tabla 5.3).

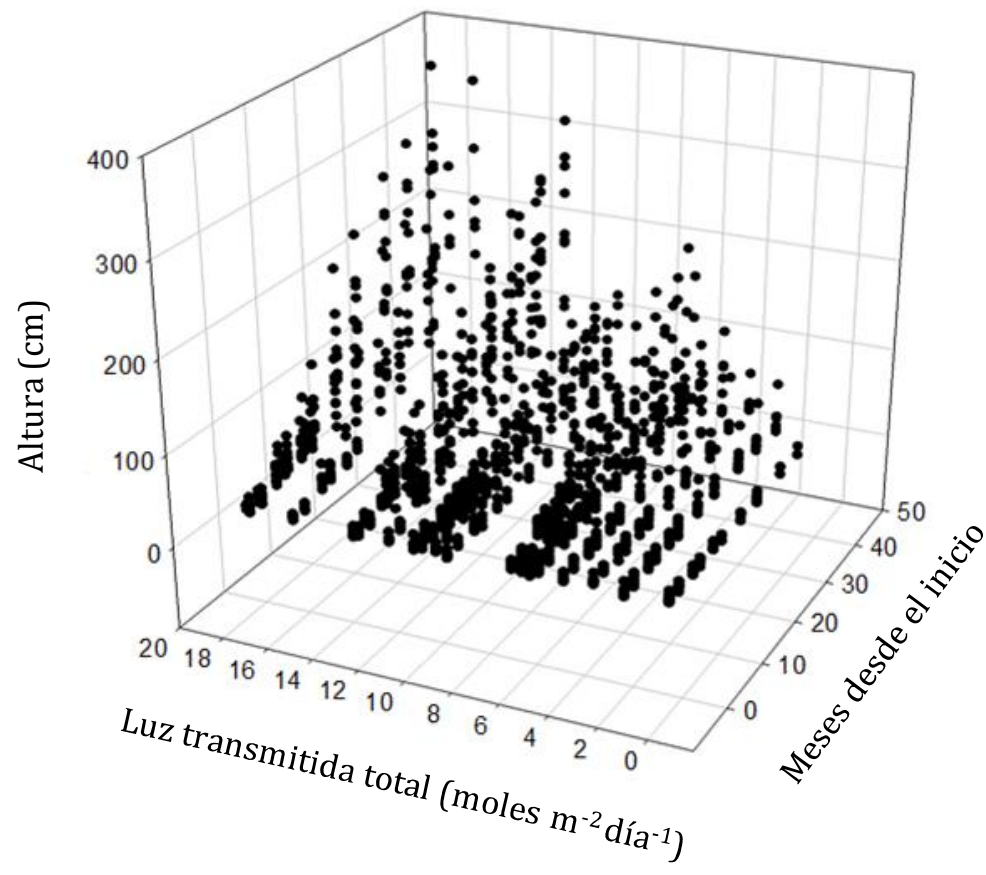

Figura 5.2: Altura $(\mathrm{cm})$ de las plantas de Cabralea canjerana a lo largo de los 44 meses (meses de crecimiento) en las diferentes condiciones de luz recibida a lo largo del año (luz transmitida total, moles $\mathrm{m}^{-2}$ $\left.d^{\prime} a^{-1}\right)$. Cada punto representa una planta en una fecha dada.

Las plantas que crecieron con luz mayor a 5 moles $\mathrm{m}^{-2}$ día ${ }^{-1}$ (luz>5) lo hicieron aproximadamente a la misma tasa de crecimiento ( $\beta 1$ ) hasta el primer año (Tabla 5.3). Luego del año, el crecimiento de las plantas fue mayor a medida que la disponibilidad de luz fue mayor. Esto puede verse en el aumento de la pendiente del segundo tramo ( $\beta 2$ ) (Tabla 5.3). La altura de las plantas de Cabralea canjerana fue mayor cuando la luz transmitida total fue superior a 15 moles $\mathrm{m}^{-2}$ día $^{-1}$ (Figura 5.3). 


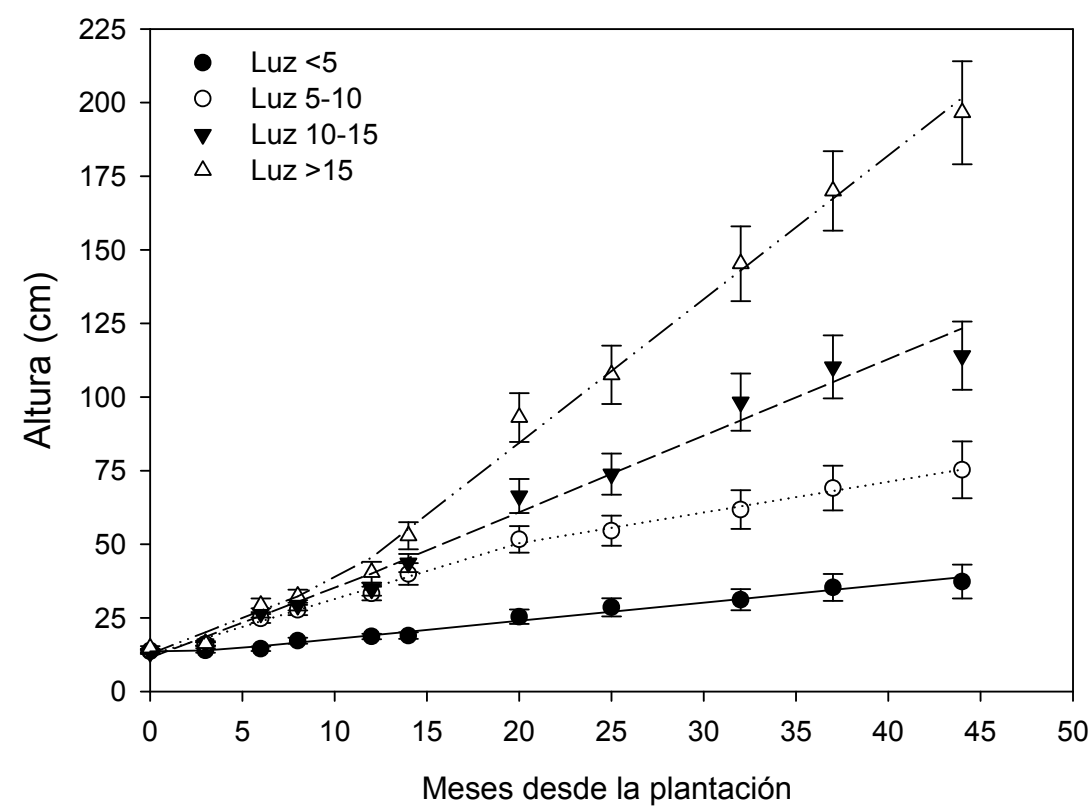

Figura 5.3: Regresiones en dos tramos entre la altura $(\mathrm{cm})$ y el tiempo desde la plantación (meses) de plantas de Cabralea canjerana en diferentes posiciones de los claros. Cada curva representan rango de luz transmitida total: menor a 5 moles $\mathrm{m}^{-2}$ día $^{-1}(<5)$, entre 5 y 10 moles m ${ }^{-2}$ día ${ }^{-1}(5-10)$, entre 10 y 15 moles m$^{-2}$ día $^{-1}(10-15)$ y mayor a 15 moles $\mathrm{m}^{-2}$ día $^{-1}(>15)$. Cada punto es la media de la altura de las plantas de ese rango de luz para cada fecha. Las barras son el error estándar de la media.

Tabla 5.3: Parámetros de las regresiones en dos tramos y sus significancias ( $p$-valor), de la altura $(\mathrm{cm})$ a lo largo del tiempo (meses) para las 4 categorías de luz transmitida: menor a 5 moles $\mathrm{m}^{-2}$ día $^{-1}(<5)$, entre 5 y 10 moles $\mathrm{m}^{-2}$ día $^{-1}(5-10)$, entre 10 y 15 moles $\mathrm{m}^{-2}$ día $^{-1}(10-15)$ y mayor a 15 moles $^{-2}$ día $^{-1}(>15)$. $\alpha$ es intersección en el eje y; $\beta 1$ es la pendiente del primer tramo; $\gamma$ es el punto de inflexión y $\beta 2$ es la pendiente del segundo tramo. Las regresiones se realizaron tomando todos los valores graficados en la Figura 5.2, asignados a cada rango de intensidad de luz.

\begin{tabular}{ccccccccc}
\hline \multicolumn{7}{c}{ Intensidad de luz transmitida $\left({\left.\text { moles } \mathrm{m}^{-2} \text { día }^{-1}\right)}\right.$} \\
\hline & $<5$ & p-valor & $5-10$ & p-valor & $10-15$ & p-valor & $>15$ & p-valor \\
\hline$\alpha$ & 13,6 & $<0,01$ & 12,4 & $<0,01$ & 13,0 & $<0,01$ & 13,3 & $\mathbf{0 , 0 4}$ \\
$\beta 1$ & 0,1 & 0,9 & 1,9 & $<0,01$ & 2,3 & $<0,01$ & 2,3 & 0,06 \\
$\mathrm{Y}$ & 4,3 & 0,6 & 19,9 & $<0,01$ & 14,1 & 0,5 & 10,3 & $\mathbf{0 , 0 1}$ \\
$\beta 2$ & 0,6 & $<0,01$ & 1,0 & $<0,01$ & 2,6 & $<0,01$ & 4,9 & $<0,01$ \\
\hline
\end{tabular}

5.4.3 Respuestas morfológicas y fisiológicas a los diferentes niveles de luz

Hasta los 3 meses las plantas no desarrollaron cambios en el área foliar del folíolo (AFF) y en el área foliar específica del folíolo (AFE del folíolo). Sin embargo, a los 6 meses el AFF de las plantas de Cabralea canjerana que crecieron con luz menor a 5 moles $\mathrm{m}^{-2}$ día $^{-1}$ (luz <5) fue significativamente menor que para las otras 3 categorías de luz (Figura 5.4 A). A los 32 meses las 
plantas de Cabralea canjerana que recibieron la mayor irradiancia (luz $>15$ moles $\mathrm{m}^{-2}$ día $^{-1}$ ) tuvieron mayor AFF y menor el AFEf que las plantas de las otras categorías de luz (Figura 5.4 A; Figura 5.4 B).

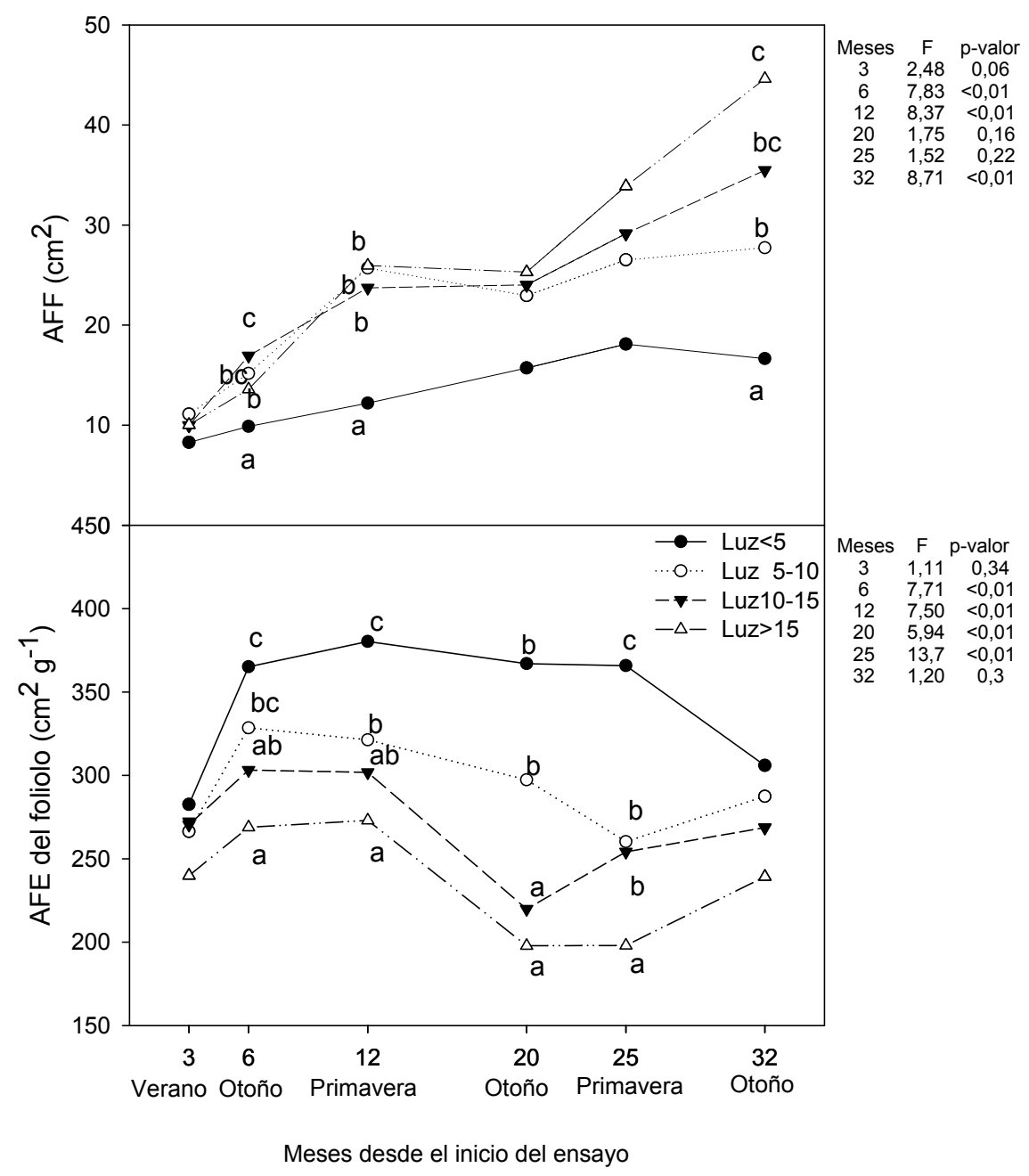

Figura 5.4: Área foliar del folíolo (AFF) $\left(\mathrm{cm}^{2}\right)$ (A) y área foliar específica del folíolo (AFE del folíolo) $\left(\mathrm{cm}^{2} \mathrm{~g}^{-1}\right.$ ) (B) de las plantas de Cabralea canjerana medido para cada fecha (meses) y por categoría de luz: menor a 5 moles $\mathrm{m}^{-2}$ día ${ }^{-1}(<5)$, entre 5 y 10 moles $\mathrm{m}^{-2}$ día $^{-1}(5-10)$, entre 10 y 15 moles $\mathrm{m}^{-2}$ día $^{-1}(10-15)$ y mayor a 15 moles $\mathrm{m}^{-2}$ día $^{-1}(>15)$. Letras distintas indican diferencias significativas entre categorías de luz para cada fecha $p<0,05$ (Test de Duncan).

La concentración de clorofila total por gramo de hoja fue mayor en las plantas que crecieron con mayor cobertura (Figura 5.5 A). Estos resultados ya se habían registrado en las plantas de canopeo de los ensayos en maceta (Capítulos 3 y 4). Sin embargo no se registraron cambios en la relación clorofila a/b entre categorías de luz para las diferentes fechas (Figura 5.5 B). 


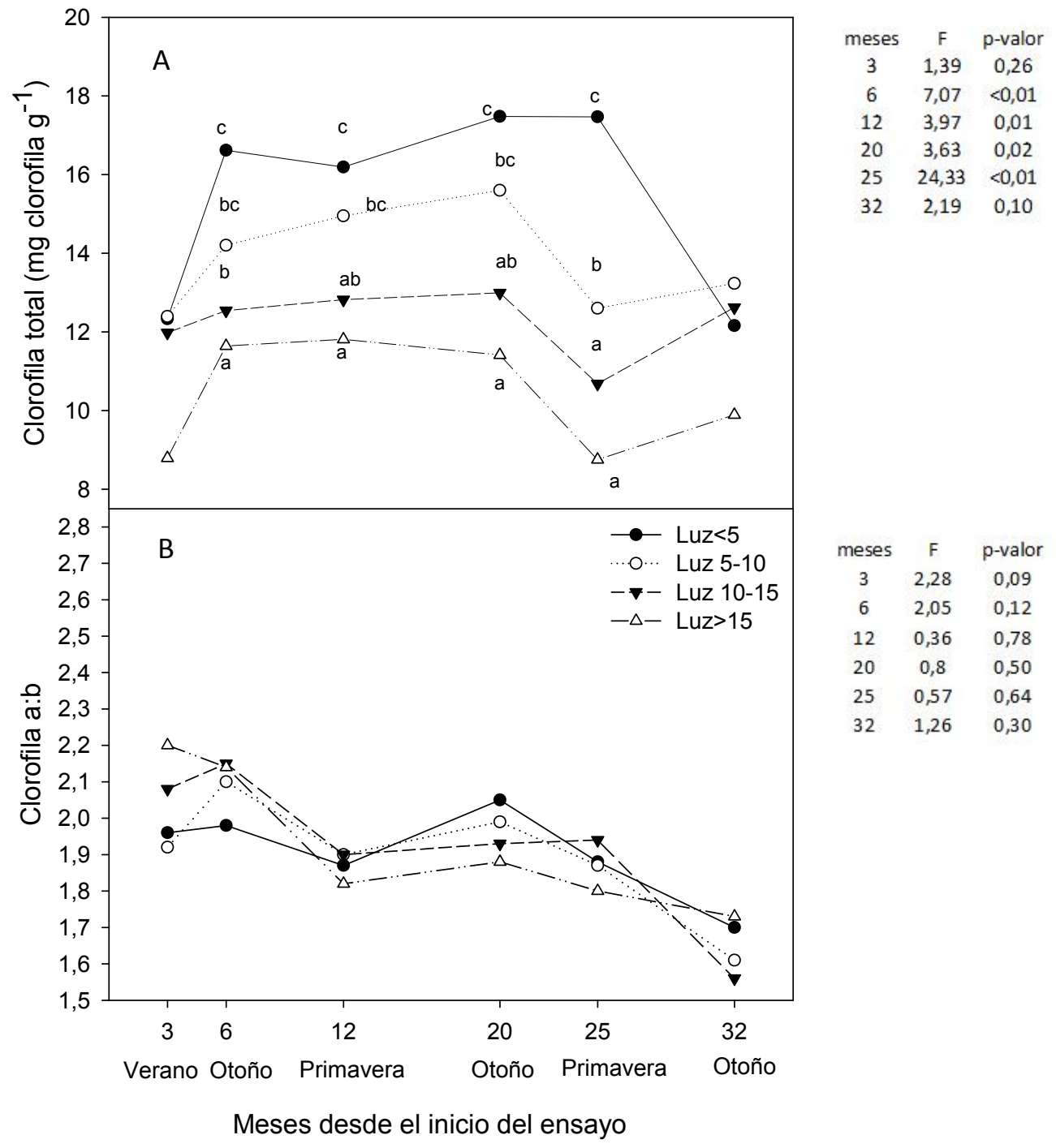

Figura 5.5: Clorofila total por gramo de hoja $\left(\mathrm{mg} \mathrm{clorofila}^{-1}\right)(\mathrm{A})$ y relación clorofila a/b (B) de las plantas de Cabralea canjerana medido para cada fecha (meses) y por categoría de luz: menor a 5 moles $\mathrm{m}^{-2} \mathrm{dí}^{-1}(<5)$, entre 5 y 10 moles $\mathrm{m}^{-2}$ día $^{-1}(5-10)$, entre 10 y 15 moles $\mathrm{m}^{-2}$ día $^{-1}(10-15)$ y mayor a 15 moles $\mathrm{m}^{-2}$ día $^{-1}$ $(>15)$. Letras distintas indican diferencias significativas entre categoría de luz por fecha $p<0,05$ (Test de Duncan).

La tasa de trasporte de electrones (ETR) fue mayor para las plantas que crecieron con luz > a 5 moles $\mathrm{m}^{-2}$ día ${ }^{-1}$ que para las que crecieron con luz < a 5 moles $\mathrm{m}^{-2}$ día ${ }^{-1}$ (Figura 5.6) en cada fecha de medición. No se observó daño por exceso de luz en ninguno de los niveles de irradiancia, reflejado en los valores de Fv/Fm altos (Tabla 5.4) para cada fecha. 


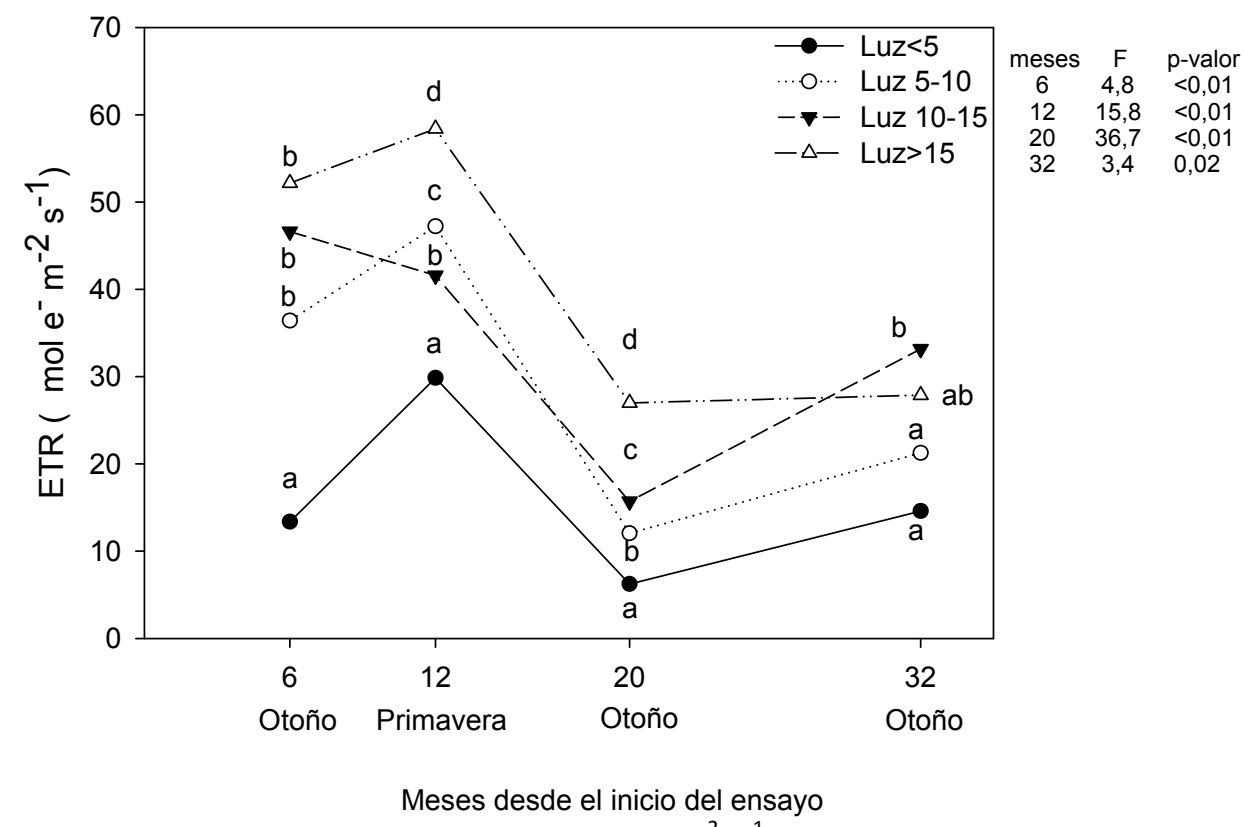

Figura 5.6: Tasa de trasporte de electrones (ETR) $\left(\mu \mathrm{mol} \mathrm{e} \mathrm{m}^{-2} \mathrm{~s}^{-1}\right)$ de las plantas de Cabralea canjerana medido para cada fecha (meses) y por categoría de luz: menor a 5 moles $\mathrm{m}^{-2} \mathrm{dí}^{-1}(<5)$, entre 5 y 10 moles $\mathrm{m}^{-}$ ${ }^{2}$ día $^{-1}(5-10)$, entre 10 y 15 moles $\mathrm{m}^{-2}$ día $^{-1}(10-15)$ y mayor a 15 moles $\mathrm{m}^{-2}$ día $^{-1}(>15)$. Letras distintas indican diferencias significativas entre categorías de luz por fecha $p<0,05$ (Test de Duncan).

Tabla 5.4 Rendimiento cuántico máximo del fotosistema II (Fv/Fm) en oscuridad de las plantas de Cabralea canjerana medido a los 6,12 , y 20 meses, por categoría de luz: menor a $5(<5)$, entre 5 y 10 (5-10), entre 10 y $15(10-15)$ y mayor a $15(>15)$ moles $\mathrm{m}^{-2} \mathrm{dia}^{-1}$. No hay diferencias significativas entre las medias de las categorías de luz para cada fecha.

\begin{tabular}{ccccc}
\hline Fv/Fm & \multicolumn{4}{c}{ Categorías de luz } \\
Meses & $<5$ & $5-10$ & $10-15$ & $>15$ \\
\hline 6 & 0,89 & 0,88 & 0,86 & 0,84 \\
12 & 0,82 & 0,81 & 0,8 & 0,79 \\
20 & 0,84 & 0,83 & 0,83 & 0,82 \\
\hline
\end{tabular}

La conductancia estomática fue significativamente mayor en las plantas de la categoría > 15 solo a los 6 meses desde el trasplante. En las diferentes fechas, tendió a ser mayor en las plantas con mayor disponibilidad de luz, aunque no se registraron diferencias significativas entre categorías de luz para las fecha (Figura 5.7). 


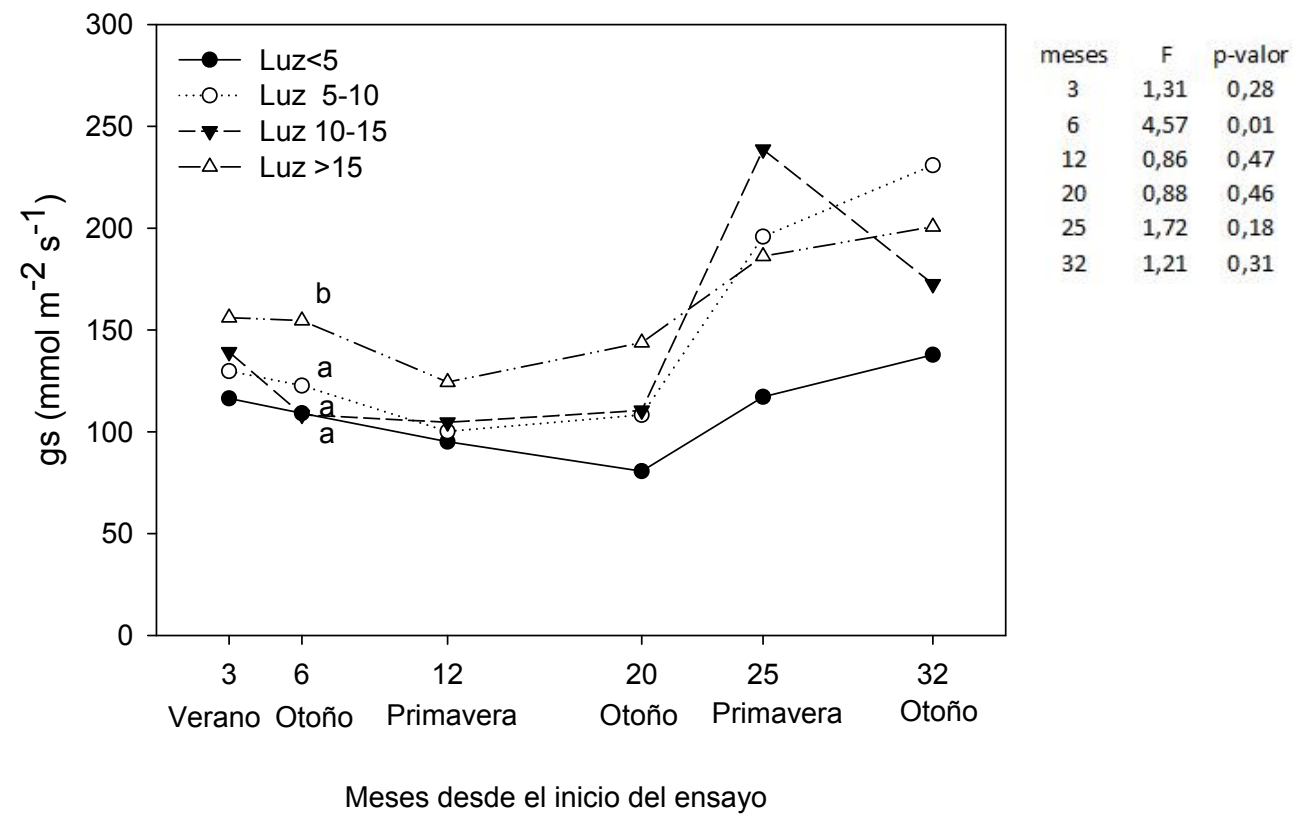

Figura 5.7: Conductancia estomática (gs) $\left(\mathrm{mmol} \mathrm{m}^{-2} \mathrm{~s}^{-1}\right)$ de las plantas de Cabralea canjerana medido para

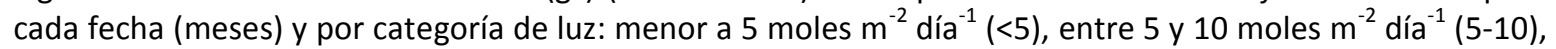
entre 10 y 15 moles $\mathrm{m}^{-2}$ día $^{-1}(10-15)$ y mayor a 15 moles $\mathrm{m}^{-2}$ día $^{-1}(>15)$. Letras distintas indican diferencias significativas entre categoría de luz por fecha $\mathrm{p}<0,05$ (Test de Duncan).

\subsection{Discusión}

Las condiciones ambientales generadas en el área abierta del claro favorecen la colonización de especies pioneras arbóreas, arbustivas y principalmente herbáceas de ciclos cortos, que crecen rápidamente y cubren el sotobosque generando una elevada competencia por los recursos (Tabarelli y Mantovani 1997; Dalling et al. 2004; Muñoz et al. 2012). Por esto es importante evaluar el enriquecimiento con especies de alto valor ecológico y económico en la selva, ya que, no solo acelera los procesos de recuperación de la funcionalidad de los ecosistemas, sino que aumenta la riqueza de especies, así como la abundancia de determinadas especies nativas.

Aproximadamente el 95\% de las plantas de Cabralea canjerana sobrevivieron inicialmente en todos los ambientes de cobertura evaluados. Se registró un elevado porcentaje de supervivencia al año de instalado el ensayo, lo cual nos indica que el claro amortigua las temperaturas bajo cero y las bajas temperaturas del invierno (se registró en junio de 2015 una temperatura mínima absoluta mensual de $-0,5^{\circ} \mathrm{C}$. En este estudio se observó un amplio gradiente 
de cobertura y luz transmitida total (Figura 5.1). Sin embargo, hubo microambientes con valores similares de porcentajes de apertura que tuvieron diferentes valores de luz incidente. Estas diferencias posiblemente se deban a la orientación y tamaño de los claros, a las características de la composición y tamaño de los árboles que conforman el borde del claro, a la presencia de árboles caducifolios y a las características del sotobosque presente (Denslow 1987; Amir 2012). El porcentaje de luz trasmitida total fue de aproximadamente $50 \%$ con respecto a cielo abierto para la categoría de luz mayor a 15 moles $\mathrm{m}^{-2} \mathrm{día}^{-1}$. En los sitios con mayor cobertura, el PAR al mediodía varió entre 3 y $1025 \mu \mathrm{mol} \mathrm{m} \mathrm{s}^{-2}$ con una media de $153 \mu \mathrm{mol} \mathrm{m} \mathrm{m}^{-2} \mathrm{~s}^{-1}$ y la relación R/RL fue de 0,5 aproximadamente (Tabla 5.1). Posiblemente los valores máximos de PAR en la categoría de luz $<5$ se deban a los flecos de luz que ingresan al sotobosque por la porosidad de las copas, la disposición de las hojas y el movimiento por el viento. La calidad de la luz, como la relación R/RL y la intensidad de luz azul son fundamentales en las respuestas fotomorfogénicas de las plantas a los ambientes de luz (Ritchie 1997). La baja relación R/RL es esperables en microambientes con mayor cobertura, ya que, la cantidad de luz roja que atraviesa el dosel es absorbida por el follaje antes de llegar al sotobosque (Valladares et al. 2004). En otro trabajo, se encontraron valores similares de relación $\mathrm{R} / \mathrm{RL}$ en el sotobosque de bosque secundarios templados (Valladares et al. 2012).

La supervivencia a los 2 años desde instalado el ensayo fue similar en todas las categorías de cobertura, sin embargo, el crecimiento fue significativamente mayor cuando la disponibilidad de luz fue mayor a 5 moles $\mathrm{m}^{-2}$ día $^{-1}$ (Tabla 5.2; Figura 5.3). En otro trabajo con 2 especies, una tolerante a la sombra y otra demandante de luz, la supervivencia a los 2 años fue menor en los sitios con mayor cobertura, para ambas especies, sin embargo la especie demandante de luz, creció más en altura cuando la cobertura fue menor (Lu et al. 2018). Este comportamiento fue observado en Cabralea canjerana a los $3 \frac{1}{2}$ años desde instalado el ensayo. Posiblemente la supervivencia de Cabralea canjerana es favorecida por la baja irradiancia los primeros 2 años de crecimiento, pero luego su crecimiento es favorecido por la mayor disponibilidad de luz. Esto podría deberse a que las especies forestales en las etapas juveniles tienen la capacidad de establecerse debajo del canopeo denso, pero luego de un tiempo necesitan mayor disponibilidad de luz para crecer (Lamprecht 1990). Las especies tolerantes a la sombra desarrollan estrategias para sobrevivir debajo de los canopeos densos, y realizan mayor inversión mecanismos de defensa a herviboría y tienen bajo o nulo crecimiento (Kitajima 1996). Sin embargo, si la baja disponibilidad de luz continúa de manera que las plantas no logran un balance neto de carbono positivo que les permita crecer, pasado un tiempo variable dependiendo de las especies, las plantas morirán. La 
baja disponibilidad de luz en los microambientes de los claros de la categoría < 5, podría explicar la mayor mortalidad de las plantas a los 44 meses desde el inicio del ensayo, y el menor crecimiento de las que sobrevivieron (Tabla 5.2; Figura 5.3).

La supervivencia y crecimiento en altura de las plantas de Cabralea canjerana a los 44 meses, fue mayor en microambientes del claro donde la cobertura era menor y la disponibilidad de luz mayor (Tabla 5.2; Figura 5.3). Si bien el crecimiento en altura de las plantas fue muy heterogéneo en los claros (Figura 5.2), la tasa de crecimiento fue mayor para las plantas que crecieron en los microambientes con luz mayor a 15 moles $\mathrm{m}^{-2}$ día $^{-1}$ (Tabla 5.3) donde la disponibilidad de luz era del $50 \%$ con respecto a un sitio abierto. Algunos individuos que crecieron con luz $>15$ alcanzaron los 3,6 m de altura a los 44 meses (Figura 5.2). La alta heterogeneidad en el crecimiento podría deberse a la gran variabilidad de microambientes en la selva, generados por la estructura vertical del dosel y las características de los claros (Figuras 5.1; Tabla 5.1). Otras especies tropicales, con diferentes requerimiento de luz, también crecieron más en altura con mayor disponibilidad de luz (Chou et al. 2017), resultado esperable en especies de la sucesión intermedia como Cabralea canjerana. Consistentemente, en un estudio con Dipteryx micrantha Harms, descripta como dependiente de los claros, las plantas crecieron más en altura en los sitios del claro donde la disponibilidad de luz era mayor, y también presentaron una elevada heterogeneidad de crecimiento según su posición en los claros (Ashton et al. 1995; Reátegui Romo 2005).

En los capítulos anteriores medimos diferentes variables morfológicas y fisiológicas para evaluar la capacidad de aclimatación de Cabralea canjerana a condiciones extremas de cobertura y al cambio abrupto en la cobertura. En este ensayo evaluamos algunas de las variables morfológicas y fisiológicas para analizar si las plantas ponían en juego los mismos mecanismos de aclimatación cuando se las plantó a campo. A los 6 y 12 meses, el AFF en plantas que crecieron con menor cobertura fue significativamente mayor que para las plantas que crecieron con mayor cobertura (Figura $5.4 \mathrm{~A}$ ), esto podría deberse al mayor crecimiento de las plantas que recibían mayor radiación con respecto a las plantas que crecieron con mayor cobertura. Además, el aparato fotosintético no presentó daños en ninguna de las categorías de disponibilidad de luz, ni siquiera en la de mayor disponibilidad de luz (Tabla 5.4, Figura 5.4). Esto nos indica que las condiciones microambientales generadas en la categoría de luz > a $15{\text { moles } \mathrm{m}^{-2} \text { día }}^{-1}$, que es menor a la irradiancia en condiciones de sol pleno, favorecen el crecimiento de las plantas de Cabralea canjerana sin causar daño. Las plantas que siempre crecieron a bajas irradiancias (luz <5 
moles $\mathrm{m}^{-2}$ día $^{-1}$ ) tuvieron mayor AFE del folíolo, mayor contenido de clorofila total por gramo de hoja y mantuvieron los estomas abiertos durante el periodo de crecimiento, por lo tanto no se produjo dehidratación de las hojas. El menor AFE del folíolo de las plantas que crecieron con menor cobertura se debe a que las hojas estaban expuestas a mayor radiación, y por lo tanto desarrollaron hojas más similares a las plantas de sol descriptas en los capítulos anteriores. Si bien las plantas que crecieron con mayor cobertura $\left(<5{\text { moles } \mathrm{m}^{-2} \text { día }}^{-1}\right)$ desarrollaron mecanismos para aclimatarse (mayor AFE del folíolo, incrementaron el contenido de clorofila total por gramo de hoja), se observó una reducción en el crecimiento en altura debido a la falta de luz (Figuras 5.4; Figura 5.2). Esto nos indica que las plantas se pueden establecer debajo del canopeo denso, pero sufren un estrés severo por falta de luz. En los capítulos anteriores se observó un estrés severo a los 6 meses desde el inicio del ensayo y un estrés severo por falta de luz al finalizar el ensayo, evidenciado en el estancamiento en el crecimiento en altura y peso seco de las plantas de canopeo. Esta aclimatación observada a campo nos indican que las plantas de Cabralea canjerana pusieron en juego algunos mecanismos similares a los observados en los ensayos en macetas, por lo tanto la evaluación morfo-fisiológica en macetas puede ser válida para conocer posibles respuestas a campo. El ensayo de plantación en claros nos permite demostrar que los mecanismos son suficientes para tolerar el sombreo denso durante 3 años, pero pasado ese período la mortalidad aumenta. Pasados 4 años, la supervivencia de plantas a radiaciones $<5$ moles $\mathrm{m}^{-2}$ día ${ }^{-1}$ es 53 \% (observación personal de mayo de 2019).

Contrariamente a lo esperado, las plantas que crecieron con menor cobertura, no disminuyeron la conductancia estomática al mediodía. Este resultado nos indica que las plantas no sufrieron estrés hídrico. El porcentaje de luz transmitida total recibido en la categoría de luz > a 15 representó en $50 \%$ de la luz con respecto al cielo abierto, esto podría explicar por qué las plantas expuestas a la menor cobertura no cerraron parcialmente los estomas al mediodía, como lo hicieron a sol pleno en el ensayo en macetas. Además en los claros hay menor turbulencia del aire y menor temperatura del aire y del suelo que la exposición a sol pleno.

La gran plasticidad morfológica y fisiológica de Cabralea canjerana, que le permite en pocos meses aclimatarse mediante cambios morfológicos y fisiológicos a la heterogeneidad de ambientes generados en claros del bosque, beneficiaron el establecimiento y supervivencia de una elevada cantidad de plantas, y generaron una respuesta heterogénea en el crecimiento. Sin embargo, las plantas de Cabralea canjerana crecieron más en la categoría de luz > a 15 moles $\mathrm{m}^{-2}$ 
día ${ }^{-1}$. La elevada supervivencia luego del primer invierno nos indica que el claro actuó de efecto amortiguador para evitar el daño por bajas temperaturas en invierno.

\subsection{Conclusiones}

Según los resultados hasta ahora evaluados, las plantas de Cabralea canjerana lograron establecerse en condiciones de cobertura muy contrastantes (sol pleno y canopeo del ensayo en macetas) y en un gradiente amplio de luz que varió entre 1,6 y $50 \%$ de luz con respecto a cielo abierto (descripto para las categorías de luz del ensayo en claros del bosque nativo). Por lo tanto, Cabralea canjerana es una especie que puede aclimatarse niveles de cobertura bajos e intermedios altos. La supervivencia durante los 2 primeros años es favorecida por la cobertura densa, sin embargo el crecimiento es menor en estos microambientes, poniéndose en juego la dicotomía entre sobrevivir y crecer. Sin embargo, luego de $3 \frac{1}{2}$ años la supervivencia las plantas de

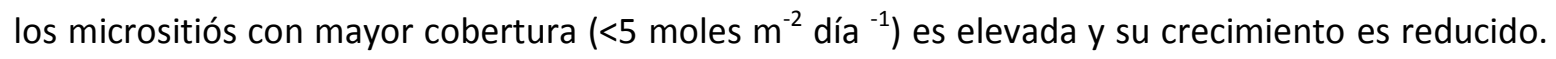
El crecimiento de las plantas a partir de 1 años de instaladas es favorecido por la mayor disponibilidad de luz, principalmente cuando la luz es mayor a 15 moles $\mathrm{m}^{-2}$ día $^{-1}$. Estas plantas no experimentan signos morfológicos y fisiológicos de estrés severo por exceso de luz ni déficit de agua. Las aclimataciones morfológicas y fisiológicas de las plantas que crecen con luz $<5$ moles $\mathrm{m}^{-2}$ día ${ }^{-1}$ son insuficientes para contrarrestar la falta de luz, y las plantas sufren un estrés severo por falta de luz, evidenciado en la reducción en el crecimiento en altura.

\subsection{Contrastación de la hipótesis}

Hipótesis:

Hipótesis 4: Las plantas de Cabralea canjerana plantadas en microambientes con menor cobertura están expuestas a mayor estrés hídrico y lumínico que las plantas con mayor cobertura, durante el primer año posterior al transplante. Pasado el primer año, las plantas con menor cobertura no sufrirán estrés hídrico ni lumínico severo debido a que están aclimatadas a dicho microambiente.

Predicción para la hipótesis 4: 
Durante el primer año, las plantas con menor cobertura crecen menos en altura y diámetro del cuello que las plantas con mayor cobertura y poseen características morfológicas y fisiológicas, que reflejan estreses hídrico y lumínico descriptos en las predicciones de la hipótesis 1 para plantas de sol. Sin embargo, a medida que pasan los años las plantas del centro del claro crecerán más porque la aclimatación será suficiente para evitar el estrés hídrico y lumínico.

Se rechaza la hipótesis. En base a los resultados obtenidos, las plantas que crecen con menor cobertura en el claros, son las que más crecieron, y no presentaron estrés hídrico ni lumínico severo. Sólo sufrieron estrés moderado por exceso de luz, que se refleja en las aclimataciones observadas (disminución en la concentración de clorofilas, menor área foliar específica). Sin embargo, las plantas ubicadas con mayor cobertura, sufrieron estrés severo por déficit lumínico, que se reflejó en bajo crecimiento en altura. 


\section{Capítulo 6: Regeneración natural de Cabralea}

\section{canjerana}






\subsection{Introducción}

El estudio ecofisiológico de Cabralea canjerana realizado en los capítulos anteriores brinda información útil acerca de los mecanismos que pone en juego esta especie para aclimatarse en ambientes con cambios abruptos y contrastantes de cobertura. El conocimiento de estos aspectos de la dinámica del rodal resulta relevante para la implementación de prácticas silvícolas que favorezcan el establecimiento de la regeneración de la especie. Para ampliar esta información, es necesario evaluar y estudiar la dinámica de la regeneración natural, y las interacciones entre individuos a nivel de rodal.

Los bosques tropicales y subtropicales se caracterizan por ser multietáneos, y de composición específica diversa, estructuralmente multiestratificados, donde conviven las especies según su dominancia de copas (dominantes, codominantes, intermedios y suprimidos). En los diferentes estratos arbóreos es posible encontrar individuos de diferentes especies de más de una categoría de copa, debido principalmente, a la dinámica de disturbios pequeños que ha modelado el establecimiento de la regeneración de nuevas cohortes de individuos. La formación de la estructura del rodal está constituida de 4 etapas, durante las cuales ocurre una serie de procesos ecológicos que definen la distribución espacial de los individuos. Las etapas del desarrollo de un rodal son: etapa de iniciación del rodal, la etapa de exclusión, la etapa de reiniciación del sotobosque y la etapa denominada del crecimiento posterior (Oliver y Larson 1996). Además, una vez establecido el rodal, una serie de factores intervienen en la dinámica de su desarrollo. La disponibilidad de semillas, los mecanismos de regeneración de cada especie, el establecimiento previo de individuos, la capacidad competitiva intra e interespecífica, la disponibilidad de espacios de crecimiento, el microclima generado, los requerimientos de las especies, la tasas de mortalidad y supervivencia y el crecimiento e interacciones entre las especies son algunos de los más importantes. Los espacios de crecimiento son pequeñas áreas donde ocurrió la muerte de algún individuo y en consecuencia quedan disponibles los recursos para los individuos que sobreviven (Oliver y Larson 1996). Además de los procesos naturales de sucesión secundaria debido a los disturbios que ocurren naturalmente, como caída de árboles por tormentas que aumentan la disponibilidad de luz en ciertos sectores y la reducen en otros, muerte por patógenos o plagas, los rodales están sujetos a efectos del manejo forestal, como cosecha de individuos, control de 
vegetación, raleos que tienen impactos sutiles en la composición y estructura de los rodales (Landsberg y Gower 1997).

El patrón de regeneración de los árboles en bosques multietáneos y multiespecíficos es generalmente agrupado. Con el paso del tiempo, surge un patrón espacial aleatorio que luego tiende a regular (Oliver y Larson 1996; Condit et al. 2000; Caldato et al. 2003; Pinazo et al. 2009b). Estos cambios del patrón de distribución ocurren debido a las interacciones entre los individuos de las diferentes especies y el medio que los rodea. Durante las etapas juveniles y adultas la competencia inter e intra específica juegan un papel importante en la supervivencia de los individuos (Oliver y Larson 1996). Si plantas de dos especies con similar tasa de crecimiento y requerimientos crecen juntas, compiten por el espacio y los recursos hasta que una domina a la otra. Esta dominancia se da por diferencias sutiles entre especies, por la diferencia de edad, el microambiente y la ventaja competitiva (Lüttge 2008). Por otro lado, individuos de dos especies que poseen diferentes tasas de crecimiento y ocupan un mismo sitio, tienen un patrón de comportamiento más predecible. Por un lado, si la especie dominada es tolerante a la sombra podrá sobrevivir un tiempo hasta que algún cambio en las condiciones de crecimiento favorezcan su desarrollo o hasta que se genere un nuevo espacio de crecimiento. Por otro lado, si la especie dominada no es tolerante a la sombra, morirá (Oliver y Larson 1996).

La regeneración y el establecimiento de las especies en general ocurren continuamente en el piso forestal o en los claros formados por la caída de ramas o árboles enteros (Harms y Paine 2003; Sharma et al. 2018). Existen diferentes factores que afectan la dispersión de las semillas y el establecimiento y desarrollo posterior de las plántulas. Las semillas de frutos carnosos grandes, tienden a caer cerca de los árboles madres, formando agrupamientos de regeneración. Sin embargo, la acción de mamíferos, hormigas y aves pueden dispersar las semillas a mayores distancias generando un patrón al azar o agrupamiento en otro sitio. Las semillas también pueden ser dispersadas por otros animales (por ejemplo, monos, roedores) generando en algunos casos, una distribución regular o agrupada, relacionada a los sitios de alimentación o dormideros de los dispersores. Por otro lado, las semillas dispersadas por el viento suelen formar agrupamientos, debido principalmente, a limitaciones en la distancia de la dispersión, o generar patrones de distribución al azar. Una vez superada la barrera de la dispersión y establecimiento en un sitio, otros procesos ecológicos y factores ambientales empiezan a jugar un rol fundamental. Por un lado, la presencia de agentes patógenos, enemigos naturales y animales que afecten el desarrollo 
de las plántulas establecidas, y por otro lado, la disponibilidad de luz, agua y nutrientes del suelo (González 1998; Condit et al. 2000; Harms y Paine 2003; Pinazo et al. 2009a).

Cabralea canjerana presenta una abundante producción de frutos carnosos que caen en las proximidades de los árboles madres y además, son dispersados por aves y hormigas. Los frutos que caen al pie de los árboles madres podrían ser fuertemente depredados por insectos y roedores. Las hormigas juegan un papel importante como agentes dispersores y facilitadores de la germinación de esta especie, ya que por un lado, alejan las semillas de los árboles madres y por otro, eliminan el arilo carnoso que posee inhibidores de la germinación, y por lo tanto su remoción facilita la germinación (Pizo y Oliveira 1998). Se ha observado que Cabralea canjerana regenera naturalmente en diversos ambientes de bosque, bajo cobertura densa, bosques secundarios (capueras) y bordes de áreas abiertas (Cargnelutti Filho et al. 2012; Carpenedo Aimi 2014). En el bosque nativo se observan grupos de individuos de Cabralea canjerana que ocupan el estrato medio del rodal asociados a los árboles adultos de la misma especie, o en otros sitios, asociados a arboles perchas. Se denomina árbol percha a aquellos que utilizan las aves para posarse y alimentarse de las semillas que seleccionan. Las semillas de Cabralea canjerana son dispersadas por aves (Pinazo et al. 2009b). Sin embargo, la mortalidad de individuos jóvenes antes de llegar a 1,3 $\mathrm{m}$ de altura es elevada.

La hipótesis de la dependencia negativa entre la distancia y la densidad establece que la supervivencia de las plántulas aumenta al aumentar la distancia a los adultos conespecíficos y se reduce al aumentar la cercanía entre plántulas de la misma especie, debido probablemente, a la presencia de agentes patógenos altamente especializados, a la competencia por los recursos y a la presencia de enemigos naturales (Comita et al. 2014). Esto, junto a la dispersión de semillas restringida por la distancia o semillas que caen cerca de los árboles madres, podría explicar por qué es baja la supervivencia de plantas pequeñas en las cercanías de los árboles adultos conespecíficos y además explicaría el mantenimiento de la elevada diversidad de especies en los bosques tropicales (Harms y Paine 2003; Comita et al. 2014; Norden 2014). El análisis de patrones espaciales de puntos es una herramienta útil para estudiar la dinámica de las poblaciones vegetales. El patrón espacial de puntos es un arreglo de objetos o atributos distribuidos en el plano o en el espacio. Esta herramienta se utiliza para examinar y describir cómo los elementos se distribuyen en el espacio (patrón al azar, agrupado, regular). Para analizar la interacción entre procesos de puntos, se utiliza la función de correlación de marcas. Esta función analiza las relaciones entre las marcas o atributos de las plantas asociados a uno o más procesos de puntos 
en el espacio. Las marcas pueden ser continuas (por ejemplo diámetro, altura) o categóricas (por ejemplo especie, sexo, clase de edad) (Ledo et al. 2013). Estas herramientas ayudan a describir y entender cómo funcionan las relaciones en la naturaleza y resultan de gran utilidad para entender la dinámica ecológica de las poblaciones y en este caso de la regeneración natural de Cabralea canjerana para diseñar estrategias de intervención. Algunas de las preguntas que se buscó responder en este capítulo de tesis fueron: ¿Cómo es la distribución de alturas de los individuos? ¿En qué categoría de altura la mortalidad de las plantas es mayor? ¿Cómo es la distribución espacial de las plantas de Cabralea canjerana en cada categoría de altura? ¿La distribución de las plantas de las categorías más pequeñas se asocia a los adultos de Cabralea canjerana?

\subsection{Objetivos e hipótesis}

\section{Objetivo 5}

Analizar la distribución espacial de la regeneración natural de Cabralea canjerana en bosques secundarios de la selva misionera y evaluar las relaciones entre categorías de altura

Hipótesis 5

La regeneración está relacionada con la presencia de árboles adultos conespecíficos. La supervivencia y crecimiento se relacionan con el grado de cobertura del dosel: las plantas requieren dosel protector los dos primeros años de vida y mayor disponibilidad de luz los años subsiguientes.

\section{Predicciones para la hipótesis 5}

1. Hay mayor densidad de individuos de entre 10 y $50 \mathrm{~cm}$ de altura de Cabralea canjerana cerca de los árboles adultos conespecíficos, ya que son los generadores de semillas y probablemente las semillas caen cerca de los árboles semilleros.

2. Las plantas entre 50 y $130 \mathrm{~cm}$ de altura estarán asociadas a árboles adultos de cualquier especie, porque su supervivencia requiere cobertura del dosel de cualquier especie.

3. La supervivencia de la las plantas mayores a $130 \mathrm{~cm}$ de altura es mayor en zonas más alejadas de árboles de gran porte, porque a partir de esa altura, las plantas requieren más luz. 


\subsection{Materiales y métodos}

En este capítulo se muestran los resultados del relevamiento de la regeneración natural de Cabralea canjerana en el bosque nativo. La metodología detallada puede visualizarse en el Capítulo 2.

\subsubsection{Análisis estadístico}

Para responder a las preguntas de investigación y analizar el patrón de dispersión (agrupado, al azar o regular) de las diferentes categorías de renovales de Cabralea canjerana y sus relaciones, se trabajó con el análisis de patrones espaciales de puntos utilizando el software $\mathrm{R}$ con las librerías spatstat, rpart y nlme (Baddeley et al. 2006).

El análisis de patrones espaciales de puntos sirve para reflejar la estructura espacial de un conjunto de datos de una población o una comunidad en un área determinada mediante coordenadas xy (de la Cruz Rot 2006). Los patrones de puntos tienen 2 propiedades intrínsecas: la propiedad de primer orden (intensidad $\lambda$ : el número esperado de puntos por unidad de área en cualquier localidad) y la de segundo orden que resume las interacciones de atracción y repulsión entre puntos (por ejemplo la probabilidad de encontrar un punto en las inmediaciones de otro).

Para analizar la distribución espacial de puntos de las categorías PP (10 a $50 \mathrm{~cm}$ de altura), $P$ (de 50 a $130 \mathrm{~cm}$ de altura) y J (más de $130 \mathrm{~cm}$ de altura y menos de $10 \mathrm{~cm}$ de DAP) se utilizó la función K de Ripley (Baddeley y Turner 2003). La función K es una función de distribución acumulada, ya que, a cada distancia $r$ (radio), todos los pares de puntos separados por una distancia menor que $r$, son usados para estimar el valor de la función. Estos valores son comparados con el número esperado de puntos bajo la hipótesis nula de aleatoriedad espacial completa (CSR, en inglés: Complete Spatial Randomness), condicionado por la densidad promedio de puntos de la muestra. Para establecer los niveles de significancia para la banda de confianza del análisis se utilizaron 99 simulaciones Monte Carlo con un nivel de significancia de $95 \%$ para las categorías P, J y AC y 19 simulaciones con un nivel de significancia para las bandas de confianza de $95 \%$ para las PP. 
Para analizar las relaciones entre procesos de puntos se utilizó la función de correlación de marcas, con la función K Ripley bivariante. Se evaluó cómo fue la distribución de árboles de Cabralea canjerana de la categoría P y J con respecto a los AC bajo la hipótesis de independencia (la hipótesis nula es que los dos procesos son independientes) (De La Cruz 2008).Todos los análisis incluyen la corrección por efecto de borde y el análisis de la función evalúa hasta una distancia de $25 \mathrm{~m}$ en las parcelas de 1 hectárea, y 2,5 metros para las subparcelas de 10×10 m de la categoría PP. Esta distancia está fijada ya que no puede superar el $1 / 3$ de la superficie total. Otra función empleada para el análisis fue la función $L(r)=(K(r) / \pi) 1 / 2$ que además de tener varianza constante, permite una interpretación más clara de los datos. En el caso de un patrón de Poisson, $L(r)=r$ y por lo tanto puede examinarse si $L(r)-r=0$ a cada distancia $r$ (radio) (Baddeley et al. 2006; De La Cruz 2008). Valores de L (r) - r> 0 indican atracción entre los dos procesos a la distancia $r$; valores $<0$ indican regularidad.

\subsection{Resultados}

\subsubsection{Distribución de alturas y supervivencia}

La distribución de las alturas de los individuos de Cabralea canjerana de las 4 parcelas permanentes tuvo una distribución J invertida. Esta distribución es característica de los bosques tropicales, se caracteriza por tener una gran cantidad de individuos en las categorías de menor tamaño, y una menor cantidad en las categorías mayores. En la categoría menor a $50 \mathrm{~cm}$ de altura (categoría 1; PP) hubo un promedio de 851 individuos por hectárea, que fue disminuyendo en las categorías siguientes (Figura 6.1). 


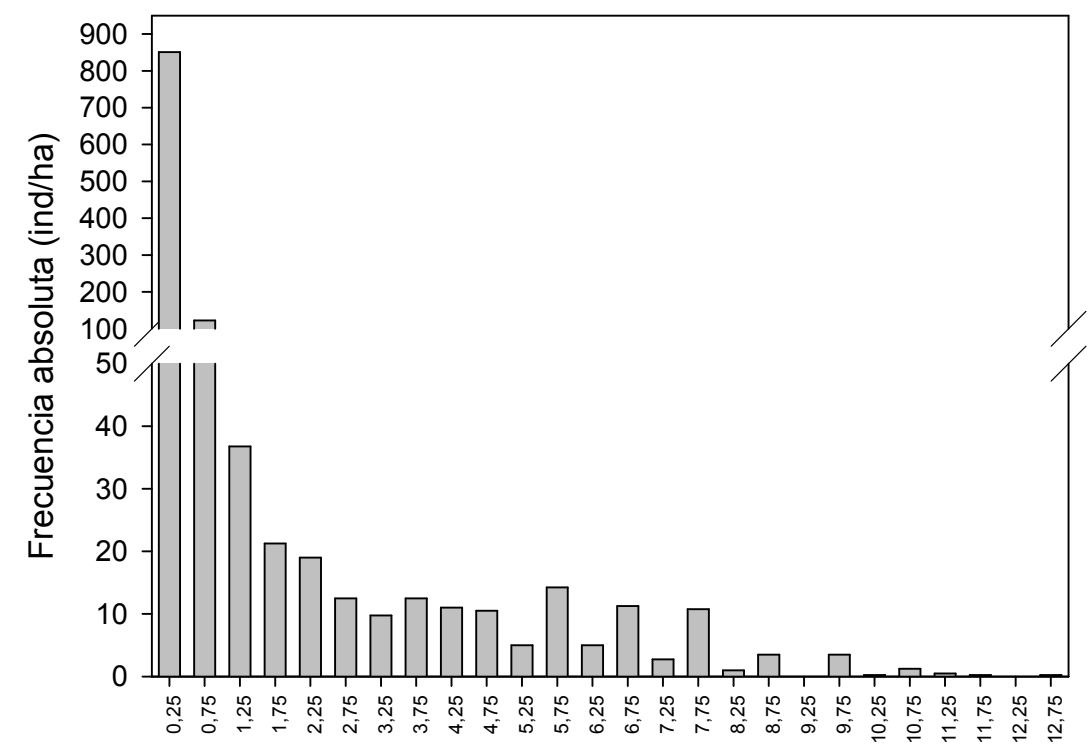

Clases de altura $(\mathrm{m})$

Figura 6.1: Distribución de alturas $(\mathrm{m})$ de la regeneración de Cabralea canjerana (ind/ha) de todas las categorías: Plántulas pequeñas (PP), Plántulas (P), Juveniles (J), en 2018 (suma de las 4 parcelas referida a 1 ha). El rango de la categoría es de 0,50 $\mathrm{m}$ de altura. En el gráfico se indica el punto medio de cada intervalo.

En el relevamiento del 2016 fueron registrados 4122 individuos de Cabralea canjerana en las 4 ha relevadas, y en 2018 fueron registrados 4838 individuos de Cabralea canjerana considerando todas las categorías de tamaño en las 4 ha relevadas, evidenciándose un aumento en el número de individuos, debido principalmente a las incorporaciones registradas en las categorías P y PP (Tabla 6.1).

La supervivencia de los individuos fue alta en todas las categorías en los diferentes años, sin embargo, en las plántulas (P) y plántulas pequeñas (PP) se registraron las mayores variaciones en cuanto a la dinámica de pérdidas e incorporaciones. Las plantas de la categoría PP que se establecieron debajo del canopeo denso, permanecieron por al menos 2 años (Tabla 6.1) con un crecimiento promedio anual en altura de $6 \mathrm{~cm}$ (Tabla 6.2). La mortalidad promedio de las PP fue de 211 individuos/ha, representando el $92 \%$ de los individuos con respecto al total que murieron y el $17 \%$ del total del individuos. Sin embargo, las incorporaciones fueron de 149 individuos/ha en 2018 (Tabla 6.1). Además se registraron movimientos internos entre categorías en las parcelas, evidenciándose en los cambios en IPr (incorporaciones promovidas de categoría) y PPr (pérdidas por promoción de categoría). 
Tabla 6.1: Número de individuos por hectárea ( $\mathrm{N}^{\circ} / \mathrm{ha}$ ) en las 4 parcelas permanentes relevadas en los años 2016-2017 y 2018, para cada categoría (Cat) (Plántulas pequeñas (PP) de 10 a $50 \mathrm{~cm}$ de altura, Plántulas (P) de 50 a $130 \mathrm{~cm}$ de altura y Juveniles $(\mathrm{J})$ con $0<\mathrm{DAP}<10 \mathrm{~cm}$ ), además se reportan los datos de $\mathrm{N}^{\circ} /$ ha de los adultos de Cabralea canjerana (AC) y adultos de otras especies (A) en las parcelas permanentes. El número de individuos por hectárea de cada fecha $\left(\mathrm{N}^{\circ} / \mathrm{ha}\right)$ representa la suma del $\mathrm{N}^{\circ} /$ ha de la fecha anterior, más las incorporaciones (I), más las incorporaciones promovidas de categoría (IPr), menos las pérdidas por promoción de categoría (PPr), menos los muertos (M) del año que estamos analizando. Los individuos vivos (V) son los que estaban vivos de un año para el otro, las incorporaciones representan los individuos que se incorporaron a una categoría en la que no estaban el año anterior, las incorporaciones promovidas de categoría (IPr) fueron los que crecieron y pasaron a una categoría superior, las pérdidas por promoción de categoría (PPr) fueron los individuos que pasaron a una categoría menor que la que tenían ese año (por ejemplo, se quebraron o rebrotaron), y las muertas son las que no sobrevivieron de un año para el otro. La suma corresponde a los individuos de las 4 parcelas y todas las categorías de Cabralea canjerana.

\begin{tabular}{|c|c|c|c|c|c|c|c|c|c|c|c|c|c|c|}
\hline \multirow[b]{2}{*}{ Parc } & \multirow[b]{2}{*}{ Cat } & \multirow{2}{*}{$\frac{2016}{\text { No/ha }}$} & \multicolumn{6}{|l|}{2017} & \multicolumn{6}{|l|}{2018} \\
\hline & & & $\mathrm{N}^{\circ} / \mathrm{ha}$ & V & 1 & $\mathrm{IPr}$ & PPr & $M$ & $\mathrm{~N}^{\circ} / \mathrm{ha}$ & V & 1 & $\mathrm{IPr}$ & PPr & $M$ \\
\hline \multirow{5}{*}{1} & A & 409 & 409 & & & & & & 409 & & & & & \\
\hline & AC & 12 & 12 & 12 & 0 & 0 & 0 & 0 & 12 & 12 & 0 & 0 & 0 & 0 \\
\hline & $\mathrm{J}$ & 44 & 45 & 44 & 0 & 1 & 0 & 0 & 43 & 43 & 0 & 0 & 2 & 0 \\
\hline & $P$ & 7 & 9 & 5 & 4 & 0 & 2 & 0 & 13 & 6 & 5 & 2 & 1 & 2 \\
\hline & PP & 75 & 112 & 56 & 50 & 6 & 0 & 19 & 143 & 75 & 63 & 6 & 0 & 38 \\
\hline \multirow{5}{*}{3} & A & 479 & 479 & & & & & & 479 & & & & & \\
\hline & $A C$ & 76 & 77 & 76 & 0 & 1 & 0 & 0 & 78 & 77 & 0 & 1 & 0 & 0 \\
\hline & $\mathrm{J}$ & 162 & 163 & 156 & 0 & 7 & 4 & 2 & 151 & 149 & 0 & 2 & 13 & 1 \\
\hline & P & 106 & 125 & 83 & 32 & 10 & 13 & 10 & 144 & 101 & 27 & 16 & 13 & 11 \\
\hline & PP & 807 & 1063 & 563 & 450 & 50 & 56 & 188 & 963 & 719 & 163 & 81 & 38 & 306 \\
\hline \multirow{5}{*}{5} & A & 383 & 383 & & & & & & 383 & & & & & \\
\hline & AC & 45 & 47 & 45 & 0 & 2 & 0 & 0 & 47 & 47 & 0 & 0 & 0 & 0 \\
\hline & $\mathrm{J}$ & 131 & 134 & 125 & 0 & 9 & 4 & 2 & 127 & 122 & 0 & 5 & 7 & 5 \\
\hline & $P$ & 166 & 179 & 137 & 34 & 8 & 20 & 9 & 205 & 145 & 49 & 11 & 19 & 15 \\
\hline & PP & 775 & 938 & 638 & 225 & 75 & 44 & 94 & 967 & 730 & 131 & 106 & 44 & 163 \\
\hline \multirow{5}{*}{$\mathrm{R}$} & A & 398 & 398 & & & & & & 398 & & & & & \\
\hline & $A C$ & 20 & 20 & 20 & 0 & 0 & 0 & 0 & 23 & 20 & 0 & 3 & 0 & 0 \\
\hline & $\mathrm{J}$ & 351 & 353 & 341 & 0 & 12 & 4 & 6 & 343 & 330 & 1 & 12 & 11 & 12 \\
\hline & $P$ & 276 & 267 & 226 & 31 & 10 & 32 & 18 & 247 & 204 & 28 & 15 & 38 & 26 \\
\hline & PP & 1069 & 1313 & 856 & 331 & 125 & 38 & 175 & 1332 & 925 & 238 & 169 & 50 & 337 \\
\hline $\begin{array}{l}\text { Suma ind } \\
\text { Cabralea } \\
\text { canjerana }\end{array}$ & & 4122 & 4857 & 3383 & 1157 & 316 & 217 & 523 & 4838 & 3705 & 705 & 429 & 236 & 916 \\
\hline
\end{tabular}


El número de individuos de las demás categorías disminuyó marcadamente con respecto a la categoría PP. Se registraron 152 individuos/ha de Cabralea canjerana en la categoría P, 166 individuos/ha en la categoría J y 40 individuos/ha en la categoría de AC.

La frecuencia de la categoría J disminuyó levemente en todas las parcelas de 2017 a 2018. Las principales causas fueron por muerte de individuos, y además por pérdidas en la categoría, debido principalmente al quiebre de individuos por caída de árboles (retrocediendo a P o PP), y en menor medida por el paso a la categoría AC. El crecimiento promedio anual (2017-2018) en altura de las $\mathrm{P}$ fue de $11 \mathrm{~cm} / a n ̃ o$ y el crecimiento promedio en diámetro al DAP de las J fue de $3 \mathrm{~mm} / \mathrm{año}$ (Tabla 6.2).

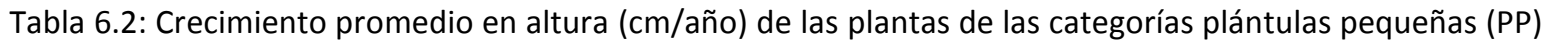
y plántulas (P) y crecimiento en diámetro a la altura del pecho (DAP) (mm/año) de la categoría juvenil (J). Se reporta el desvío estándar (D.E).

\begin{tabular}{ccc}
\hline Categoría & Crecimiento & D.E. \\
\hline J- DAP(mm/año) & 3 & 5,5 \\
P- altura (cm/año) & 11 & 13,5 \\
PP altura (cm/año) & 6 & 7,1 \\
\hline
\end{tabular}

\subsubsection{Distribución espacial de Cabralea canjerana}

La intensidad de la distribución espacial de las plantas de las diferentes categorías fue similar en 3 de las 4 parcelas (en las parcelas 3, 5 y R). El promedio de individuos adultos de todas las especies incluyendo Cabralea canjerana fue de 457 individuos por hectárea ( $\mathrm{N} / \mathrm{ha})$. La distribución espacial de las plantas adultas de todas las especies fue agrupada hasta un radio de 12 metros, aunque con algunas variaciones según la parcela (Tabla 6.3; Figura 6.4). En la parcela 1 se registraron agrupamientos de los individuos adultos entre 6 y 11 metros de distancia. En 3 de las 4 parcelas la distribución espacial de las AC fue agrupada hasta un radio de 10 metros (Figura 6.3). Las categorías P y J, en general también tuvieron una distribución espacial agrupada hasta 18 y 25 metros de radio dependiendo de la parcela (Figura 6.3; Tabla 6.3). El radio de agrupamiento de la categoría J varió según la parcela, entre 15 y 25 metros. 
A
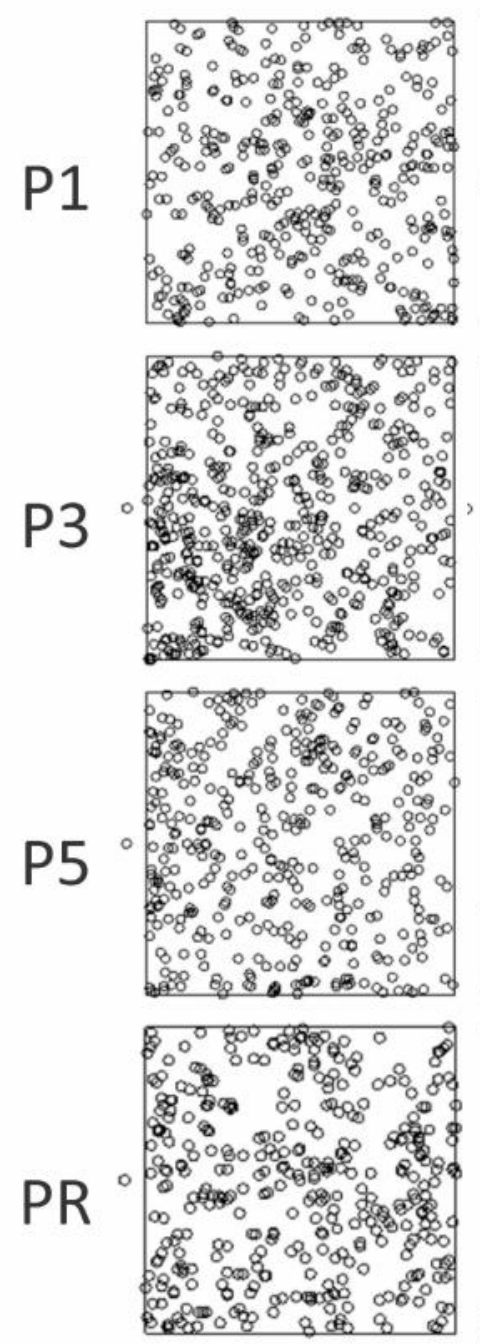

AC
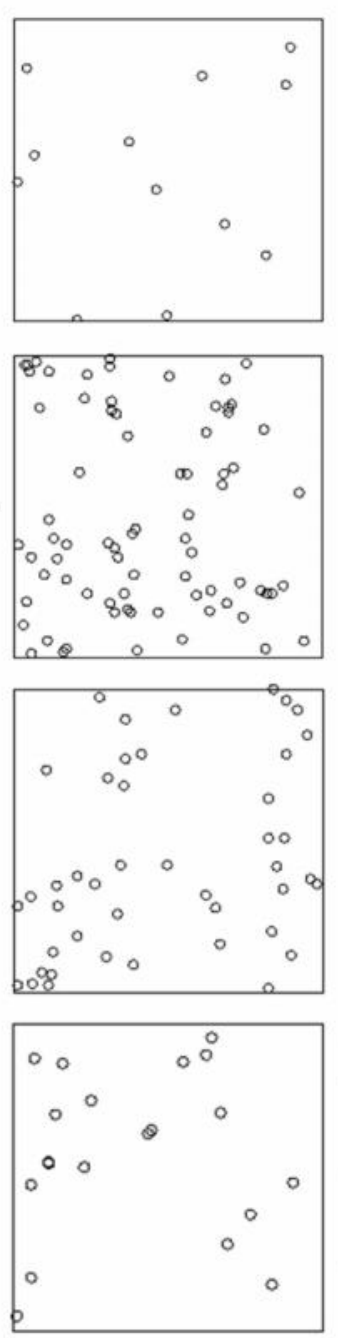

J
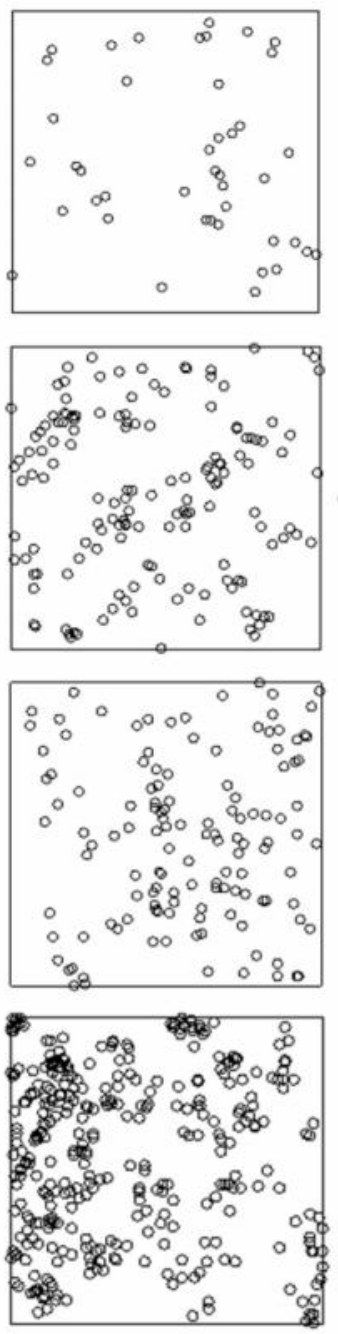

$P$
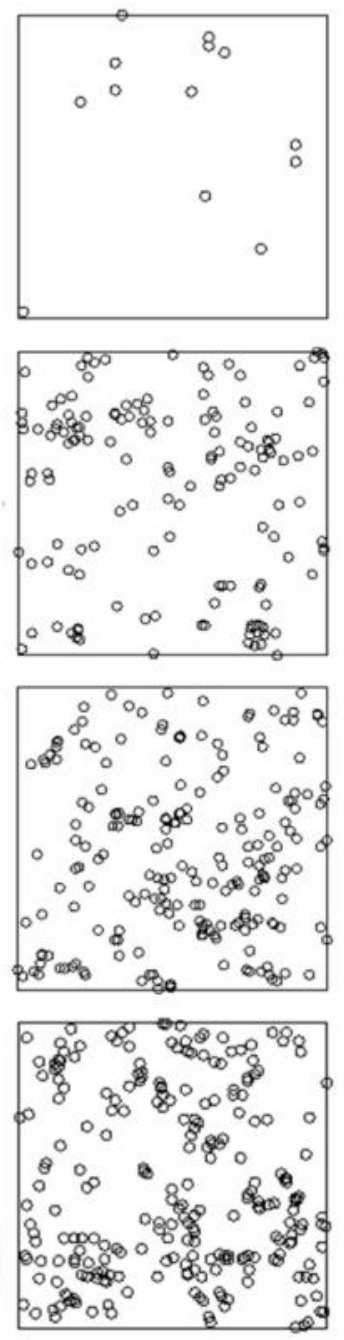

Figura 6.2: Distribución espacial de los individuos de Cabralea canjerana en cada parcela (P 1; P2;P3 y PR) de 1 ha $(100 \times 100 \mathrm{~m})$ para cada categoría (adultos de todas las especies menos Cabralea canjerana (A), Adultas de Cabralea canjerana (AC), Juveniles (J) y Plántulas (P). Cada planta está representada por un círculo. 
Tabla 6.3: Resumen de los resultados de los análisis de patrones espaciales de puntos para cada una de las 4 parcelas (1, 3, 5 y R) y para cada categoría (adultos de todas las especies (A), Adultas de Cabralea canjerana $(A C)$, Juveniles $(J)$ y Plántulas $(P))$. Los análisis se realizaron con la función $K$ de Ripley, con99 simulaciones con bandas de confianza del $95 \%$.

\begin{tabular}{|c|c|c|c|c|}
\hline Parcela\Categoría & A & $A C$ & $\mathrm{~J}$ & $P$ \\
\hline 1 & $\begin{array}{l}\text { Agrupado entre } 6 \\
\text { y } 11 \mathrm{~m} \text {, luego azar }\end{array}$ & Azar & $\begin{array}{l}\text { Agrupado hasta } \\
5 \mathrm{~m} \text {, luego azar }\end{array}$ & Azar \\
\hline 3 & $\begin{array}{l}\text { Agrupado hasta } \\
\qquad 25 \mathrm{~m}\end{array}$ & $\begin{array}{l}\text { Agrupado hasta } \\
10 \mathrm{~m} \text {, luego azar }\end{array}$ & $\begin{array}{l}\text { Agrupado desde } \\
2 \mathrm{~m} \text { hasta } 15 \mathrm{~m}, \\
\text { después azar }\end{array}$ & $\begin{array}{c}\text { Agrupado desde } 2 \\
\mathrm{~m} \text { hasta } 22 \mathrm{~m}\end{array}$ \\
\hline 5 & $\begin{array}{c}\text { Agrupado hasta } 3 \\
\text { m, luego azar }\end{array}$ & Azar & $\begin{array}{c}\text { Agrupado desde } 7 \\
\text { m hasta } 25 \mathrm{~m}\end{array}$ & $\begin{array}{c}\text { Agrupado hasta } \\
18 \text { m, luego al } \\
\text { azar }\end{array}$ \\
\hline $\mathrm{R}$ & $\begin{array}{l}\text { Agrupado hasta } \\
18 \mathrm{~m} \text {, luego azar }\end{array}$ & $\begin{array}{c}\text { Agrupadas hasta } 6 \\
\text { m, luego azar }\end{array}$ & $\begin{array}{l}\text { Agrupado hasta } \\
25 \mathrm{~m}\end{array}$ & $\begin{array}{l}\text { Agrupado hasta } \\
25 \mathrm{~m}\end{array}$ \\
\hline
\end{tabular}
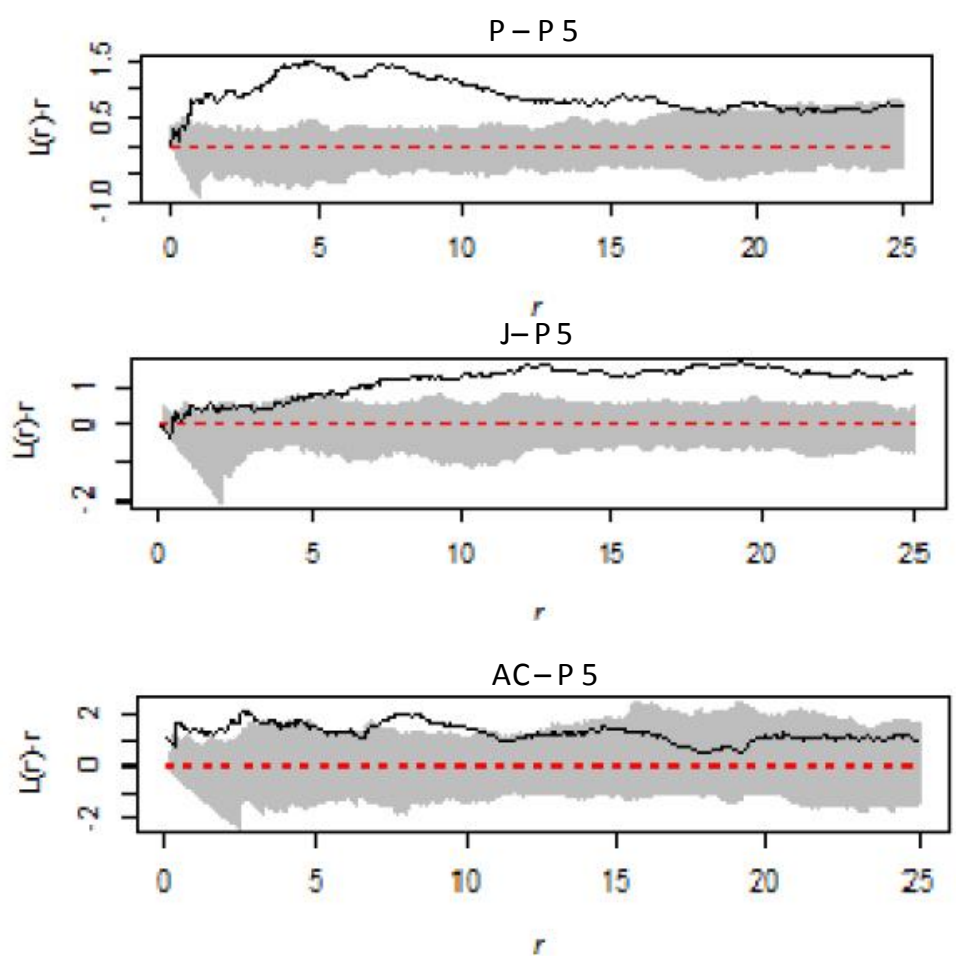

Figura 6.3: Análisis de distribución espacial de las categorías Plántula (P), juvenil $(\mathrm{J})$ de la parcela 5 y Análisis de distribución espacial de las categorías adulto de Cabralea canjerana (AC) de la parcela 3. Se muestran solo estos gráficos a modo de ejemplo. El análisis se realizó con la función $L(r)=(K(r) / \pi)^{1 / 2}$, con un nivel de significancia para los límites de confianza de 95\%, y realizadas con 99 simulaciones Monte Carlos. Esta función permite una visualización más clara de los datos. Línea punteada roja representa la distribución al azar, la línea negra los valores observados para la función y la envuelta gris son las generadas por las simulaciones. 


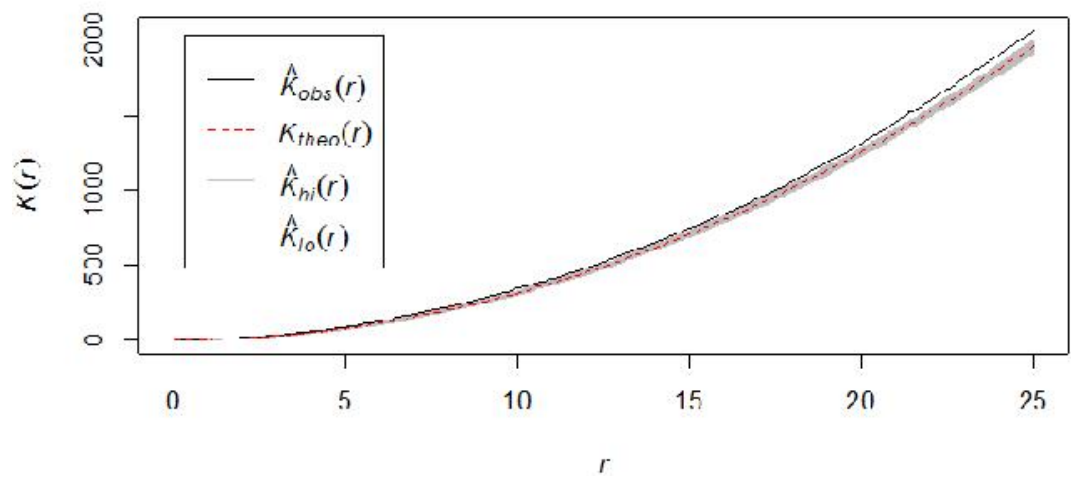

Figura 6.4: Análisis de distribución espacial de la categoría adultos (A) de la parcela 3 con distribución agrupada. El análisis se realizó con la función K de Ripley, con un nivel de significancia para la banda de 95\%, y realizadas con 99 simulaciones Monte Carlos. $\mathrm{K}$ obs $(r)$ valores observados, Ktheo( $r$ ) valor teórico de $\mathrm{K}(\mathrm{r})$ para CSR, Khi (r) y Klo ( $r$ ) son las envueltas por encima y por debajo de las simulaciones para $\mathrm{K}(\mathrm{r})$.

El análisis de la distribución espacial de las 16 subparcelas de la parcela 1 no se realizó debido al bajo número de individuos por subparcela ( $<4$ ind/subparcela) (Tabla 6.4). Por lo tanto se realizaron los análisis en las subparcelas de las parcelas 3, 5 y $\mathrm{R}$ de PP (Figura 6.5). La distribución espacial de las plantas de la categoría PP fue principalmente agrupada hasta aproximadamente 2,5 metros (Figura 6.6), con variaciones en el radio de entre 0,5 y 2,50 metros según la subparcela (Tabla 6.4). Por otro lado, también se registraron subparcelas donde la distribución espacial de los individuos fue al azar, por lo tanto no hay un patrón claro de la distribución (Figura 6.5).

Tabla 6.4: Resumen de las 16 subparcelas de plántulas pequeñas (PP) en las 4 parcelas de 1 hectáreas (1, 3, 5 y R). Se realizó el análisis de las 16 subparcelas en cada una de las hectáreas y se clasificaron los resultados en cantidad de parcelas agrupadas, azar y regular. Además se contabilizaron las subparcelas que no se pudieron analizar debido al bajo número de plantas en la subparcela de 10×10m.

\begin{tabular}{ccccc}
\hline Parcela & $\begin{array}{c}\text { Descartadas por } \\
\text { bajo } n\end{array}$ & Agrupadas & Azar & Regular \\
\hline 1 & 16 & - & - & - \\
3 & 5 & 4 & 6 & 1 \\
5 & 5 & 8 & 3 & 0 \\
R & 3 & 8 & 5 & 0 \\
\hline
\end{tabular}




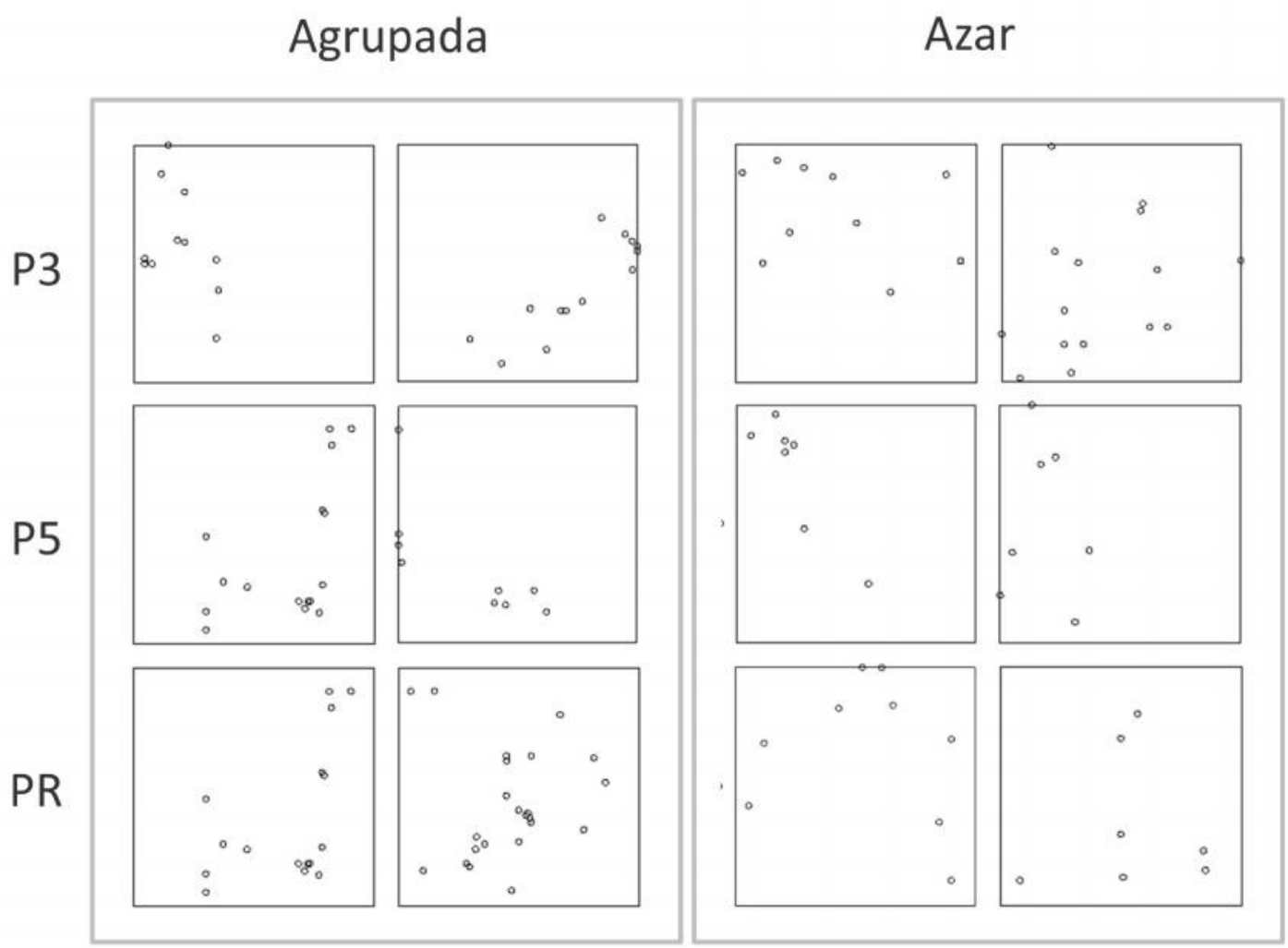

Figura 6.5: Distribución espacial de los individuos de Cabralea canjerana de la categoría plántulas pequeñas (PP) (plantas entre 10 y $50 \mathrm{~cm}$ de altura) en cada subparcela de $10 \times 10 \mathrm{~m}\left(100 \mathrm{~m}^{2}\right)$ para cada parcela (P3, P5 y PR). Se presentan como ejemplo 2 subparcelas con distribución agrupada y 2 con distribución al azar, por cada parcela. La parcela 1 no está representada ya que las subparcelas no tenían un número de plantas suficiente para realizar el análisis.

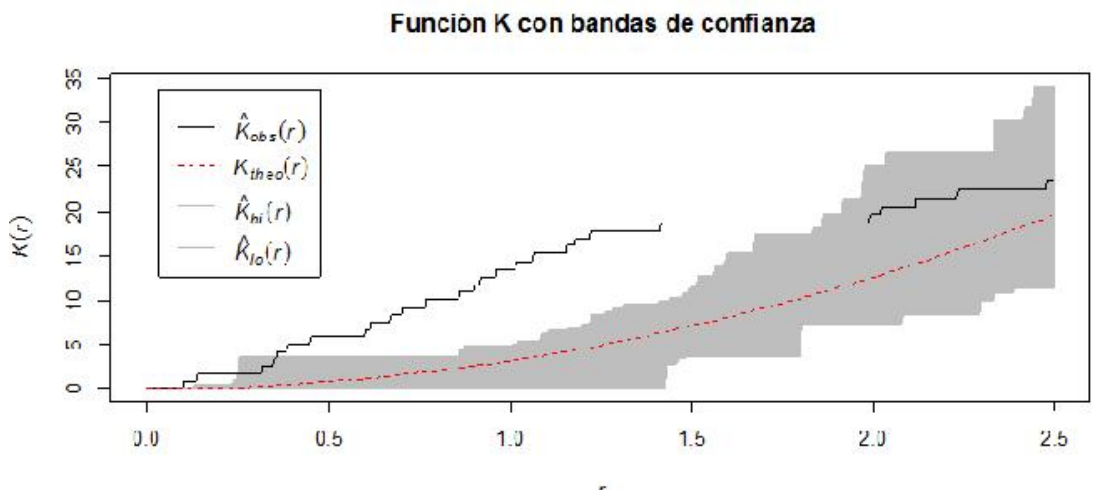

Figura 6.6: Análisis de distribución espacial de la categoría PP de una subparcela de la parcela $\mathrm{R}$ con distribución agrupada. Se presenta solo la parcela $\mathrm{R}$ a modo ilustrativo. El análisis se realizó con la función $\mathrm{K}$ de Ripley, con un nivel de significancia para los límites de confianza de $95 \%$, y realizadas con 19 simulaciones Monte Carlo. Línea punteada roja representa la distribución al azar, la línea negra los valores observados para la función y la envuelta gris son las generadas por las simulaciones. 


\subsubsection{Análisis con función de correlación de marcas}

El análisis de correlación de marcas nos brinda información acerca de cómo se relacionan dos patrones de puntos a los que se les asigna una marca o atributo. La distribución espacial de las plantas de la categoría $\mathrm{P}$ con respecto a las adultas de todas las especies es principalmente al azar, sin embargo en la parcela 5, luego de los $10 \mathrm{~m}$ se repelen (Tabla 6.5; Figura 6.7). En la parcela 3 también se repelen después de los $10 \mathrm{~m}$, pero a diferencia de las anteriores, se registró un agrupamiento entre los 3 y $7 \mathrm{~m}$. Las $P$ con respecto a las $A C$ también presentaron un patrón al azar, con un agrupamiento entre 9 y 11 m en la parcela 5 (Tabla 6.6; Figura 6.8). La relación entre las categorías J y A también fue principalmente al azar, sin embargo, en 2 parcelas se registraron agrupamientos entres los 3 y 16 m (Tabla 6.5). La distribución espacial de las J con respecto a las $A C$ también fue principalmente al azar, aunque en la parcela $R$ se registraron agrupamientos desde los 7 hasta los $25 \mathrm{~m}$ (Tabla 6.6).

Tabla 6.5: Resumen del análisis de las relación entre la distribución espacial de los individuos de Cabralea canjerana de la categoría plántulas $(\mathrm{P})$ con respecto a los adultos $(\mathrm{A})$ y de los individuos de la categoría juvenil (J) con respecto a los A, para cada parcela (parcela 1, 3, 5 y R).

\begin{tabular}{ccc}
\hline & P y & J y $A$ \\
\hline 1 & Azar & Azar \\
3 & $\begin{array}{c}\text { Agrupado entre } 3 \text { y } 7 \text { metros, } \\
\text { luego de } 10 \mathrm{~m} \text { se repelen }\end{array}$ & $\begin{array}{c}\text { Agrupado entre } 3 \text { y } 13 \mathrm{~m} \text {, luego } \\
\text { azar }\end{array}$ \\
5 & Azar hasta $10 \mathrm{~m}$, luego repelen & Azar hasta $6 \mathrm{~m}$, luego repelen \\
$\mathrm{R}$ & Repelen hasta $2 \mathrm{~m}$, luego azar & $\begin{array}{c}\text { Agrupado entre } 3 \text { y } 16 \mathrm{~m} \text {, luego } \\
\text { azar }\end{array}$ \\
\hline
\end{tabular}




\section{J y $A$}

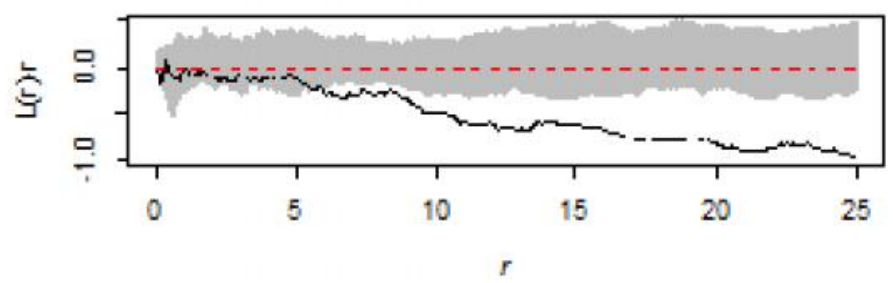

Py $A$

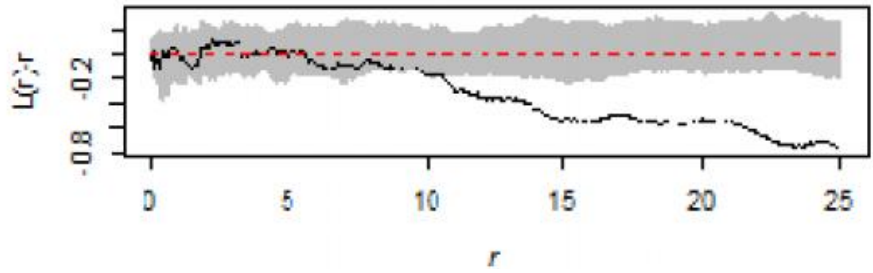

Figura 6.7: Análisis de distribución espacial de la categoría juvenil (J) con respecto a las (A), y análisis de la distribución espacial de la categoría plántula $(P)$ con respecto a las adultas $(A)$. El análisis se realizó con la función $L(r)=(K(r) / \pi) 1 / 2$, con un nivel de significancia para la banda de $95 \%$, y realizadas con 99 simulaciones Monte Carlo. Línea punteada roja representa la distribución al azar, la línea negra los valores observados para la función y la envuelta gris son las generadas por las simulaciones.

Tabla 6.6: Resumen del análisis de las relación entre la distribución espacial de los individuos de Cabralea canjerana de la categoría plántulas (P) con respecto a los adultos de Cabralea canjerana (AC) y de los individuos de la categoría juvenil (J) con respecto a los AC, para cada parcela (parcela 1, 3, 5 y R).

\begin{tabular}{ccc}
\hline & P con AC & J con AC \\
\hline 1 & Azar & Azar \\
& Azar & $\begin{array}{c}\text { Agrupado a los } 2 \text { metros, luego } \\
\text { azar }\end{array}$ \\
5 & Agrupado entre 9 y $11 \mathrm{~m}$ & Regular entre 2 y 4 metros, luego \\
& azar
\end{tabular}




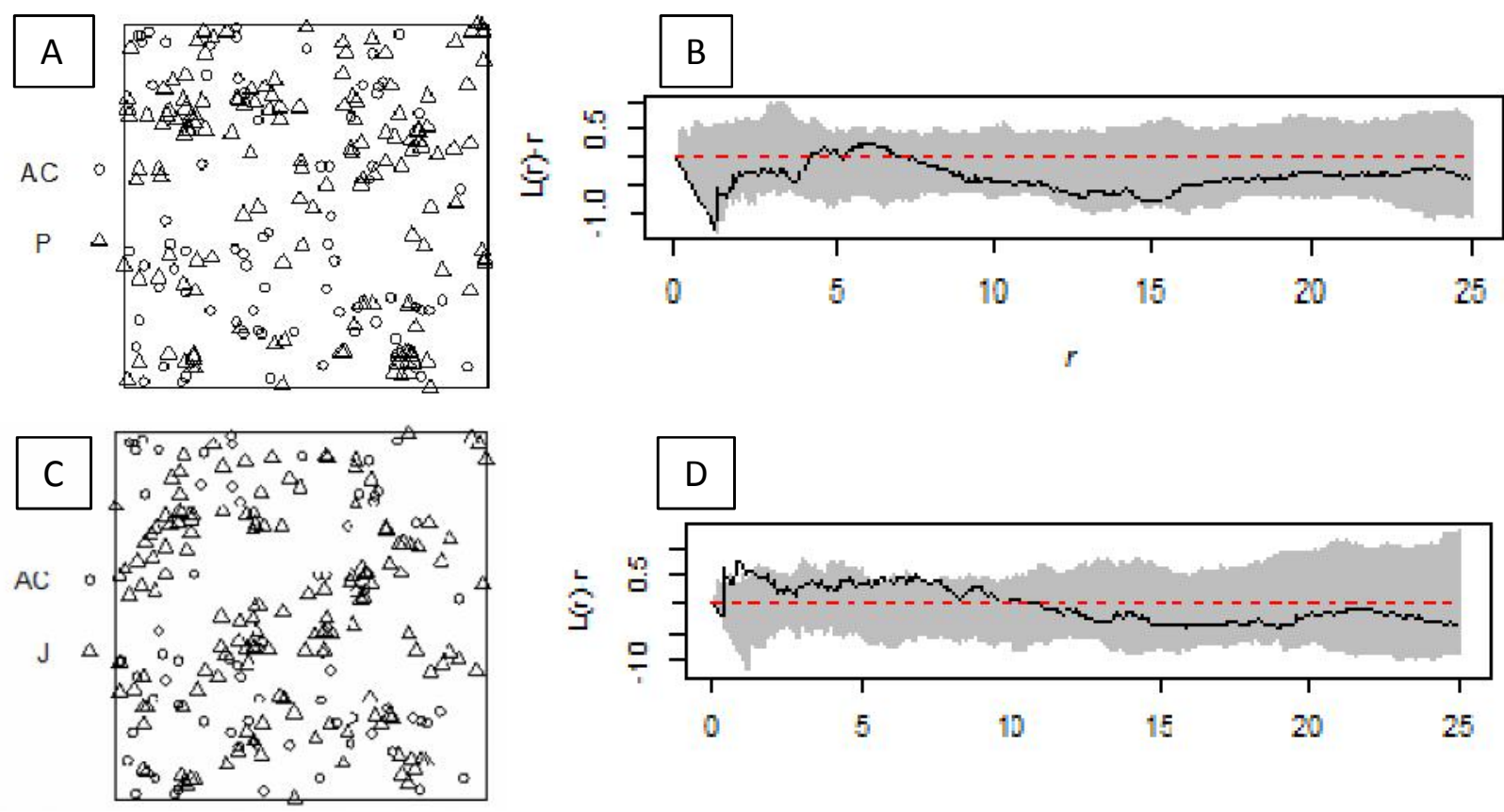

Figura 6.8: Distribución espacial de los individuos de las categorías adulto de Cabralea canjerana (AC) (círculos),y plántula (P) (triángulos) (A); Adultos de Cabralea canjerana (AC) (círculos) y juvenil (J) (triángulos) (C),en la parcela 3 (superficie $100 \times 100 \mathrm{~m}$ ). Se muestran solo los graficos de la parcela 3 a modo de ejemplo. Análisis de distribución espacial de la categoría juvenil (P) con respecto a la de $A C$ (B) y análisis de la distribución espacial de la categoría J con respecto a la $A C(D)$. El análisis se realizó con la función $L(r)=(K$ $(\mathrm{r}) / \pi) 1 / 2$, con un nivel de significancia para la banda de $95 \%$, y realizadas con 99 simulaciones Monte Carlo. Esta función permite una visualización más clara de los datos. Línea punteada roja representa la distribución al azar, la línea negra los valores observados para la función y la envuelta gris son las generadas por las simulaciones.

\subsection{Discusión}

Actualmente la gran mayoría de los bosques subtropicales, son bosques secundarios constituidos principalmente por especies secundarias con rasgos funcionales propios de especies tempranas y tardías y heliófitas de rápido crecimiento. Para poder establecer pautas de manejo de estos bosques y propiciar su conservación, es necesario conocer la estructura y la dinámica del desarrollo de las especies (Caldato et al. 2003). Sin embargo, la gran mayoría de la información encontrada sobre la distribución de las especies está centrada en bosques tropicales y templados (Forget et al. 1999; Franklin y Rey 2007).

En los sucesivos relevamientos realizados, se registró un aumento del número promedio de individuos por hectárea (Tabla 6.1). En otro trabajo de tesis que evaluó la dinámica de 
distribución de Cabralea canjerana también se registró un aumento en el número de individuos en el tiempo (Schussler 2006). El aumento en el número de individuos de Cabralea canjerana podría deberse a la alta disponibilidad de semillas, a la acción de los agentes dispersores, principalmente hormigas y aves y posiblemente, a la alta plasticidad fenotípica de la especie, que tiene la capacidad de germinar y establecerse en el sotobosque (capítulos anteriores) (Schussler 2006). También puede estar evidenciando que los disturbios que se han producido son benificiosos para el establecimiento de la regeneración de esta especie. Desde este punto de vista, que hayamos relevado que las plantas pueden sobrevivir hasta 4 años debajo del canopeo denso, sin cambio en la altura (Capítulo 5), nos indica que en la categoría menor (de 10 a $50 \mathrm{~cm}$ de altura) se pueden acumular individuos que germinaron durante 4 años, y que no promueven de categoría por falta de luz. Esto nos indicaría que los grupos de PP pueden haberse generado en varios años diferentes, y que incluso en un mismo grupo de regeneración, plantas de altura similar pueden pertenecer a diferentes cohortes.

La dinámica de la regeneración en la selva se caracteriza por tener una distribución de los individuos como una función de J invertida constituyendo poblaciones disetáneas. Esta distribución representa una gran abundancia de individuos de menor tamaño, generalmente de menor edad, que disminuye a medida que crecen y pasan a las categorías de mayor tamaño. La regeneración ocurre continuamente, sin una fase de comienzo y finalización, por lo que la dinámica demográfica con incorporaciones y cambios de una categoría a otra es característica de los bosques subtropicales (Lamprecht 1990). La distribución por clase de alturas de Cabralea canjerana se comportó como una J invertida. Además, se registró una fuerte caída en el número de individuos hacia las clases de mayor altura, lo que podría deberse a que ocurre una alta tasa de mortalidad inicial de la especie. Estas elevadas tasas de mortalidad de la regeneración inicial podría ser característica de la especie y de la dinámica de desarrollo, lo cual resulta un patrón característico de rodales naturales (Oliver y Larson 1996). Sin embargo, dada la capacidad de respuesta al cambio abrupto de cobertura que hemos descripto en el Capítulo 4, la mortalidad podría disminuirse con el manejo de la competencia, ya sea controlando especies del sotobosque, como de los estratos intermedios y superiores. De esta manera podría propiciarse que más individuos que regeneran espontáneamente, lleguen a las clases de altura superiores, si bien son necesarios estudios adicionales para corroborar estas ideas propuestas.

En el capítulo anterior las plantas de Cabralea canjerana que crecieron con baja disponibilidad de luz tuvieron la mayor mortalidad con respecto a los individuos que crecieron en 
condiciones de mayor disponibilidad de luz. Sin embargo, algunos individuos sobrevivieron al menos 4 años, aunque prácticamente sin crecimiento. El microclima generado en el sotobosque de las parcelas está condicionado por la estructura vertical del bosque, conformada por el dosel superior, el intermedio y las especies propias del sotobosque. A su vez estos estratos están constituidos por una gran diversidad de especies que conviven y compiten por los recursos. Sin embargo, los sitios donde se presenta la regeneración está influenciado por la presencia de árboles semilleros y la actividad de los dispersores. Los individuos de la categoría plántulas pequeñas (PP) tuvieron principalmente una distribución espacial agrupada desde 0,5 hasta 2,5 metros de radio, aunque en algunas parcelas se distribuyeron al azar. Si bien la asociación con los árboles adultos no se pudo evaluar para la categoría PP, la gran abundancia de árboles adultos de todas las especies y la distribución agrupada entre PP, podría explicar en parte la gran mortalidad registrada en esta categoría (Tabla 6.1). La gran densidad de copas de los individuos adultos reduce la llegada de luz al sotobosque, que podría causar en algunos años la muerte de las plántulas por estrés lumínico por déficit de luz. Es importante remarcar que el experimento de plantación en claros presentado en el Capítulo 5, nos permitió corroborar que los individuos plantados en microambientes con cobertura $<5$ moles $\mathrm{m}^{-2}$ día ${ }^{-1}$ sobrevivieron al menos $3 \frac{1}{2}$ años sin crecimiento en altura, con un elevado \% de mortalidad comparado con los otros niveles de cobertura. En el relevamiento de regeneración natural presentado en este capítulo no podemos definir la edad de los individuos PP. Por lo tanto, posiblemente gran parte de la mortalidad de individuos de estas categorías ocurrió por el agotamiento de las reservas en tallos y raíces, similar a lo observado en el ensayo de plantación en claros (Capítulo 5). Por otro lado, los grupos de regeneración (PP) están expuestos a diversos factores bióticos y abióticos que podrían causar la mortalidad, por ejemplo la presencia de hongos $u$ otros enemigos naturales que afecten a los grupos de regeneración (Lüttge 2008). Por lo general, los individuos que regeneran cerca de los árboles adultos son propensos a ser atacados por agentes patógenos específicos que causan la muerte de los individuos de la misma especie, y propiciando indirectamente la presencia de individuos de otras especies. Esto podría explicar en parte la gran coexistencia de especies en las selvas tropicales (Comita et al. 2014; Norden 2014). Otras causas que podría explicar la muerte de los individuos en la categoría PP son la ocurrencia de pequeños disturbios que causen la muerte de grupos de plantas (Oliver y Larson 1996), como la caída de porciones de las copas de los árboles, o incluso de árboles completos, tal como hemos observado en las parcelas relevadas. 
La distribución espacial de los individuos de Cabralea canjerana de las categorías P y J, también fue agrupada. Se registraron agrupamientos de hasta 18 y 25 metros de radio. En otro estudio con Cabralea canjerana y otras especies nativas de Misiones, también se reportaron agrupamiento en la categoría J de la regeneración, hasta 22 metros en Cabralea canjerana y 15 metros en las demás especies (Pinazo et al. 2009b). Los agrupamientos reportados para Cabralea canjerana y las demas especies, estuvieron asociado a los agentes dispersores de semillas. En otro estudio con Ocotea puberula (Nees et Mart.) Nees, también se observaron patrones de distribución agrupados, para categorías similares a las categorías P y J de esta tesis. En el trabajo con $O$. puberula la causa de la distribución se asoció principalmente a los requerimientos de mayores cantidades de luz asociado a claros en el bosque (Caldato et al. 2003). Por otro lado, varias especies de la selva nublada en canarias tuvieron patrones de regeneración agrupados en una categoría equivalente a J, tanto en especies pioneras como intermedias, o persistentes con semillas pequeñas, medianas o grandes (Ganivet et al. 2019). Estos resultados indican que el agrupamiento de la regeneración es habitual en especies tropicales, posiblemente por diferentes motivos. En nuestro caso, como conocemos las características ecofisiológicas de la especie, suponemos que la categoría J y P muestran una distribución agrupada que estaría asociada a los sitios de mayor llegada de luz (aperturas de dosel), dado que estas categorías de tamaño requieren niveles de radiación más altos que los que llegan bajo el dosel cerrado. Por lo tanto, la distribución principalmente agrupada de las plántulas pequeñas (Tabla 6.4) genera que las plántulas también se encuentren agrupadas (Tabla 6.3). Dado que las plántulas no se asocian positivamente con los adultos de Cabralea canjerana (Tabla 6.6), es evidente que la germinación se produce agrupada, posiblemente producto de la acción de los dispersores, relativamente lejos de los árboles semilleros. Esos agrupamientos de regeneración sobreviven como grupos hasta la etapa de juveniles, por lo tanto las condiciones dentro del grupo serían mejores para la supervivencia que fuera del grupo. Si la mortalidad dentro de los grupos fuera elevada, la distribución de las plántulas y juveniles debería tender a ser al azar o regular. Conociendo los resultados de los ensayos de plantación en los claros, es posible que estos grupos de regeneración estén ubicados en sitios con estratos intermedios no arbóreos menos densos, ya que no hay una clara repulsión con los adultos que conforman los estratos arbóreos (Tabla 6.5) que son los que condicionan la cobertura del dosel superior. Con estos resultados se torna evidente que es fundamental relevar los estratos intermedios y bajos en las evaluaciones de la regeneración natural. 
La distribución espacial de los individuos adultos de Cabralea canjerana tuvo una distribución agrupada hasta 10 metros en 2 parcelas ( 3 y R) y al azar en las otras 2 parcelas ( 1 y 5 ) (Tabla 6.3). Estas variaciones en las distribución espacial entre parcelas podría deberse a la dinámica propia de los rodales, a la presencia de árboles semilleros, a la presencia de dispersores, entre otros factores. En otro estudio con una especie de la selva misionera también se registró una distribución al azar de los individuos adultos (Pinazo et al. 2009a). Este cambio en el patrón de distribución cuando los individuos crecen, es característico de la dinámica de los rodales, ya que, los procesos competitivos entre individuos de todas las especies se acentúa con el aumento de los tamaños y por la menor disponibilidad de recursos. Esta competencia produce la muerte de los individuos que tengan menor capacidad competitiva. Estas muertes generan nuevos espacios de crecimientos que son aprovechados por las especies que ganaron la competencia (Oliver y Larson 1996).

En resumen, la distribución espacial de cada categoría ( $P P, P, J$ y $A C$ ) fue generalmente agrupada en alguna distancia, aunque se registraron variaciones entre parcelas para cada categoría. La distribución espacial agrupada es característica de la dinámica natural en selvas tropicales y subtropicales debido principalmente a la dispersión (Condit et al. 2000; Caldato et al. 2003; Pinazo et al. 2009b). Las hormigas y las aves juegan un papel importante como agentes dispersores y facilitadores de la germinación de Cabralea canjerana. Las plántulas pequeñas (PP) se agruparon principalmente entre 0,5 y 2,5 metros de radio (Tabla 6.4), al pasar a la categoría siguiente (P) la densidad de individuos disminuyó notablemente y la distribución de los individuos continuó siendo agrupada (Tabla 6.3). Posiblemente las plantas que sobreviven y pasan a la siguiente categoría estén ubicadas, dentro del grupo, en sitios con mayor disponibilidad de luz. Esto podría respaldarse en la distribución mayormente al azar de los individuos de la categoría P con respecto a las plantas adultas de Cabralea canjerana (AC) y adultas de las demás especies (A), ya que, al no estar cerca de los adultos podrían estar establecidos en microclimas más favorables para su crecimiento (Tabla 6.5; Tabla 6.6). Las plantas de la categoría $P$ también sobreviven con un patrón de distribución agrupado (entre 2 y 25 metros en la mayoría de las parcelas), que se evidencia en el agrupamiento registrado en la categoría siguiente (J). Las plantas de la categoría J también se encuentran agrupadas, sin embargo, ocurre una disminución en el número promedio de individuos al pasar a la categoría siguiente (AC) (de 167 ind/ha en J a 40 ind/ha en AC). La competencia por espacios de crecimiento y recursos, se incrementa entre los individuos más grandes (Oliver y Larson 1996). Posiblemente la competencia entre Cabralea canjerana y las otras 
especies del estrato superior se incremente produciéndose la muerte de algunos individuos juveniles de Cabralea canjerana, y por tanto se reduce su densidad poblacional.

El patrón de distribución de Cabralea canjerana en los rodales evaluados fue cambiando en las diferentes categorías de plantas. Iniciamente se produce una abundante regeneración principalmente agrupada, luego se produce una alta mortalidad de individuos pequeños (PP) y se reduce el número de individuos por hectárea, y la distribución espacial en las próximas categorías ( $\mathrm{P}$ y J) sigue siendo agrupada. Por último, ocurre otra disminución de la densidad poblacional al pasar de la categoría J a AC. La dinámica de rodal que se registró en este trabajo, es caracteristica para rodales multietáneos y multiespecificos descriptos en la teoría de dinámica de rodales (Oliver y Larson 1996). Una vez que se generan claros o aperturas en bosques tropicales y subtropicales, son recolonizados por la vegetación, con una composición florística que dependerá de una variedad de factores como la diversidad de la vegetación adyacente, la edad de la comunidad cercana, el clima lumínico, la disponibilidad de propágulos, el banco se semillas y plántulas, las posibilidades de dispersión, las diferencias de tasas de mortalidad y supervivencia entre especies con diferente plasticidad fenotípica en la partición de carbono y uso de los recursos del suelo. Considerando todos los factores que intervienen en la diversidad florística del bosque, es claro que pequeñas diferencias en las condiciones iniciales en las áreas disturbadas, pueden tener marcado impacto en el desarrollo posterior de la estructura del bosque (Lüttge 2008). La corroboración del patrón de distribución de la regeneración, unido al conocimiento exhaustivo de los requerimientos de la especie y su tolerancia a estreses por exceso o falta de luz, y déficit hídrico dan herramientas suficientes para proponer prácticas de manejo de Cabralea canjerana en el bosque nativo, que se discutirán en el capítulo final.

\subsection{Conclusiones}

La regeneración de plántulas pequeñas de entre 10 y $50 \mathrm{~cm}$ de altura de Cabralea canjerana se establece inicialmente principalmente agrupada, y permanece en el sotobosque sombreado por varios años sin promover a categorías mayores. En el Capítulo 5 se observó que las plantas se establecen y permanecen en el sotobosque hasta por lo menos 3 años en sitios con alta cobertura, y en este Capítulo se corrobora que algunos individuos sobreviven al menos 3 años sin pasar de categoría. Luego en las categorías plántulas (de 50 a $130 \mathrm{~cm}$ de altura) y juveniles $(0<\mathrm{DAP}<10 \mathrm{~cm})$ se produce una disminución del número de individuos. Las plantas de la categoría 
plántulas y juveniles también están agrupadas. Es importante destacar que los grupos de regeneración sobreviven y que la baja en el número de individuos en las categorías de mayor altura se produce por la muerte de algunos individuos en los grupos, mientras que otros individuos sobreviven y crecen. Esto refuerza la idea de que cambios microambientales sutiles condicionan la supervivencia dentro de los grupos de regeneración, posiblemente debido a la gran plasticidad fenotípica de la especie, que facilita que los individuos se aclimaten y obtengan los recursos necesarios en respuesta a cambios dinámicos en la cobertura del dosel y del sotobosque.

El avance en el conocimiento de esta dinámica natural de la regeneración y su desarrollo hacia estructuras maduras permitirá aplicar prácticas silviculturales que tiendan a acelerar los procesos de establecimiento de rodales enriquecidos con Cabralea canjerana.

\subsection{Contrastación de hipótesis}

\section{Hipótesis}

La regeneración está relacionada con la presencia de árboles adultos conespecíficos, pero la supervivencia y crecimiento se relacionará con el grado de cobertura del dosel: las plantas requieren dosel protector los dos primeros años de vida y mayor disponibilidad de luz los años subsiguientes.

\section{Predicciones}

1. Hay mayor densidad de individuos de entre 10 y $50 \mathrm{~cm}$ de altura de Cabralea canjerana cerca de los árboles adultos conespecíficos, ya que son los generadores de semillas y probablemente las semillas caen cerca de los árboles semilleros.

La predicción no se cumple. La regeneración de los individuos de Cabralea canjerana se distribuye al azar con respecto a los AC. Esto sugeriría que los dispersores juegan un rol importante en la distribución espacial de la regeneración.

2. Las plantas entre 50 y $130 \mathrm{~cm}$ de altura estarán asociadas a árboles adultos de cualquier especie, porque su supervivencia requiere cobertura del dosel de cualquier especie.

Esta predicción no se cumple. Si bien la regeneración de la categorías plántulas y juveniles es agrupada, no están asociadas positivamente con los árboles adultos. Por lo tanto, la regeneración 


\section{Ana Paula Moretti - Tesis doctoral 2019}

de más de $50 \mathrm{~cm}$ de altura no requiere ni es afectada negativamente por la cobertura del dosel superior.

3. La supervivencia de la las plantas mayores a $130 \mathrm{~cm}$ de altura es mayor en zonas más alejadas de árboles de gran porte, porque a partir de esa altura, las plantas requieren más luz.

Esta predicción no se cumple, dado que no se observó repulsión entre los juveniles y los adultos. Esto indica que condiciones microambientales en menor escala condicionan la supervivencia y crecimiento de los individuos dentro de los grupos. 


\section{Capítulo 7: Consideraciones finales}

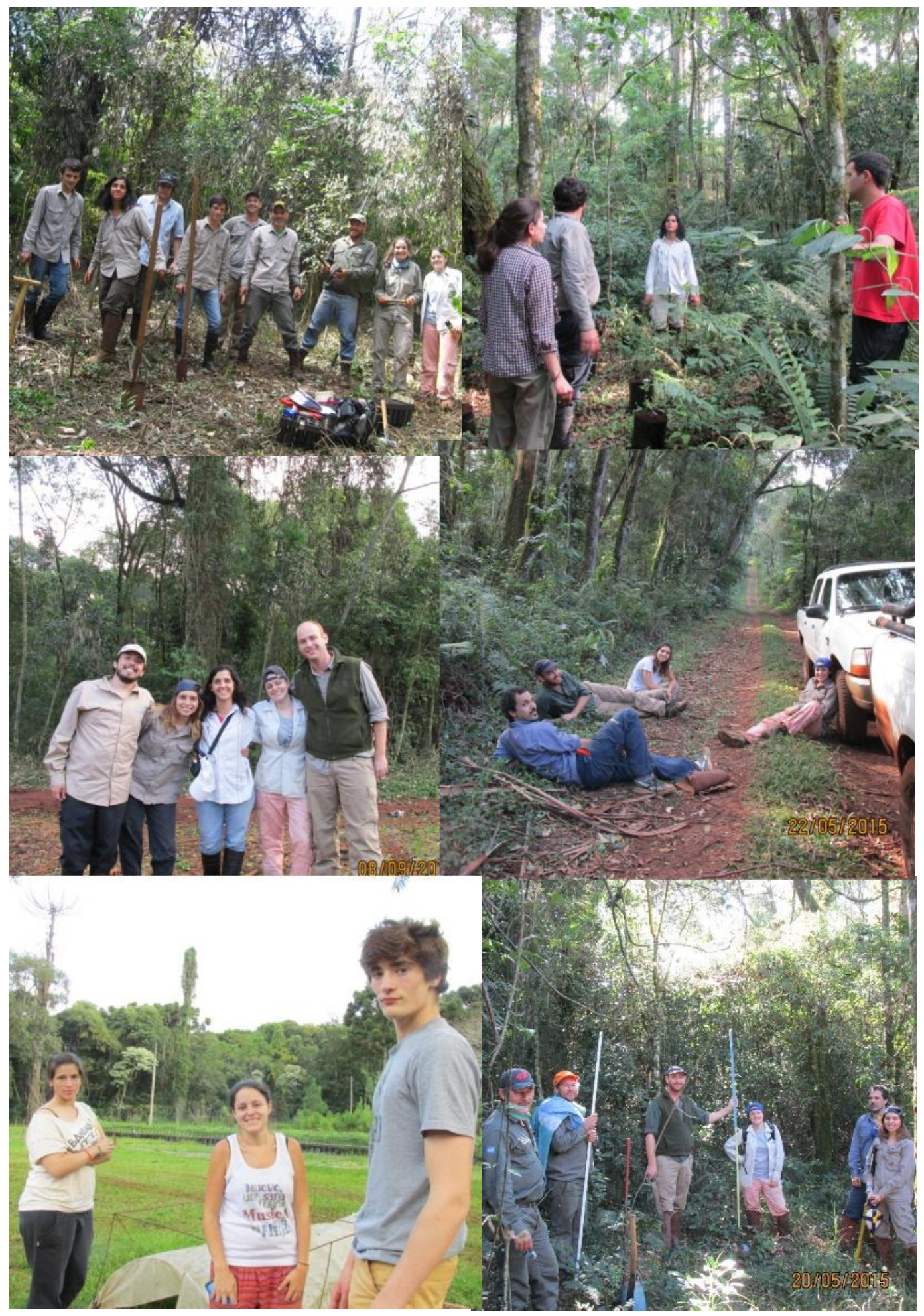




\subsection{Conclusiones finales}

La gran mayoría de los bosques en Argentina presentan un alto nivel de degradación y fragmentación debido principalmente a las acciones del hombre. La restauración ecológica es una práctica importante a la hora de recuperar estas áreas. Sin embargo, la escasa información acerca de los requerimientos de las especies y de su plasticidad fenotípica, muchas veces tornan difícil la propuesta de prácticas silviculturales que aseguren el cumplimiento de los objetivos de manejo. La evaluación y entendimiento de los mecanismos que ponen en juego las plantas para sobrevivir y crecer en un sitio determinado son fundamentales para llevar adelante la restauración de los ambientes, ya que esta información permite planificar mejor la plantación y garantizar el establecimiento de individuos de determinada especie.

Cabralea canjerana es una especie de la selva misionera de alto valor ecológico y económico que se establece y crece en el sotobosque. Sin embargo, durante el establecimiento sufre una alta tasa de mortalidad, posiblemente debida a la falta de luz. La regeneración de la especie, considerada como aquellos individuos menores a $10 \mathrm{~cm}$ de DAP, es agrupada, posiblemente por a la acción de los agentes dispersores. Sin embargo, pocos individuos llegan a adultos. Si bien no se evaluaron las causas, posiblemente sea debido a la combinación de factores bióticos y abióticos, como caída de árboles, patógenos, enemigos naturales, falta de luz, competencia, entre otros. Es importante destacar que todas las categorías de regeneración permanecen agrupadas, por lo tanto la heterogeneidad ambiental dentro de los grupos de regeneración posiblemente condiciona la supervivencia de los individuos dentro de los grupos.

Según los resultados de esta tesis, Cabralea canjerana es una especie intermedia en cuanto a los requerimientos de luz o parcialmente tolerante a la sombra, ya que sobrevive en el sotobosque por al menor 3 años luego del transplante, pero luego de un año de plantadas en los claros necesitan mayor cantidad de luz para crecer, ya que se registraron los mayores crecimientos con luz > 15 moles $\mathrm{m}^{-2} \mathrm{dia}^{-1}$. Por otro lado, Cabralea canjerana se establece y crece a sol pleno, pero las plantas se podrían ser afectadas por las bajas temperaturas del invierno durante la etapa inicial de establecimiento. En este trabajo se observó que las bajas temperaturas del primer invierno, luego del transplante, afectaron las plantas que crecieron a sol pleno, causando la muerte de la parte aérea. Sin embargo, presentaron una gran capacidad de rebrote durante la temporada siguiente. Las plantas que se establecieron en diferentes microambientes generados 
por los claros no fueron afectadas durante el invierno, lo que indica que el efecto amortiguador del claro es suficiente para evitar la muerte de la parte aérea de las plantas por las bajas temperaturas. Las plantas de Cabralea canjerana que crecieron a sol pleno sufrieron un estrés moderado por déficit de agua y exceso de luz. Sin embargo, los mecanismos de aclimatación puestos en juego le permitieron crecer más en peso seco que bajo canopeo denso. Por lo tanto la especie es más exitosa en sobreponerse al estrés por exceso de luz y déficit hídrico que por déficit de luz.

Cabralea canjerana es una especie con una elevada plasticidad fenotípica. En pocos meses modifica su morfología, fisiología y arquitectura hidráulica para aclimatarse a ambientes contrastantes de cobertura (sol y canopeo) y al cambio abrupto de cobertura. Los microclimas generados en los claros del bosque nativo, principalmente donde la disponibilidad de luz fue mayor, favorecieron el crecimiento y el estado fisiológico de las plantas. En estos sitios las plantas encuentran un ambiente propicio para su crecimiento, que llegan en 4 años a más de 3 metros de altura, con un buen estado general.

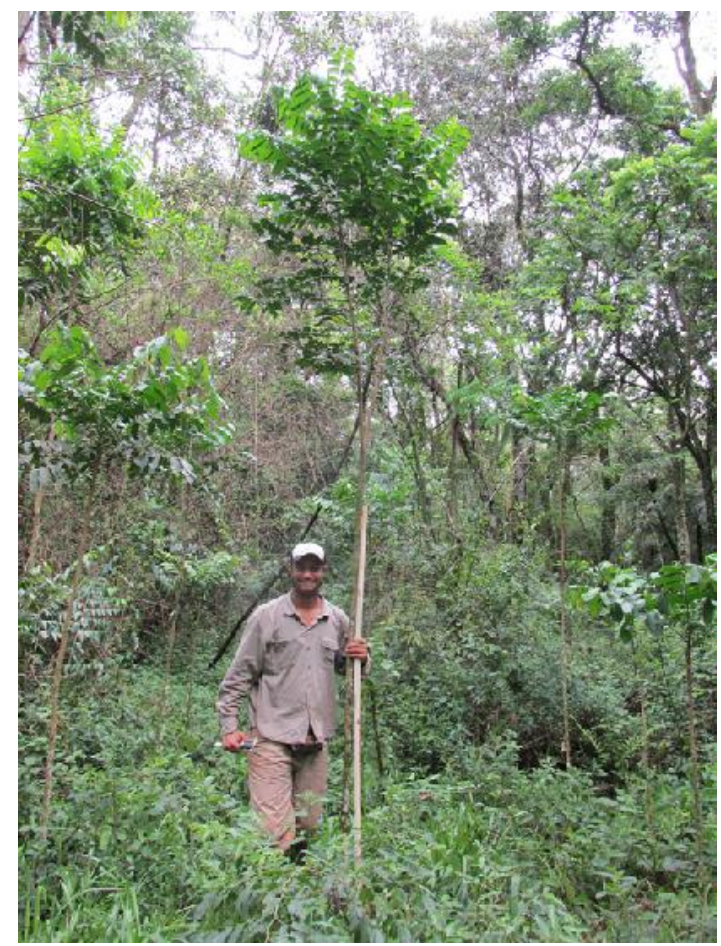

Figura 1: Cabralea canjerana plantada en el centro de un claro, 4 años luego de la plantación. 


\subsection{Recomendaciones de manejo y silvicultura}

La regeneración natural de Cabralea canjerana requiere la presencia de árboles semilleros, que provean semillas, pero su distribución está relacionada a la actividad de los dispersores. Por lo tanto es importante mantener la conectividad del paisaje con existencia de árboles padres y una adecuada estructura y funcionalidad del bosque para asegurar la presencia de los agentes dispersores de semillas.

A nivel de rodal, sería ideal contar con árboles maduros de Cabralea canjerana para asegurar el aporte de suficientes semillas para lograr una regeneración adecuada de la especie. Además, adultos de otras especies pueden actuar de cobertura en las primeras etapas de la regeneración, hasta que los individuos lleguen a la adultez (más de $10 \mathrm{~cm}$ de DAP). Los individuos del dosel superior no afectan el crecimiento de plántulas y juveniles, ya que los grupos de regeneración no se repelen de los árboles adultos (Capítulo 6). Sin embargo, en base a los resultados de plantación en los claros, se puede establecer que una corta de mejora de estratos medios o bajos podría generar las condiciones para el crecimiento de los individuos de más de 50 $\mathrm{cm}$ de altura. En este caso, más que el manejo del dosel superior, debe evaluarse la posibilidad de ralear individuos de los estratos medios y bajos, para disminuir la competencia densodependiente interespecífica. La vegetación de los estratos intermedios e inferiores son los que producen la mayor intercepción de luz (luz incidente $<5$ moles $\mathrm{m}^{-2}$ día ${ }^{-1}$ ), tal como se observó en el ensayo de plantación en los claros.

Las plántulas se establecen en el suelo forestal, sin embargo sufren una gran mortalidad en dos periodos importantes. Primero, las plántulas pequeñas entre 10 y $50 \mathrm{~cm}$ de altura y segundo cuando las plantas pasan a la etapa adulta (más de $10 \mathrm{~cm}$ de DAP). Para favorecer el establecimiento de las plantas y aumentar la supervivencia en la primera etapa de establecimiento, se podrían generar pequeños claros y una limpieza del sotobosque cada 3 años, para garantizar el crecimiento de las plantas que sobreviven aún debajo del canopeo denso. Esta práctica sería posible ya que Cabralea canjerana tiene la capacidad de soportar un cambio abrupto de la cobertura, y además responde al crecimiento cuando se genera una mayor disponibilidad de luz. En consecuencia, prácticas de manejo como la liberación de las plantas del sotobosque serían de utilidad para propiciar el crecimiento de las plantas de categorías más pequeñas para que lleguen al dosel superior. Una cobertura de 90\% como máximo permite el crecimiento de Cabralea canjerana, aunque el mejor crecimiento se logrará con coberturas no mayores a $75 \%$. 
Si se plantea el enriquecimiento del bosque mediante la plantación de individuos producidos en vivero, deben elegirse los sitios con por lo menos un $50 \%$ de luz con respecto a un área abierta, o garantizar esa disponibilidad de luz durante los tres años posteriores a la plantación.

\subsection{Aportes de la tesis para futuros trabajos}

En cuanto al conocimiento de la especie, esta Tesis permitió definir que Cabralea canjerana es una especie con una alta plasticidad fenotípica; en 3 meses activó los mecanismos de respuesta mediante cambios morfológicos y fisiológicos para aclimatarse a condiciones de cobertura contrastantes y al cambio en la cobertura.

Las plantas de Cabralea canjerana a bajas irradiancias sufren un estrés severo por déficit de luz luego de 1 1/2 años de instaladas las plantas, sin embargo ponen en juego mecanismos de aclimatación para sobrevivir por al menos $3 \frac{1}{2}$ años. Esta información es importante para definir frecuencia de intervención en caso que se quiera controlar la vegetación del sotobosque para estimular su crecimiento.

Cabralea canjerana es una especie que a sol pleno puede ser afectada por las temperaturas bajo cero del invierno. Es por esto que durante las primeras etapas de crecimiento las plantas necesitan protección contra el frío. Sin embargo, tiene una alta capacidad de rebrote. Por otro lado, el efecto amortiguador del claro sobre las temperaturas favoreció la supervivencia de las plantas durante el invierno. Sería interesante evaluar el umbral de tolerancia al frío y a las heladas.

Cabralea canjerana tiene una alta tasa de crecimiento cuando es plantada en claros del bosque nativo, principalmente asociada a microambientes donde la disponibilidad de luz es más alta. En 3 1 $1 / 2$ años las plantas crecieron en promedio 1,80 metros de altura en los sectores del claro que recibieron mayor disponibilidad de luz. Es de destacar que algunos individuos superaron los 3 metros de altura a los $3 \frac{1}{2}$ años, si estaban expuestos a intensidad de luz incidente mayor a 15 moles $\mathrm{m}^{-2}$ día $^{-1}$. Con esta información se pueden seleccionar sitios con luz incidente mayor a ese umbral, o realizar el control de vegetación para asegurar al menos ese nivel de luz incidente. Sería interesante evaluar las respuestas a cierre de dosel, de manera similar que se evaluó la respuesta al shock lumínico, y establecer lapsos de tolerancia al sombreo en plantas de mayor tamaño. 
En cuanto al área de estudio, este trabajo aportó información muy valiosa sobre la dinámica de regeneración de una especie forestal de valor ecológico y económico del bosque subtropical. Esto es relevante dado que la mayoría de los trabajos tienen información principalmente de bosques tropicales y templados. Se identificó que la regeneración es agrupada, como en muchas especies tropicales.

En referencia a la metodología de trabajo empleada, esta tesis puso en juego un modelo de estudio integrado, en el que se evaluaron aspectos ecofisiológicos de una especie nativa del bosque subtropical para entender y poder explicar los mecanismos con que cuenta para aclimatarse a diferentes microambientes. El estudio se realizó a diferentes escalas de análisis, un primer ensayo con plantas en macetas y mediciones destructivas, otro con plantación a campo en claros del bosque nativo, y por último un relevamiento de la regeneración natural de Cabralea canjerana en el bosque nativo. Esta metodología podría servir de modelo de estudio para evaluar aspectos ecofisiológicos en otras especies nativas de la selva. La mayoría de los estudios no evalúan de manera integrada las variables morfológicas y fisiológicas para explicar la mortalidad, el crecimiento y la supervivencia de las plantas regeneradas naturalmente o de plantación. El modelo de estudio en macetas permitió, seleccionar variables fisiológicas y morfológicas a medir a campo. Las mediciones morfológicas y fisiológicas realizadas en el ensayo en maceta que sirvieron para explicar la aclimatación a ambientes contrastantes, nos permitieron entender algunos mecanismos de respuesta de la especie e interpretar con más seguridad los resultados de la regeneración natural.

Por lo expuesto, esta tesis aporta información fundamental para comenzar a diseñar estrategias de restauración de áreas degradadas. Como la especie demostró tener elevada capacidad de aclimatación, es posible plantarla en un amplio rango de microambientes. Serán necesarios nuevos ensayos para poder evaluar planes de restauración en ambientes con diferente grado de degradación.

\subsection{Perspectivas futuras}

Seguir evaluando la supervivencia de Cabralea canjerana en sitios con cobertura densa, para estimar cuantos años podría sobrevivir con baja disponibilidad de luz. 


\section{Ana Paula Moretti - Tesis doctoral 2019}

Evaluar las condiciones de cobertura de la regeneración natural de Cabralea canjerana para ajustar el análisis de las posibles causas de la mortalidad de la regeneración, con especial énfasis en estratos intermedios y bajos.

Implementar parcelas de manejo en el bosque nativo, que nos permitan evaluar acciones de manejo para favorecer el crecimiento de individuos de Cabralea canjerana.

Profundizar el análisis de patrones espaciales que integren la distribución espacial de la mortalidad y del crecimiento de los individuos que quedan vivos.

Evaluar este modelo de estudio ecofisiológico en otras especies maderables de la selva misionera, para proponer las especies más adecuadas para enriquecer microambientes de la selva. 
Ana Paula Moretti - Tesis doctoral 2019

Anexo 


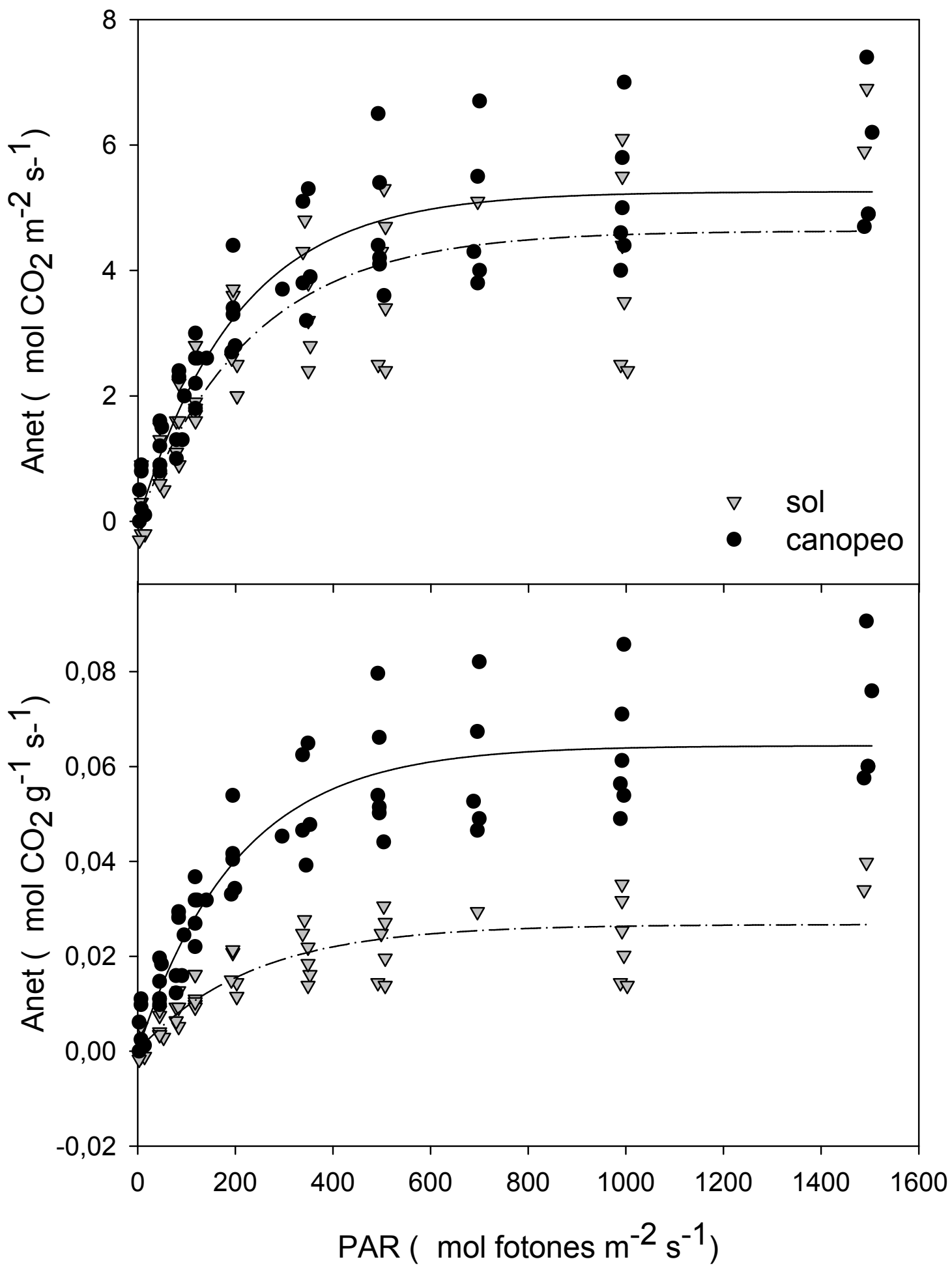

Figura A1: Curvas de Fotosíntesis neta (Anet) en respuesta a la luz (PAR) en plantas de sol y canopeo, expresadas en base al área foliar y en base al peso seco de hojas. 


\section{Bibliografía}

Amir AA (2012) Canopy gaps and the natural regeneration of Matang mangroves. Forest Ecology and Management 269:60-67. doi: 10.1016/j.foreco.2011.12.040

Aro EM, Virgin I, Andersson B (1993) Photoinhibition of Photosystem II. Inactivation, protein damage and turnover. BBA - Bioenergetics 1143:113-134. doi: 10.1016/00052728(93)90134-2

Ashton PMS, Gunatilleke CVS, Gunatilleke IAUN, Journal S (1995) Seedling Survival and Growth of Four Shorea Species in a Sri Lankan Rainforest. Journal of Tropical Ecology 11:263-279

Baddeley A, Gregori P, Mahiques JM, et al (2006) Case Studies in Spatial Point Process Modeling. Springer-Verlag, New York

Baddeley A, Turner R (2003) Introduction to spatstat. Help manual for the R package 'spatstat 1-42. doi: 10.1007/s00415-011-6369-2

Barotto AJ, Monteoliva S, Gyenge J, et al (2018) Functional relationships between wood structure and vulnerability to xylem cavitation in races of Eucalyptus globulus differing in wood density. Tree Physiology 38:243-251. doi: 10.1093/treephys/tpx138

Brodribb TJ, Jordan GJ (2008) Internal coordination between hydraulics and stomatal control in leaves. Plant, Cell \& Environment 31:1557-1564

Brodribb TJ, Jordan GJ (2011) Water supply and demand remain balanced during leaf acclimation of Nothofagus cunninghamii trees. New Phytologist 192:437-448

Brokaw NVL (1982) The definition of treefall gap and its effect on measures of forest dynamics. Biotropica 14:158-160

Burkart R, Bárbaro NO, Sánchez RO, Gómez DA (1999) Eco-regiones de la Argentina. Administración de Parques Nacionales, Buenos Aires

Cabrera AL (1976) Regiones fitogeográficas argentinas, 2o. Editorial ACME SACl, Buenos Aires, Argentina

Caldato S, Vera N, Mac Donagh P (2003) Esatructura poblacional de Ocotea puberula en un bosque secundario y primario de la selva mixta misionera. Ciencia Florestal 13:25-32

Calzavara AK, Bianchini E, Mazzanatti T, et al (2015) Morphoanatomy and ecophysiology of tree seedlings in semideciduous forest during high-light acclimation in nursery. Photosynthetica 53:597-608. doi: 10.1007/s11099-015-0151-0

Camacho M, Bellefleur P (1996) Aclimatación morfológica a la luz en seis especies arbóreas de los bosques montanos de Costa Rica. Rev Biol Trop 44:71-79 
Camargo JL, Kapos V (1995) Complex edge effects on soil moisture and microclimate in central Amazonian forest. Journal of Tropical Ecology 11:205-221. doi: $10.1017 / \mathrm{S} 026646740000866 \mathrm{X}$

Campanello PI, Gatti MG, Goldstein G (2008) Coordination between water-transport efficiency and photosynthetic capacity in canopy tree species at different growth irradiances. Tree physiology 28:85-94

Campanello PI, Genoveva Gatti M, Ares A, et al (2007) Tree regeneration and microclimate in a liana and bamboo-dominated semideciduous Atlantic Forest. Forest Ecology and Management 252:108-117. doi: 10.1016/j.foreco.2007.06.032

Campanello PI, Villagra M, Garibaldi JF, et al (2012) Liana abundance, tree crown infestation, and tree regeneration ten years after liana cutting in a subtropical forest. Forest Ecology and Management 284:213-221

Canham CD, Denslow JS, Platt WJ, et al (1990) Light regimes beneath closed canopies and tree-fall gaps in temperate and tropical forests. Canadian Journal of Forest Research 20:620-631. doi: $10.1139 / \times 90-084$

Caquet B, Barigah TS, Cochard H, et al (2009) Hydraulic properties of naturally regenerated beech saplings respond to canopy opening. Tree physiology 29:1395-1405. doi: 10.1093/treephys/tpp067

Cargnelutti Filho A, Machado Araujo M, Gasparin E, de Avila AL (2012) Sample size for evaluating the height and diameter of seedlings Cabralea canjerana. (English). Ciencia Rural 42:1204-1211

Carpenedo Aimi S (2014) Tecnologia de sementes e crecimiento inicial de mudas de Cabralea canjerana (Vell.) Mart. Universidade Federal de Santa Maria (UFSM,RS), Brazil

Carter JL, White DA (2009) Plasticity in the Huber value contributes to homeostasis in leaf water relations of a mallee Eucalypt with variation to groundwater depth. Tree Physiology 29:1407-1418. doi: 10.1093/treephys/tpp076

Carvalho PER (1996) Influência da intensidade luminosa e do substrato no crescimento, no conteúdo de clorofila e na fotossíntese de Cabralea canjerana ( vell .) Mart. Subsp. canjerana, Calophyllum basiliense Camb. E. Centrolobium robustum (Vell.) Mart. ex Benth., na fase juvenile. Tesis Universidade Federal do Paraná, Curitiba, PR, Brazi, 173 pp. 
Chambel MR, Climent J, Alía R, Valladares F (2005) Phenotypic plasticity: a useful framework for understanding adaptation in forest species. Investigación agraria Sistemas y recursos forestales 14:334-344

Choat B, Sack L, Holbrook NM (2007) Diversity of hydraulic traits in nine Cordia species growing in tropical forests with contrasting precipitation. New Phytologist 175:686-698

Chou CB, Hedin LO, Pacala SW (2017) Functional groups, species and light interact with nutrient limitation during tropical rainforest sapling bottleneck. Journal of Ecology 157-167. doi: $10.1111 / 1365-2745.12823$

Christman M a., Sperry JS, Adler FR (2009) Testing the «rare pit» hypothesis for xylem cavitation resistance in three species of Acer. New Phytologist 182:664-674

Clewell A, Aronson J, Winterhalder K, et al (2004) Principios de SER internacional sobre la restauración ecológica. 1-15

Coates KD (2002) Tree recruitment in gaps of various size, clearcuts and undisturbed mixed forest of interior British Columbia, Canada. Forest Ecology and Management 155:387-398. doi: 10.1016/S0378-1127(01)00574-6

Comita LS, Queenborough SA, Murphy SJ, et al (2014) Testing predictions of the JanzenConnell hypothesis: A meta-analysis of experimental evidence for distance- and densitydependent seed and seedling survival. Journal of Ecology 102:845-856. doi: 10.1111/13652745.12232

Condit R, Ashton P, Baker P, Bunyavejchewin S (2000) Spatial patterns in the distribution of tropical tree species. Science 288:1414-1418. doi: 10.1126/science.288.5470.1414

Crawford AJ, McLachlan DH, Hetherington AM, Franklin KA (2012) High temperature exposure increases plant cooling capacity. Current Biology 22:R396-R397. doi: 10.1016/j.cub.2012.03.044

Crechi E, Fernandez R, Domecq C, et al (2005) Crecimiento inicial de 3 especies latifoliadas nativas de interés económico en Misiones (Cordia trichotoma (Vell .) Arrab. ex Steudel, Balfourodendron redelianum (Engl.) Engl, Enterolobium contortisiliquum (Vell.) Morong.). Yvyrareta 13:1-9

Curtis PG, Slay CM, Harris NL, et al (2018) Classifying drivers of global forest loss. Science 361:1108-1111. doi: 10.1126/science.aau3445

Dalling JW, Winter K, Hubbell SP (2004) Variation in growth responses of neotropical pionners to simulated forest gaps. Journal of Ecology 18:725-736 
de Carvalho AL, d'Oliveira MVN, Putz FE, de Oliveira LC (2017) Natural regeneration of trees in selectively logged forest in western Amazonia. Forest Ecology and Management 392:3644. doi: 10.1016/j.foreco.2017.02.049

De La Cruz M (2008) Métodos para analizar datos puntuales. Introducción al Análisis Espacial de Datos en Ecología y Ciencias Ambientales: Métodos y Aplicaciones 75-127

De la Cruz Rot M (2006) Introdución al análisis de datos mapeados o algunas de las (muchas) cosas que puedo hacer si tengo coordenadas. Ecosistemas 3:1-21

De Lima RAF, De Moura LC (2008) Gap disturbance regime and composition in the Atlantic Montane Rain Forest: The influence of topography. Plant Ecology 197:239-253. doi: $10.1007 / \mathrm{s} 11258-007-9374-x$

Denslow JS (1987) Tropical rainforest gaps and tree species diversity. Annual Review of Ecology and Systematics 18:431-451. doi: 10.1146/annurev.es.18.110187.002243

Denslow JS, Ellison AM, Sanford RE (1998) Treefall gap size effects on above- and below-ground processes in a tropical wet forest. Journal of Ecology 86:597-609. doi: 10.1046/j.1365-2745.1998.00295.x

Denslow JSS, Hartshorn GSS (1994) Tree-fall gap environments and forest dynamic processes. En: McDade LA, Bawa KS, Hespenheide HA, Hartshorn GS (eds) La Selva: ecology and natural history of a neotropical rain forest. University of Chicago Press, Chicago, pp 120-127

Di Bitetti M., Placci G, Dietz LA (2003) Una Visión de Biodiversidad para la Ecorregión del Bosque Atlántico del Alto Paraná: Diseño de Paisaje para la Conservación de la Biodiversidad y prioridades para las acciones de conservación. World Wildlife Fund, Washington

Di Rienzo JA, Casanoves F, Balzarini MG, et al (2015) InfoStat vesión 2015. Grupo InfoStat, FCA, Universidad Nacional de Cordoba, Argentina. Grupo InfoStat, FCA, Universidad Nacional de Córdoba, Argentina., Córdoba, Argentina

Donoso CZ (1994) Bosques templados de Chile y Argentina: Variación intraespecífica en las especies arbóreas de los bosques templados de Chile y Argentina. Editorial Universitaria

Drozd AA (2011) Dinámica espacial y temporal de la estructura del paisaje del Valle de Cuña Pirú y sus alrededores, misiones en relación al uso de la tierra. Tesis de Doctorado, Facultad de Ciencias Naturales y Museo, Universidad nacional de La Plata. Disponible en: http://sedici.unlp.edu.ar/handle/10915/26892 
Elgar AT, Freebody K, Pohlman CL, et al (2014) Overcoming barriers to seedling regeneration during forest restoration on tropical pasture land and the potential value of woody weeds. Frontiers in Plant Science 5:1-10. doi: 10.3389/fpls.2014.00200

Felippi M, Araújo MM, Longhi SJ (2015) Morfologia da flor, fruto, semente, plântula e muda de Cabralea canjerana (Vell.) Mart. Cerne 21:387-394. doi: $10.1590 / 01047760201521031466$

Felton A, Felton AM, Wood J, Lindenmayer DB (2006) Vegetation structure, phenology, and regeneration in the natural and anthropogenic tree-fall gaps of a reduced-impact logged subtropical Bolivian forest. Forest Ecology and Management 235:186-193. doi: 10.1016/j.foreco.2006.08.011

Fetcher N, Oberbauer S, Chazdon RL (1994) Physiological ecology of plants. En: McDade LA, Bawa KS, Hespenheide HA, Hartshorn GS (eds) La Selva: ecology and natural history of a neotropical rain forest. University of Chicago Press, Chicago, pp 128-141

Forget PM, Mercier F, Collinet F (1999) Spatial patterns of two rodent-dispersed rain forest trees Carapa procera (Meliaceae) and Vouacapoua americana (Caesalpiniaceae) at Paracou, French Guiana. Journal of Tropical Ecology 15:301-313. doi: 10.1017/S0266467499000838

Fracheboud Y, Leipner J (2003) The application of chlorophyll fluorescence to study light, temperature, and drought stress. En: DeEll JR, Toivonen PMA (eds) Practical Applications of Chlorophyll Fluorescence in Plant Biology. Springer US, Boston, MA, pp 125-150

Franklin J, Rey SJ (2007) Spatial patterns of tropical forest trees in Western Polynesia suggest recruitment limitations during secondary succession. Journal of Tropical Ecology 23:1. doi: $10.1017 / \mathrm{S} 0266467406003774$

Franks PJ, Drake PL, Froend RH (2007) Anisohydric but isohydrodynamic: Seasonally constant plant water potential gradient explained by a stomatal control mechanism incorporating variable plant hydraulic conductance. Plant, Cell and Environment 30:19-30. doi: 10.1111/j.13653040.2006.01600.x

Frazer G, Canham C, Lertzman K (1999) Gap Light Analyzer (GLA): Imaging software to extract canopy structure and gap light transmission indices from true-colour fisheye photographs. Users manual and program documentation, Version 2.0. 36. doi: citeulike-article-id:4887176

Gálhidy L, Mihók B, Hagyó A, et al (2006) Effects of gap size and associated changes in light and soil moisture on the understorey vegetation of a Hungarian beech forest. Plant Ecology 183:133-145. doi: 10.1007/s11258-005-9012-4 
Gandolfi S, Joly CA, Leitão Filho HDF (2009) «Gaps of deciduousness»: cyclical gaps in tropical forests. Scientia Agricola 66:280-284. doi: 10.1590/S0103-90162009000200020

Ganivet E, Flores O, Balguerías E, et al (2019) Ecological strategies of tree species in the laurel forest of Tenerife (Canary Islands): an insight into cloud forest natural dynamics using longterm monitoring data. European Journal of Forest Research 138:93-110. doi: 10.1007/s10342-018$1156-6$

Garbarino M, Mondino EB, Lingua E, et al (2012) Gap disturbances and regeneration patterns in a Bosnian old-growth forest: A multispectral remote sensing and ground-based approach. Annals of Forest Science 69:617-625. doi: 10.1007/s13595-011-0177-9

Givnish TJ (1988) Adaptation to sun and shade: a whole-plant perspective. Australian Journal of Plant Physiology 15:63-92

Gomez RE, Ferrero BG (2011) Estilos de desarrollo sustentable en el norte de Misiones. Cadernos de Campo, São Paulo 20:125-142

González de Andrés E, Camarero JJ, Martínez I, Coll L (2014) Uncoupled spatiotemporal patterns of seed dispersal and regeneration in Pyrenean silver fir populations. Forest Ecology and Management 319:18-28. doi: 10.1016/j.foreco.2014.01.050

González JG (1998) Dispersión de semillas por murciélagos: su importancia en la conservación y regeneración del bosque tropical. Acta zoológica mexicana 73:57-74

González PA, Barth SR (2003) Estudio ecológico y silvicultural de Cordia trichotoma, Cabralea canjerana y Picrasma crenata. Su potencialidad en la diversificación productiva. En MAGPyA, editor. Jornadas PIAS 2013. MAGPyA, Buenos Aires, Argentina

Greer DH, Robinson S, Walting J, et al (2017) Sunlight and plant production. En: Plants in Action. pp 1-58

Guzmán JAQ, Cordero RRAS (2013) Growth and photosynthetic performance of five tree seedlings species in response to natural light regimes from the Central Pacific of Costa Rica. Rev Biol Trop 61:1433-1444. doi: 10.15517/rbt.v61i3.11970

Harms KE, Paine CE (2003) Regeneración de árboles tropicales e implicaciones para el manejo de bosques naturales. Ecosistemas: Revista científica y técnica de ecología y medio ambiente 12:2

Hart J, Kleinman J, Hart JL, Kleinman JS (2018) What are intermediate-severity forest disturbances and why are they important? Forests 9:579. doi: 10.3390/f9090579 
Haworth M, Elliott-Kingston C, McElwain JC (2011) The stomatal $\mathrm{CO}_{2}$ proxy does not saturate at high atmospheric $\mathrm{CO}_{2}$ concentrations: Evidence from stomatal index responses of Araucariaceae conifers. Oecologia 167:11-19. doi: 10.1007/s00442-011-1969-1

Inskeep WP, Bloom PR (1985) Extinction coefficients of chlorophyll a and b in N,Ndimethylformamide and 80\% acetone. Plant Physiol 77:483-485

Josse J, Husson F (2016) missMDA: A Package for Handling Missing Values in Multivariate Data Analysis. Journal of Statistical Software 70:1-31. doi: 10.18637/jss.v070.i01

Kalaji HM, Schansker G, Ladle RJ, et al (2014) Frequently asked questions about in vivo chlorophyll fluorescence: practical issues. Photosynthesis Research 122:121-158. doi: $10.1007 / \mathrm{s} 11120-014-0024-6$

Kitajima K (1996) Ecophysiology of tropical tree seedlings. En: Tropical Forest Plant Ecophysiology. Springer US, Boston, MA, pp 559-596

Krause GH, Koroleva OY, Dalling JW, Winter K (2001) Acclimation of tropical tree seedlings to excessive light in simulated tree-fall gaps. Plant, Cell and Environment 24:1345-1352. doi: 10.1046/j.0016-8025.2001.00786.x

Krause GH, Winter K, Matsubara S, et al (2012) Photosynthesis, photoprotection, and growth of shade-tolerant tropical tree seedlings under full sunlight. Photosynthesis Research 113:273-285. doi: 10.1007/s11120-012-9731-z

Kuehne C, Nosko P, Horwath T, Bauhus J (2014) A comparative study of physiological and morphological seedling traits associated with shade tolerance in introduced red oak (Quercus rubra) and native hardwood tree species in southwestern Germany. Tree physiology 34:184-93. doi: 10.1093/treephys/tpt124

Lambers H, Chapin III FS, Pons YL (1998) Plant physiological ecology. Springer-Verlag, New York

Lamprecht H (1990) Silvicultura en los trópicos. Los ecosistemas forestales en los bosques tropicales y sus especies arbóreas -posibilidades y métodos para un aprovechamiento sostenido. GTZ GmbH, Eschborn

Landsberg JJ, Gower ST (1997) Applications of physiological ecology to forest management. Academic Press, San Diego

Larcher W (2003) Physiological plant ecology. Ecophysiology and stress physiology of functional groups, 4th edn. Springer, Berlin 
Larcher W (2005) Climatic constraints drive the evolution of low temperature resistance in woody plants. Journal of Agricultural Meteorology 61:189-202. doi: 10.2480/agrmet.61.189

Le S, Josse J, Husson F (2008) FactoMineR: An R Package for Multivariate Analysis. Journal of Statistical Software 25:1-18. doi: 10.18637/jss.v025.i01

Ledo A, Montes F, Cañellas I (2013) Nuevas herramientas para el estudio de la interacción entre especies en el espacio y en el tiempo. Ecosistemas 22:52-57. doi: 10.7818/ECOS.2013.223.080

Lens F, Sperry JS, Christman MA, et al (2011) Testing hypotheses that link wood anatomy to cavitation resistance and hydraulic conductivity in the genus Acer. New Phytologist 190:709723. doi: $10.1111 /$ j.1469-8137.2010.03518.x

Liu J, Dazzo FB, Glagoleva O, et al (2001) CMEIAS: A computer-aided system for the image analysis of bacterial morphotypes in microbial communities. Microbial Ecology 41:173-194. doi: $10.1007 / \mathrm{s} 002480000004$

Lu D, Wang GG, Zhang J, et al (2018) Converting larch plantations to mixed stands: Effects of canopy treatment on the survival and growth of planted seedlings with contrasting shade tolerance. Forest Ecology and Management 409:19-28. doi: 10.1016/j.foreco.2017.10.058

Lussetti D, Axelsson EP, Ilstedt U, et al (2016) Supervised logging and climber cutting improves stand development: 18 years of post-logging data in a tropical rain forest in Borneo. Forest Ecology and Management 381:335-346. doi: 10.1016/j.foreco.2016.09.025

Lüttge U (2008) Physiological ecology of tropical plants. Springer Berlin Heidelberg, Berlin, Heidelberg

Martins SV, Ribeiro Rodrigues R (2002) Gap-phase regeneration in a semideciduous mesophytic forest, South-eastern Brazil. Plant Ecology 163:51-62. doi: 10.1023/A:1020395519430

McDowell N, Pockman WT, Allen CD, et al (2008) Mechanisms of plant survival and mortality during drought: why do some plants survive while others succumb to drought? New Phytologist 178:719-739

Melcher PJ, Holbrook NM, Burns MJ, et al (2012) Measurements of stem xylem hydraulic conductivity in the laboratory and field. Methods in Ecology and Evolution 3:685-694. doi: 10.1111/j.2041-210X.2012.00204.x

Mohammed GH, Zarco-Tejada P, Miller JR (2003) Applications of chlorophyll fluorescence in forestry and ecophysiology. En: Practical Applications of Chlorophyll Fluorescence in Plant Biology. Springer US, Boston, MA, pp 79-124 
Montagnini F, Eibl B, Fernandez R, Brewer M (2006) Strategies for restoration of forest landscapes. Experiences from Misiones, Argentina. En: Actas II Congreso Forestal Latinoamericano IUFRO. Talca, Chile, pp 2-14

Montagnini F, Jordan CF (2005) Tropical forest ecology. The basis of conservation and management, 1st Ed. Springer Berlin Heidelberg, 295pp

Monteoliva S, Rivera SM Maderas Argentinas: Facultad de Ciencias Agrarias y Forestales, UNLP. http://www.maderasenargentina.com.ar/

Montgomery RA, Chazdon RL (2002) Light gradient partitioning by tropical tree seedlings in the absence of canopy gaps. Oecologia 131:165-174. doi: 10.1007/s00442-002-0872-1

Morales L V., Fuentealba B, Sevillano S, et al (2018) Oportunidades para acercar la ciencia a la práctica de la restauración de bosques y arbustales de Polylepis I. Ecología Austral 291-300

Moscovich F, Dummel C, Pinazo M, et al (2010) Caracterización fitosociológica de una porción de bosque nativo misionero secundario, con intervención antrópica. Quebracho 18:24-36

Mulkey SS, Chazdon RL, Smith AP (1996) Tropical Forest Plant Ecophysiology. Springer US, Boston, MA

Muñoz AA, González ME, Celedón C, Veblen TT (2012) Respuesta inicial de la regeneración arbórea luego de la floración y muerte de Chusquea culeou (Poaceae) en bosques andinos del centro-sur de Chile. Bosque (Valdivia) 33:9-10. doi: 10.4067/S0717-92002012000200005

Murphy MRC, Jordan GJ, Brodribb TJ (2014) Acclimation to humidity modifies the link between leaf size and the density of veins and stomata. Plant Cell and Environment 37:124-131. doi: $10.1111 /$ pce. 12136

Murphy MRC, Jordan GJ, Brodribb TJ (2012) Differential leaf expansion can enable hydraulic acclimation to sun and shade. Plant Cell and Environment 35:1407-1418. doi: 10.1111/j.1365-3040.2012.02498.x

Nascimento CK, Hernandez Pastorini L, Barion Romagnolo M, De Souza LA (2015) Do Eugenia hiemalis seedling leaves under different light conditions develop phenotypic plasticity? Plant Ecology 216:1571-1581. doi: 10.1007/s11258-015-0540-2

Niinemets $U$ (2010) Responses of forest trees to single and multiple environmental stresses from seedlings to mature plants: Past stress history, stress interactions, tolerance and acclimation. Forest Ecology and Management 260:1623-1639. doi: http://dx.doi.org/10.1016/j.foreco.2010.07.054 
Norden N (2014) Del porqué la regeneración es tan importante para la coexistencia de especies en los bosques tropicales. Colombia Forestal 17:247-261. doi: 10.14483/udistrital.jour.colomb.for.2014.2.a08

Oliver CD, Larson BC (1996) Forest Stand Dynamics: Update Edition. John Wiley \& Sons, $520 \mathrm{pp}$

Olson DM, Dinerstein E (2002) The Global 200: Priority ecoregions for global conservation. Annals of the Missouri Botanical Garden 89:199-224

Paulilo MTS, Duz SR, Siminski A, Santos M (2007) Responses to light changes in tropical seedlings of the Brazilian Atlantic rainforest tree species Cecropia glazioui (Cecropiaceae) and Cedrela fissilis (Meliaceae). Australian Journal of Botany 55:795-802. doi: 10.1071/BT04089

Pinazo M, Moscovich F, Dummel C, Knebel O (2009a) Patrón espacial de la regeneración de Aspidosperma polyneuron Müll. Arg. en un bosque sometido a aprovechamiento selectivo en el norte de la provincia de Misiones. Ciencia Florestal 19:237-245

Pinazo MA, Moscovich FA, Dummel C, Knebel OE (2009b) Patrón espacial de la regeneración de dos especies leñosas en un sector aprovechado de la Selva Paranaense. Ecología Austral 19:139-148

Pinna MS, Cañadas EM, Bacchetta G (2014) Initial constraints in seedling dynamics of Juniperus macrocarpa Sm. Plant Ecology. doi: 10.1007/s11258-014-0337-8

Pizo MA, Oliveira PS (2000) The use of fruits and seeds by ants in the Atlantic Forest of Southeast Brazil. Biotropica 32:851-861

Pizo MA, Oliveira PS (1998) Interaction between ants and seeds of a nonmyrmecochorous neotropical tree, Cabralea canjerana (Meliaceae), in the Atlantic Forest of Southeast Brazil. American Journal of Botany 85:669-674

Plata L, Goya JF, Pérez C, et al (2003) Impacto de la cosecha y destino de los residuos sobre la estabilidad del capital de nutrientes en plantaciones de Pinus taeda L. Ecologia Austral 13:139150

Poorter H, Bühler J, Van Dusschoten D, Climent J, Postma J A (2012) Pot size matters : a meta-analysis of the effects of rooting volume on plant growth. Functional Plant Biology 39:839850

Prado K, Maurel C (2013) Regulation of leaf hydraulics: from molecular to whole plant levels. Frontiers in Plant Science 4:1-14. doi: 10.3389/fpls.2013.00255 
Quevedo-Rojas A, García-Núñez C, Jerez-Rico M, et al (2018) Leaf acclimation strategies to contrasting light conditions in saplings of different shade tolerance in a tropical cloud forest. Functional Plant Biology 45:968-982. doi: https://doi.org/10.1071/FP17308

Reátegui Romo M (2005) Efecto de la luz en el crecimiento de planturlas de dipteryx micrantha harms "shihuahuaco» tranplantadas a sotobosque, claros y plantaciones. Ecología Aplicada 4:1-8

Ríos RC, Galvão F, Curcio GR (2008) Variaciones estructurales de la vegetación arbórea en tres ambientes de una selva con araucaria en Misiones, Argentina. Floresta (Curitiba, PR) 38:743756

Ritchie GA (1997) Evidence for red:far-red signaling and photomorphogenic growth response in Douglas-fir (Pseudotsuga menziesii) seedlings. Tree Physiology 17:161-168

Rodríguez-Calcerrada J, Pardos JA, Gil L, Aranda I (2008) Ability to avoid water stress in seedlings of two oak species is lower in a dense forest understory than in a medium canopy gap. Forest Ecology and Management 255:421-430

Rodriguez ME, Cardozo A, Díaz MR, Prado DE (2005) Los bosques nativos misioneros: estado actual de su conocimiento y perspectivas. En: Goya JF, Frangi JL, Arturi M (eds) Ecología y manejo de los bosques de Argentina. Editorial de la Universidad Nacional de La Plata (EDULP), La Plata

Rungwattana K, Hietz P (2018) Radial variation of wood functional traits reflect size-related adaptations of tree mechanics and hydraulics. Functional Ecology 32:260-272. doi: 10.1111/13652435.12970

Runkle J (1992) Guidelines and sample protocol for sampling forest gaps. En: Gen. Tech. Rep. PNW-GTR-283. USDA Forest Service, Pacific Northwest Research Station, p 44

Sanches MC, Marzinek J, Bragiola NG, Terra Nascimento AR (2017) Morpho-physiological responses in Cedrela fissilis Vell. submitted to changes in natural light conditions: implications for biomass accumulation. Trees - Structure and Function 31:215-227. doi: 10.1007/s00468-016-14746

Schall P, Lödige C, Beck M, Ammer C (2012) Biomass allocation to roots and shoots is more sensitive to shade and drought in European beech than in Norway spruce seedlings. Forest Ecology and Management 266:246-253 
Schurr U, Walter a., Rascher U (2006) Functional dynamics of plant growth and photosynthesis - from steady-state to dynamics - from homogeneity to heterogeneity. Plant, Cell and Environment 29:340-352. doi: 10.1111/j.1365-3040.2005.01490.x

Schussler G (2006) Dinamica populacional e aspectos da regeneracao natural de Cabralea canjerana ( $v$ ell.) Mart. (Meliaceae) em uma zona de contato entre as florestas ombrófilas montanas, RS. Tesis. Universidade Federal do Rio Grande do Sul, Brazil, 114 pp

Schwartz G, Lopes JC, Kanashiro M, et al (2014) Disturbance level determines the regeneration of commercial tree species in the Eastern Amazon. Biotropica 46:148-156

Schymanski SJ, Or D, Zwieniecki M (2013) Stomatal control and leaf thermal and hydraulic capacitances under rapid environmental fluctuations. PLoS ONE 8:. doi: 10.1371/journal.pone.0054231

Sharma LN, Shrestha KB, Måren IE (2018) Tree regeneration in gap-understory mosaics in a subtropical Shorea robusta (Sal) forest. Journal of Forestry Research. doi: 10.1007/s11676-0180747-x

Shimizu M, Ishida A, Hogetsu T (2005) Root hydraulic conductivity and whole-plant water balance in tropical saplings following a shade-to-sun transfer. Oecologia 143:189-197

Siefritz F, Tyree MT, Lovisolo C, et al (2002) PIP1 Plasma membrane aquaporins in tobacco: from cellular effects to function in plants. The Plant Cell 14:869-876. doi: 10.1105/tpc.000901

Siegert CM, Levia DF (2011) Stomatal conductance and transpiration of co-occurring seedlings with varying shade tolerance. Trees - Structure and Function 25: 1091-1102. doi: 10.1007/s00468-011-0584-4

Smith WK, Berry ZC (2013) Sunflecks? Tree Physiology 33:233-237. doi: 10.1093/treephys/tpt005

Strauss-Deberiedetti S, Bazzaz FA (1996) Photosynthetic characteristics of tropical trees along successional gradients. En: Mulkey SS, Chazdon RL, Smith AP (eds) Tropical Forest Plant Ecophysiology. Springer, Boston, MA, Boston, MA, pp 162-186

Szymańska R, Ślesak I, Orzechowska A, Kruk J (2017) Physiological and biochemical responses to high light and temperature stress in plants. Environmental and Experimental Botany 139:165-177. doi: 10.1016/j.envexpbot.2017.05.002

Tabarelli M, Mantovani W (1997) Colonização de clareiras naturais na floresta atlântica no sudeste do Brasil. Revista Brasileira de Botânica 20:57-66. doi: 10.1590/S010084041997000100006 
Takahashi S, Badger MR (2011) Photoprotection in plants: A new light on photosystem II damage. Trends in Plant Science 16:53-60. doi: 10.1016/j.tplants.2010.10.001

Tortorelli L (2009) Maderas y bosques argentinos, 2 edición. Orientación Grafica Editora Buenos Aires, Argentina.

Traissac S, Pascal J-P (2014) Birth and life of tree aggregates in tropical forest: hypotheses on population dynamics of an aggregated shade-tolerant species. Journal of Vegetation Science 25:491-502. doi: 10.1111/jvs.12080

Valladares F, Aranda I, Sánchez-Gómez D (2004) La luz como factor ecológico y evolutivo para las plantas y su interacción con el agua. En: Valladares $F$ (ed) Ecología del bosque mediterráneo en un mundo cambiante. EGRAF S.A., Madrid, España, pp 335-370

Valladares F, Niinemets Ü (2008) Shade tolerance, a key plant feature of complex nature and consequences. Annual Review of Ecology, Evolution, and Systematics 39:237-257. doi: doi:10.1146/annurev.ecolsys.39.110707.173506

Valladares F, Saldaña A, Gianoli E (2012) Costs versus risks: Architectural changes with changing light quantity and quality in saplings of temperate rainforest trees of different shade tolerance. Austral Ecology 37:35-43. doi: 10.1111/j.1442-9993.2011.02245.x

Vanclay JK (2009) Managing water use from forest plantations. Forest Ecology and Management 257:385-389. doi: 10.1016/j.foreco.2008.09.003

Vilhar U, Simončič P (2012) Water status and drought stress in experimental gaps in managed and semi-natural silver fir--beech forests. European Journal of Forest Research 131:1-17. doi: $10.1007 / \mathrm{s} 10342-012-0605-\mathrm{x}$

Walters RG (2005) Towards an understanding of photosynthetic acclimation. Journal of Experimental Botany 56:435-447. doi: 10.1093/jxb/eri060

Wang Z, Yang H, Wang D, Zhao Z (2019) Spatial distribution and growth association of regeneration in gaps of Chinese pine (Pinus tabuliformis Carr.) plantation in northern China. Forest Ecology and Management 432:387-399. doi: 10.1016/j.foreco.2018.09.032

Wright JS, Muller-Landau HC, Condit R, Hubbell SP (2003) Gap-dependent recruitment, realized vital rates, and size distributions of tropical trees. Ecology 84:3174-3185

Yang W, Liu F, Zhou L, et al (2011) Trade-offs between growth and survival of non-pioneer light-demanding tree seedlings in tropical forest of Hainan Island, China. Journal of Tropical Ecology 27:611-620. doi: 10.1017/S0266467411000435 
Ana Paula Moretti - Tesis doctoral 2019 